Florida International University FIU Digital Commons

$11-6-2015$

\title{
The Effect of Disturbance and Freshwater Availability on Lower Florida Keys' Coastal Forest Dynamics
}

Danielle E. Ogurcak

Florida International University, dogur001@fiu.edu

DOI: $10.25148 /$ etd.FIDC000187

Follow this and additional works at: https://digitalcommons.fiu.edu/etd

Part of the Environmental Chemistry Commons, Forest Biology Commons, Geophysics and

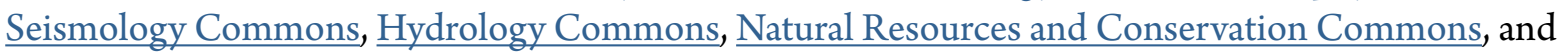
the Terrestrial and Aquatic Ecology Commons

\section{Recommended Citation}

Ogurcak, Danielle E., "The Effect of Disturbance and Freshwater Availability on Lower Florida Keys' Coastal Forest Dynamics" (2015). FIU Electronic Theses and Dissertations. 2288.

https://digitalcommons.fiu.edu/etd/2288 


\title{
FLORIDA INTERNATIONAL UNIVERSITY
}

Miami, Florida

\section{THE EFFECT OF DISTURBANCE AND FRESHWATER AVAILABILITY ON LOWER FLORIDA KEYS’ COASTAL FOREST DYNAMICS}

\author{
A dissertation submitted in partial fulfillment of \\ the requirements for the degree of \\ DOCTOR OF PHILOSOPHY \\ in \\ EARTH SYSTEMS SCIENCE \\ by \\ Danielle E. Ogurcak
}

2015 
To: Dean Michael R. Heithaus

College of Arts and Sciences

This dissertation, written by Danielle E. Ogurcak, and entitled The Effect of Disturbance and Freshwater Availability on Lower Florida Keys' Coastal Forest Dynamics, having been approved in respect to style and intellectual content, is referred to you for judgment.

We have read this dissertation and recommend that it be approved.

Joyce Maschinski

René M. Price

Leonel Sternberg

Dean Whitman

Keqi Zhang

Michael S. Ross, Major Professor

Date of Defense: November 6, 2015

The dissertation of Danielle E. Ogurcak is approved.

$\begin{array}{r}\hline \begin{array}{r}\text { Dean Michael R. Heithaus } \\ \text { College of Arts and Sciences }\end{array} \\ \hline \begin{array}{r}\text { Dean Lakshmi N. Reddi } \\ \text { University Graduate School }\end{array}\end{array}$

Florida International University, 2015 
(C) Copyright 2015 by Danielle E. Ogurcak All rights reserved. 


\section{DEDICATION}

For Augustine, Roy Winfield, Susan, Mark, and Annetta: your deep appreciation of nature and learning continues to inspire me. 


\section{ACKNOWLEDGMENTS}

I would like to thank my major advisor, Dr. Michael Ross, and committee members, Dr. Joyce Maschinski, Dr. René Price, Dr. Leonel Sternberg, Dr. Dean Whitman, and Dr. Keqi Zhang for their support and mentorship of my dissertation research over the past seven years. I would like to especially thank Dr. Ross for providing me the encouragement, tools, and affording me the freedom to pursue and develop my scientific interests over these years. My research, writing, and critical thinking have benefitted immensely from his accumulated knowledge in the field of plant community ecology. I have been incredibly fortunate to work with an advisor whose devotion to conservation science and student development drives the work in his lab.

My research has been a large endeavor of many years and would not have been possible without the combined efforts and assistance of many people. Its interdisciplinary nature required expertise and facilities both inside and outside of FIU. Thank you to Dr. René Price, Dr. Leonel Sternberg, Dr. Bill Anderson, Dr. Steve Oberbauer, Dr. Dean Whitman, and Dr. Keqi Zhang for giving me access to lab space and field equipment and for sharing the expertise of their individual disciplines. I feel extremely lucky to have been the recipient of such a tremendous education.

The work could not have been completed without the tireless efforts of many who volunteered their time to help me install a network of groundwater monitoring wells, collect samples, and record data, often in very hot and buggy conditions in the Florida Keys. I would like to especially thank Dr. Pamela Sullivan, Dr. David Lagomasino, Nicole Tucker, Dr. Albert Forson, Bina Thapa, Adam Spitzig, Susana Stoffella, Suresh 
Subedi, Tatiana Gaona, and the late Steve Whelchel for the many hours of help they provided in the field. I have greatly appreciated their kindness and friendship.

Many hours were spent in the lab processing and analyzing samples. That process was greatly enhanced by the efforts of Patrick and Patricia Ellsworth in the Sternberg Lab, Mark Kershaw at SERC, John Harris and Carrie Rebenack in the Stable Isotope Lab, and Pam Sullivan in the Price Lab. I would like to thank them for their attention to detail, meticulous care of samples, and for fielding my many questions regarding the use of lab equipment.

The logistics of this research project required exhaustive efforts by two extraordinary problem-solvers. I cannot thank Diane Pirie enough for the hours she devoted to getting the mobile drill rig functioning and outfitting a department vehicle to get me into the field. Thank you to Pablo Ruiz for going above and beyond, endlessly procuring field and lab supplies, coordinating equipment, and always checking on me during my field campaigns. Thank you to Daniel Gann and Himadri Biswas in the FIU GIS Center for many helpful discussions regarding remote sensing and spatial data analysis. Thanks to my lab mates in the South Florida Terrestrial Ecosystem Lab for support and feedback of my work. A special thanks to Dr. Jay P. Sah for sharing his statistical expertise, ideas, and constantly fielding my questions. My research has improved tremendously by his contributions and mentorship.

Many thanks go to the U.S. Fish and Wildlife Service National Key Deer Refuge for financial and logistical support of this project. I would like to specifically acknowledge Anne Morkill and Phillip Hughes for their continual support of my research, helpful discussions, and providing field housing and access to refuge property. 
Thank you to John Demott for allowing the installation of groundwater monitoring wells and collection of plant material throughout his property on Big Pine Key. I am especially grateful to Ron Niksic and Frances Turner for opening their home on Big Pine to me and allowing me to use it as a base of operations for fieldwork for the last couple years of my research.

My research was supported by the FIU Doctoral Evidence Acquisition Fellowship which allowed me to fully devote a year to field data collection in the Florida Keys for this project. Thank you to the Department of Earth and Environment in the College of Arts and Sciences for providing teaching assistant support. Thank you to Gail Excell, Sabrina Delgado, and Caridad Machado for helping me to navigate through forms and deadlines.

I would like to thank my early mentors in plant ecology and remote sensing, Drs. Elizabeth Farnsworth and Magdalene Laba, for providing opportunities to collaborate from which I became immersed in those respective disciplines. I have greatly appreciated their guidance and friendship over these many years. Thank you to my friends and family for their love and support. I would especially like to thank my parents, Marlys and $\mathrm{Al}$, who have always encouraged me to pursue my dreams. Finally, I would like to thank my sister, Alana, for being my first companion in the exploration of the natural world near our childhood home. It is from this place where my love of ecology sprang. 


\title{
ABSTRACT OF THE DISSERTATION \\ THE EFFECT OF DISTURBANCE AND FRESHWATER AVAILABILITY ON \\ LOWER FLORIDA KEYS’ COASTAL FOREST DYNAMICS
}

by

\author{
Danielle E. Ogurcak
}

Florida International University, 2015

Miami, Florida

\section{Professor Michael S. Ross, Major Professor}

Coastal forest retreat in the Florida Keys during the $20^{\text {th }}$ century has been attributed to a combination of sea level rise and hurricane storm surge impacts, but the interactions between these two disturbances leading to forest decline are not well understood. The goal of my research was to assess their effects over a period spanning more than two decades, and to examine the relationships between these press and pulse disturbances and freshwater availability in pine rockland, hardwood hammock, and supratidal scrub communities. Impacts and recovery from two storm surges, Hurricanes Georges (1998) and Wilma (2005), were assessed with satellite-derived vegetation indices and multiple change detection techniques. Impacts were greater at lower elevations, and in hardwood hammock, spectral signatures indicative of plant stress and productivity returned to predisturbance levels within a few years. In pine rockland, impacts were predominately related to Hurricane Wilma, however, a similar return to pre-disturbance conditions was absent, suggesting that trajectories of disturbance recovery differed between the two communities. Long-term monitoring of forest composition, structure, and groundwater salinity showed that compositional shifts in the low shrub stratum were associated with 
salinization of the freshwater resource attributable to sea level rise. Throughout the course of twelve months of climate and groundwater monitoring (2011-2012), groundwater salinity generally decreased in response to large precipitation events. Modeling of geophysical data indicated that groundwater salinity was an important predictor of community type. Isotopic analysis of $\delta^{18} \mathrm{O}$ in plant stem water and foliar $\delta^{13} \mathrm{C}$ was used to determine temporal and spatial patterns in water use and plant stress in two community dominants, slash pine, Pinus elliottii var. densa, and buttonwood, Conocarpus erectus. Both species relied heavily on groundwater, and plant stress was related to increasing groundwater salinity. The results of this work suggest that the interaction of press and pulse disturbances drive changes in community composition by causing mortality of salt-sensitive species and altering the freshwater resource. 


\section{TABLE OF CONTENTS}

\section{CHAPTER}

PAGE

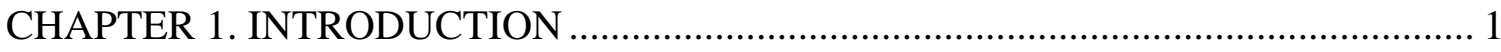

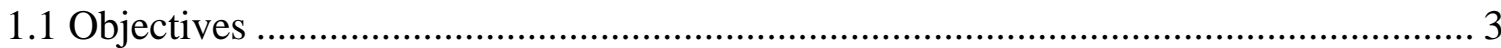

1.2 Dissertation Organization ............................................................................. 4

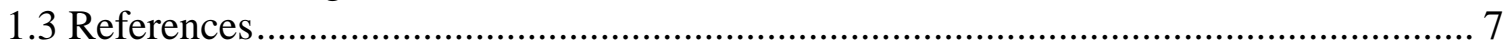

\section{CHAPTER 2. A REMOTELY-SENSED HURRICANE DISTURBANCE HISTORY}

OF COASTAL FORESTS OF THE LOWER FLORIDA KEYS (FLORIDA, USA)....... 9

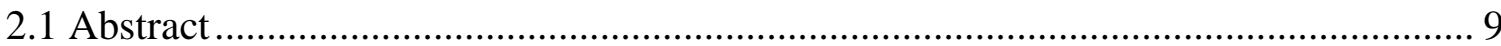

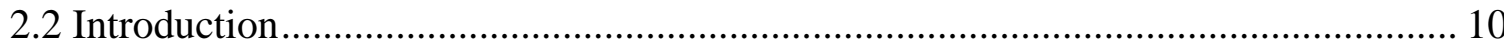

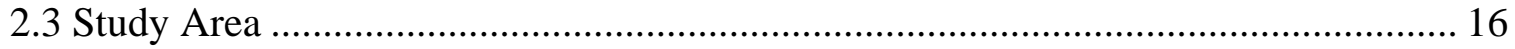

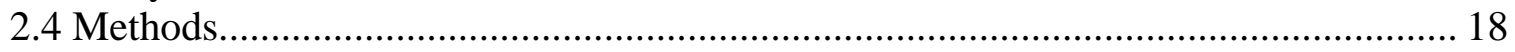

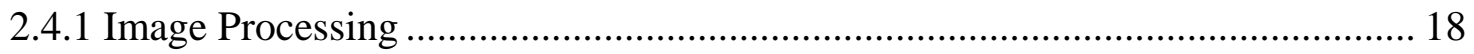

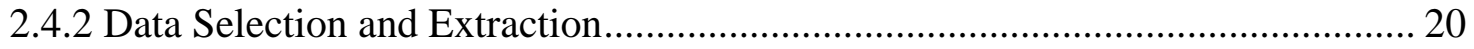

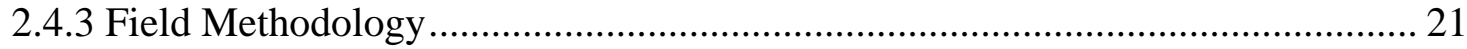

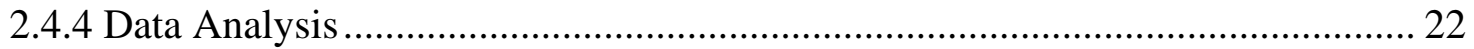

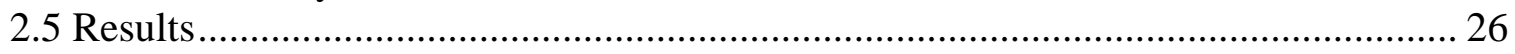

2.5.1 Seasonality and Vegetation Indices …………….............................................. 26

2.5.2 Comparison of Vegetation Indices................................................................... 27

2.5.3 Differences in Hurricane Impact and Recovery................................................... 28

2.5.4 Relationship between Vegetation Indices and Stand Parameters .......................... 31

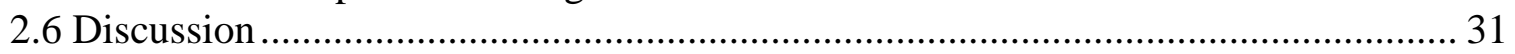

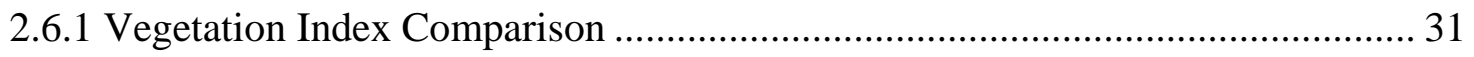

2.6.2 Storm Impacts and Island Elevation .................................................................. 33

2.6.3 Differences in Impact and Recovery between Community Types ........................ 35

2.6.4 The Effect of Post Hurricane Climate Conditions ................................................. 37

2.6.5 Relationship between Vegetation Indices and Stand Parameters ........................ 39

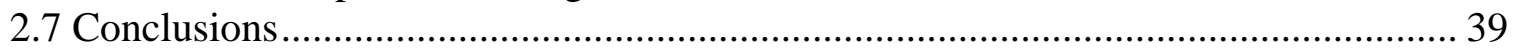

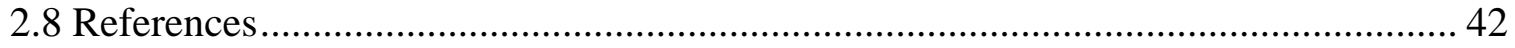

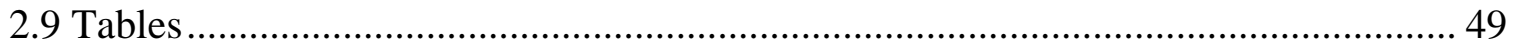

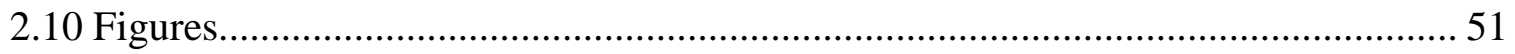

CHAPTER 3. INTERACTION OF PULSE AND PRESS DISTURBANCES:

EVIDENCE OF THE EFFECTS OF SEA LEVEL RISE ON THE COASTAL FORESTS OF THE LOWER FLORIDA KEYS (FLORIDA, USA) ………………........6 66

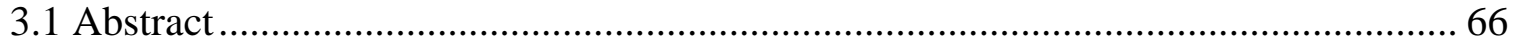

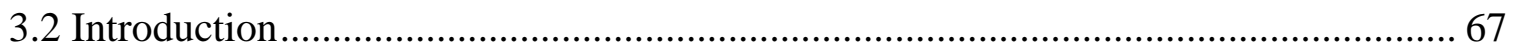

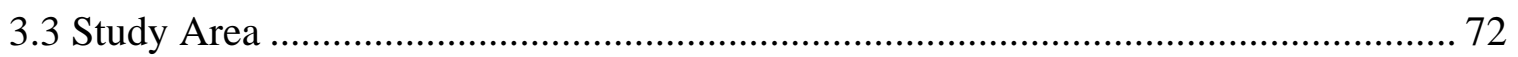

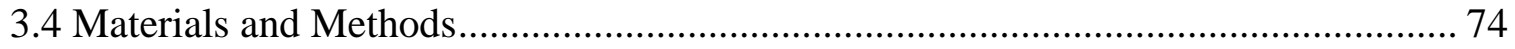

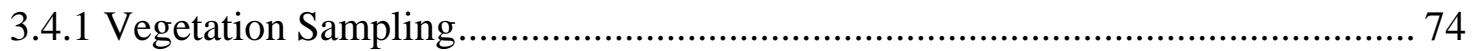

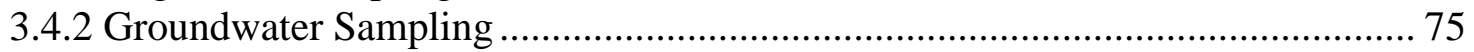

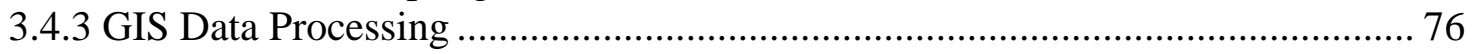


3.4.4 Sea Level and Meteorological Data.................................................................. 77

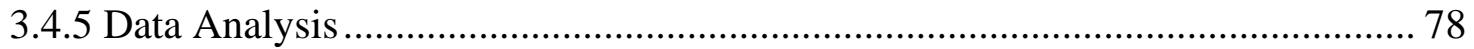

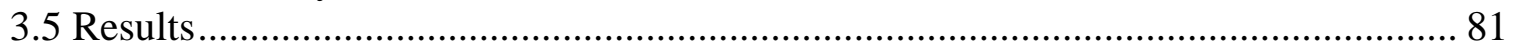

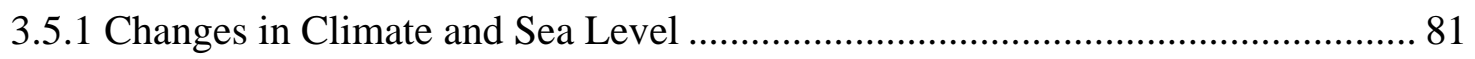

3.5.2 Changes in Groundwater Salinity ........................................................................ 82

3.5.3 Changes in Stand Structure, Species Composition, and Richness....................... 83

3.5.4 Relationship between Community Composition and Environmental Variables . 84

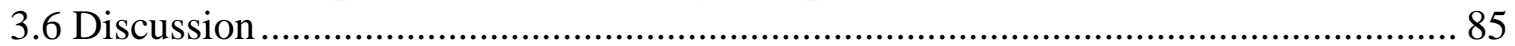

3.6.1 The Effect of Climate on Groundwater Resources and Coastal Forests.............. 86

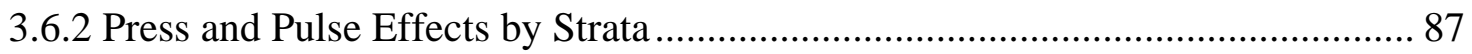

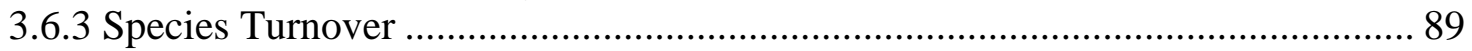

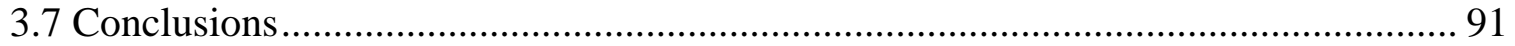

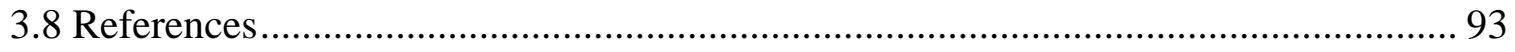

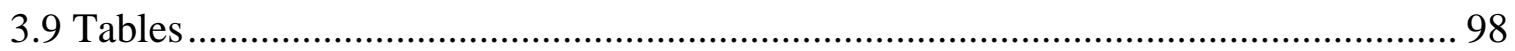

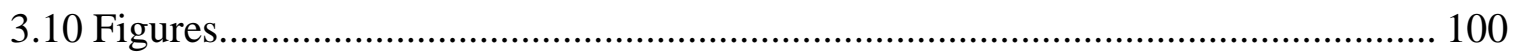

CHAPTER 4. THE RELATIONSHIP BETWEEN CLIMATE, GROUNDWATER SALINITY, AND COASTAL FOREST ZONATION ON THE LIMESTONE ISLANDS OF THE LOWER FLORIDA KEYS (FLORIDA, USA)………………...... 107

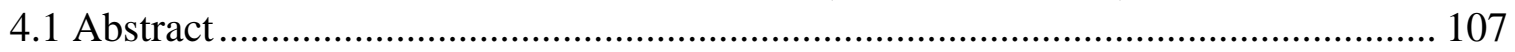

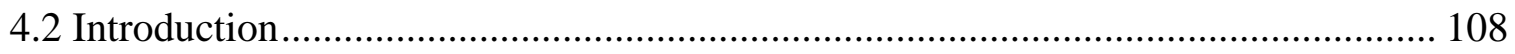

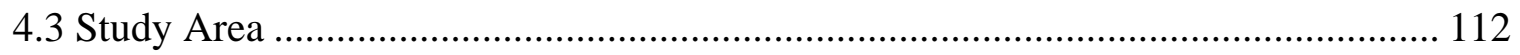

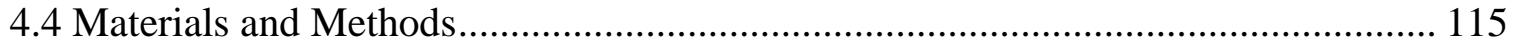

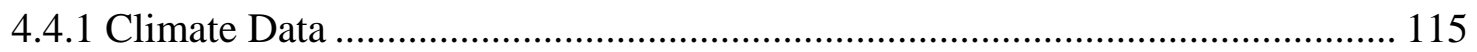

4.4.2 Groundwater Salinity Sampling and Analysis........................................... 116

4.4.3 ERT Theory and Background ....................................................................... 118

4.4.4 ERT Data Collection................................................................................ 119

4.4.5 ERT Inverse Modeling............................................................................... 120

4.4.6 Groundwater Salinity Calculation................................................................ 121

4.4.7 Transect Vegetation Characterization................................................................. 122

4.4.8 Prediction of Community Types .................................................................... 124

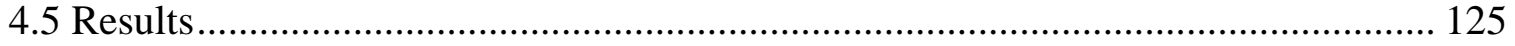

4.5.1 Precipitation and Potential Evapotranspiration.............................................. 125

4.5.2 Seasonal Changes in the Freshwater Lens ................................................. 126

4.5.3 Porosity and Seasonality Effects Evident in Profiles......................................... 127

4.5.4 Community Boundaries and Characteristic Species ............................................ 129

4.5.5 Prediction of Coastal Forest Communities ...................................................... 130

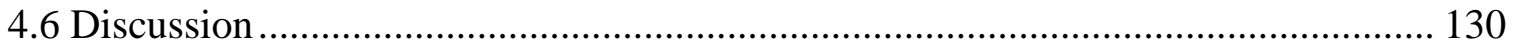

4.6.1 Effects of Bedrock Porosity on ERT-Estimation of Groundwater Salinity ....... 131

4.6.2 Effects of Precipitation and ET on the Freshwater Lens .................................... 132

4.6.3 Characteristic Species, Environmental Drivers, and Community Succession... 134

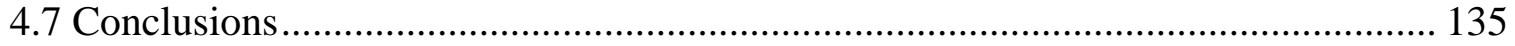

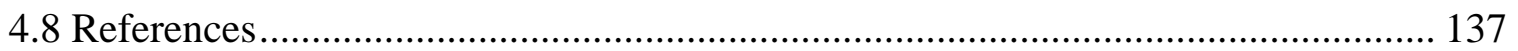

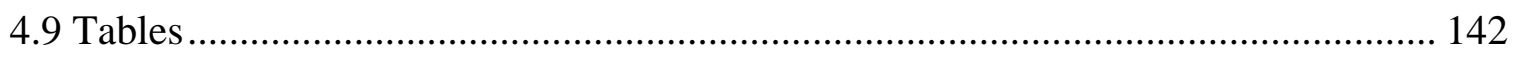

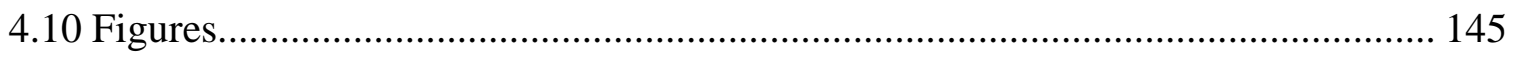


CHAPTER 5. WATER SOURCE PARTITIONING AND PLANT STRESS IN TWO COASTAL TREE SPECIES, PINUS ELLIOTTII VAR. DENSA AND

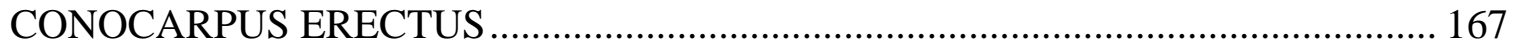

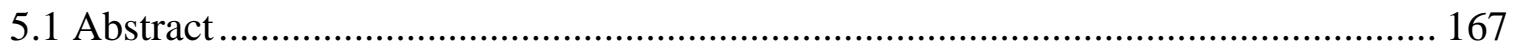

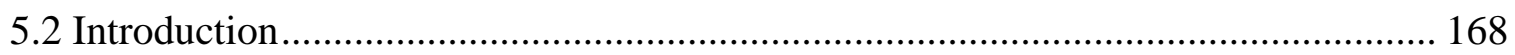

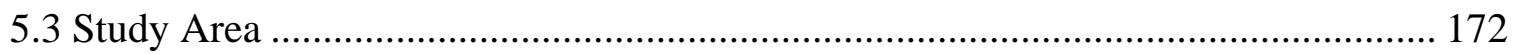

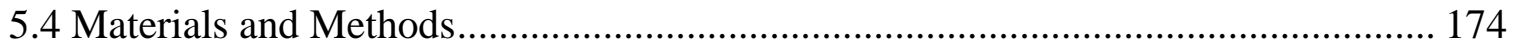

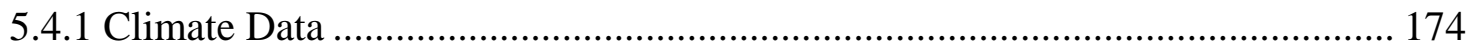

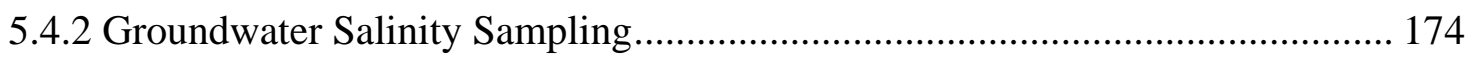

5.4.3 Collection of Source Waters and Stem Waters.................................................... 176

5.4.4 Stem and Source Water Extraction and Analysis ............................................... 179

5.4.5 Leaf Collection and Foliar $\delta^{13} \mathrm{C}$ Analysis..................................................... 180

5.4.6 Collection of Site Environmental Variables and Species Metrics ....................... 181

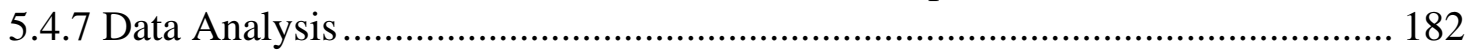

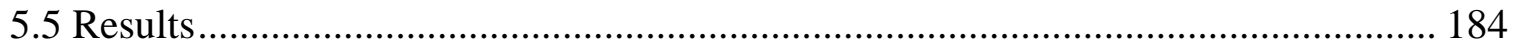

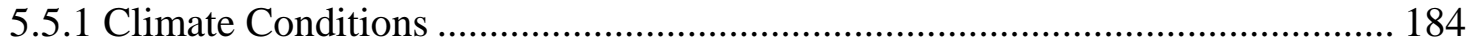

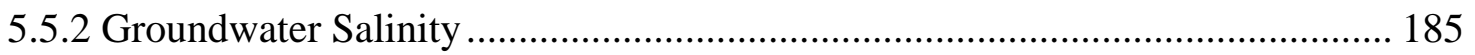

5.5.3 Species Cover and Site Environmental Variables .......................................... 186

5.5.4 Plant Water Use End-Member Identification .................................................... 186

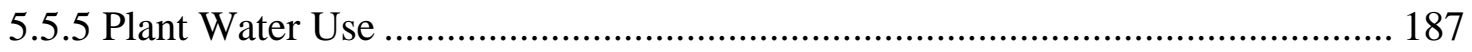

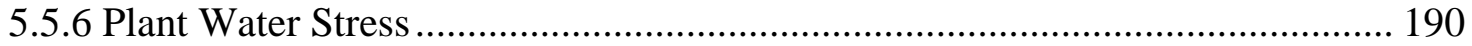

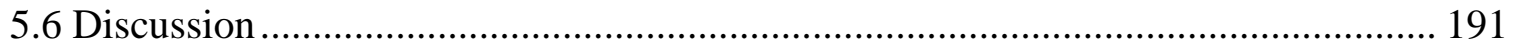

5.6.1 Plant Water Source Partitioning....................................................................... 192

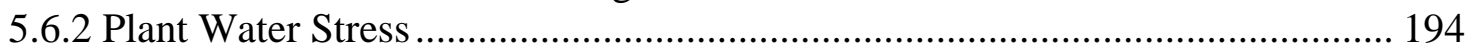

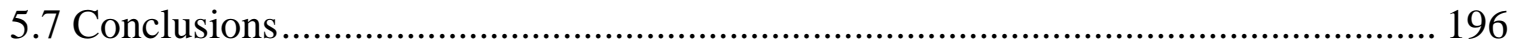

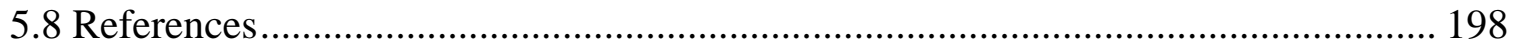

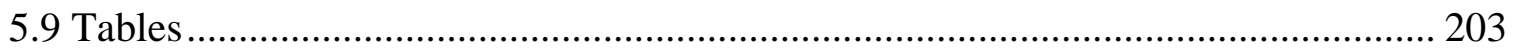

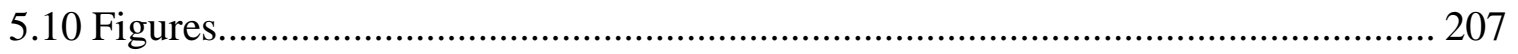

CHAPTER 6: SUMMARY AND CONCLUSIONS .................................................... 222

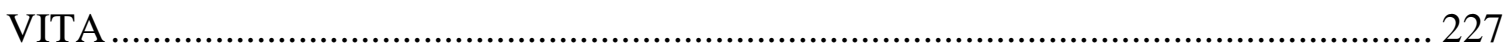




\section{LIST OF TABLES}

TABLE

PAGE

Table 2.1 Dates of Landsat TM 4-5 images used in analyses. *Image not used for EOF analysis, **Landsat 7 etm+ image substituted since no cloud-free Landsat TM 4-5 images available.

Table 2.2 Environmental variables and locations of each permanent plot. Island codes refer to Big Pine Key (BPK) and Upper Sugarloaf Key (SLK) while habitat codes refer to pine rockland (PR) and hardwood hammock $(\mathrm{HH})$ coastal forest communities. Average elevation includes the entire area covered by the Landsat TM pixel. *Indicates plot having fewer than 6 subplots. **Indicates plot where fewer than 9 Landsat pixels were available in contiguous area.

Table 2.3 Mean (+/- SD) vegetation indices (VIs) for 1996 and change in VI postpre Hurricane Wilma (2005-2006) in hardwood hammock ( $\mathrm{n}=6123)$, pine rockland on Big Pine Key $(\mathrm{n}=3841)$ and pine rockland on all other islands combined $(n=1094)$.

Table 2.4 Pearson correlation coefficients for vegetation indices and forest stand parameters, ${ }^{*} \mathrm{p}<.05,{ }^{* *} \mathrm{p}<.001, \mathrm{n}=14$.

Table 3.1. Permanent plot environmental variables and average salinity in ppt for each sample period. Island codes: BPK = Big Pine Key, SLK = Sugarloaf Key. Habitat codes: $\mathrm{PR}=$ pine rockland; $\mathrm{HH}=$ hardwood hammock. ${ }^{*}$ Distance to coast. ..... 98

Table 3.2 Mean +/- SE of distance to coast and height above local mean sea level for sites on and off the freshwater lens. * Distance to coast.

Table 3.3 Estimate and standard error for each fixed effect from linear mixed effect modeling of $\log _{10}$ salinity at 7 wells with 65 sampling events from 1990s to 2010s. Estimates and SE are reported as salinity in ppt, $\mathrm{n}=237$.

Table 3.4 Means +/- SE of groundwater salinity (PPT) for inside and outside lens locations in each period (1990s and 2010s). P-values for each pairwise comparison are reported.

Table 3.5 Fitted vectors with correlation coefficients for each stratum. Significant correlations are indicated as $* * * \mathrm{p}<0.001,{ }^{* *} \mathrm{p}<0.01, * \mathrm{p}<0.05$. 
Table 4.1. Well codes and location, habitat (Hab), elevation, distance to coast (DTC), and average depth to water table (m) and average salinity (ppt) measured monthly in each well sampled during the study time period (May 2011 to April 2012). Means $+/-$ SE are reported $(n=12)$ for depth to water table and salinity. Elevation is the average of pixels from Lidar DTM contained within a 10 m radius circle inscribing each well. Habitat types: hardwood hammock (HH), high elevation pine rockland (HP), low elevation pine rockland (LP), and supratidal scrub (STS).

Table 4.2 ERT transect location, length (m), elevation range (m), number of wells located along each transect, and dates of each survey $(\mathrm{BPK}=$ Big Pine Key, SLK = Upper Sugarloaf Key).

Table 4.3 Mean +/- SE of ERT-derived groundwater salinity at $107 \mathrm{~cm}$ below ground surface for May and November 2011 in each community type. Salinity (ppt) was determined at $1 \mathrm{~m}$ intervals along each transect. Elevation is in NAVD88 meters. DTC is distance to nearest coastline in meters.

Table 4.4 Average percent cover and percent contribution and cumulative contribution of species to the similarity between samples assigned to each community type. Only species contributing greater than 5\% to species composition of the community are included. Habitat types include: supratidal scrub (STS), hardwood hammock $(\mathrm{HH})$, low elevation pine rockland (LP), and high elevation pine rockland (HP).

Table 5.1 Location, habitat, elevation, distance to coast (DTC), and average salinity (ppt) measured monthly during the study time period (May 2011 to April 2012) for each well with associated plant samples. Means $+/-$ SE are reported $(n=12)$ for salinity. Elevation is the average of pixels from Lidar DTM contained within a 10 $m$ radius circle inscribing each well. Habitat (Hab) codes: supratidal scrub (STS), hardwood hammock $(\mathrm{HH})$, and pine rockland (PR). Groundwater salinity zone (GW zone): freshwater lens (FWL), mixing zone (MZ), and tidal (TDL).

Table 5.2 Mean +/- SE of measured site environmental variables for each habitat and study species within that habitat: supratidal scrub (STS), hardwood hammock $(\mathrm{HH})$, and pine rockland (PR). Groundwater salinity was measured at each site once each month for 12 months. Species cover refers to percent cover of either Conocarpus erectus (CE) or Pinus elliottii var. densa (PE) in the particular habitat only at sites where it was sampled. Site-level (average yearly salinity, elevation, DTC, and \% species cover) $n=3$ (CE STS), 5 (CE HH), 8 (CE PR), and 7 (PE PR). Soil depth $n=45$ (CE STS), 72 (CE HH), 119 (CE PR), and 104 (PE PR). Tree height $n=15$ (CE STS), 25 (CE HH), 40(CE PR), and 35 (PE PR). ${ }^{\text {a }} \mathrm{GW}=$ groundwater. ${ }^{\mathrm{b}} \mathrm{DTC}=$ distance to coast. ${ }^{\mathrm{c}}$ Canopy cover is equal to the average total percent cover of all species having a height greater than $1 \mathrm{~m}$ in each habitat type scaled to that of hardwood hammock. ${ }^{\mathrm{d}}$ Fine litter production values were obtained from Ross et al. 2002 for those habitat types in the Keys. 
Table 5.4 Mean, standard error, and upper and lower 95\% confidence interval (CI) for each sampling month for $P$. elliottii var. densa proportion groundwater usage for 7 sites in 3 sample periods (May 2011, November 2011, and February 2012) (n $=102)$

Table 5.5 Estimate and standard error for each fixed effect from linear mixed effect modeling of C. erectus proportion groundwater use for 16 sites in 3 sample periods (May 2011, November 2011, and February 2012) $(\mathrm{n}=219)$.

Table 5.6 Mean, standard error, and upper and lower 95\% confidence interval (CI) for each sampling month for proportion groundwater usage by C. erectus for 16 sites in 3 sample periods (May 2011, November 2011, and February 2012) (n = 219).

Table 5.7 Estimate and standard error for each fixed effect from linear mixed effect modeling of C. erectus $\delta^{13} \mathrm{C}$ for 16 sites in 3 sample periods (May 2011, November 2011, and February 2012) $(\mathrm{n}=237)$...

Table 5.8 Estimate and standard error for each fixed effect from linear mixed effect modeling of $P$. elliottii var. densa foliar $\delta^{13} \mathrm{C}$ for 7 sites in 3 sample periods (May 2011, November 2011, and February 2012) $(\mathrm{n}=105)$. 


\section{LIST OF FIGURES}

\section{FIGURE}

PAGE

Figure 2.1 Study area in the lower Florida Keys. The locations of permanent plots are indicated by red dots. Hardwood hammock pixels included in the study are colored purple. Pine rockland pixels included in the study are colored green. 51

Figure 2.2 Relationship between Julian date of the Landsat image and the NDMI in non-disturbance years (pre-Hurricane Wilma). (a) Mean NDMI for pine rockland pixels in each image averaged by island (or separate burn units for BPK). (b) Mean NDMI for hardwood hammock pixels in each image averaged by island.

Figure 2.3 Frequency distribution of change in (a) NDVI and (b) NDMI post-pre Hurricane Wilma (red) and year of no disturbance (1997-1996) (blue), n = 11058 pixels.

Figure 2.4 Means +/- 95\% CI for NDMI between 1986 and 2011 in (a) low (20 to $60 \mathrm{~cm})$, (b) medium $(60 \mathrm{~cm}$ to $100 \mathrm{~cm})$, and (c) high $(>100 \mathrm{~cm})$ elevation pixels in hardwood hammock and pine rockland habitat. Arrows indicate timing of Hurricane Georges (1998) and Hurricane Wilma (2005).

Figure 2.5 Average decrease in NDMI pre-post Hurricane Georges and Wilma in $10 \mathrm{~cm}$ elevation intervals in pine rockland ( $\mathrm{n}=4935$ pixels). Means $+/-95 \% \mathrm{CI}$.

Figure 2.6 Average decrease in NDMI pre-post Hurricane Georges by island. Islands are arranged (left to right) by decreasing longitude. Means +/- 95\% CI. 56

Figure 2.7 Average decrease in NDMI pre-post Hurricane Georges and Wilma in $10 \mathrm{~cm}$ elevation intervals in hardwood hammock ( $n=6123$ pixels) Means $+/-95 \%$ CI.

Figure 2.8 Relationship between the percentage of pixels with elevations less than 1 meter and average decrease pre-post Hurricane Wilma in NDMI in hardwood hammock $(\mathrm{HH})$ and pine rockland (PR) on each island. Pine rockland on BPK falls much farther below the regression line compared coastal forests on other islands as a result of the large area subjected to prescribed burns on BPK in 2004.

Figure 2.9 Mean percent reflectance in bands 3, 4, and 5 by image date for hardwood hammock (solid line) and pine rockland (dashed line) pixels below $1 \mathrm{~m}$ in elevation.

Figure 2.10 Temporal (a) EOF 1 (tEOF 1) and temporal (b) EOF 2 (tEOF2) scores for NDMI for each image date. 
Figure 2.11 Distribution of spatial EOF 1 (sEOF 1) scores for NDMI on No Name Key. Areas of pine rockland are outlined in green, while areas of hardwood hammock are outlined in purple.

Figure 2.12 Relationship between pixel elevation (m) and sEOF 1 scores for NDMI on No Name Key in hardwood hammock $(\mathrm{HH})(\mathrm{n}=1071)$ and pine rockland (PR) $(n=317)$. For hardwood hammock, correlation is only between sEOF1 scores and pixels at elevations $<=1 \mathrm{~m}$.

Figure 2.13 Distribution of spatial EOF 2 (sEOF 2) scores for NDMI on No Name Key. Areas of pine rockland are outlined in green, while areas of hardwood hammock are outlined in purple.

Figure 2.14 Scatterplot of spatial EOF scores for sEOF 1 and sEOF 2 for NDMI on No Name Key. T-test of sEOF 2 scores for hardwood hammock $(n=1071)$ and pine rockland $(n=317)$ was significant at $\mathrm{p}<0.001$.

Figure 2.15 Relationship between NDMI and average permanent plot tree basal area per hectare in pine rockland $(\mathrm{PR})(\mathrm{n}=6)$ and hardwood hammock $(\mathrm{HH})(\mathrm{n}=8)$ in 1990 and 2011.

Figure 3.1 Study area includes the islands of Big Pine Key and Upper Sugarloaf Key, indicated by the arrows. Two permanent plots are located on Big Pine Key and five are located on Upper Sugarloaf Key.

Figure 3.2 Location of $600 \mathrm{~m} 2$ permanent plots and associated groundwater monitoring wells on Big Pine (BPK) and Upper Sugarloaf Keys (SLK) are displayed on a digital elevation map derived from LiDAR data (2007). Areas of higher elevation are white, while areas of lower elevation are black. The boundary of the freshwater lens on each island is indicated in blue (BPK boundary is from Aug 1987 survey, Wightman 1990; and SLK boundary is from a 1990 survey, Caballero 1993)......

Figure 3.3 Annual mean sea level (mm) at Key West Tide Gauge (1914 - 2013). Data obtained from the Permanent Service for Mean Sea Level (PSMSL). Rate of sea level rise is equal to the slope of the regression line.

Figure 3.4 Deviation from the 30-year average annual precipitation received at Key West International Airport from 1984 to 2013 (http://www.ncdc.noaa.gov), SD of mean $=14.57 \mathrm{~cm}$. Years of groundwater monitoring are indicated in red for $1990 \mathrm{~s}$ and blue for 2010s.

Figure 3.5 Mean +/- SE groundwater salinity (ppt) at each plot in each sampling period (1990s versus 2010s). Plots are arranged from left to right according to increasing groundwater salinity in 2010s. For 2010s sampling, $n=6$. For 1990s sampling, $n=34$ or 35 for all wells, except for B2 where $n=24$. 
Figure 3.6 Percent change in tree stratum basal area per hectare and change in percent cover of high and low shrub strata (left y-axis) between 1990 and 2012 sampling events with corresponding height above local mean sea level (right yaxis) for each site. Sample sites, either pine rockland (PR) or hardwood hammock $(\mathrm{HH})$, are arranged from left to right according to increasing groundwater salinity in the 2010s.

Figure 3.7 NMDS ordination of (a) tree stratum, (b) high shrub / sapling stratum, and (c) low shrub / herb stratum at seven sites in the 1990s (open symbols) and 2010s (closed symbols). Inside lens sites are colored blue, while outside lens sites are colored red. Pine rockland sites are represented by triangles and hardwood hammock sites are represented by squares. Vectors (black arrows) indicating increasing values of three environmental variables (groundwater salinity in ppt, distance to coast in $\mathrm{m}$, and height above local mean sea level in $\mathrm{m}$ ). Colored arrows indicate movement from 1990s to 2010s composition for each plot.

Figure 4.1 Big Pine and Upper Sugarloaf Key ERT transects, vegetation transects, and well locations.

Figure 4.2 Total precipitation (mm) received on Big Pine Key in each month prior to groundwater monitoring (May 2011 through April 2012). Five-year average monthly precipitation totals (mm) for the time period starting at the onset of the wet season in June 2007 to the end of the dry season in May 2012 are included for comparison.

Figure 4.3 Ratio of total monthly precipitation to potential evapotranspiration (P:ET) beginning November 2010 (6 months prior to dry season ERT survey) through October 2011 (month prior to wet season ERT survey) with 5-year monthly averages plotted (Jun-07 through May-12) for comparison.

Figure 4.4 Relationship between measured groundwater salinities at wells along transect B1 (obtained at monthly intervals) and daily precipitation totals from April 1, 2011 to April 30, 2012. Wells are located along the transect with B11 nearest and B15 farthest from the coast.

Figure 4.5 Relationship between measured groundwater salinities at wells along transect B2 (obtained at monthly intervals) and daily precipitation totals from April 1, 2011 to April 30, 2012. Wells are located along the transect with B21 nearest and B26 farthest from the coast.

Figure 4.6 Relationship between measured groundwater salinities at wells along transect B3 (obtained at monthly intervals) and daily precipitation totals from April 1, 2011 to April 30, 2012. Wells are located along the transect with B31 nearest and B35 farthest from the coast. 
Figure 4.7 Relationship between measured groundwater salinities at wells along transect S2 (obtained at monthly intervals) and daily precipitation totals from April 1, 2011 to April 30, 2012. Wells are located along the transect with S21 nearest and S23 farthest from the coast.

Figure 4.8 Relationship between measured groundwater salinities at wells along transect S3 (obtained at monthly intervals) and daily precipitation totals from April 1, 2011 to April 30, 2012. Wells are located along the transect with S31 nearest and S35 farthest from the coast.

Figure 4.9 Transect B1 groundwater salinity profile derived from May and November 2011 ERT surveys with 3 ppt contour lines identified, red for May survey, blue for November survey (PR = pine rockland, $\mathrm{STS}=$ supratidal scrub).

Figure 4.10 Transect B3 groundwater salinity profile derived from May and November 2011 ERT surveys with 3 ppt contour lines identified, red for May survey, blue for November survey (PR = pine rockland, $\mathrm{STS}=$ supratidal scrub).

Figure 4.11 Transect S2 groundwater salinity profile derived from May and November 2011 ERT surveys with 3 ppt contour lines identified, red for May survey, blue for November survey (PR = pine rockland).

Figure 4.12 Transect S3 groundwater salinity profile derived from May and November 2011 ERT surveys with 3 ppt contour lines identified, red for May survey, blue for November survey (PR = pine rockland, STS = supratidal scrub).

Figure 4.13 ERT-derived groundwater salinity profiles for wells on transect B1 for May 2011 (red line) and November 2011 (blue line) surveys compared to salinity measured in wells at time of each survey (circles).

Figure 4.14 ERT-derived groundwater salinity profiles for wells on transect B3 for May 2011 (red line) and November 2011 (blue line) surveys compared to salinity measured in wells at time of each survey (circles).

Figure 4.15 ERT-derived groundwater salinity profiles for wells on transect S2 for May 2011 (red line) and November 2011 (blue line) surveys compared to salinity measured in wells at time of each survey (circles).

Figure 4.16 ERT-derived groundwater salinity profiles for transect S3 in May 2011 (red) and November 2011 (blue) compared to salinity measured in wells at time of each survey (circles). 
Figure 4.17 ERT-derived groundwater salinity at a depth of $107 \mathrm{~cm}$ below ground surface for May 2011 and November 2011 surveys on transect B1 with associated coastal forest communities as defined by Bray-Curtis dissimilarity for woody vegetation $\geq 1.0 \mathrm{~m}$ in height using a moving window of size 5 . Arrows indicate breakpoints that distinguish boundaries between adjacent communities. Coastal forest types include: supratidal scrub (STS), high elevation pine rockland (PR), and low elevation pine rockland (PR).

Figure 4.18 ERT-derived groundwater salinity at a depth of $107 \mathrm{~cm}$ below ground surface for May 2011 and November 2011 surveys on transect B3 with associated coastal forest communities as defined by Bray-Curtis dissimilarity for woody vegetation $\geq 1.0 \mathrm{~m}$ in height using a moving window of size 5 . Arrows indicate breakpoints that distinguish boundaries between adjacent communities. Coastal forest types include: supratidal scrub (STS), HH (hardwood hammock), low elevation pine rockland (PR), and high elevation pine rockland (PR).

Figure 4.19 ERT-derived groundwater salinity at a depth of $107 \mathrm{~cm}$ below ground surface for May 2011 and November 2011 surveys on transect S2 with associated coastal forest communities as defined by Bray-Curtis dissimilarity for woody vegetation $\geq 1.0 \mathrm{~m}$ in height using a moving window of size 5. Arrows indicate breakpoints that distinguish boundaries between adjacent communities. Coastal forest types include: HH (hardwood hammock), low elevation pine rockland, and high elevation pine rockland.

Figure 4.20 ERT-derived groundwater salinity at a depth of $107 \mathrm{~cm}$ below ground surface for May 2011 and November 2011 surveys on transect S3 with associated coastal forest communities as defined by Bray-Curtis dissimilarity for woody vegetation $\geq 1.0 \mathrm{~m}$ in height using a moving window of size 5 . Arrows indicate breakpoints that distinguish boundaries between adjacent communities. Coastal forest types include: STS (supratidal scrub), HH (hardwood hammock) high elevation pine rockland (PR), and low elevation pine rockland (PR). The zone to the right of low PR is a freshwater wetland.

Figure 4.21 NMDS ordination of sample plots in 4 transects separated into 6 community types. Community types are as follows: hardwood hammock (purple open square), low elevation hardwood hammock (purple solid square), high elevation pine rockland (green solid triangle), exterior low elevation pine rockland (blue solid diamond), interior low elevation pine rockland (blue open diamond) and supratidal scrub (red circle), $n=169$ 
Figure 4.22 Conditional density plots of each coastal forest community type along each environmental gradient (a) elevation (cm), (b) distance to coast (m), (c) ERTderived May 2011 salinity (ppt), and (d) ERT-derived November 2011 salinity (ppt). Community types are as follows: high elevation pine rockland (HP), hardwood hammock (HH), low elevation hardwood hammock (HHl), exterior low elevation pine rockland (LPe), interior low elevation pine rockland (LPi) and supratidal scrub (STS).

Figure 5.1 Transects on BPK (B1 - B3) and SLK (S2 - S3) with locations marked for each well and sampled trees.

Figure 5.2 Total precipitation $(\mathrm{mm})$ received on Big Pine Key for each month beginning in May 2010 through the end of the groundwater sampling period, April 2012. Five-year average monthly precipitation totals +/- SE for the time period beginning June 2007 through May 2012 are shown for comparison. Stem and leaf sampling occurred at the beginning of the month in May 2011, November 2011, and February 2012.

Figure 5.3 Monthly (May 2011 - April 2012) groundwater salinity (ppt) in monitoring wells (right y-axis) located in the supratidal scrub (STS) community with daily precipitation totals (cm) from April 1, 2011 to April 30, 2012 (left yaxis). Groundwater salinity zone codes: freshwater lens (FWL) and mixing zone (MZ).

Figure 5.4 Monthly (May 2011 - April 2012) groundwater salinity (ppt) in monitoring wells (right y-axis) located in the hardwood hammock (HH) community with daily precipitation totals (cm) from April 1, 2011 to April 30, 2012 (left yaxis). Groundwater salinity zone codes: freshwater lens (FWL), mixing zone (MZ), and tidal (TDL).

Figure 5.5 Monthly (May 2011 - April 2012) groundwater salinity (ppt) in monitoring wells (right y-axis) located in the pine rockland (PR) community with daily precipitation totals (cm) from April 1, 2011 to April 30, 2012 (left y-axis). Groundwater salinity zone codes: mixing zone (MZ) and tidal (TDL).

Figure 5.6 Relationship between average salinity and mean +/- SE for $\delta^{18} \mathrm{O}(\%)$ of groundwater at all sample sites organized by coastal forest community (pine rockland - PR, hardwood hammock - HH, and supratidal scrub - STS) and groundwater salinity zone (freshwater lens - FWL, mixing zone - MZ, and tidal TDL) for the three sample months (May 2011, November 2011, and February 2012). Bay water is the average value $(n=4)$ from surface samples taken near Tarpon Belly Keys (N 24.73, W 81.52) on 4/26/11, 7/25/11, 12/7/11, and 2/8/12. Precipitation is the weighted average value $(\mathrm{n}=12)$ of monthly collections on Big Pine Key beginning April 3, 2011 and ending April 2, 2012. 
Figure 5.7 Average $\delta^{18} \mathrm{O}$ and $\delta^{2} \mathrm{H}$ (\%) of groundwater at all sample sites organized by coastal forest community (pine rockland - PR, hardwood hammock - HH, and supratidal scrub - STS) and groundwater salinity zone (freshwater lens - FWL, mixing zone - MZ, and tidal - TDL) for three sample months (May 2011, November 2011, and February 2012). Bay water is the average value $(n=4)$ from surface samples taken near Tarpon Belly Keys (N 24.73, W 81.52) on 4/26/11, $7 / 25 / 11,12 / 7 / 11$, and 2/8/12. Precipitation is the weighted average value $(n=12)$ of monthly collections on Big Pine Key beginning April 3, 2011 and ending April 4, 2012. Global mean water line (GMWL): $\delta^{2} \mathrm{H}=\delta 18 \mathrm{O} * 8+10 \%$.

Figure 5.8 May 2011 average +/- SE $\delta^{18} \mathrm{O}$ and $\delta^{2} \mathrm{H}$ (\%) of stem water and source water end members organized by groundwater salinity zone: freshwater lens (blue), mixing zone (green), and tidal (red). Mean precip is the weighted average value $(n=12)$ of monthly precipitation collections on Big Pine Key beginning April 3, 2011 and ending April 4, 2012. Apr precip includes accumulated precipitation for the month of April preceding the sampling event. Bay water was sampled near Tarpon Belly Keys (N 24.73, W 81.52) on 4/26/11. Global mean water line (GMWL): $\delta^{2} \mathrm{H}=\delta^{18} \mathrm{O} * 8+10 \%$.

Figure 5.9 November 2011 average +/- SE $\delta^{18} \mathrm{O}$ and $\delta^{2} \mathrm{H}$ (\%) of stem water and source water end members organized by groundwater salinity zone: freshwater lens (blue), mixing zone (green), and tidal (red). Mean precip is the weighted average value $(n=12)$ of monthly collections of precipitation on Big Pine Key beginning April 3, 2011 and ending April 4, 2012. Oct precip includes accumulated precipitation for the month of October preceding the sampling event. Bay water was sampled near Tarpon Belly Keys (N 24.73, W 81.52) on 12/7/11. Global mean water line (GMWL): $\delta^{2} \mathrm{H}=\delta^{18} \mathrm{O} * 8+10 \%$.

Figure 5.10 February 2012 average $+/-\mathrm{SE} \delta^{18} \mathrm{O}$ and $\delta^{2} \mathrm{H}$ (\%) of stem water and source water end members organized by groundwater salinity zone: freshwater lens (blue), mixing zone (green), and tidal (red). Mean precip is the weighted average value $(n=12)$ of monthly collections of precipitation on Big Pine Key beginning April 3, 2011 and ending April 4, 2012. Jan precip includes accumulated precipitation for the month of January preceding the sampling event. Bay water was sampled near Tarpon Belly Keys (N 24.73, W 81.52) on 2/8/12. Global mean water line (GMWL): $\delta^{2} \mathrm{H}=\delta^{18} \mathrm{O} * 8+10 \%$.

Figure 5.11 Relationship between site mean groundwater salinity (ppt) and percent groundwater use (\%) for (a) Pinus elliottii var. densa and (b) C. erectus in May 2011 (brown), November 2011 (green), and February 2012 (pink) where $n=5$ for each site.

Figure 5.12 Percent groundwater usage by C. erectus by habitat type in each sample period: May 2011 (brown), November 2011 (green), February 2012 (pink). Different subscripts indicate statistically significant difference between factor levels at $\mathrm{p}<0.05$ in pairwise contrasts using Bonferroni 2-sided tests. 
Figure 5.13 Average percent use of each source water type, groundwater (gw), soil water (soil), and precipitation (precip), in November 2011 by Pinus elliottii var. densa (PE) and Conocarpus erectus (CE) organized by habitat: hardwood hammock $(\mathrm{HH})$, pine rockland (PR), and supratidal scrub (STS). Each symbol represents the average for stems of each species at that site $(n=5)$...

Figure 5.14 Relationship between site average annual groundwater and mean +/SE foliar $\delta^{13} \mathrm{C}$ in \%o for (a) C. erectus and (b) P. elliottii var. densa in May 2011 (brown), November 2011 (green), and February 2012 (pink) where $n=5$ for each site.

Figure 5.15 Box plots of median $\delta^{13} \mathrm{C}$ values for Pinus elliottii var. densa in freshwater lens sites (blue) and mixing zone sites (green) for three sample months: May 2011, November 2011, and February 2012. Different subscripts indicate statistically significant difference between factor levels at $\mathrm{p}<0.05$ in pairwise contrasts using Bonferroni 2-sided tests. 


\section{ABBREVIATIONS AND ACRONYMS}

above mean sea level

AMSL

Big Pine Key

BPK

Big Torch Key

BTK

Cudjoe Key

CUD

diameter at breast height

$\mathrm{DBH}$

distance to coast

DTC

digital terrain model

DTM

electromagnetic

EM

empirical orthogonal function

EOF

electrical resistivity tomography

ERT

potential evapotranspiration

ET

freshwater lens

FWL

global meteoric water line

GMWL

hardwood hammock

$\mathrm{HH}$

high elevation pine rockland

HP

leaf area index

LAI

local mean sea level

LMSL

low elevation pine rockland

LP

Little Pine Key

LPK

Little Torch Key

LTK

mid infrared

MIR

Middle Torch Key

MTK 
mixing zone

North American Datum of 1983

NAD83

North American Vertical Datum of 1988

NAVD88

normalized differenced moisture index

NDMI

normalized differenced vegetation index

NDVI

near infrared

NIR

nonmetric multidimensional scaling

NMDS

No Name Key

NNK

pseudoinvariant feature

PIF

parts per thousand

PPT

pine rockland

PR

Sugarloaf Key

SLK

supratidal scrub

STS

tidally influenced

TDL

univariate image differencing

UID

vegetation index

VI 


\section{CHAPTER 1. INTRODUCTION}

Coastal forests are dynamic, disturbance-adapted systems, which provide a host of ecosystem services, including providing species habitat and storm protection, and carbon sequestration (Maass et al., 2005; Martínez et al., 2007). In the lower Florida Keys, forests that require freshwater inhabit a unique position on low-elevation limestone islands as glycophyte-dominated forests located in close proximity to saline water. Coastal forests in the greater Caribbean basin are also subject to periodic disturbance from hurricanes and tropical storms, but which typically are not stand-replacing events (Brokaw and Walker, 1991; Yih et al., 1991; Bellingham et al., 1992). Collectively, these forests are high in species diversity (Snyder et al., 1990) and include the following communities: pine rocklands, dominated by slash pine, Pinus elliottii var. densa; hardwood hammocks (dry tropical forests) of West Indian affinity; and supratidal scrub, dominated by buttonwood, Conocarpus erectus. Within the United States, south Florida is the only location where these coastal communities are found.

The present rate of sea level rise of $\sim 23 \mathrm{~cm}$ over the past 100 years at Key West (Zervas, 2009) has led to increases in groundwater salinity, inundation frequency, and subsequent shifts in species composition in Florida’s coastal forests (Alexander, 1974; Ross et al., 1994; Williams et al., 1999). However, anthropogenic climate change is predicted to cause a rise of sea level between 0.5 to 1.4 meters by 2100 (Rahmstorf, 2007), result in an increased frequency of category 4 and 5 hurricanes impacting the western Atlantic (Bender et al., 2010), and possibly increase summer drought conditions in the Caribbean region (Neelin et al., 2006). These conditions would favor a combination of disturbance, 
drought, and salinity tolerant species, as groundwater salinity increases (Guha and Panday, 2012) and coastal forests are exposed more frequently to major storms, with shrinking recovery periods between such events (Lugo, 2000). Additionally, the interaction of press and pulse events will increase the likelihood of surface inundation by salt water during the storm surge as coastal height above mean sea level decreases (Tebaldi et al., 2012), impacting both species and the freshwater resource. Combined with high population pressure in coastal regions, the effects of climate change will have immediate consequences for coastal ecosystems in south Florida and worldwide.

Given that the current rate of sea level rise is greater than at any time within the last 2000 years (Kemp et al., 2011), species and communities will be exposed to a combination of climate and disturbance regimes possibly outside of their ability to keep pace. The capacities of coastal communities to migrate upslope rather than being overstepped by sea level rise are highly variable and dependent on local context. The tolerances of individual species to water and salinity stress, responses to altered disturbance regimes, and abilities to access freshwater resources will lead to the appearance of novel assemblages and no-analog communities (Williams and Jackson, 2007). As stress from drought and salinity increases in coastal forest communities, identifying the responses of species to environmental drivers will prove essential to understanding the structure of current and future community assemblages. The coastal forests of the lower Florida Keys provide a unique laboratory for understanding the effect that changes in climate will have on freshwater availability and freshwater-requiring habitats at the species and community levels. 


\subsection{Objectives}

This dissertation research investigates the relationship between extreme disturbance and the variability in available freshwater resources on coastal forest dynamics in the lower Florida Keys over a range of temporal and spatial scales. Chapter 2 considers a 26-year period (1986-2011) of hurricane disturbance on two communities. Chapter 3 addresses the effect of over two decades (1990-2012) of sea level rise on these same two communities. Chapter 4 investigates the seasonal relationship over the course of one year (2011-2012) between climate, groundwater salinity, and plant community zonation across three communities. Chapter 5 considers changes in water source partitioning and plant water stress over the course of one year (2011-2012) for two species of woody plants located in these communities.

The specific objectives addressed by this work include the following:

I. to assess the impact and recovery from hurricanes in freshwater-requiring coastal forests;

II. to determine how sea level rise impacts the groundwater resource and influences trajectories in community composition;

III. to analyze seasonal changes in the freshwater resource and determine drivers of coastal forest community zonation;

IV. to determine the effect of climate and groundwater salinity on water source partitioning and plant stress in two dominant species within these coastal forests. 


\subsection{Dissertation Organization}

Following the introduction, this dissertation is organized as four chapters in manuscript format for submission to peer-reviewed scientific journals. References, tables, and figures are placed at the end of each chapter. Chapter 6 summarizes the overall conclusions from chapters 2 through 5.

Chapter 2 (to be submitted to Global Change Biology) compares and contrasts the effect of and recovery from storm surge of varying magnitude, represented by Hurricanes Georges (1998) and Wilma (2005), using a temporal sequence of Landsat TM images. Impact and recovery were assessed using image-derived vegetation indices which were compared to pre- and post-storm assessments of forest stand parameters. Small differences in elevation were determined to be an important factor in determining the magnitude of disturbance impact. Post-disturbance responses differed sharply among forest types; hardwood hammocks recovered within a couple years of Hurricane Wilma, while pine rockland had still not attained pre-disturbance values of the vegetation indices six years post-Hurricane Wilma. An optimal combination of change detection techniques and vegetation indices were identified for tracking hurricane impact and recovery.

Chapter 3 (to be submitted to Applied Vegetation Science) considers the effects of more than two decades of sea level rise (1990 to 2012) on the composition and structure of hardwood hammock and pine rockland forests at locations inside and outside the freshwater lenses on two lower Keys islands. Groundwater salinity and plant community composition and structure in three height strata were sampled in permanent plots at the 
start and end of the period. The results indicated that after accounting for differences in precipitation, sites located outside the boundary of the freshwater lens increased in groundwater salinity, driving changes in composition of the low shrub strata toward more halophytic assemblages.

Chapter 4 (to be submitted to Ecosystems) considers how seasonal differences in climate affect the lateral and vertical extent of the freshwater lens, groundwater salinity, and community zonation. Employing a combination of groundwater monitoring and electrical resistivity tomography (ERT) surveys, I tracked groundwater salinity along coastal gradients throughout the course of a year (2011-2012) on two islands. Boundaries between adjacent forest types were located based on coincident vegetation sampling and subsequent analysis using a split-moving window technique. Using random forest classification, ERT-derived groundwater salinity and topographic location were assessed for their ability to predict the location of forest communities. Results depicted vertical shifts in the freshwater lens occurring between dry and wet seasons for both islands, but lateral shifts were observed only on the smaller island. Similarly, decreases in groundwater salinity after large rain events were observed primarily at locations on the smaller island. Coastal proximity and groundwater salinity were the most important variables for predicting coastal forest community location, and in general, communities had high probability of occurrence in discrete ranges of groundwater salinity.

Chapter 5 (to be submitted to Ecohydrology) investigates shifts in plant water use and stress in two woody plants located along a coastal gradient in fresh-water requiring 
coastal forests. Slash pine, Pinus elliottii var. densa, and buttonwood, Conocarpus erectus, were sampled three times over the course of nine months in 2011/2012. Both plant water source and plant water stress were determined through isotopic analysis, i.e., $\delta^{18} \mathrm{O}$ of stem water and foliar $\delta^{13} \mathrm{C}$, respectively. Both species relied heavily on groundwater throughout the study. After a large rain event, slash pine used a larger percentage of precipitation as a water source than buttonwood. Temporal differences in groundwater use were observed for buttonwood across the three habitat types in which it occurred. Plant stress as indicated by $\delta^{13} \mathrm{C}$ increased throughout the extended drought that occurred over the study period, and stress was associated with increasing groundwater salinity.

Chapter 6 summarizes the major findings of the work and concludes by considering the possible implications these findings have for freshwater-requiring coastal forests in the Keys. The VITA is the last part of the dissertation. Data used in this dissertation can be obtained at a variety of locations. Satellite imagery is available for download from the USGS Earth Resources Observation and Science Center (EROS) at glovis.usgs.gov. Climate data for Key West is available from the National Climatic Data Center at http://www.ncdc.noaa.gov, while climate data for Big Pine Key is available from MesoWest at http://raws.wrh.noaa.gov/cgi-bin/roman/meso_base.cgi?stn=TS607. Annual mean sea level data for Key West is available from the Permanent Service for Mean Sea Level at http://www.psmsl.org/data/obtaining/stations/188.php. Groundwater chemistry data will be made available via the Florida International University Southeast Environmental Research Center (SERC) and can be obtained by contacting serc@fiu.edu. 


\subsection{References}

Alexander, T.R., 1974. Evidence of recent sea level rise derived from ecological studies on Key Largo, FL. Miami Geol. Soc. 2, 219-222.

Bellingham, P.J., Kapos, V., Varty, N., Healey, J.R., Tanner, E.V.J., Kelly, D.L., Dalling, J.W., Burns, L.S., Lee, D., Sidrak, G., 1992. Hurricanes need not cause high mortality: the effects of hurricane Gilbert on forests in Jamaica. J. Trop. Ecol. 8, 217-223.

Bender, M.A., Knutson, T.R., Tuleya, R.E., Sirutis, J.J., Vecchi, G.A., Garner, S.T., Held, I.M., 2010. Modeled Impact of Anthropogenic Warming on the Frequency of Intense Atlantic Hurricanes. Science 327, 454-458.

Brokaw, N.V.L., Walker, L.R., 1991. Summary of the effects of Caribbean hurricanes on vegetation. Biotropica 23, 442-447.

Guha, H., Panday, S., 2012. Impact of sea level rise on groundwater salinity in a coastal community of south Florida. J. Am. Water Resour. Assoc. 48, 510-529.

Kemp, A.C., Horton, B.P., Donnelly, J.P., Mann, M.E., Vermeer, M., Rahmstorf, S., 2011. Climate related sea-level variations over the past two millennia. Proc. Natl. Acad. Sci. 108, 11017-11022.

Lugo, A.E., 2000. Effects and outcomes of Caribbean hurricanes in a climate change scenario. Sci. Total Environ. 262, 243-251.

Maass, J.M., Balvanera, P., Castillo, A., Daily, G.C., Mooney, H.A., Ehrlich, P., Quesada, M., Miranda, A., Jaramillo, V.J., García-Oliva, F., others, 2005. Ecosystem services of tropical dry forests: insights from longterm ecological and social research on the Pacific Coast of Mexico. Ecol. Soc. J. Integr. Sci. Resil. Sustain. 10, 1-23.

Martínez, M.L., Intralawan, A., Vázquez, G., Pérez-Maqueo, O., Sutton, P., Landgrave, R., 2007. The coasts of our world: Ecological, economic and social importance. Ecol. Econ. 63, 254-272.

Neelin, J.D., Münnich, M., Su, H., Meyerson, J.E., Holloway, C.E., 2006. Tropical drying trends in global warming models and observations. Proc. Natl. Acad. Sci. 103, 6110-6115.

Rahmstorf, S., 2007. A semi-empirical approach to projecting future sea-level rise. Science 315, 368-370.

Ross, M.S., O’Brien, J.J., da Silveira Lobo Sternberg, L., 1994. Sea-level rise and the reduction in pine forests in the Florida Keys. Ecol. Appl. 4, 144-156. 
Snyder, J.R., Herndon, A., Robertson, W.B., 1990. South Florida rockland, in: Myers, R.L., Ewel, J.J. (Eds.), Ecosystems of Florida. University of Central Florida Press, Orlando, FL, pp. 230-277.

Tebaldi, C., Strauss, B.H., Zervas, C.E., 2012. Modelling sea level rise impacts on storm surges along US coasts. Environ. Res. Lett. 7, 1-11.

Williams, J.W., Jackson, S.T., 2007. Novel climates, no-analog communities, and ecological surprises. Front. Ecol. Environ. 5, 475-482.

Williams, K., Ewel, K.C., Stumpf, R.P., Putz, F.E., Workman, T.W., 1999. Sea-level rise and coastal forest retreat on the west coast of Florida, USA. Ecology 80, 20452063.

Yih, K., Boucher, D.H., Vandermeer, J.H., Zamora, N., 1991. Recovery of the rain forest of southeastern Nicaragua after destruction by Hurricane Joan. Biotropica 23, 106-113.

Zervas, C., 2009. Sea level variations of the United States 1854-2006. (NOAA Technical Report NOS CO-OPS 053). National Oceanic and Atmospheric Administration (NOAA) National Ocean Service (NOS), Silver Spring, MD. 
CHAPTER 2. A REMOTELY-SENSED HURRICANE DISTURBANCE HISTORY OF

COASTAL FORESTS OF THE LOWER FLORIDA KEYS (FLORIDA, USA)

\subsection{Abstract}

Hurricanes and tropical storms bring both high winds and storm surge flooding into coastal ecosystems, leading to a range of consequences for plants and ecosystems in which they occur. To identify these effects on coastal forests in the lower Florida Keys, a temporal sequence of Landsat TM images was used to assess the impact of two hurricanes, Hurricane Georges (1998) and Hurricane Wilma (2005). Specifically, I asked whether forest recovery, or a lack thereof, varied along an elevation gradient and between two coastal forest communities, hardwood hammock and pine rockland. Two vegetation indices derived from satellite imagery, the normalized differenced vegetation index (NDVI) and the normalized differenced moisture index (NDMI), identified disturbance impact and recovery. Empirical orthogonal function (EOF) analysis was employed to assess spatiotemporal patterns of disturbance impact and recovery (1986 to 2011) and assess differences between these two communities and topographic elevation. Finally, the relationship between vegetation indices and measured forest stand parameters within permanent plots was evaluated. While both vegetation indices showed a sharp departure from the pre-disturbance control, NDMI showed a greater capacity to detect impacts from hurricane disturbance. The magnitude of the decrease and the time to recovery of NDMI values varied by community and between the two events, with much greater decreases observed post-Hurricane Wilma. The results of EOF analysis showed disturbance impact and recovery varied as a function of both elevation and community type and indicated 
two separate trajectories for post-disturbance recovery. While hardwood hammock NDMI values returned to pre-disturbance levels within a couple years, six years after Hurricane Wilma, pine rockland NDMI values were still depressed. A strong positive correlation between NDMI and basal area per hectare in both community types indicated that satellite-derived data can be applied to coastal forests of various successional stages. The results confirm that proper selection of index is essential to forest disturbance monitoring, and the incorporation of EOF analysis revealed diverging spatial trends in recovery in the two communities that were not visible from a snapshot of pre - post disturbance images.

\subsection{Introduction}

Hurricanes and tropical storms are a frequent component of the western Atlantic climate, altering the structural and ecosystem functions of coastal forests through disturbance from both and wind and storm surge flooding. Specifically, tropical and subtropical coastal forests subject to frequent tropical cyclones are lower in stature, higher in density, and perhaps higher in species diversity than coastal forests in less frequently disturbed areas (Gouvenain and Silander, 2003; Van Bloem et al., 2007; Vandermeer, 2000). Having co-existed with a specific frequency of hurricane disturbance over the past several thousand years, projected global climate change and sea level rise of the $21^{\text {st }}$ century will likely change both the effect of and recovery from tropical storms they experience. The projected increase in the frequency of category 4 and 5 hurricanes impacting the western Atlantic (Bender et al., 2010) would favor disturbance tolerant species by exposing coastal forests more frequently to storms, while shrinking the 
recovery period between events (Lugo, 2000). Projected increases in sea level of 0.5 to 1.4 m (Rahmstorf, 2007) would simultaneously increase the likelihood of storm surge inundation and bring water tables closer to the ground surface. As climate and disturbance envelopes shift and species are eliminated that cannot tolerate the new environmental conditions, recovery and successional dynamics of coastal forests as the currently exist will surely change.

Hurricane winds cause immediate damage to vegetation, ranging from minor leaf defoliation and loss of branches to uprooted or snapped tree trunks (Brokaw and Walker, 1991). While damage may be severe, tree mortality from even the strongest of hurricanes is usually not excessive (Bellingham, 1991; Walker, 1991), and recovery to primary forest can be rapid (Yih et al., 1991). The magnitude and pattern of damage depends on a combination of factors, including: hurricane wind speed and storm duration, site topographical setting, stand structure, and species biophysical properties (Boose et al., 1994; Foster and Boose, 1992). While the response of individual species is determined by wood density and architecture (Putz et al., 1983), the physiographic setting influences both the magnitude of disturbance experienced at a location (Bellingham et al., 1994; Reilly, 1991) and subsequent recovery.

In contrast to hurricane damage resulting purely from wind disturbance, visible damage to vegetation from storm surge typically develops as leaves are shed over periods of weeks to several months (Conner and Inabinette, 2003; Gardner et al., 1991), with initial effects those of osmotic stress and subsequent effects attributable to salt toxicity (Munns, 
2002). Salinity effects on non-halophytic vegetation include decreases in productivity, changes to plant anatomy (Kozlowski, 1997), and mortality is frequently observed (Conner et al., 1997; Conner and Inabinette, 2003). Recovery from a storm surge event may be impeded by low nutrient availability as plants first drop leaves without reabsorption of nutrients, and salinization of soil disrupts microbial processes, leading to decreases in microbial immobilization and subsequent nitrogen loss from the system (Blood et al., 1991). Individual species' response to osmotic and salt stress is an overriding factor in storm surge (Chapman et al., 2008), and a crucial determinant of the structure and composition of the post-disturbance coastal forest.

To predict how structure and extent of coastal forests will change in a future of anthropogenic climate change, it is imperative that we quantify how these communities have responded to frequency and magnitude of disturbances in the past. Quantification of the effect of disturbance on forest recovery is greatly facilitated by the recent widespread availability of remotely sensed data at both a temporal and spatial scale adequate to capture more than just a before and after picture of the effect of disturbance on ecological phenomena (Kennedy et al., 2014). Vegetation indices derived from satellite data, specifically the normalized differenced vegetation index (NDVI), have been widely used to assess plant stress from disturbance and quantify forest biomass in many locales (Pettorelli et al., 2005). The NDVI utilizes a combination of reflectance in the red and near-infrared (NIR) portion of the electromagnetic spectrum. Changes in red reflectance are helpful in identifying leaf senescence and photosynthetic activity in plants, while high NIR reflectance is observed in forests with thick canopies resulting from the canopy 
effect (Jensen, 2005). While NDVI has been successfully used to document changes in coastal wetlands in Alabama after Hurricane Katrina (Rodgers et al., 2009) and in Louisiana after Hurricane Rita (Steyer et al., 2013), recent work has shown vegetation indices derived from a combination of the NIR and mid-infrared (MIR) portion of the electromagnetic spectrum to be superior for detecting forest disturbance (Wang et al., 2010; Wilson and Sader, 2002). Under non-stress conditions, plants reflect much of the NIR energy as a result of scattering by the spongy mesophyll (Tucker, 1979). Thus, changes in NIR are helpful in identification of amount of biomass present, decreases in which may be indicative of storm damage. The usefulness of the MIR bands is found in the relationship between leaf reflectance and leaf moisture content; as leaf moisture content decreases, reflectance increases in the MIR bands (Pu et al., 2003). This relationship between reflectance and leaf moisture in the MIR bands imparts information on plant water stress and moisture status.

Given the established physiological relationships between vegetation structure and leaf and canopy reflectance, aboveground biomass and forest structure have been estimated in a variety of forest types (both temperate and tropical) using Landsat TM data with varying degrees of success, dependent on both landscape context and forest complexity parameters (Lu, 2005; Sader et al., 1989; Steininger, 2000). While NDVI has been widely used, work conducted in mature and successional rain forests (Lu et al., 2004) and in Atlantic coastal forests of Brazil (Freitas et al., 2005), determined that indices that included MIR bands provided the best correlations to stand parameters. Using a timeseries dataset of Landsat TM and MSS images, disturbance history metrics have been 
derived to estimate forest structure in the temperate Northwest (Pflugmacher et al., 2012). Extending the relationship between forest disturbance and recovery as assessed from vegetation indices and measured forest stand parameters, both spatially across coastal forest types and temporally across a hurricane-disturbed landscape, will be very useful for both coastal forest monitoring and prediction of future forest structure across large spatial swaths.

Using an approach that combines a 26-year temporal sequence of Landsat TM data (1986-2011) and ground-based measurements of forest stand parameters (1990 and 2011), this study quantifies the ecological effects of two hurricanes that struck the islands of the lower Florida Keys, Hurricane Georges (1998) and Hurricane Wilma (2005). Specifically, it considers whether forest recovery, or a lack thereof, varied along an elevation gradient and between two coastal forest communities, hardwood hammock and pine rockland. Hurricane Georges, a category 2 storm at time of landfall at Key West, FL on September 25, 1998, produced a storm surge of 1.5 to $1.8 \mathrm{~m}$ from the Atlantic, while Hurricane Wilma, a category 3 storm at the time of landfall near Naples, FL on October $24^{\text {th }}, 2005$, produced two separate storm surges (Kasper, 2007). The first surge of $1.5 \mathrm{~m}$ came from the Atlantic, while the second surge of 1.8 to $2.4 \mathrm{~m}$ piled up water from the shallow Florida Bay and inundated the islands of the lower Keys to all but the highest elevations. Owing to the differences in the paths and sizes of the two storms, the wind speeds experienced observed in the lower Keys were similar between storms and the variation across the islands was small, with 40 to $45 \mathrm{~m} / \mathrm{s}$ winds for $10+$ hours from Georges and 30 to $40 \mathrm{~m} / \mathrm{s}$ winds recorded for Wilma (Powell et al., 1998; Zehr and 
Knaff, 2007). While there was clear evidence of wind damage to vegetation from both storms, my work argues that the differences in severity of impact to vegetation from the two storms resulted primarily from variation in the extent of the storm surge flooding, rather than any differences in wind effects between the two storms.

The present study addresses three scientific questions. First, is there an alternative vegetation index which performs better than NDVI in assessing hurricane disturbance and subsequent recovery processes in pine rockland and hardwood communities in the lower Florida Keys? Secondly, what is the difference between these two communities in response to storm surge disturbance and how does the topographic elevation influence the response? Finally, are previously established relationships between satellite-derived vegetation indices and forest stand parameters also observed in broadleaf subtropical and conifer forests of the lower Florida Keys? To address the above questions, I compare the ability of two vegetation indices, NDVI and the normalized difference moisture index (NDMI), in identifying disturbance impact and recovery. To assess change in vegetation indices, I employ both a standard bi-temporal technique, univariate image differencing (UID), and a technique that uses a temporal sequence of images, specifically, Empirical Orthogonal Function analysis (EOF). EOF provides a powerful tool to describe and identify the spatiotemporal pattern of a dataset, and has been widely used in meteorological and oceanographic research to describe variability and reduce high dimensionality data into its deterministic and stochastic components (Preisendorfer, 1988; Storch and Zwiers, 1999). Finally I compare the vegetation indices to measured 
stand parameters in permanent plots in both hardwood hammock and pine rockland forests for pre- and post-disturbance sample periods.

\subsection{Study Area}

In the lower Florida Keys, where elevations exceeding two meters are uncommon and where an increase in sea level of $23 \mathrm{~cm}$ has been documented over the past century (Key West Tide Gauge, NOAA), changes to coastal forests are already evident, and appear to be attributable to a combination of disturbance impacts and increases in sea level (Ross et al., 2009). The $20^{\text {th }}$ century increase in sea level is significant compared to the rate of 4 cm per 100 years observed for the previous 3000 years (Wanless et al., 1994). Hardwood hammock and pine rockland forests provide habitat for many south Florida endemic, threatened and endangered species (Snyder et al., 1990). In the U.S., these forests are only found in the Florida Keys and a few locations on mainland south Florida. While degradation and loss in extent has resulted from urbanization and altered fire regimes, hurricanes of the past couple decades have also affected the structure and composition of these forests (Ross et al., 2009; Saha et al., 2011).

The study area spans 30 kilometers across the lower Florida Keys and includes eight islands with areas of coastal forest that are owned/managed by the USFWS National Key Deer Refuge, including: Big Pine Key (BPK), Little Pine Key (LPK), No Name Key (NNK), Little Torch Key (LTK), Middle Torch Key (MTK), Big Torch Key (BTK), Cudjoe Key, (CUD) and Sugarloaf Key (SLK) (Figure 2.1). Freshwater-requiring coastal forest types considered in the study are hardwood hammock, consisting of woody plant 
species of West Indian origin, and pine rockland, dominated by the tree Pinus elliottii var. densa Engelm., with an understory of shrubs and palms (Snyder et al. 1990). Elevations for each habitat across the eight islands range from $0.2 \mathrm{~m}$ to $1.5 \mathrm{~m}$ for pine rockland and from 0.2 to $2 \mathrm{~m}$ for hardwood hammock. While both communities can occur within 50 meters of the coast, hardwood hammock is typically found coastward of pine rockland, with the mean distance to coast generally several hundred meters greater for pine rockland than hardwood hammock. Coastal distance and elevation are not necessarily well-correlated on the uneven surface of the lower Florida Keys. While hardwood hammock trees are rooted in soil depths ranging from just a few centimeters to $0.35 \mathrm{~m}$ of organic soil, pine rocklands typically have just 0.01 to $0.1 \mathrm{~m}$ of soil present (Ross et al., 1992), and trees often root directly into crevices in the exposed bedrock (Snyder et al., 1990).

The bedrock consists of two distinct layers, both of Late Pleistocene age (Perkins, 1977). The upper layer, the Miami Limestone (Hoffmeister et al., 1967), is several meters thick (Coniglio and Harrison, 1983) and overlies the Key Largo Limestone (Hoffmeister and Multer, 1968). While both formations are highly permeable, differences in the origin of the facies and subsequent diagensis have resulted in greater secondary porosity in the underlying Key Largo Limestone (Coniglio and Harrison, 1983). The lower secondary porosity of the Miami Limestone results in a fresh water lens that is truncated just below the contact between the facies (Vacher et al., 1992). The presence of the pine rockland community in the lower Florida Keys has been attributed to the existence of fresh water 
lens on these islands, as pines are rather intolerant of salt water and rely at least partially on freshwater from the lens (Ross et al., 1994).

The climate of the Keys is characterized by extended wet (June through October) and dry seasons (November through May), with typically more than two-thirds of annual precipitation falling during the wet season (average annual precipitation of $1027 \mathrm{~mm}$ for 1984-2013 at Key West International Airport, http://www.ncdc.noaa.gov). Temperatures range from an average monthly low of 20 degrees Celsius in January to an average monthly high of 29 degrees Celsius in August (30-year average, KWIA). While the majority of plant species within both the pine rockland and hardwood hammock are evergreen, a few species are drought deciduous and drop their leaves toward the end of the dry season. Additionally, evergreen species can become water stressed during the dry season after a long period without substantial precipitation (Ogurcak, unpublished data).

\subsection{Methods}

\subsubsection{Image Processing}

Landsat 4-5 TM images (path 15, row 43) with a spatial resolution of $30 \times 30$ m were downloaded from glovis.usgs.gov for the years spanning 1983 to 2011. The earliest relatively cloud-free image of each calendar year (January through March) was selected. A Landsat 7 ETM+ image was selected for 2003 as no cloud-free Landsat 4-5 TM imagery was available for the period. Downloaded images had been previously geometrically corrected and registered to the NAD83 datum by USGS (data product L1) and were checked against road features to verify georeferencing. Images were 
radiometrically calibrated and then atmospherically corrected using the FLAASH module in ENVI 5.0. The atmospheric model used for correction was selected according to the temperature at the time of image acquisition at the Key West International Airport; tropical was used for temperatures above 24 degrees Celsius and mid-latitude summer was selected as the model for temperatures below this threshold. The aerosol model selected was maritime, and 2 Band Aerosol retrieval using the Kauth-Thomas method was selected.

I selected pseudo-invariant features (PIFs) (Philpot and Ansty 2013) across the Landsat scene which covered the geographic area of the Florida Keys from Boca Chica Key to Upper Key Largo. PIFs are landscape features that experience little change in percent reflectance on a seasonal or annual basis and provide a good check on the reliability of the atmospheric correction for each image. Features used in this analysis include: an airstrip at the Marathon airport (N 24.724, W -81.057), open ocean located 20 kilometers south of Marathon (N 24.536, W -81.011), and a red mangrove island just south of No Name Key (N 24.667 W -81.326). An $8100 \mathrm{~m}^{2}$ area (9 pixels in a 3 x 3 arrangement) was selected to represent each PIF. Band values were extracted from the corresponding pixels in each image using the Extract Multi Values to Points tool within the Spatial Analyst toolbox in ArcGIS 10.0. An average value was calculated for each band for each image date at each PIF and deviations from the average value were compared to assess the quality of atmospheric correction. Images having PIFs with reflectance values in Landsat TM bands 1 through 5 deviating by more than $+/-3.5 \%$ reflectance from the average value of the corrected images in several PIFs were discarded and not used in the study. 
Additionally, images found to have too many clouds obscuring the study area were removed from the dataset, resulting in a total of 19 images used in the analysis (Table 2.1).

\subsubsection{Data Selection and Extraction}

Band values for over 11,000 Landsat TM pixels, corresponding to all areas of hardwood hammock (6123 pixels) and pine rockland (4935 pixels) (minimum size of 3 contiguous pixels), were extracted for the analysis (Figure 2.1). The boundaries of coastal forest areas included in this study were obtained from a land cover map created from a combination of elevation and canopy height derived from LiDAR collected in 2007 and high resolution aerial imagery from 2006 (Zhang et al., 2010). To avoid mixed pixels and reflection from adjacent land cover types, pixels located within 10 meters of a land cover polygon boundary were eliminated from the analysis. The selection of $10 \mathrm{~m}$ distance was based on a moving window analysis of coastal forest community change on two of these islands that identified a $5 \mathrm{~m}$ window as most effective at distinguishing adjacent community types (Ogurcak, unpublished data). A centroid was created for each pixel and band reflectance values were extracted from each of the 19 images. Average elevation of each pixel was obtained from a 5 x 5 m resolution DTM derived from Lidar data (Zhang

et al., 2010). Landsat pixels with average elevations below $20 \mathrm{~cm}$ were eliminated from the analysis; these pixels typically corresponded to open rock flats or small sinkholes containing wetland vegetation within the surrounding pine rockland or hammock forest. A small percentage of pixels obscured by cloud cover in three images (1991, 2000, and 
2011) were set to no data for those years for the calculation of means, while affected pixels and/or image date (1991) were eliminated entirely for the EOF analysis.

The NDVI and NDMI were calculated from band values for each image date. Both indices use a combination of Landsat TM band 4 (wavelength 0.76 to $0.90 \mu \mathrm{m}$ ) in the NIR and one other band. NDVI uses Landsat TM band 3 (0.63 to $0.69 \mu \mathrm{m}$ ), red band, in the visible spectrum, while NDMI uses Landsat TM band $5(1.55$ to $1.75 \mu \mathrm{m})$ in the MIR. Equations for each index are derived as follows:

$N D V I=\left(N I R_{T M 4}-\operatorname{Re} d_{T M}\right) /\left(N I R_{T M 4}-\operatorname{Re} d_{T M 3}\right)$, (Rouse et al., 1973),

$N D M I=\left(N I R_{T M 4}-M I R_{T M 5}\right) /\left(N I R_{T M 4}-M I R_{T M 5}\right),($ Hardisky et al. 1983; Wilson and Sader, 2002). While each of the above indices can take a value from -1 to 1 , areas covered with vegetation generally have values greater than 0 , and non-disturbed forested areas typically have values that range from 0.2 to 0.9 for NDVI and 0.2 to 0.6 for NDMI. Vegetation index values from Florida Keys coastal forests typically are lowest at the end of the dry season, when drought-deciduous species have lost their leaves and plants are under the most water stress, and reach the highest values during the wet season (Ogurcak, unpublished data).

\subsubsection{Field Methodology}

Seven $60 \mathrm{~m}$ by $10 \mathrm{~m}$ permanent plots, three located in pine rockland and four in hardwood hammock, that had been sampled for tree basal area and percent shrub cover in 1990 were resampled using the same methodology in 2012 (Figure 2.1, Table 2.2). Permanent plots consisted of a belt transect of six 10 x 10 m subplots, with the exception 
of one plot that contained only five subplots. In each subplot, diameter at breast height (dbh) was recorded for all trees greater than $2 \mathrm{~m}$ in height and having a dbh greater than 3 $\mathrm{cm}$. An average basal area per hectare was calculated for each permanent plot. Percent shrub cover was estimated in two understory strata in a $5 \times 5 \mathrm{~m}$ quadrat located at the center of each subplot. The high shrub strata included woody plants with dbh less than 3 $\mathrm{cm}$ and height greater than $1 \mathrm{~m}$, while the low shrub strata consisted of herbaceous plants and woody shrubs less than $1 \mathrm{~m}$ in height. Percent shrub cover was estimated in the following categories, with the midpoint of each category used for subsequent analyses: 0 $=0 \%, 1=<1 \%, 2=1-4 \%, 3=4-16 \%, 4=16-32 \%, 5=32-66 \%$, and $6=66-100 \%$.

\subsubsection{Data Analysis}

Prior to performing analyses, I assessed the effect that the date of image acquisition may have had on vegetation index values and subsequent patterns observed in the data. While the annual images selected for analysis spanned a short time period in the middle of the dry season (70 days) and should capture reflectance from vegetation at approximately the same phenological state, I wanted to quantify the extent of any relationship between index values and day of year. Additionally I determined if a relationship existed between the amount of recent precipitation and index values as has been observed between NDVI and rainfall in the Sahel (Nicholson et al., 1990; Davenport and Nicholson, 1993) and the American Midwest (Wang et al., 2003). Since the amount of recently received precipitation could affect leaf water status and subsequent reflectance values, I considered 30 and 90 day accumulations prior to each image acquisition date. I then compared the average NDVI and NDMI in both hardwood hammock and pine rockland 
habitats on each island to the day of year of image acquisition and to precipitation totals. A subset of the image dates was used in this analysis to avoid the effect of disturbance on the indices and focus on the amount, if any, of underlying variation in the indices related to the above stated factors. For hardwood hammock, I selected the seven images acquired prior to Hurricane Georges (1986-1998) and the five images acquired prior to Hurricane Wilma (2001-2005) for a total of twelve images. In pine rockland, both wildfire and prescribed burns affected several locations over that same time period, therefore years immediately post-fire were removed and analyses were conducted separately on areas of pine rockland in separate management units having different fire histories. Fire history data, including date and area of burn, was obtained from the Key Deer National Wildlife Refuge for all areas of pine rockland. Daily precipitation data was obtained from Key West International Airport (http://www.ncdc.noaa.gov) and was used to calculate the total amount of precipitation received in 30 and 90 day intervals prior to image acquisition. Each image date was converted to the Julian day, and relationships were assessed using linear regression.

To address the first objective, evaluating the performance of selected vegetation indices, a frequency distribution of change in spectral index by pixel was generated using UID for images obtained before and after Hurricane Wilma (2005 and 2006) compared to an interval of no change (1996 to 1997) prior to both storms. The latter interval was selected for this purpose because it pre-dates both hurricanes and fire had not occurred within hammock or pine rockland since 1994 (Bergh and Wisby, 1996) and did not recur until August 1998 (Sah et al., 2006). Additionally, the mean and standard deviation of each 
index for 1996 was calculated to compare pre-disturbance index values between community types. Pine rockland was separated into areas of pine occurring on BPK and pine in the other four islands combined (CUD, LPK, NNK, and SLK). These areas were separated to account for the historically more frequent fire return interval on BPK compared to that of the smaller islands (Carlson et al., 1993). Shorter fire-return intervals influence stand structure by decreasing the amount of shrubby biomass, leading to more open savannah-type pine forests, and have the effect of decreasing vegetation reflectance and index values.

The mean NDMI +/- 95\% confidence interval for the temporal sequence of image dates was plotted for all pixels in each community type in three elevation intervals: low elevation $(0.20$ to $0.60 \mathrm{~m})$, mid elevation $(0.60$ to $1.0 \mathrm{~m})$, and high elevation $(\geq 1 \mathrm{~m})$. Additionally, the mean reflectance $+/-95 \%$ confidence interval for bands 3, 4, and 5 for hardwood hammock and pine rockland pixels occurring at an elevation below $1 \mathrm{~m}$ was plotted for the temporal sequence. Using UID, the average decrease in NMDI pre-post Hurricane Georges (1998 - 1999) and pre-post Hurricane Wilma (2005 - 2006) was plotted in 0.10 m elevation intervals in each community type. All pixels greater than 1.0 m were combined into a single category. Additionally, to identify any island effects, the average change in NDMI was similarly plotted for all pixels on each island in both communities and was related to the longitude of each island along the west to east orientation of the study site. 
To identify spatiotemporal patterns of the dataset, I employed EOF analysis in the manner of Small (2012). The output of the analysis consists of uncorrelated spatial and temporal patterns that correspond to the eigenvectors of the covariance matrix. A time series of pixels at specific spatial locations $P(x, y, t)$ can be represented as a linear combination of temporal patterns $c_{k}(t)$ and their spatial components $e_{k}(x, y)$ using the following formula:

$$
P(x, y, t) \approx \overline{P(x, y, t)}+\sum_{k=1}^{m} c_{k}(t) e_{k}(x, y)
$$

where $m$ is the number of temporal points, $P$ is the number of spatial points, $k$ is the number of dimensions, and $\overline{P(x, y, t)}$ is the average of $P(x, y, t)$ over time. The spatial empirical orthogonal functions (sEOFs) represent the weight contributed by each temporal empirical orthogonal function (tEOF) at a given location. The EOF analysis was run in Matlab v.8.1 on a matrix of NDMI values in an arrangement of pixels (rows) by 18 image dates (columns). The analysis was conducted on 10983 pixels, 6095 occurring in hardwood hammock and 4888 in pine rockland. The 1991 image was not used in the computation of covariance because of the presence of scattered cloud-cover across the image. Weights for each dimension of temporal EOF 1 and 2 were plotted on a bar graph. The distribution of spatial EOFs 1 and 2 were plotted for each pixel in hardwood hammock and pine rockland in the study area by using a spatial join in ArcGIS 10.1 to combine the results of the EOF analysis with the centroid associated with each pixel location. The relationships between elevation and spatial EOFs were assessed with linear regression. T-tests were used to compare the mean scores for spatial EOF 2 for each community type on each island. 
To determine the relationship between measured stand parameters and vegetation indices, the average basal area per ha and percent cover for each permanent plot in both sampling periods $(\mathrm{n}=14)$ were compared to NDVI and NDMI values for Landsat TM pixels coincident with the permanent plots. Nine Landsat TM pixels, which included the plot itself as well as surrounding habitat of the same coastal forest type, were selected for comparison between vegetation indices generated from the 1990 and 2011 images. Fewer than nine pixels were selected for two plots in which the surrounding habitat was not sufficiently large (Table 2.2). Pearson correlation coefficients were used to assess the relationships and p-values $<0.05$ were reported as significant.

\subsection{Results}

\subsubsection{Seasonality and Vegetation Indices}

Despite a difference of $30 \mathrm{~cm}$ of precipitation received between dry-season image dates, no correlation was found between NDVI or NDMI values in pre-disturbance images and precipitation totals for the 30 or 90 days prior to the image, indicating that previous precipitation did not influence the spectral signature observed in hardwood hammock or pine rockland. Julian Day was significantly negatively correlated with average vegetation index value for non-disturbance years for both indices on a majority of islands / management units (Figure 2.2a and 2.2b, NDMI shown). The negative relationship between vegetation index and Julian date over the window of image acquisition indicates that there are some detectable changes in moisture stress or phenology (senescent leaves in some species) occurring over the time period that likely integrate the effects of increasing number of daylight hours and amount of solar radiation observed at this time 
of year. However, the mean change in indices (+/- SE) over the time period from earliest image acquisition date (January 3, 1997) to latest image acquisition date (March 11, 1998) was minimal; hardwood hammock decreased by $0.03+/-0.003$ for NDMI and 0.02 +/- 0.004 for NDVI, while pine rockland decreased by $0.07+/-0.01$ for NDMI and 0.04 +/- 0.01 for NDVI. A total of 19 days separates the 2005 and 2006 image dates bracketing Hurricane Wilma, making the pre-post hurricane decrease in NDMI attributable to increasing Julian date -0.02 in pine rockland and -0.01 in hardwood hammock. Thus, I considered the effects of seasonality on the selection of image dates negligible and attribute observed changes in index values greater than 0.1 to disturbance events.

\subsubsection{Comparison of Vegetation Indices}

While changes post-pre disturbance for both vegetation indices showed a sharp departure from the pre-disturbance control interval (1997-1996), NDMI showed a greater capacity to detect impacts from hurricane disturbance than NDVI, as indicated by the larger mean decrease observable in its frequency distribution for 2006-2005 (Figure 2.3a and b). With a mean near 0 and a small standard deviation $(0.03+/-0.04$ for NDVI and $0.04+/-0.04$ for NDMI), the pre-disturbance control interval for both vegetation indices is as expected for UID between years of no intervening disturbance. The mean decrease in NDMI was greater than that of NDVI in the post-pre disturbance comparison when community types were considered separately and when pine was divided into areas located both on and off Big Pine Key (Table 2.3). The standard deviation around the mean change was similar (0.08 to 0.12 ) for both indices in each community type for the post-pre hurricane interval 
and was larger than that of the control interval, as would be expected, as a function of differential effect of storm surge on pixels across the entire elevation gradient. Additionally, the observed decrease in vegetation index following Hurricane Wilma varied by community type; hardwood hammock pixels displayed a greater mean decrease in both indices compared to pine rockland (Table 2.3). The average 1996 pre-disturbance values for both indices were lower in pine rockland, but only for areas located on Big Pine Key. This relationship is expected given the greater historical frequency of fire in pine rockland on Big Pine Key compared to that of the smaller islands that have moved further along in the successional stage and have greater component of woody hardwood species (Carlson et al., 1993). Since NDVI and NDMI share band 4 (NIR) in the calculation of the vegetation index, the observed differences in magnitude of change in NDMI versus NDVI must be attributable to greater post-hurricane increases in band 5 reflectance compared to increases in band 3 reflectance. While an average increase of $1 \%$ was observed post-Wilma for band 3 reflectance, a decrease of $4 \%$ and increase of $10 \%$ were observed for band 4 and 5 reflectance, respectively.

\subsubsection{Differences in Hurricane Impact and Recovery}

Disturbance impact from Hurricane Georges (1998) and Wilma (2005) was recorded as a visible decrease in NDMI in subsequent year(s) in both communities. However, the magnitude of the decrease and the time to recovery of pre-disturbance values varied by community and between the two events (Figure 2.4a-c). Damage to pine rockland from Hurricane Georges at all elevations was less than the change attributable to seasonal variation in NDMI (Figure 2.5), except for slight decreases on the easternmost islands of 
No Name and Little Pine Keys (Figure 2.6). While a decrease in NDMI was visible in hardwood hammock at all elevation ranges from Hurricane Georges, it was most noticeable at elevations below $0.7 \mathrm{~m}$ (Figure 2.7) and was most pronounced on the easternmost islands (Figure 2.6). Index values in hardwood hammock recovered to those of the pre-disturbance image by February 2000. Decreases in NDMI from Hurricane Wilma were much larger than those of from Georges, and were largest at elevations below $1 \mathrm{~m}$ (Figure 2.4a and 2.4b). The percent decrease in NDMI varied by elevation interval and between community types. Hardwood hammock had approximately the same percent decrease across all elevation intervals below $1 \mathrm{~m}$, while pine rockland decreased most at lower elevations. In both communities, the average change in NDMI by island was predicted by the percentage of pixels occurring at elevations below 1 meter (Figure 2.8). For both habitats, NDMI values at elevations above $1 \mathrm{~m}$ recovered to predisturbance levels by February 2007 for (Figure 2.4c). However, at elevations below 1 m, recovery differed between the two community types. In hardwood hammock, NDMI values returned to the previous level by the February 2009 image, while in pine rockland, NDMI values did not even reach pre-disturbance condition by February 2011 (Figure 2.4a and b). Individually plotting reflectance values for bands 3, 4, and 5 for pine rockland and hardwood hammock pixels below 1 m elevation (Figure 2.9) demonstrated the difference in both magnitude and duration of change in reflectance by band across the time series. Band 3 reflectance increased by an average of 2 to 3 percent post-Hurricane Wilma for both communities, but returned to pre-disturbance reflectance by the next image date. For bands 4 and 5, the mean change in reflectance and time to recovery varied by community. An immediate decrease of $6 \%$ occurred in band 4 in hardwood 
hammock post-Wilma, but a smaller and delayed response was observed in pine rockland. The band 5 increase in reflectance, while slightly smaller in pine rockland, returned to pre-disturbance values only in hardwood hammock community by the 2011 image.

The results of the EOF analysis mirror the visual trend in NDMI over the 26-year period, but provide an additional spatial component to the variability. The first two temporal EOFs (tEOFs) explain $78 \%$ of the variability in the temporal dataset (tEOF 1 explains 67\%, tEOF 2 explains 11\%). Temporal EOF 1 primarily weights the negative effect of Hurricane Wilma on NDMI values in the first two post-disturbance images, with 2006 having the greatest magnitude, to that of pre-disturbance years, with 1997 having the greatest positive value (Figure 2.10a). Temporal EOF 2 reflects the ratio of immediate post-hurricane NDMI values for Georges and Wilma (1999 and 2006 images) to those of the later stages of post-Wilma recovery (2007 to 2011) (Figure 2.10b). Disturbance impact from Hurricane Wilma can be seen to vary with spatial EOF 1 (sEOF1) as a function of elevation while spatial EOF 2 (sEOF2) highlights the contrasting response between community types. Using No Name Key as an example, sEOF1 scores are distributed with high elevation pixels having values near 0 and low elevation pixels reaching a maximum of 0.016 (Figure 2.11). A statistically significant negative relationship exists between elevation and sEOF1 scores until approximately $1.0 \mathrm{~m}$ in elevation which may represent the upper limit of storm surge waters on No Name Key (Figure 2.12). Spatial EOF 2 (Figure 2.13) illustrates two diverging trends in impact and recovery between hardwood hammock and pine rockland. Areas of pine rockland are characterized by negative values, while areas of hardwood hammock take on positive 
values (Figure 2.14). This pattern was found on all islands having both hardwood hammock and pine rockland (t-tests: $\mathrm{p}<0.001)$. There exists a clear difference in the trajectories that these two communities are taking.

\subsubsection{Relationship between Vegetation Indices and Stand Parameters}

Decreases in basal area per hectare of permanent plots differed between community types with hardwood hammock experiencing decreases ranging from 3 to $48 \%$, while pine rockland basal area per hectare decreased 47 to $77 \%$ of its 1990 value. A positive linear relationship was found between both NDMI and NDVI and two structural variables, basal area per hectare and percent cover of the high shrub layer (Table 2.4). In both communities, the strongest relationship was observed between NDMI and basal area per hectare (Figure 2.15). No significant relationship was observed between either index and low shrub cover. For the same value of NDMI, hardwood hammock had larger tree basal area than pine rockland, which is expected given the more open nature of the pine rockland overstory that allows more of the spectral signal to be attributed to shrub cover. The correlation between NDMI and high shrub cover in pine rockland and hardwood hammock was 0.73 and $0.65(\mathrm{p}<0.10)$, respectively.

\subsection{Discussion}

\subsubsection{Vegetation Index Comparison}

While both vegetation indices were found to be show evidence of hurricane disturbance, NDMI was a better indicator of disturbance and recovery. The combination of Landsat TM bands 4 and 5 (NDMI) better represented both the magnitude of disturbance effect 
and recovery compared to that of bands 3 and 4 (NDVI) (Figure 2.3b). Decreases in NDMI were greater than those of NDVI for both community types (Table 2.3). Previous comparisons of these two indices in an estimation of leaf and canopy moisture content yielded similar results of the superiority of NDMI (Hardisky et al. 1983). In contrast to the findings that an increase in leaf reflectance in the visible spectrum is the most consistent signature of plant stress as the plant absorbs less energy in the chlorophyll absorption bands (Carter, 1993; Carter et al., 1996), the best indicator of disturbance effect and recovery seems to be tied to plant moisture stress. Changes to canopy biomass and leaf moisture content post-disturbance are likely both important factors in determining effects of and recovery from hurricane disturbance. The biophysical parameters captured by the range of EM spectrum corresponding to Landsat band 5 can be interpreted as the persisting effect of storm surge, indicating that decreases in canopy moisture and increases in plant water stress can persist at a minimum six years posthurricane disturbance in pine rockland in the Florida keys (Figure 2.9), making this the most recognizable post-storm surge symptom of plant community stress within pine rockland. While small declines in photosynthetic capacity associated with increased reflectance in band 3 are more transitory, the decrease in band 4 and increase in band 5 are prolonged. Differences in recovery time of reflectance in these bands between hardwood hammock and pine rockland might be attributable to a variation in fresh water availability post-hurricane, as well as differing regeneration strategies of species that dominate these communities. 


\subsubsection{Storm Impacts and Island Elevation}

While a couple studies exist contrasting the effects of wind disturbance from hurricanes to these two forest types (Boucher et al., 1990; Craighead and Gilbert, 1962), a search of the literature found 0 studies having contrasted the impact and effects of hurricane storm surge in these communities. In a region frequently impacted by hurricanes, this is likely explained by the higher elevation of most coastal forests across the Greater Caribbean region that would rarely be inundated by storm surge. The Florida Keys provide a unique opportunity to study storm surge effects on coastal forests given their extremely low elevations that make them susceptible to storm surge impact. A combination of restricted aerial extent, the similar range in wind speeds of both storms, and the flat topography of the Florida Keys, rules out wind as the primary stressor for differential damage patterns to hardwood hammock and pine rockland from the two hurricanes.

While wind can be considered constant across the habitats within each island, differences in sustained winds from Hurricane Georges varied across the study area between islands with the strongest winds on No Name and Little Pine Keys (Powell et al., 1998). The only visible decreases in vegetation indices in pine rockland occurred on these two islands (Figure 2.6). The storm surge from Hurricane Georges came from the Atlantic and high water mark elevations were recorded after the storm at 1.8 meters NAVD88 on east side of Cudjoe and 1.4 meters NAVD88 on eastern Big Pine (Sea Systems Corporation, 1998). While these heights are easily large enough to have flooded hardwood hammock near the coast, they were not large enough to have flooded interior pine rockland locations. Combined with the lack of decrease in NDMI in lower elevation 
pine rockland on other islands to the west, small decreases in NDMI observed postGeorges in pine rockland are most likely attributable to wind damage. In hardwood hammock, a combination of storm surge and wind led to coastal forest damage. While similarly larger decreases in NDMI were observed in the eastern islands, the larger magnitude of change in NDMI in low versus high elevation hammock indicates storm surge as the over-riding factor.

In contrast, the largest magnitude decrease in spectral index over the 26-year period in both community types is observed in the 2006 image - post Hurricane Wilma (Figures 2.4a-c). The high weighting of tEOF1 (Figure 2.10a) in the post-Wilma image implicates storm surge flooding from Hurricane Wilma as the primary cause of disturbance to these forests. The relationship with sEOF1 and elevation (Figure 2.12) provides quantitative evidence for what was readily apparent to those giving first-hand accounts of the storm; damage from Hurricane Wilma was attributable to flooding rather than effects of wind. Wind speeds generated from the HRD hurricane wind analysis (Powell et al.1998) and those recorded before instrument failure (Kasper et al. 2007) were fairly consistent across the study area. The second surge from Hurricane Wilma came from Florida bay (Kasper, 2007) and generated high water elevation marks over 2 m NAVD88 at the northern ends of Upper Sugarloaf and Cudjoe Keys, with a southern interior location on Big Pine Key recorded at over $1 \mathrm{~m}$ (URS Group, Inc., 2006). The result was that all but the highest locations received storm surge waters and most islands were completely inundated. No Name Key, with the highest elevations in the study area and 30\% of the area in both communities greater than 1 meter elevation, was one of the few islands where flood 
waters did not entirely cover the coastal forests and correspondingly, a much smaller change in index is observed at the island level (Figure 2.8).

In pine rockland, the greater decrease in NDMI observed at lower elevations (Figure 2.4a) could be explained by increased damage from the effect that increasing amounts of salt water flooding has on the dominant species, Pinus elliotti var. densa. In an experimental study of slash pine seedling flooding with salt water, increased injury resulted and chloride content increased with greater depths of salt water above the soil surface (Land, Jr., 1974). An assessment of pine mortality post-Wilma on Big Pine and Upper Sugarloaf Keys found that the percentage survival increased with elevation (Ross et al., 2009). Differential mortality attributable to topographic location was observed in the aftermath of storm surge generated by Hurricane Hugo in South Carolina (Gardner et al., 1991), as inundated trees on a ridge survived while trees located in swales where saline water collected died. The role of microtopography on mortality and recovery from disturbance is clearly important especially in an area of such low elevation and topography as the Florida Keys. This in turn will interact with species-specific responses to disturbance.

\subsubsection{Differences in Impact and Recovery between Community Types}

On all islands, except on Big Pine where frequent prescribed fires have kept the pine forest open, pre- hurricane vegetation index values were similar for the two communities (Table 2.3), with NDMI ranging from 0.4 to 0.5 (Figure 2.2a and 2.2b). Yet post-Wilma, both the magnitude of decrease in NDMI and the number of years for the index to regain 
the pre-disturbance value varied greatly between these two communities (Figures 2.4a-c), with larger magnitude decreases observable in pine rockland and lack of recovery to predisturbance index values at elevations below $1 \mathrm{~m}$. However, the difference in postdisturbance recovery between pine rockland and hardwood hammock only becomes clear after EOF analysis of the temporal dataset. Spatially this is illustrated for No Name Key in Figure 2.13. There exists a clear difference in the trajectories that these two communities are taking as tEOF2 contrasts the immediate effect of both hurricanes to that of the recovery over six years after hurricane Wilma (Figure 2.10b). Differences in physiological tolerances to salt stress and the method of regeneration for dominant species in each community play an important explanatory role in the trends in impact and recovery observed in this study.

The ability of many hardwood species to resprout post-disturbance undoubtedly affects the rate of forest recovery in hardwood hammock. Stem sprouting in hardwoods especially in areas with greater damage (Van Bloem et al., 2005) has been found to increase survivorship (Bellingham et al., 1994) and likely provides a large portion of the explanation for the observed quick recovery in vegetation indices in hardwood hammock community post Wilma. Winds from Hurricane Joan in 1988 damaged coastal forests in Nicaragua; while leaving more pine trees standing in the pineland compared to hardwood trees in the rainforest, the ability of hardwoods to resprout ultimately resulted in comparatively less overall mortality in the rain forest (Boucher et al., 1990). In an experimental salt water flooding of bald cypress and loblolly pine seedlings, a few days of flooding caused mortality in both species, but bald cypress seedlings that survived 
resprouted after dying back (Conner and Askew, 1992). As pines do not stump sprout, they must regenerate through seed dispersal and subsequent germination. Post-storm surge soil conditions likely play an important role in seed germination and seedling establishment. The relatively shorter amount of time required for hardwood hammocks to regain pre-hurricane leaf area index (LAI) values as observed in several studies ( $<1$ year) (Lugo, 2008), compared to the amount of time needed for slash pine seedlings to establish and grow into mature trees ( 15 years) (M. Ross pers. comm., 2015) provides an indication of the constraints on recovery time for each of these forests.

\subsubsection{The Effect of Post Hurricane Climate Conditions}

Climatic conditions post-disturbance have an important effect on forest recovery in both wind and storm surge scenarios, but research on this interaction is limited. On the west coast of Florida, tree mortality resulted from the interaction of storm disturbance and drought in coastal forest that was in decline as a result of increasing sea level (Williams et al., 2003). The timing of Hurricane Wilma at the onset of the dry season very likely contributed to increased mortality in these forests. The subsequent dry season was atypical in that the amount of rain received was $60 \%$ below average $(12 \mathrm{~cm}$ at Marathon November 2005 through April 2006). Additionally, very little precipitation accompanied the hurricane; only $5 \mathrm{~cm}$ was recorded at Key West. The combination of these factors would have permitted a greater amount of salt to remain in the soil for an extended period, at levels toxic to plants. Previous studies have directly documented the effect of storm surge on soil chemistry. Four months after receiving storm surge from Hurricane Hugo (1989), soils in South Carolina's coastal forests displayed total ionic content values 
58 to 142 times pre-disturbance level, however, the amount of sodium in the A horizon declined as precipitation increased in the aftermath (Blood et al., 1991). In addition to salinization of soil, the effect of salt intrusion on the groundwater is important for certain species, like pine, that access groundwater to meet a portion of their freshwater requirements (Ross et al., 1994), compared to species within the hardwood hammock which primarily utilize soil water (Ish-shalom et al., 1992). While the length of time that the freshwater lens remains brackish post storm surge has not been directly studied, increases in lens conductivity were documented after Hurricane Wilma. Compared to predisturbance values, two to three-fold increases in groundwater specific conductivity were observed in wells located in interior pine rockland locations on Big Pine and No Name Keys, three years after Hurricane Wilma (Florida Department of Environmental Protection Integrated Watershed Resource Monitoring Program). Differences in water source partitioning between hardwood hammock and pine rockland species and subsequent plant stress could account for the observed difference in the post-storm sEOF2 trajectories, especially if those trajectories are being driven by differences in band 5 reflectance values. The increased salt load and decreased availability of freshwater resource during the recovery period is a combination that appears to make storm surge a stand replacing event for pine rockland. Projected increases in temperature of the region (Neelin et al., 2006) that exacerbate dry-season drought conditions would further impact the recovery of these forests. 


\subsubsection{Relationship between Vegetation Indices and Stand Parameters}

The high correlation found between vegetation indices and basal area per hectare in two community types over a 20-year period (Figure 2.15, Table 2.4) provides strong evidence of the application of vegetation indices derived from remotely-sensed data to monitor post-disturbance impact and recovery to coastal forests in the Florida Keys. The additional strong relationship observed between vegetation indices and high shrub layer is clearly attributable to the openness of the canopy in both community types. These findings are in contrast to the work of Gillespie et al. (2006) in south Florida hammocks, which instead found relationships between NDVI and stem density and NDMI and maximum tree height, but only showed a relationship between basal area per hectare and an index combining Landsat TM bands 5 and 7. This difference could be attributed to the broader focus in this current study of multiple forest types as well as multiple image dates used. The difference in findings highlights the importance of careful consideration of both spatial and temporal scales required for correlating measured stand parameters with the most appropriate vegetation index. Continued ground sampling in multiple coastal forests regions will be required to establish correlations with vegetation indices since climate and topography vary regionally.

\subsection{Conclusions}

Compared to the three years required for vegetation indices in hardwood hammock to recover to pre-disturbance values observed in this study and the two to three years observed for mangroves in south Florida (Wang, 2012), pine rockland will require a much longer recovery period to attain pre-disturbance NDMI values. The failure of pine 
rockland to recover to pre-disturbance values of NDMI six years post-hurricane points to both the longer time scales of post-disturbance monitoring necessary to capture recovery and most importantly to the question of how post-disturbance recovery in coastal forests will be impacted in a future climate of predicted increases in frequency of severe hurricanes combined with sea level rise. The prediction of future disturbance recovery rates in coastal forest communities will require not only a consideration of the type of forest, but must also include the effects of previous legacy of disturbance and particular ecosystem process in question (Beard et al., 2005). And while recovery of vegetation indices does not necessarily equate with full recovery of forest structure to that of predisturbance state, it does provide important measures of regained photosynthetic capacity, biomass, and plant stress depending on the selected index.

This study confirms that proper selection of vegetation indices is essential to disturbance monitoring (Wang and $\mathrm{Xu}, 2009$ ), but additionally finds that the use of multiple change detection techniques elucidates spatial patterns in recovery. The ability to assess disturbance impacts using a time series dataset revealed diverging trends in recovery in two coastal forests and should serve as a tool to predict changes to coastal forests in the future. The strong relationship between vegetation indices and basal area within the permanent plots located in hardwood hammock and pine rockland demonstrate the flexibility of remotely-sensed data to quantify changes on the ground in a variety of coastal forest types. The absence of relationship between indices and climatic variables and the small change in indices within the dry season support the utility and widespread use of these indices in hurricane disturbance monitoring in the coastal forests of the 
greater Caribbean region. Employing a combination of remotely-sensed data and sampled stand parameters will be integral to projecting how forests will change into the future in a climate of increasing strong tropical cyclones and increases in sea level. 


\subsection{References}

Beard, K.H., Vogt, K.A., Vogt, D.J., Scatena, F.N., Covich, A.P., Sigurdardottir, R., Siccama, T.G., Crowl, T.A., 2005. Structural and functional responses of a subtropical forest to 10 years of hurricanes and droughts. Ecological Monographs 75, 345-361.

Bellingham, P.J., 1991. Landforms influence patterns of hurricane damage: evidence from Jamaican montane forests. Biotropica 23, 427-433.

Bellingham, P.J., Tanner, E.V.J., Healey, J.R., 1994. Sprouting of trees in Jamaican montane forests, after a hurricane. Journal of Ecology 82, 747-758.

Bender, M.A., Knutson, T.R., Tuleya, R.E., Sirutis, J.J., Vecchi, G.A., Garner, S.T., Held, I.M., 2010. Modeled impact of anthropogenic warming on the frequency of intense Atlantic hurricanes. Science 327, 454-458.

Bergh, C., Wisby, J., 1996. Fire history of lower Keys pine rocklands. The Nature Conservancy, Florida Keys Initiative.

Blood, E.R., Anderson, P., Smith, P.A., Nybro, C., Ginsberg, K.A., 1991. Effects of Hurricane Hugo on coastal soil solution chemistry in South Carolina. Biotropica 23, 348-355.

Boose, E.R., Foster, D.R., Fluet, M., 1994. Hurricane impacts to tropical and temperate forest landscapes. Ecological Monographs 64, 369-400.

Boucher, D.H., Vandermeer, J.H., Yih, K., Zamora, N., 1990. Contrasting hurricane damage in tropical rain forest and pine forest. Ecology 71, 2022-2024.

Brokaw, N.V.L., Walker, L.R., 1991. Summary of the effects of Caribbean hurricanes on vegetation. Biotropica 23, 442-447.

Carlson, P.C., Tanner, G.W., Wood, J.M., Humphrey, S.R., 1993. Fire in Key Deer habitat improves browse, prevents succession, and preserves endemic herbs. The Journal of Wildlife Management 57, 914-928.

Carter, G.A., 1993. Responses of leaf spectral reflectance to plant stress. American Journal of Botany 80, 239-243.

Carter, G.A., Cibula, W.G., Miller, R.L., 1996. Narrow-band reflectance imagery compared with thermal imagery for early detection of plant stress. Journal of Plant Physiology 148, 515-522. 
Chapman, E.L., Chambers, J.Q., Ribbeck, K.F., Baker, D.B., Tobler, M.A., Zeng, H., White, D.A., 2008. Hurricane Katrina impacts on forest trees of Louisiana's Pearl River basin. Forest Ecology and Management 256, 883-889.

Coniglio, M., Harrison, R.S., 1983. Facies and diagenesis of late Pleistocene carbonates from Big Pine Key, FL. Bulletin of Canadian Petroleum Geology 31, 135-147.

Conner, W.H., Askew, G.R., 1992. Response of baldcypress and loblolly pine seedlings to short-term saltwater flooding. Wetlands 12, 230-233.

Conner, W.H., Inabinette, L.W., 2003. Tree growth in three South Carolina (USA) swamps after Hurricane Hugo: 1991-2001. Forest Ecology and Management 182, 371-380.

Conner, W.H., McLeod, K.W., McCarron, J.K., 1997. Flooding and salinity effects on growth and survival of four common forested wetland species. Wetlands Ecology and Management 5, 99-109.

Craighead, F.C., Gilbert, V.C., 1962. The effects of Hurricane Donna on the vegetation of southern Florida. Quarterly Journal of the Florida Academy of Sciences 25, 1-28.

Davenport, M.L., Nicholson, S.E., 1993. On the relation between rainfall and the normalized difference vegetation index for diverse vegetation types in East Africa. International Journal of Remote Sensing 14, 2369-2389.

Foster, D.R., Boose, E.R., 1992. Patterns of forest damage resulting from catastrophic wind in central New England, USA. Journal of Ecology 80, 79-98.

Freitas, S.R., Mello, M.C.S., Cruz, C.B.M., 2005. Relationships between forest structure and vegetation indices in Atlantic Rainforest. Forest Ecology and Management 218, 353-362.

Gardner, L.R., Michener, W.K., Blood, E.R., Williams, T.M., Lipscomb, D.J., Jefferson, W.H., 1991. Ecological impact of Hurricane Hugo - salinization of a coastal forest. Journal of Coastal Research 8, 301-317.

Gillespie, T.W., Zutta, B.R., Early, M.K., Saatchi, S., 2006. Predicting and quantifying the structure of tropical dry forests in South Florida and the Neotropics using spaceborne imagery. Global Ecology and Biogeography 15, 225-236.

Gouvenain, R.C. de, Silander, J.A., 2003. Do tropical storm regimes influence the structure of tropical lowland rain forests? Biotropica 35, 166-180.

Hardisky, M.A., Klemas, V., Smart, R.M., 1983. The influence of soil salinity, growth form, and leaf moisture on the spectral radiance of Spartina alterniflora canopies. Photogramm. Eng. Remote Sens. 49, 77-83. 
Hoffmeister, J.E., Multer, H.G., 1968. Geology and origin of the Florida Keys. Geological Society of America Bulletin 79, 1487-1502.

Hoffmeister, J.E., Stockman, K.W., Multer, H.G., 1967. Miami Limestone of Florida and its recent Bahamian counterpart. Geological Society of America Bulletin 78, 175190.

Ish-Shalom, N., Sternberg, L. da S.L., Ross, M., O’Brien, J., Flynn, L., 1992. Water utilization of tropical hardwood hammocks of the lower Florida Keys. Oecologia 92, 108-112.

Jensen, J.R., 2005. Introductory digital image processing: a remote sensing perspective, 3rd ed. Pearson Prentice Hall, Upper Saddle River, NJ.

Kasper, K., 2007. Hurricane Wilma in the Florida Keys. National Oceanic and Atmospheric Administration (NOAA)/National Weather Service (NWS) Weather Forecast Office (WFO), Key West, FL.

Kennedy, R.E., Andréfouët, S., Cohen, W.B., Gómez, C., Griffiths, P., Hais, M., Healey, S.P., Helmer, E.H., Hostert, P., Lyons, M.B., Meigs, G.W., Pflugmacher, D., Phinn, S.R., Powell, S.L., Scarth, P., Sen, S., Schroeder, T.A., Schneider, A., Sonnenschein, R., Vogelmann, J.E., Wulder, M.A., Zhu, Z., 2014. Bringing an ecological view of change to Landsat-based remote sensing. Frontiers in Ecology and the Environment 12, 339-346.

Kozlowski, T.T., 1997. Responses of woody plants to flooding and salinity. Tree Physiology Monograph 1, 1-29.

Land, Jr., S.B., 1974. Depth effects and genetic influences on injury caused by artificial sea water floods to loblolly and slash pine seedlings. Canadian Journal of Forest Research 179, 179-185.

Lu, D., 2005. Aboveground biomass estimation using Landsat TM data in the Brazilian Amazon. International Journal of Remote Sensing 26, 2509-2525.

Lu, D., Mausel, P., Brondízio, E., Moran, E., 2004. Relationships between forest stand parameters and Landsat TM spectral responses in the Brazilian Amazon Basin. Forest Ecology and Management 198, 149-167.

Lugo, A.E., 2008. Visible and invisible effects of hurricanes on forest ecosystems: an international review. Austral Ecology 33, 368-398.

Lugo, A.E., 2000. Effects and outcomes of Caribbean hurricanes in a climate change scenario. Science of the Total Environment 262, 243-251. 
Munns, R., 2002. Comparative physiology of salt and water stress. Plant, Cell and Environment 25, 239-250.

Neelin, J.D., Münnich, M., Su, H., Meyerson, J.E., Holloway, C.E., 2006. Tropical drying trends in global warming models and observations. Proceedings of the National Academy of Sciences 103, 6110-6115.

Nicholson, S.E., Davenport, M.L., Malo, A.R., 1990. A comparison of the vegetation response to rainfall in the Sahel and East Africa, using normalized difference vegetaion index from NOAA AVHRR. Climate Change 17, 209-241.

Perkins, R.D., 1977. Depositional framework of Pleistocene rocks in south Florida, in: Enos, P., Perkins, R.D. (Eds.), Quarternary Sedimentation in South Florida. Geological Society of America, pp. 131-198.

Pettorelli, N., Vik, J.O., Mysterud, A., Gaillard, J.-M., Tucker, C.J., Stenseth, N.C., 2005. Using the satellite-derived NDVI to assess ecological responses to environmental change. Trends in Ecology \& Evolution 20, 503-510.

Pflugmacher, D., Cohen, W.B., E. Kennedy, R., 2012. Using Landsat-derived disturbance history (1972-2010) to predict current forest structure. Remote Sensing of Environment 122, 146-165.

Philpot, W., Ansty, T., 2013. Analytical description of pseudoinvariant features. IEEE Trans. Geosci. Remote Sens. 51, 2016-2021.

Powell, M.D., Houston, S.H., Amat, L.R., Morisseau-Leroy, N., 1998. The HRD realtime hurricane wind analysis system. Journal of Wind Engineering and Industrial Aerodynamics 77, 53-64.

Preisendorfer, R.W., 1988. Principal component analysis in meteorology and oceanography. Elsivier, Amsterdam.

Pu, R., Ge, S., Kelly, N.M., Gong, P., 2003. Spectral absorption features as indicators of water status in coast live oak (Quercus agrifolia) leaves. International Journal of Remote Sensing 24, 1799-1810.

Putz, F.E., Coley, P.D., Lu, K., Montalvo, A., Aiello, A., 1983. Uprooting and snapping of trees: structural determinants and ecological consequences. Canadian Journal of Forest Research 13, 1011-1019.

Rahmstorf, S., 2007. A semi-empirical approach to projecting future sea-level rise. Science 315, 368-370.

Reilly, A.E., 1991. The effects of Hurricane Hugo in three tropical forests in the U.S. Virgin Islands. Biotropica 23, 414-419. 
Rodgers, J., Murrah, A., Cooke, W., 2009. The impact of Hurricane Katrina on the coastal vegetation of the Weeks Bay Reserve, Alabama from NDVI data. Estuaries and Coasts 32, 496-507.

Ross, M.S., O’Brien, J.J., da Silveira Lobo Sternberg, L., 1994. Sea-level rise and the reduction in pine forests in the Florida Keys. Ecological Applications 4, 144-156.

Ross, M.S., O’Brien, J.J., Flynn, L.J., 1992. Ecological site classification of Florida Keys terrestrial habitats. Biotropica 24, 488-502.

Ross, M.S., O’Brien, J.J., Ford, R.G., Zhang, K., Morkill, A., 2009. Disturbance and the rising tide: the challenge of biodiversity management on low-island ecosystems. Frontiers in Ecology and the Environment 7, 471-478.

Rouse, J.W., Hass, R.H., Schell, J.A., Deering, D.W., 1973. Monitoring vegetation systems in the Great Plains with ERTS, in: Proceedings, Third Earth Resources Technology Satellite (ERTS) Symposium. NASA, pp. 48-62.

Sader, S.A., Waide, R.A., Lawrence, W.T., Joyce, A.T., 1989. Tropical forest biomass and successional age class relationships to a vegetation index derived from Landsat TM data. Remote Sensing of Environment 28, 143-156.

Saha, S., Bradley, K., Ross, M.S., Hughes, P., Wilmers, T., Ruiz, P.L., Bergh, C., 2011. Hurricane effects on subtropical pine rocklands of the Florida Keys. Climatic Change 107, 169-184.

Sah, J.P., Ross, M.S., Snyder, J.R., Koptur, S., Cooley, H.C., 2006. Fuel loads, fire regimes, and post-fire fuel dynamics in Florida Keys pine forests. International Journal of Wildland Fire 15, 463-478.

Sea Systems Corporation, 1998. South Florida High Water Marks Post Hurricane Georges: Key West to Key Largo, Florida Flamingo to Fort Myers, Florida (No. USCOE Survey Number 98-282). Prepared for the U.S. Army Corps of Engineers Jacksonville District.

Small, C., 2012. Spatiotemporal dimensionality and time-space characterization of multitemporal imagery. Remote Sensing of Environment 124, 793-809.

Snyder, J.R., Herndon, A., Robertson, W.B., 1990. South Florida rockland, in: Ecosystems of Florida. University of Central Florida Press, Orlando, FL, pp. 230277.

Steininger, M.K., 2000. Satellite estimation of tropical secondary forest above-ground biomass: Data from Brazil and Bolivia. International Journal of Remote Sensing 21, 1139-1157. 
Steyer, G.D., Couvillion, B.R., Barras, J.A., 2013. Monitoring vegetation response to episodic disturbance events by using multitemporal vegetation indices. Journal of Coastal Research 63, 118-130.

Storch, H. v, Zwiers, F.W., 1999. Statistical analysis in climate research. Cambridge University Press, Cambridge; New York.

Tucker, C.J., 1979. Red and photographic infrared linear combinations for monitoring vegetation. Remote Sensing of Environment 8, 127-150.

URS Group, Inc., 2006. Final Coastal High Water Mark Collection for Hurricane Wilma in Florida (No. HMTAP Task Order 460). Prepared for Federal Emergency Management Agency Region IV Atlanta, GA.

Vacher, H.L., Wightman, M.J., Stewart, M.T., 1992. Hydrology of meteroic diagenesis: effect of Pleistocene stratigraphy on freshwater lenses of Big Pine Key, Florida, In: Fletcher, C.H., III, Wehmiller, J.F. (Eds.), Quarternary Coasts of the United States: Marine and Lacustine Systems, SEPM (Society for Sedimentary Geology). pp. 213-219.

Van Bloem, S.J., Murphy, P.G., Lugo, A.E., 2007. A link between hurricane-induced tree sprouting, high stem density and short canopy in tropical dry forest. Tree Physiology 27, 475-480.

Van Bloem, S.J., Murphy, P.G., Lugo, A.E., Ostertag, R., Costa, M.R., Bernard, I.R., Colon, S.M., Mora, M.C., 2005. The Influence of Hurricane Winds on Caribbean Dry Forest Structure and Nutrient Pools. Biotropica 37, 571-583.

Vandermeer, J., 2000. Hurricane Disturbance and Tropical Tree Species Diversity. Science 290, 788-791.

Walker, L.R., 1991. Tree damage and recovery from Hurricane Hugo in Luquillo Experimental Forest, Puerto Rico. Biotropica 23, 379-385.

Wang, F., Xu, Y.J., 2009. Comparison of remote sensing change detection techniques for assessing hurricane damage to forests. Environmental Monitoring and Assessment 162, 311-326.

Wang, J., Rich, P.M., Price, K.P., 2003. Temporal responses of NDVI to precipitation and temperature in the central Great Plains, USA. International Journal of Remote Sensing 24, 2345-2364.

Wang, W., Qu, J.J., Hao, X., Liu, Y., Stanturf, J.A., 2010. Post-hurricane forest damage assessment using satellite remote sensing. Agricultural and Forest Meteorology $150,122-132$. 
Wang, Y., 2012. Detecting vegetation recovery patterns after hurricanes in South Florida using NDVI time series. (M.S. Thesis). University of Miami, Coral Gables, FL.

Wanless, H.R., Parkinson, R.W., Tedesco, L.P., 1994. Sea level control on stability of Everglades wetlands., In: Ogden, J.C. (Ed.), Everglades: The Ecosystem and Its Restoration. St. Lucie Press, pp. 199-222.

Williams, K., MacDonald, M., Sternberg, L. da S.L., 2003. Interactions of storm, drought, and sea-level rise on coastal forest: a case study. Journal of Coastal Research 1116-1121.

Wilson, E.H., Sader, S.A., 2002. Detection of forest harvest type using multiple dates of Landsat TM imagery. Remote Sensing of Environment 80, 385-396.

Yih, K., Boucher, D.H., Vandermeer, J.H., Zamora, N., 1991. Recovery of the rain forest of southeastern Nicaragua after destruction by Hurricane Joan. Biotropica 23, 106-113.

Zehr, R.M., Knaff, J.A., 2007. Atlantic major hurricanes, 1995-2005-Characteristics based on best-track, aircraft, and IR images. Journal of Climate 20, 5865-5888.

Zhang, K., Ross, M.S., Ogurcak, D.E., Houle, P., 2010. Lower Florida Keys digital terrain model and vegetation analysis for the National Key Deer Refuge (Final Report submitted to the U.S. Fish and Wildlife Service National Key Deer Refuge, Big Pine Key, FL). Florida International University, Miami, FL. 


\subsection{Tables}

Table 2.1 Dates of Landsat TM 4-5 images used in analyses. *Image not used for EOF analysis, **Landsat 7 etm+ image substituted since no cloud-free Landsat TM 4-5 images available.

\begin{tabular}{|c|}
\hline Image Date \\
\hline 5-Jan-1986 \\
\hline 8-Jan-1987 \\
\hline 16-Jan-1990 \\
\hline 4-Feb-1991* \\
\hline 18-Feb-1996 \\
\hline 3-Jan-1997 \\
\hline 11-Mar-1998 \\
\hline 25-Jan-1999 \\
\hline 13-Feb-2000 \\
\hline 14-Jan-2001 \\
\hline 18-Feb-2002 \\
\hline 13-Feb-2003** \\
\hline 23-Jan-2004 \\
\hline 10-Feb-2005 \\
\hline 1-Mar-2006 \\
\hline 31-Jan-2007 \\
\hline 5-Feb-2009 \\
\hline 8-Feb-2010 \\
\hline 27-Feb-2011 \\
\hline
\end{tabular}


Table 2.2 Environmental variables and locations of each permanent plot. Island codes refer to Big Pine Key (BPK) and Upper Sugarloaf Key (SLK) while habitat codes refer to pine rockland $(\mathrm{PR})$ and hardwood hammock $(\mathrm{HH})$ coastal forest communities. Average elevation includes the entire area covered by the Landsat TM pixel. *Indicates plot having fewer than 6 subplots. **Indicates plot where fewer than 9 Landsat pixels were available in contiguous area.

\begin{tabular}{|c|c|c|c|c|c|c|c|}
\hline Plot & Island & Habitat & $\begin{array}{c}\text { \# of } \\
\text { Subplots }\end{array}$ & $\begin{array}{c}\text { Plot } \\
\text { Area } \\
\left(\mathrm{m}^{2}\right)\end{array}$ & $\begin{array}{c}\text { Distance } \\
\text { to coast } \\
(\mathrm{m})\end{array}$ & $\begin{array}{c}\text { Average } \\
\text { Elevation (m) }\end{array}$ & $\begin{array}{c}\text { \# of TM } \\
\text { pixels }\end{array}$ \\
\hline B2 & BPK & PR & 6 & 600 & 189 & $0.46+/-0.01$ & 9 \\
\hline S3 & SLK & PR & 6 & 600 & 758 & $0.43+/-0.01$ & 9 \\
\hline S5 & SLK & PR & 6 & 600 & 535 & $0.71+/-0.01$ & 9 \\
\hline B3** & BPK & HH & 6 & 600 & 46 & $0.46+/-0.02$ & 6 \\
\hline S2** & SLK & HH & 6 & 600 & 282 & $0.52+/-0.01$ & 8 \\
\hline S4* & SLK & HH & 5 & 500 & 633 & $0.32+/-0.004$ & 9 \\
\hline S7 & SLK & HH & 6 & 600 & 308 & $0.59+/-0.01$ & 9 \\
\hline
\end{tabular}

Table 2.3 Mean (+/- SD) vegetation indices (VIs) for 1996 and change in VI post-pre Hurricane Wilma (2005-2006) in hardwood hammock $(n=6123)$, pine rockland on Big Pine Key $(\mathrm{n}=3841)$ and pine rockland on all other islands combined $(\mathrm{n}=1094)$.

\begin{tabular}{|l|c|c|c|c|}
\hline \multirow{2}{*}{$\begin{array}{c}\text { Coastal } \\
\text { Forest }\end{array}$} & \multicolumn{2}{|c|}{ 1996 Pre-disturbance VI } & \multicolumn{2}{c|}{ 2006-2005 Change in VI } \\
\cline { 2 - 5 } & NDVI & NDMI & NDVI & NDMI \\
\hline Pine (BPK) & $0.72+/-0.08$ & $0.25+/-0.11$ & $-0.12+/-0.11$ & $-0.17+/-0.12$ \\
\hline Pine (not BPK) & $0.83+/-0.05$ & $0.44+/-0.06$ & $-0.16+/-0.08$ & $-0.25+/-0.10$ \\
\hline Hammock & $0.84+/-0.07$ & $0.41+/-0.08$ & $-0.23+/-0.10$ & $-0.37+/-0.12$ \\
\hline
\end{tabular}

Table 2.4 Pearson correlation coefficients for vegetation indices and forest stand parameters, ${ }^{*} \mathrm{p}<.05,{ }^{* *} \mathrm{p}<.001, \mathrm{n}=14$.

\begin{tabular}{|c|c|c|c|}
\hline $\begin{array}{c}\text { Vegetation } \\
\text { Indices }\end{array}$ & Basal Area per ha & \% Cover High Shrub & \% Cover Low Shrub \\
\hline NDVI & $0.79^{* *}$ & $0.59^{*}$ & 0.04 \\
\hline NDMI & $0.83^{* *}$ & $0.64^{*}$ & 0.15 \\
\hline
\end{tabular}




\subsection{Figures}

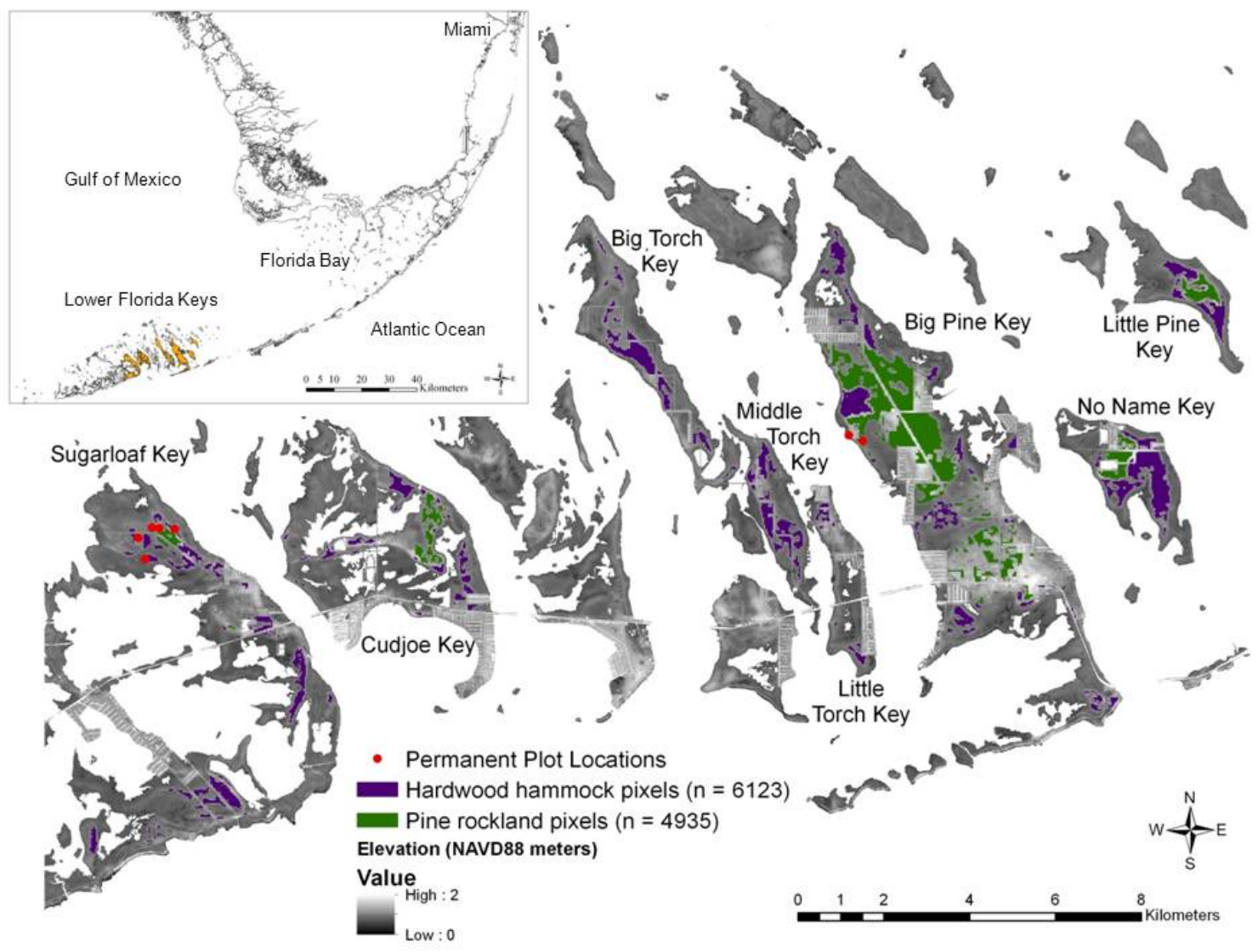

Figure 2.1 Study area in the lower Florida Keys. The locations of permanent plots are indicated by red dots. Hardwood hammock pixels included in the study are colored purple. Pine rockland pixels included in the study are colored green. 

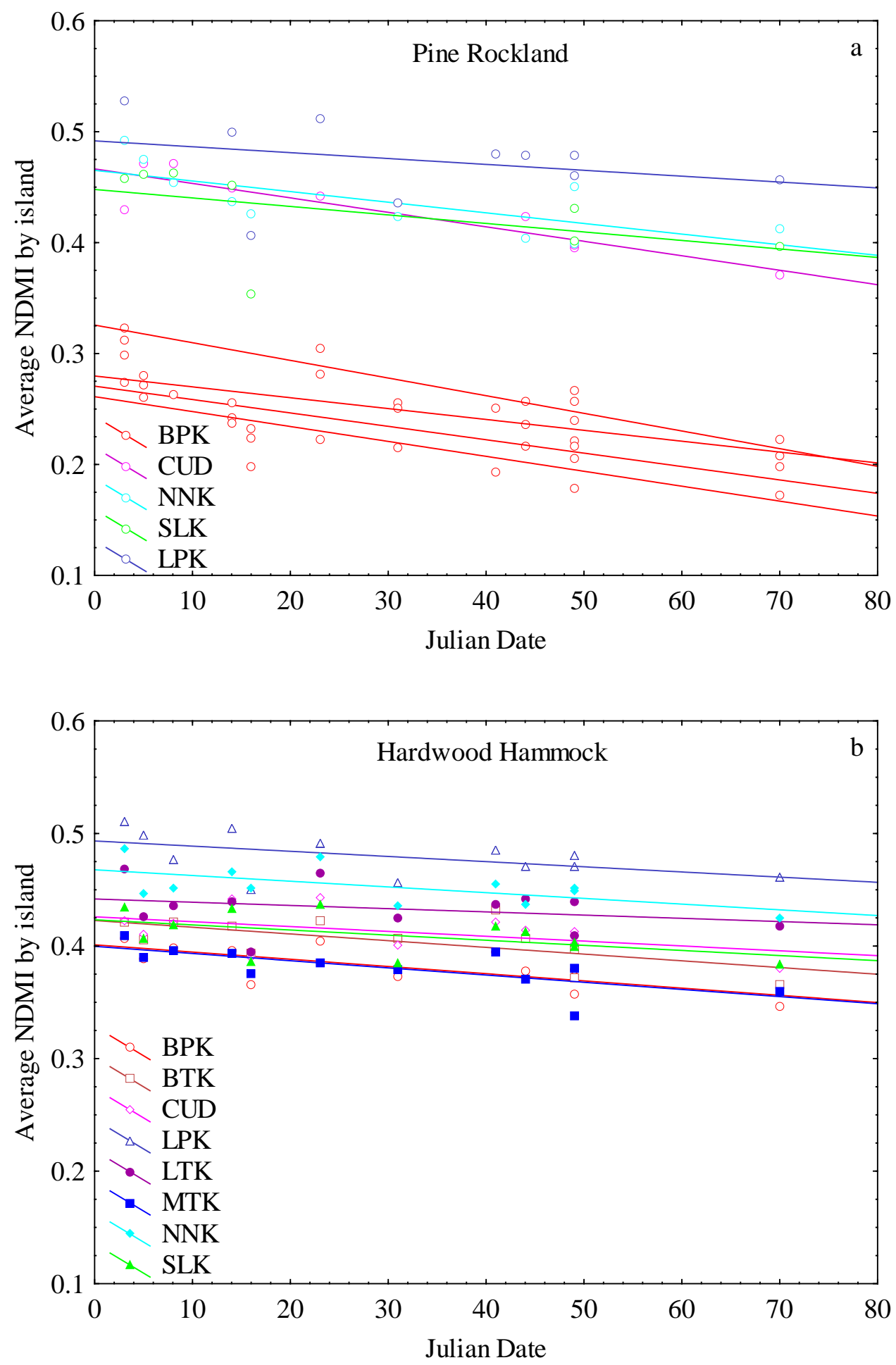

Figure 2.2 Relationship between Julian date of the Landsat image and the NDMI in nondisturbance years (pre-Hurricane Wilma). (a) Mean NDMI for pine rockland pixels in each image averaged by island (or separate burn units for BPK). (b) Mean NDMI for hardwood hammock pixels in each image averaged by island. 

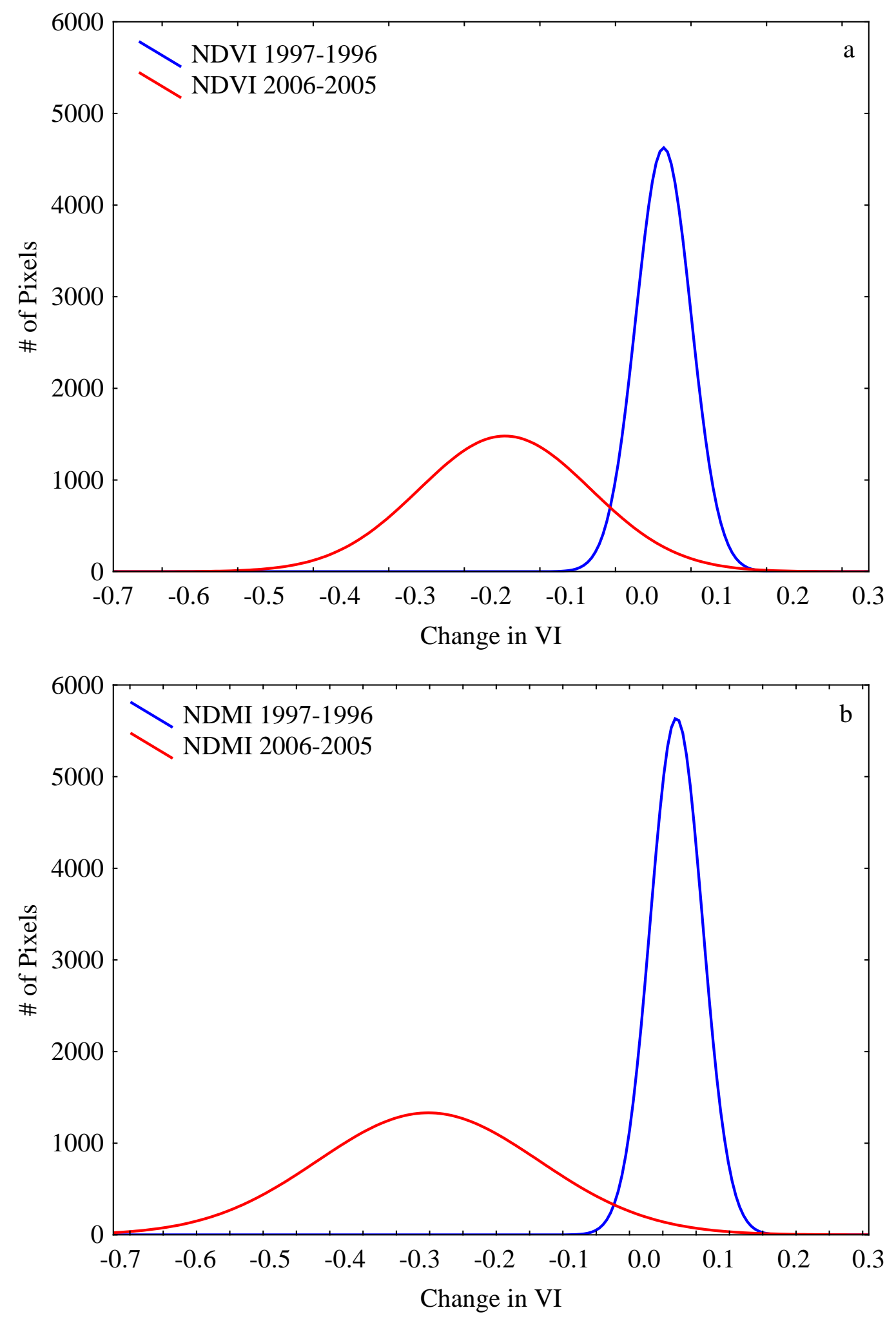

Figure 2.3 Frequency distribution of change in (a) NDVI and (b) NDMI post-pre Hurricane Wilma (red) and year of no disturbance (1997-1996) (blue), $n=11058$ pixels. 

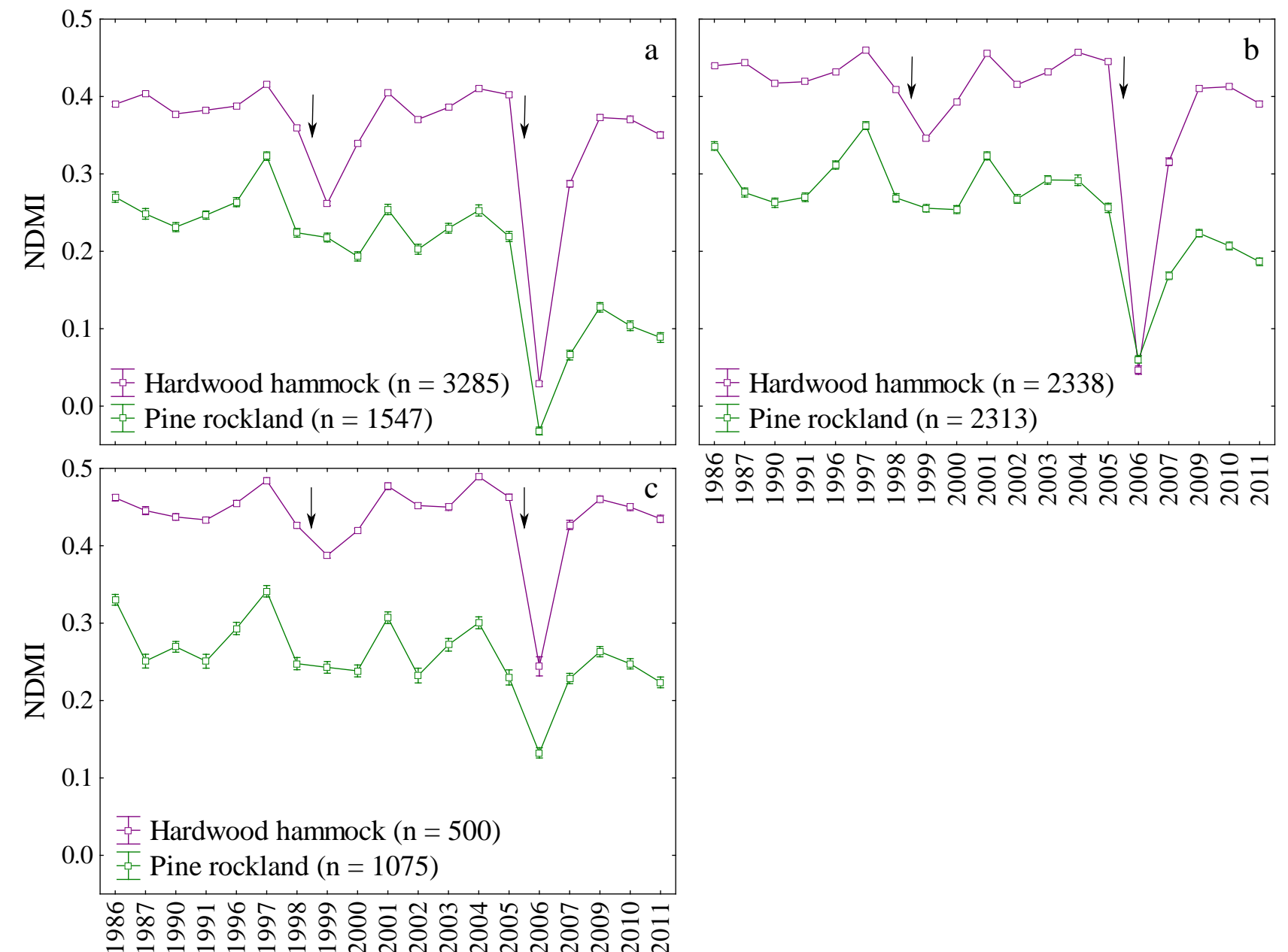

Figure 2.4 Means +/- 95\% CI for NDMI between 1986 and 2011 in (a) low (20 to $60 \mathrm{~cm})$, (b) medium (60 cm to 100cm), and (c) high $(>100 \mathrm{~cm})$ elevation pixels in hardwood hammock and pine rockland habitat. Arrows indicate timing of Hurricane Georges (1998) and Hurricane Wilma (2005). 


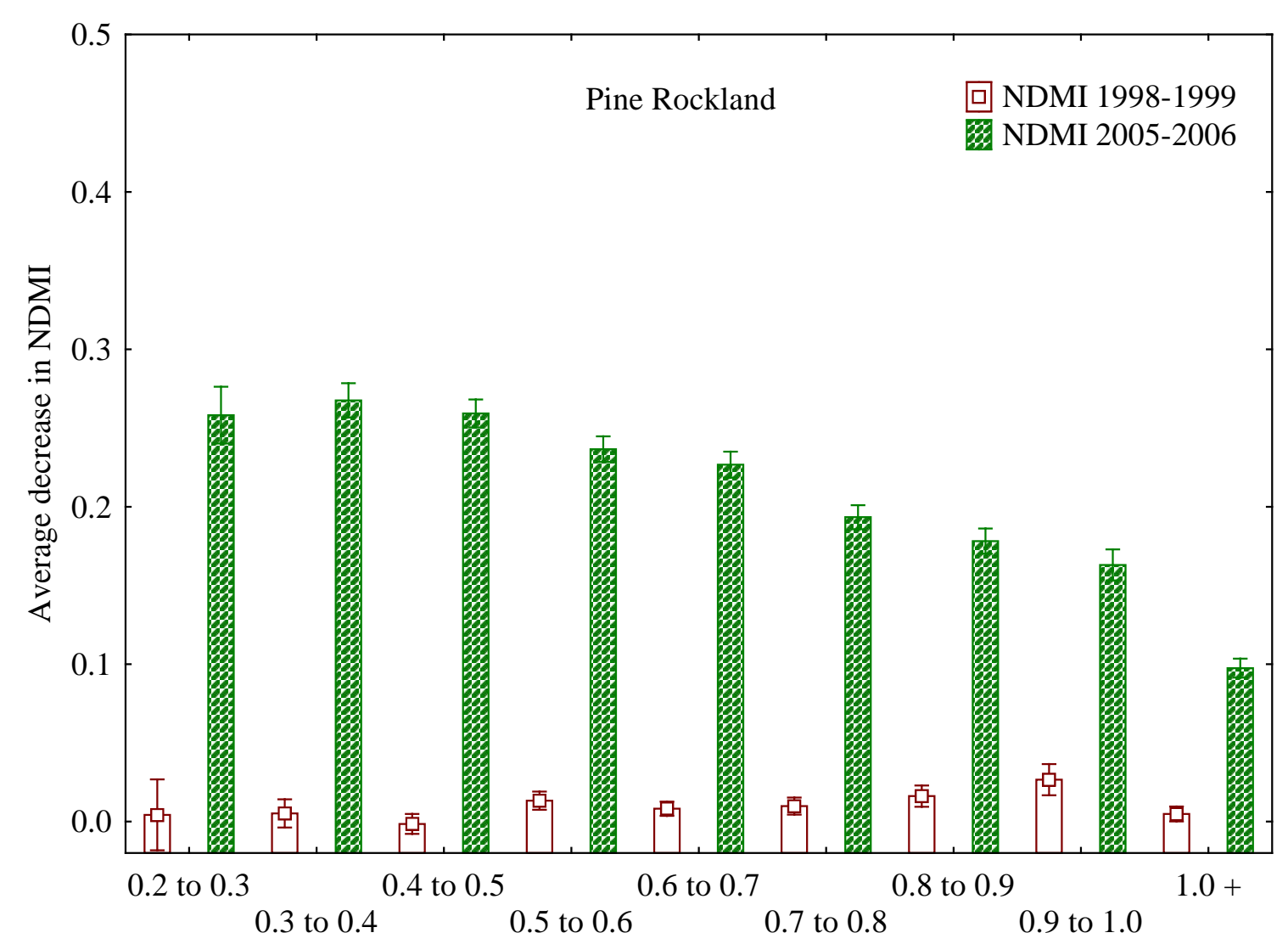

Figure 2.5 Average decrease in NDMI pre-post Hurricane Georges and Wilma in $10 \mathrm{~cm}$ elevation intervals in pine rockland ( $\mathrm{n}=4935$ pixels). Means $+/-95 \%$ CI. 


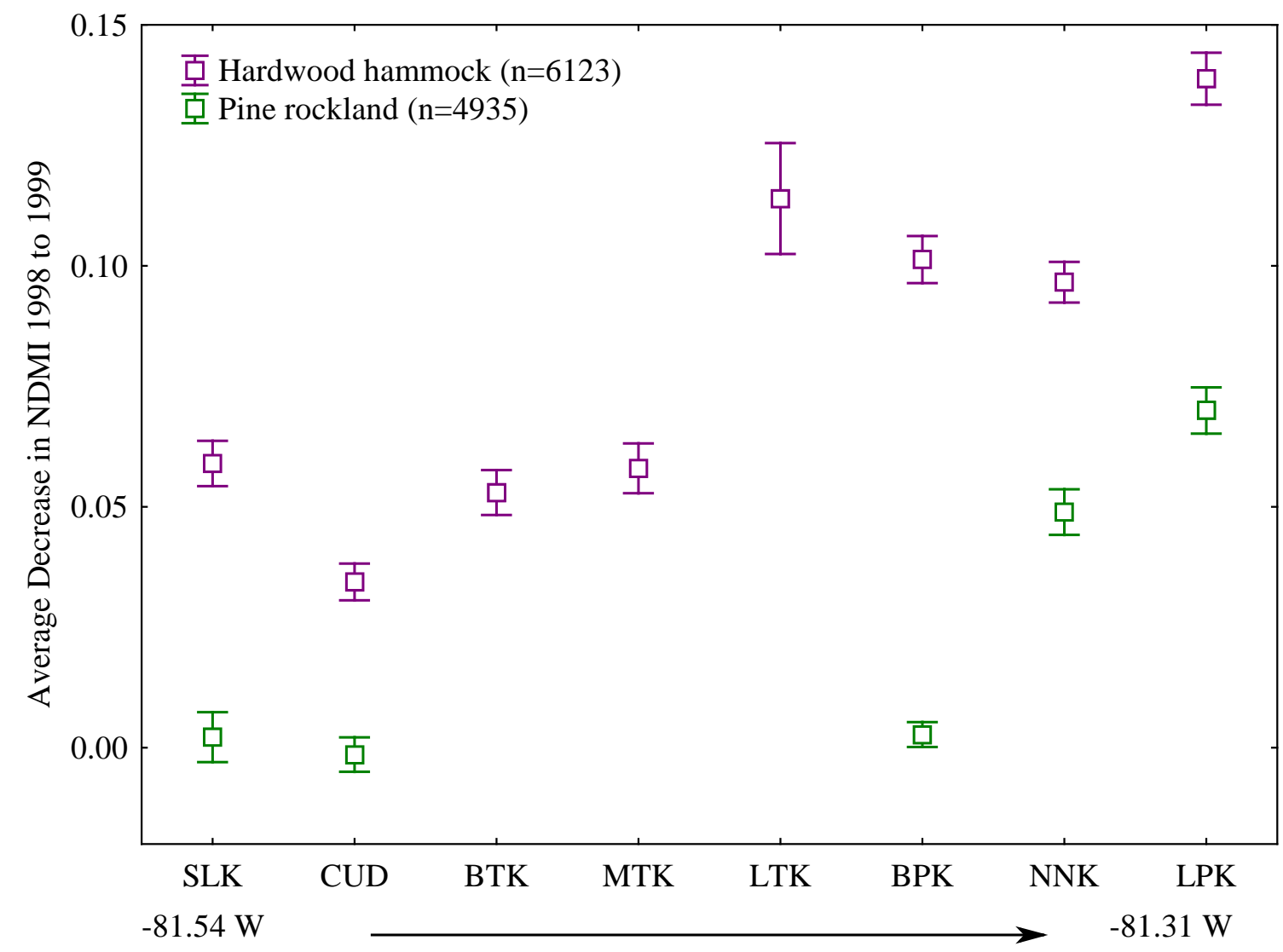

Figure 2.6 Average decrease in NDMI pre-post Hurricane Georges by island. Islands are arranged (left to right) by decreasing longitude. Means +/- 95\% CI. 


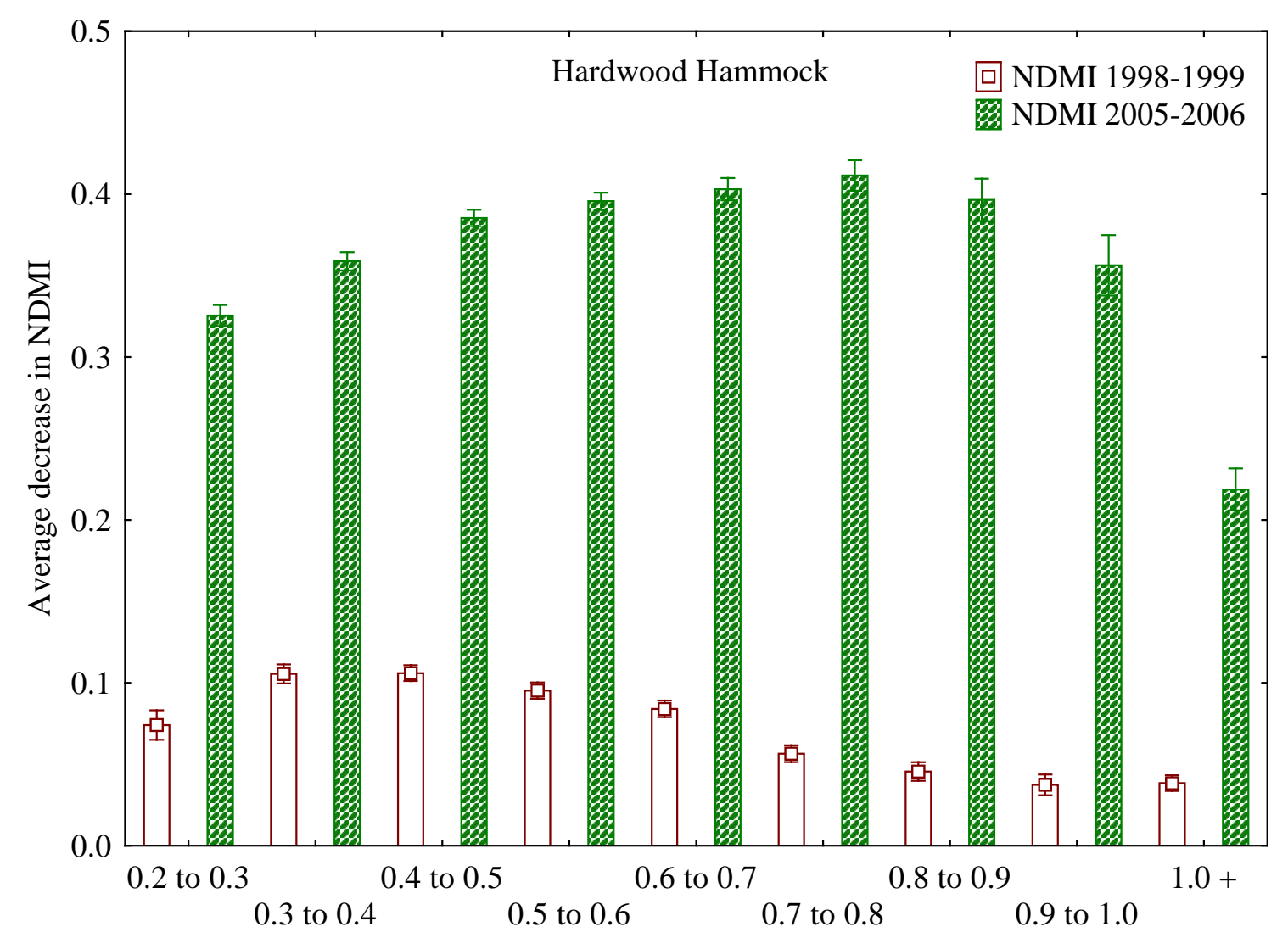

Figure 2.7 Average decrease in NDMI pre-post Hurricane Georges and Wilma in $10 \mathrm{~cm}$ elevation intervals in hardwood hammock ( $n=6123$ pixels) Means $+/-95 \%$ CI. 


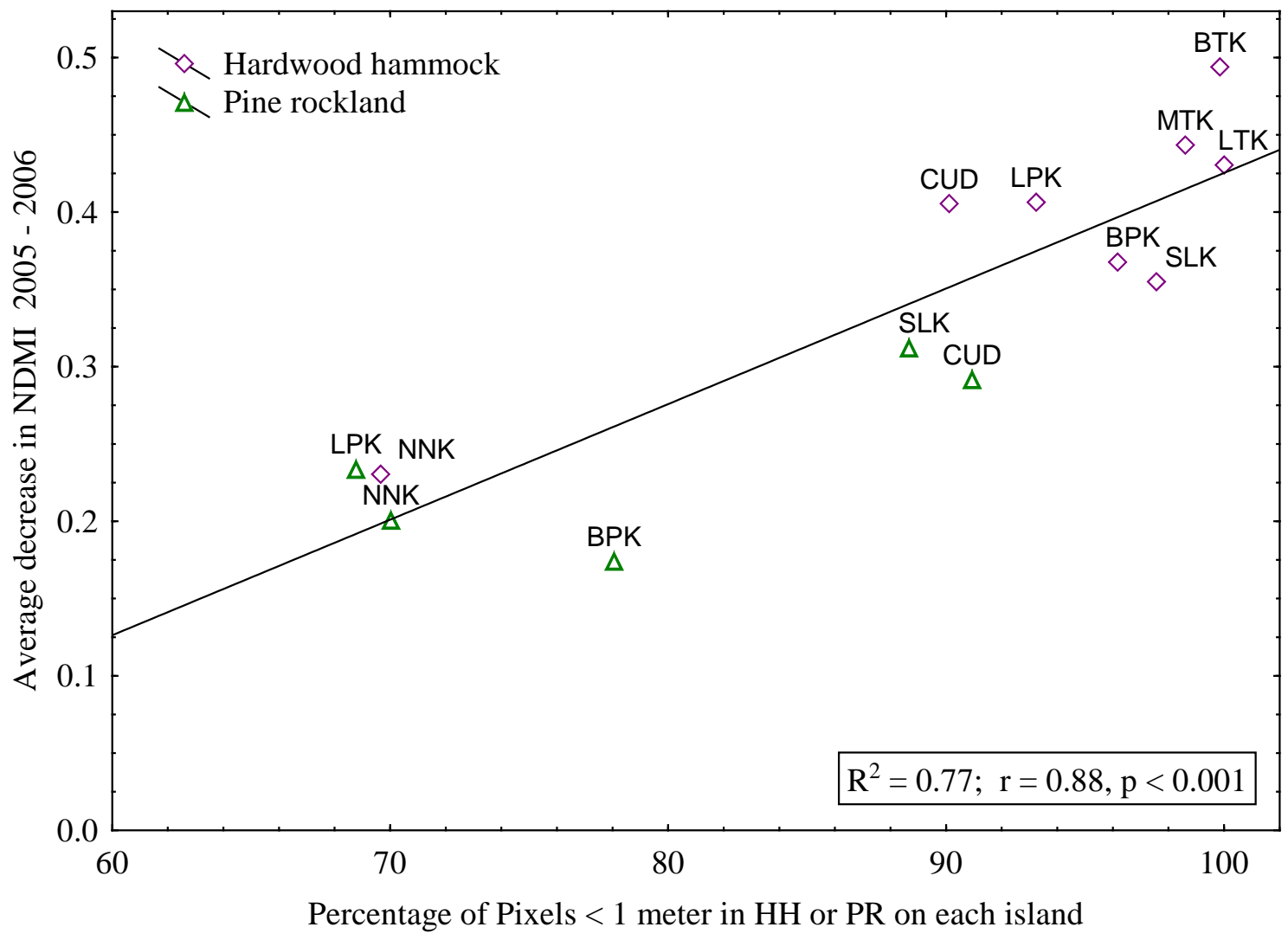

Figure 2.8 Relationship between the percentage of pixels with elevations less than 1 meter and average decrease pre-post Hurricane Wilma in NDMI in hardwood hammock $(\mathrm{HH})$ and pine rockland (PR) on each island. Pine rockland on BPK falls much farther below the regression line compared coastal forests on other islands as a result of the large area subjected to prescribed burns on BPK in 2004. 


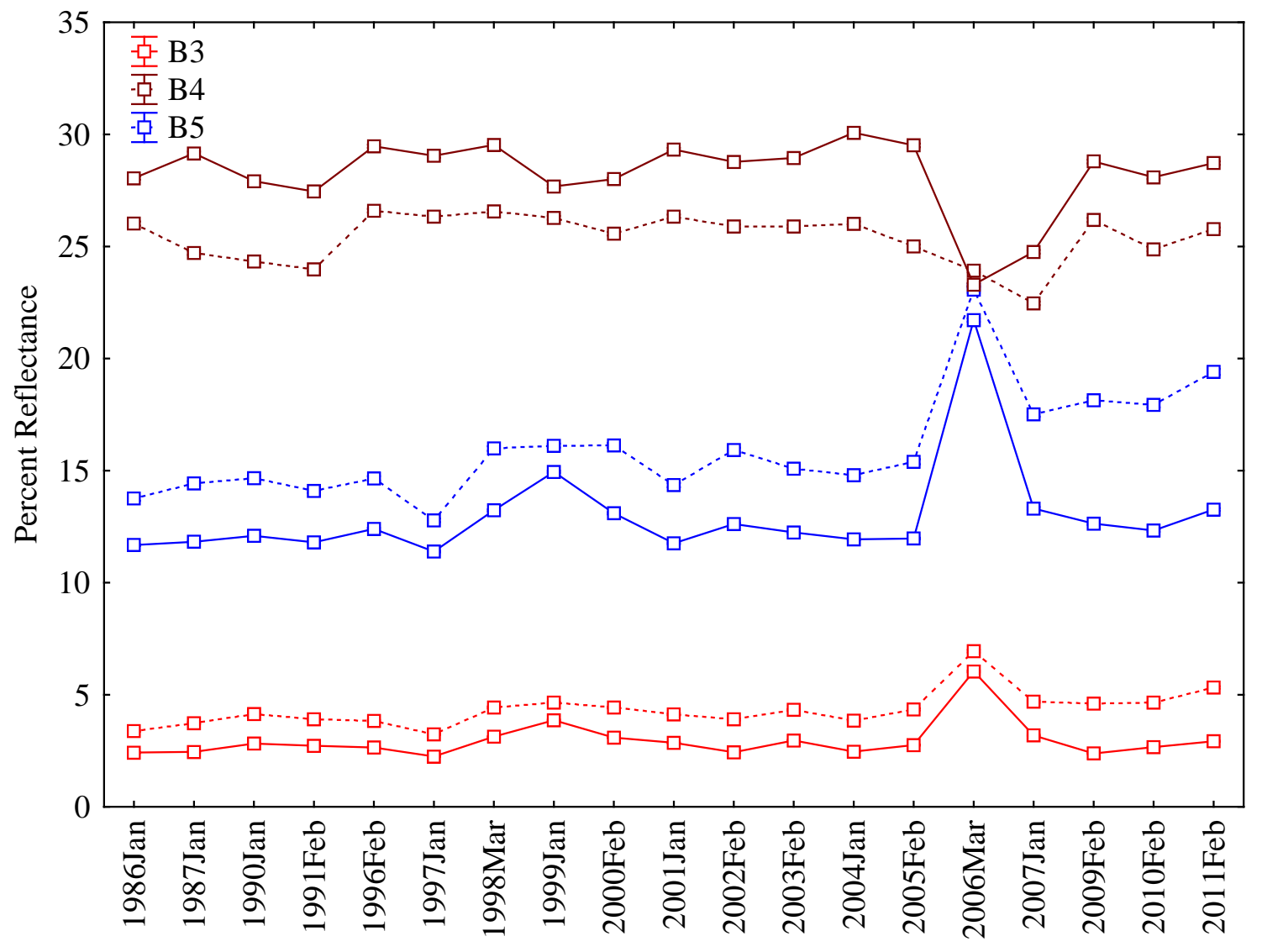

Figure 2.9 Mean percent reflectance in bands 3, 4, and 5 by image date for hardwood hammock (solid line) and pine rockland (dashed line) pixels below $1 \mathrm{~m}$ in elevation. 

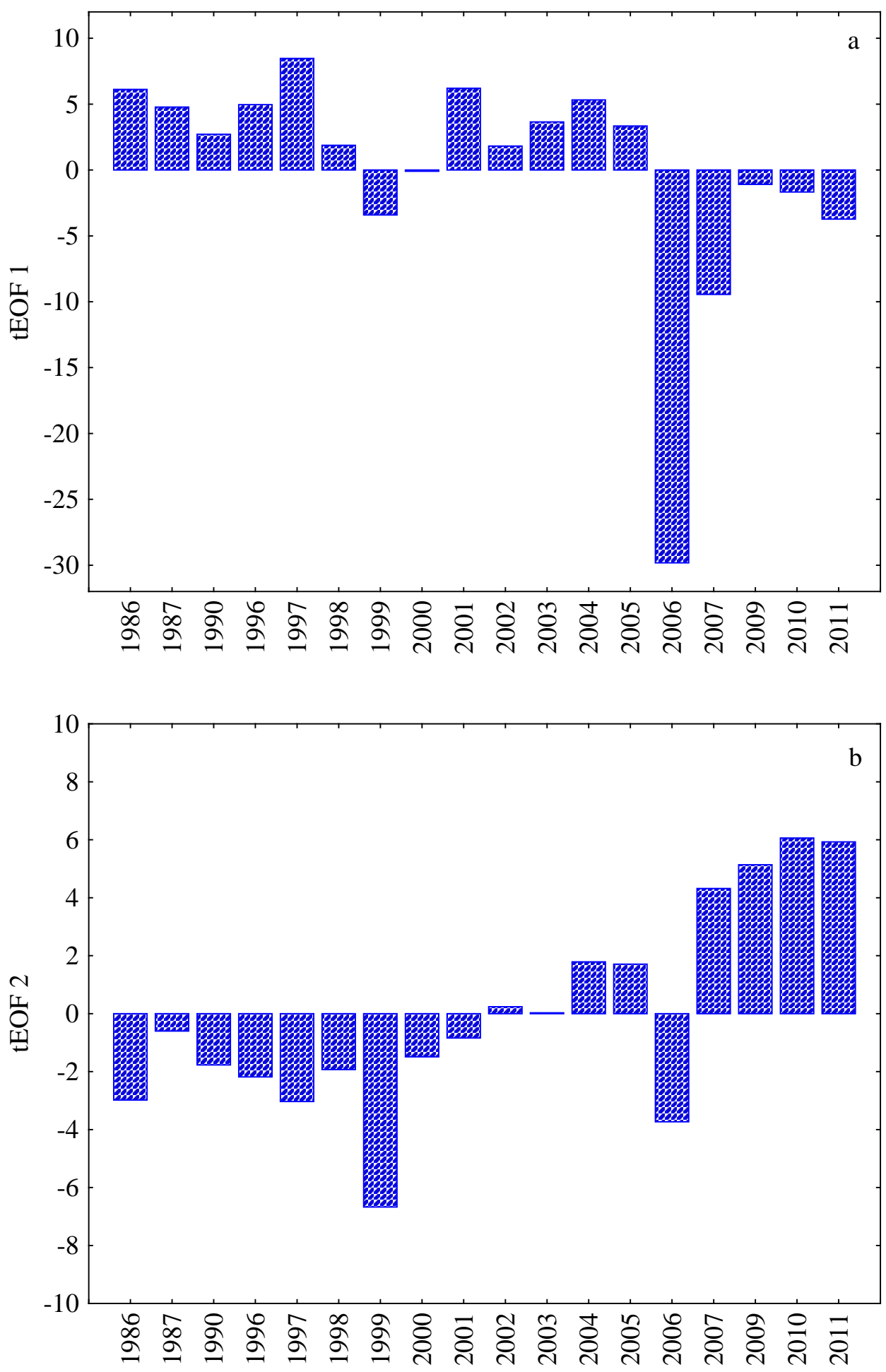

Figure 2.10 Temporal (a) EOF 1 (tEOF 1) and temporal (b) EOF 2 (tEOF2) scores for NDMI for each image date. 


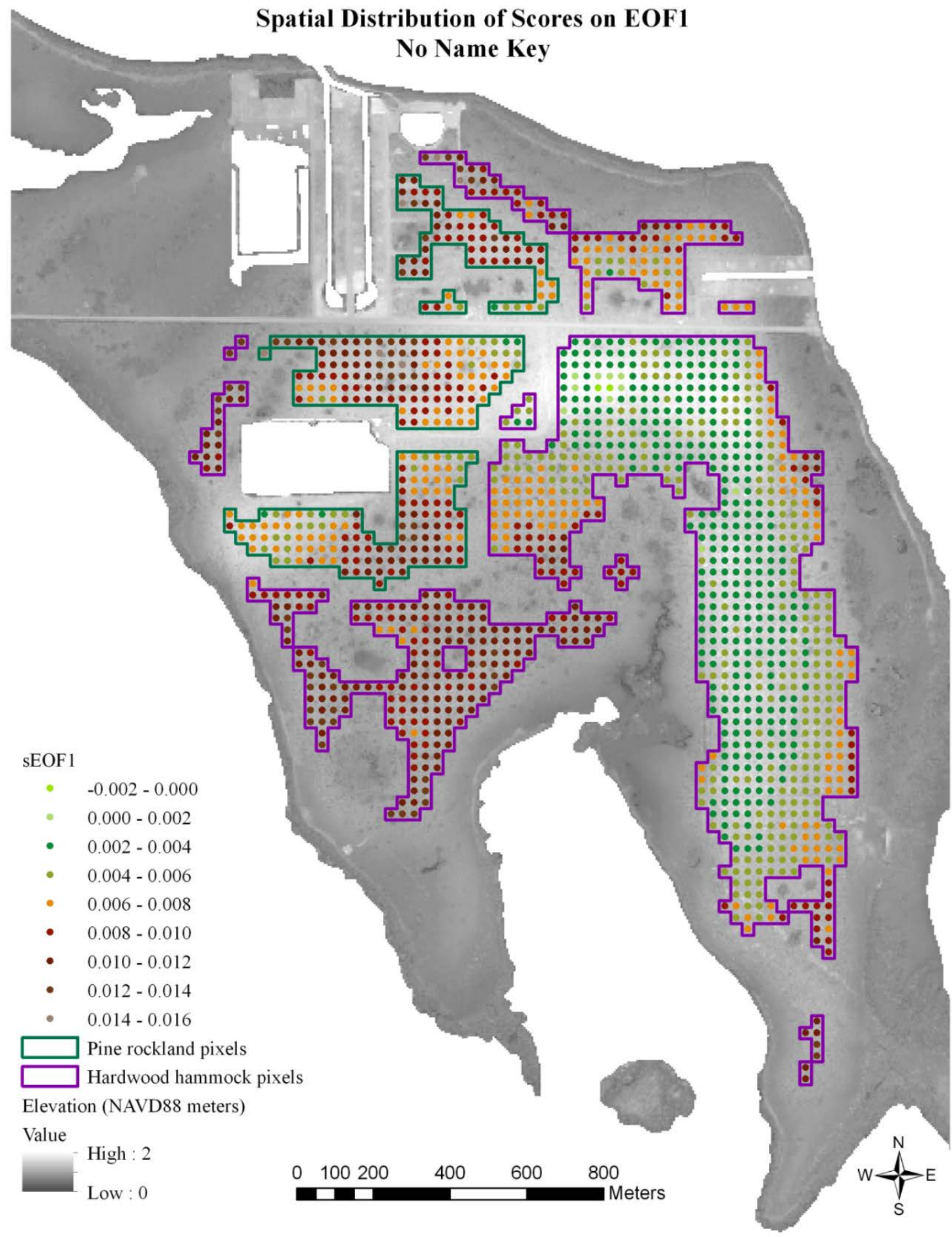

Figure 2.11 Distribution of spatial EOF 1 (sEOF 1) scores for NDMI on No Name Key. Areas of pine rockland are outlined in green, while areas of hardwood hammock are outlined in purple. 


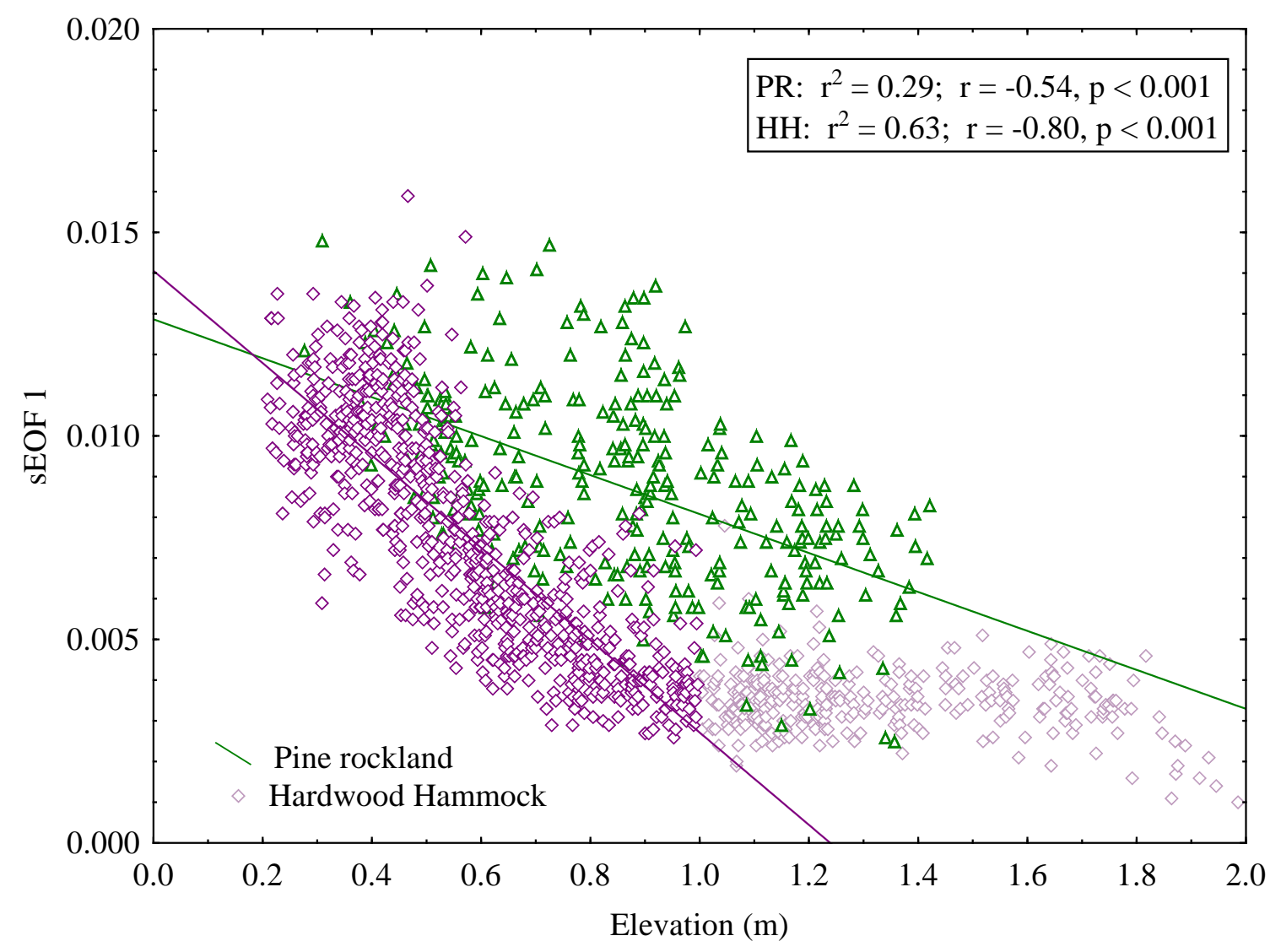

Figure 2.12 Relationship between pixel elevation (m) and sEOF 1 scores for NDMI on No Name Key in hardwood hammock $(\mathrm{HH})(\mathrm{n}=1071)$ and pine rockland $(\mathrm{PR})(\mathrm{n}=317)$. For hardwood hammock, correlation is only between sEOF1 scores and pixels at elevations $<=1 \mathrm{~m}$. 


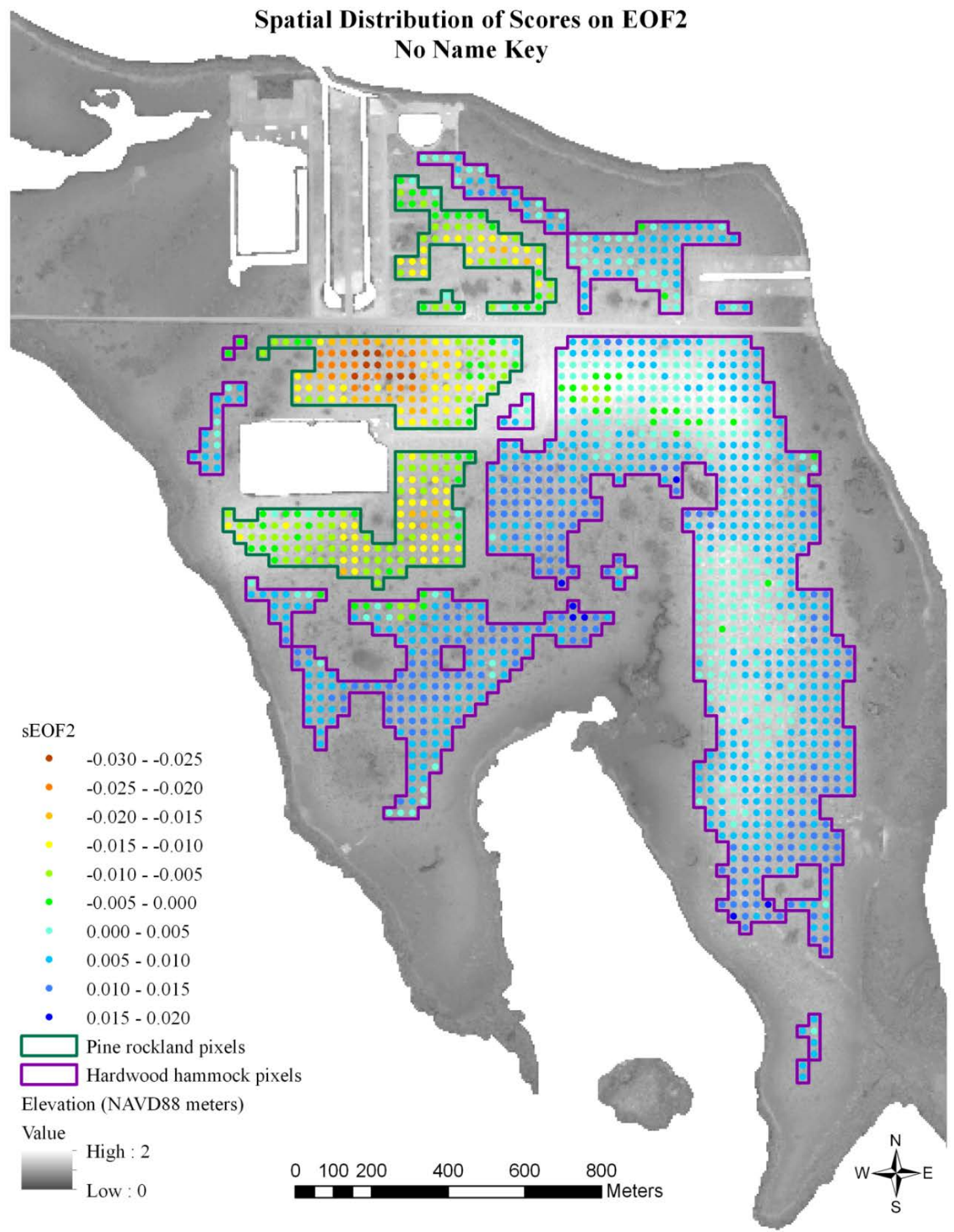

Figure 2.13 Distribution of spatial EOF 2 (sEOF 2) scores for NDMI on No Name Key. Areas of pine rockland are outlined in green, while areas of hardwood hammock are outlined in purple. 


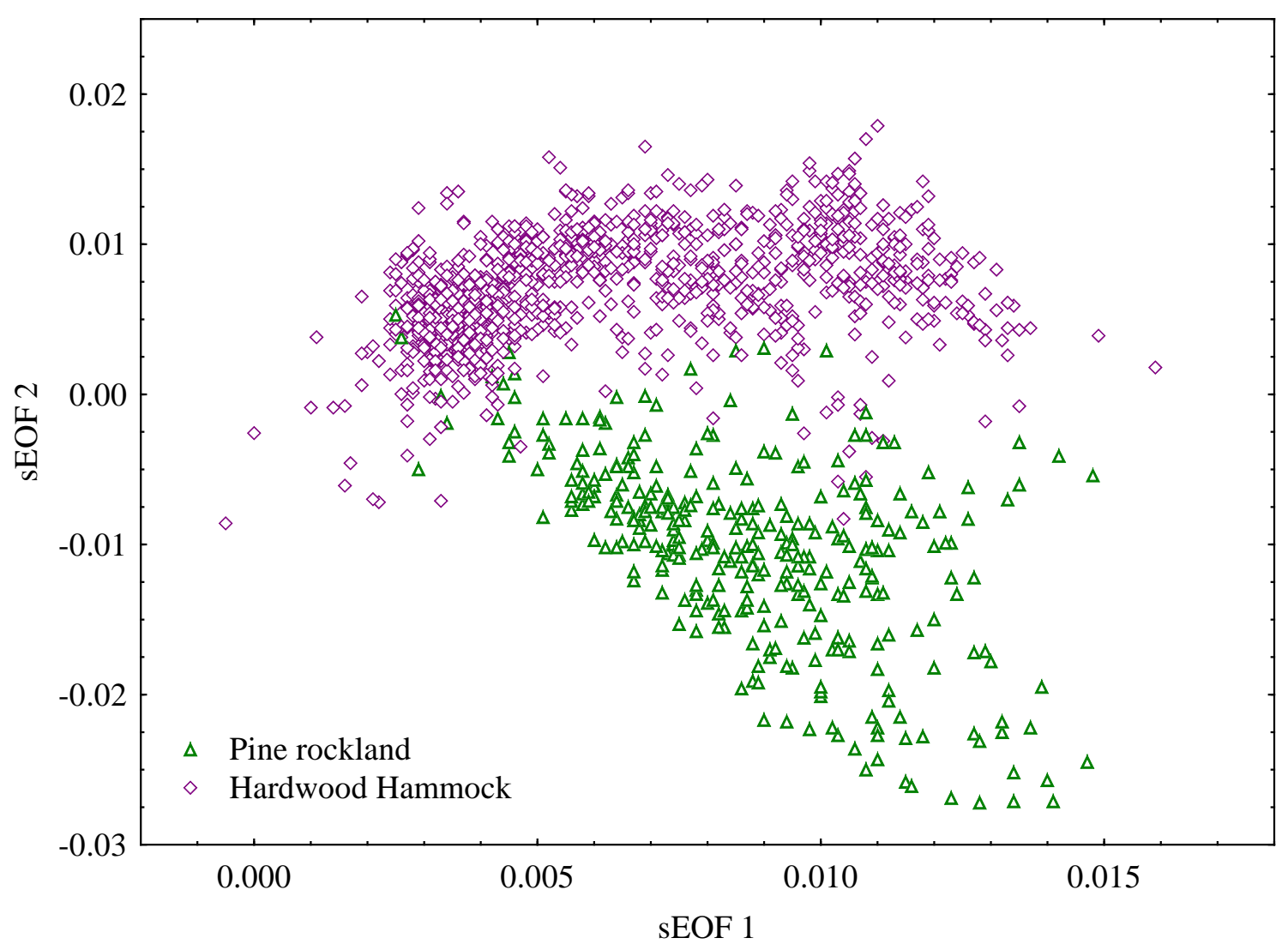

Figure 2.14 Scatterplot of spatial EOF scores for sEOF 1 and sEOF 2 for NDMI on No Name Key. T-test of sEOF 2 scores for hardwood hammock $(\mathrm{n}=1071)$ and pine rockland $(\mathrm{n}=317)$ was significant at $\mathrm{p}<0.001$. 


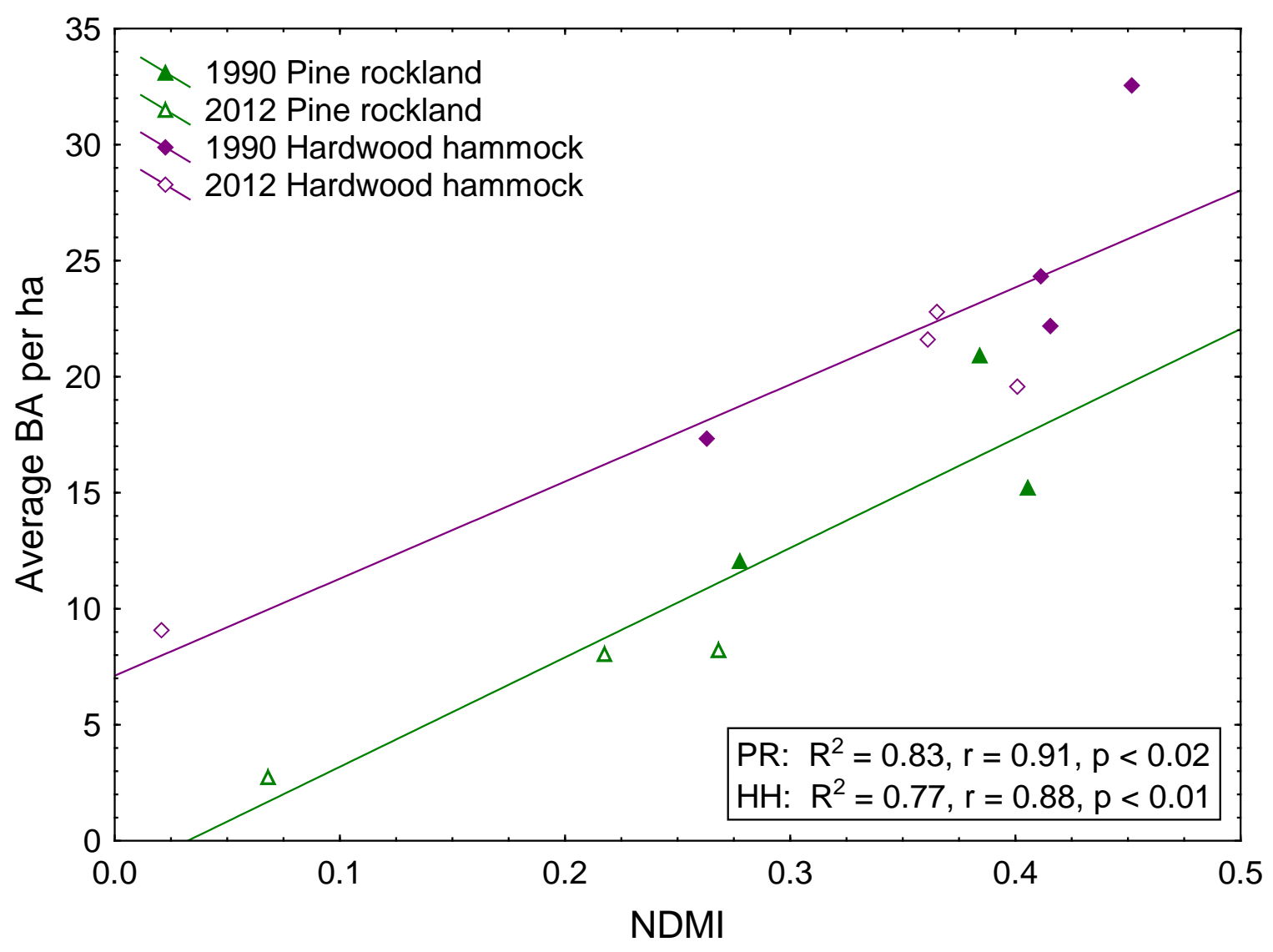

Figure 2.15 Relationship between NDMI and average permanent plot tree basal area per hectare in pine rockland (PR) $(n=6)$ and hardwood hammock $(\mathrm{HH})(\mathrm{n}=8)$ in 1990 and 2011. 


\section{CHAPTER 3. INTERACTION OF PULSE AND PRESS DISTURBANCES: EVIDENCE OF THE EFFECTS OF SEA LEVEL RISE ON THE COASTAL FORESTS OF THE LOWER FLORIDA KEYS (FLORIDA, USA)}

\subsection{Abstract}

The rate of sea level rise has increased during the last century, leading to changes in coastal ecosystems related to inundation and salinization. In the Florida Keys, the upslope retreat of coastal forests has been observed for well over half a century. This present study investigates the effects that the press disturbance of sea level rise has had on the groundwater resource on islands in the lower Keys and subsequently has had on the composition and structure of these forests over 22-year period. Within the same time period, these forests were also impacted by pulse disturbances, Hurricanes Georges (1998) and Wilma (2005), causing inundation by storm surge waters. Groundwater salinity and vegetation composition and structure were sampled in the early 1990s and again in 2012/2013 in permanent plots located both inside and outside the boundaries of the islands' previously mapped freshwater lenses. I asked whether changes in groundwater salinity varied between these two groups and whether forest structure and composition in three height strata were correlated with changes in salinity. Results of linear mixed effects modeling revealed that groundwater salinity underlying plots outside the freshwater lens increased over the two decades. Salinity of groundwater at plots inside the freshwater lens did not change over time, but was affected by prior precipitation. While basal area per hectare decreased in all plots, likely as a result of hurricane impact, the greatest decreases occurred outside the lens where groundwater 
salinity was highest. Percent cover increased in the low shrub stratum in plots outside the freshwater lens, and these communities also experienced the greatest shift in composition along a gradient of increasing salinity, specifically gaining species typical of supratidal scrub forest. While the effects of the pulse disturbance were evident throughout the tree stratum across all sites, changes observed in composition and structure of the low shrub stratum were restricted to sites located outside the freshwater lens. These findings strongly support a conclusion of an interaction between hurricane storm surge and sea level rise in these forests at sites of increasing groundwater salinity over the past two decades.

\subsection{Introduction}

Plant communities near the confluence of land and sea hold particular scientific and conservation interest owing to projected increases in sea level (Rahmstorf 2007) that will dramatically change their structure and composition in the near future. Over the last few decades, forest retreat and composition changes have been documented in a variety of coastal forest types, from mangrove forests (Ellison, 1993) to hydric hammocks (Williams et al., 1999; Saha et al., 2011). In low elevation terrestrial coastal forests, increasing sea level operates as a press or ramp disturbance (Glasby and Underwood, 1996; Lake, 2000), leading to higher water tables (Rotzoll and Fletcher, 2012) and increasing groundwater salinity as the salt water intrudes into freshwater aquifers (Guha and Panday, 2012). The result is the replacement of glycophytes by a halophytic plant community. Additionally, in the western Atlantic, coastal forests are frequently impacted by hurricanes, pulse disturbances that are typically accompanied by strong winds and 
storm surge flooding. Disturbance from hurricanes influence both forest structure (Van Bloem et al. 2006) and composition (Vandermeer, 2000), and has been found to amplify trends in forest succession related to variable resistance of species to storm-induced mortality (Ross et al., 2001). In combination, pulse and press disturbances may lead to different ecological outcomes than either disturbance individually (Glasby and Underwood, 1996), and can change successional trajectories (Ross et al., 2009). For instance, while increasing sea level decreases the availability of freshwater to plants in coastal communities, it also increases the likelihood of surface inundation by salt water during the pulse event as coastal height above mean sea level decreases (Tebaldi et al., 2012). A coastal forest community would be expected to recover rather quickly from a hurricane storm surge of a particular magnitude occurring at a relatively low stand of sea level, but at projected future sea levels, the same magnitude disturbance could serve as a tipping point for community change to an alternative state as the increasing sea level alters the ‘stability domain’ (Scheffer et al., 2001).

Changes in forest composition and structure from a pulse disturbance such as a hurricane will often result from direct mortality of salt sensitive canopy trees, as was observed after Hurricanes Hugo (Gardner et al., 1991; Conner and Inabinette, 2003) and Wilma (Ross et al., 2009). In contrast, gradual increases in sea level could first lead to changes in the understory strata as establishment of seedlings of canopy tree species is inhibited by increasing soil salinity (Williams et al., 1999). As a consequence, changes in one stratum might be expected to precede that of another depending on the interaction of these disturbances. In response to these disturbances, the relative abundance and diversity of 
species may increase or decrease, depending on the frequency and severity of the disturbance and the time frame over which compositional changes are evaluated (Williams et al., 1999; Ford and Brooks, 2002; Tanner and Bellingham, 2006; Gornish and Miller, 2010). In the long-term, increases in sea level should lead to a site-level decrease in species diversity as a few species of mangroves and associated species -three true mangrove species in South Florida (Tomlinson, 1986) -- dominate a landscape once occupied by a hardwood forest. When both disturbances are present simultaneously, identifying independent effects of the press disturbance can be a challenge if drastic changes to forest structure have concurrently resulted from a pulse event. However, in cases where vulnerability to the press effect varies predictably across the landscape, but susceptibility to the pulse effect is uniform, the two types of effect may be distinguished through strategic sampling.

The combined effects of rising sea level and hurricane impact on coastal vegetation communities are especially pressing in south Florida, where large areas of land exist at elevations only a few meters above sea level. The coastal forests located here, especially pine rockland and dry tropical broadleaf forest (hardwood hammock), host a unique assemblage of species, many endemic to south Florida (Snyder et al., 1990). On the lowlying islands of the Florida Keys, where maximum elevation is typically less than $2 \mathrm{~m}$, declines in the extent of fresh-water requiring coastal forests have been well-documented; pine stumps were found at the edge of coastal mangrove wetlands on northern Key Largo in the 1950s (Alexander, 1974). In the Keys, the extent of pine forests, as well as adjacent patches of hammock, has been decreasing since the end of the last ice age 
(18,000 year ago), as sea level rose to modern-day levels and dissected the island chain and isolated it from the once contiguous landmass of south Florida (Lidz and Shinn, 1991). The most recent study of coastal forest decline in the Florida Keys attributed landscape-scale changes in community boundaries to changes in elevation above local mean sea level (LMSL) (Ross et al., 1994). The results of the study implicated the $20^{\text {th }}$ century sea level rise of $23 \mathrm{~cm}$, measured at Key West, FL (Zervas 2009) as the proximate cause for the upslope retreat of pine rockland community, which was replaced by salt tolerant vegetation types. While it was not determined whether this was a gradual process or one punctuated by die-off events, the retreat did not result from a single catastrophic event (Ross et al., 1994).

Both among and within hardwood hammock and pine rockland forests, heterogeneity in stand structure and species composition exists as a function of vegetation physiognomy, disturbance history, and stand location defined by a site’s height above LMSL and coastal proximity. Coastal proximity and elevation not only can predict the extent of impact from hurricane-induced storm surge at a site, but additionally determine the salinity of groundwater at each location. In the lower Florida Keys, available fresh water occurs in lenses that are recharged by precipitation. These freshwater lenses float on the underlying salt water and their lateral extent is determined by the island topography combined with the amount of seasonal precipitation. Surveys employing electrical resistivity tomography (ERT) and electromagnetic (EM) techniques in the lower Keys have identified central lenses of fresh groundwater surrounded by increasingly brackish groundwater toward the coastline (Vacher et al., 1992; Meadows et al., 2004). Coastal forests in the lower 
Florida Keys occur at locations both inside and outside the central lens of freshwater. I hypothesize that if the press disturbance of sea level rise is currently affecting these forests, sites located outside of the freshwater lens might experience changes in structure and composition of greater magnitude than those located within the freshwater lens.

Building on the 1994 study that retrospectively investigated community boundary movement of coastal forests of the lower Florida Keys (Ross et al., 1994) and 2008 work that linked small differences in site elevation to pine mortality from a pulse event (Ross et al., 2009), this study investigates temporal changes in coastal forest structure and composition in pine rockland and hardwood hammock communities on two islands of the lower Florida Keys and quantifies the role that increases in groundwater salinity from rising sea level had on vegetation succession over two decades from 1990 to 2012. Within this time period, two hurricanes, Hurricane Georges in 1998 and Hurricane Wilma in 2005, impacted the lower Keys, bringing a combination of damaging winds and storm surge to the study location. I hypothesized that although impact from the pulse disturbance should be highly evident across the sites, additional changes in plant composition and structure should be observable at locations in which groundwater salinity had increased in response to the press disturbance of sea level rise.

My research first considers whether sea level rise over a 22-year period has increased ground water salinity within seven coastal forest patches in pine rockland and hardwood hammock forest at locations inside and outside the freshwater lenses of these islands. Using linear mixed effects modeling, I quantified changes in groundwater salinity across 
sampling locations. After accounting for variation in precipitation, I attributed any changes in groundwater salinity between the first and second sampling periods to increasing sea level. I then compared changes in forest structure and composition between coastal forests located inside and outside the freshwater lenses. Finally, using non metric multidimensional scaling (NMDS) and vector fitting, I investigated whether changes in plant community composition can be explained by changes in groundwater salinity.

\subsection{Study Area}

Big Pine and Upper Sugarloaf Keys (N 24.67, W 81.36, and N 24.66, W 81.53, respectively) are islands in the lower (southwestern) Florida Keys (Figure 3.1) separated by a distance of $17 \mathrm{~km}$. Plots on Big Pine Key are separated from each other by less than $0.5 \mathrm{~km}$ and those on Upper Sugarloaf Key are located within $1 \mathrm{~km}$ of each other. Study sites are located within $0.8 \mathrm{~km}$ of the coast of Florida Bay and at elevations less than $1 \mathrm{~m}$ above local mean sea level (LMSL) (Table 3.1). Both Hurricane Georges, a category 2 storm at the time of landfall in Key West on September 25 ${ }^{\text {th }}$, 1998, and Hurricane Wilma, a category 3 storm at time of landfall near the Cape of Florida on October $24^{\text {th }}$, 2005, flooded the islands with salt water and brought winds ranging in speed of 30 to $40 \mathrm{~m} / \mathrm{s}$. A combination of field evidence (Sah et al., 2010) and remotely-sensed data (see Chapter 2 p. 29) confirm that all island locations below $1 \mathrm{~m}$ received storm surge flooding from Hurricane Wilma. While the wind speeds in the two storms were similar, the extent of storm surge flooding was much greater in Hurricane Wilma (Kasper, 2007). 
These islands are situated on limestone bedrock composed of high permeability Key Largo Limestone (Hoffmeister and Multer, 1968), overlain by several meters of less permeable Miami Limestone (Hoffmeister et al., 1967), both of Late Pleistocene age (Perkins, 1977). Freshwater lenses exist on these islands as a result of differing secondary permeability of the two facies (Coniglio and Harrison, 1983) with the depth truncated near the contact between the facies (Vacher et al., 1992). Recharged by seasonal precipitation, these lenses provide a source of fresh groundwater to the constituent plants of the coastal forests. The Florida Keys encompass a strong climatic gradient, becoming increasingly drier and warmer as one moves away from mainland south Florida, and are typified by a dry season that stretches from November through May and a wet season from June through October, during which approximately two-thirds of the year's precipitation falls (102.2 cm yearly average for years 1984-2013 at Key West International Airport, http://www.ncdc.noaa.gov).

Both pine rockland and hardwood hammock forest communities are composed of species that share a requirement for access to the limited freshwater resources, but have some level of tolerance to periodic drought occasioned by the seasonal nature of precipitation in south Florida, and salt stress related to proximity to coastal salt water. Pine rocklands of the lower Florida Keys are characterized by the presence of a single dominant canopy species, Pinus elliottii var. densa Engelm., with a shrub layer consisting of West Indian hardwood species and palms, and a diverse herbaceous layer of approximately 150 species (Snyder et al., 1990). These forests can be found at elevations as low as 0.4 meters amsl. Soils are shallow at 0 to $10 \mathrm{~cm}$ in depth (Ross et al., 2003) with little 
organic matter and much exposed limestone (Snyder et al., 1990). Canopy heights of pine range from 7 to $13 \mathrm{~m}$ (Ross et al., 1992). In the absence of fire, pine rocklands are invaded by many of the species found in hardwood hammocks, lose their herbaceous flora, and move along a successional trajectory toward hammock (Snyder et al., 1990). P. elliottii is generally less salt tolerant than many hardwood species. By contrast, hardwood hammocks are generally found coastward of the pine rockland community and are characterized by species that display a range of salt tolerance. Hardwood hammocks of the lower Florida Keys have a diverse assemblage of woody species of West Indian origin with several palm species, but virtually no herbaceous plants (Ross et al., 1992). The majority of hardwood hammock canopies in the lower Keys range in height from 4 to $7 \mathrm{~m}$ (Ross et al., 1992). Hammocks are found at a range of elevations from $0.3 \mathrm{~m}$ amsl to the highest elevations of the lower Keys still in forest $(\sim 2 \mathrm{~m})$, with lower elevation hammocks including a component of more salt tolerant species. Soils are organic and are typically less than $0.2 \mathrm{~m}$ in depth (Ross et al., 2003).

\subsection{Materials and Methods}

\subsubsection{Vegetation Sampling}

Seven permanent plots were sampled in pine rockland (three plots) and hardwood hammock habitat (four plots) of varying elevations and coastal proximity on Big Pine (two plots) and Sugarloaf Keys (five plots) in 1990 and again in 2012 (Table 3.1, Figure 3.2). Each plot was $600 \mathrm{~m}^{2}$, consisting of six square $100 \mathrm{~m}^{2}$ subplots, except for one hardwood hammock plot of $500 \mathrm{~m}^{2}$ where area of habitat was limited. Plots were marked at the corner of each subplot with a metal rebar and GPS coordinates were obtained with 
a Garmin GPSmap76Cx having horizontal accuracy of $5 \mathrm{~m}$. Basal area was calculated from diameter at breast height $(\mathrm{DBH})$ for all tree species greater than $3 \mathrm{~cm} \mathrm{DBH}$ and taller than 2 m. Percent cover of herbaceous vegetation and low shrubs (0-1 m height), and saplings and high shrubs ( $>1 \mathrm{~m}$ height and $<3 \mathrm{~cm} \mathrm{DBH}$ ) was estimated for each species present in a 5 x $5 \mathrm{~m}$ quadrat located at the center point of each subplot. Cover was estimated using the following cover classes: $1=<1 \%, 2=1-4 \%, 3=4-16 \%, 4=16-32 \%$, $5=32-66 \%$, and $6=66-100 \%$. The midpoint of each cover class was used as the percent cover for each species in subsequent analyses.

\subsubsection{Groundwater Sampling}

Salinity data were collected periodically at wells associated with each plot to capture the yearly range in salinity for both the 1990 and 2012 sampling periods (Table 1). Wells were located within $5 \mathrm{~m}$ of the outside boundary of each permanent plot (Figure 2). Wells were drilled into the bedrock to a depth of approximately 1 meter. An open-ended PVC pipe having an inside diameter of 3.2 inches was placed to the bottom of the drilled hole. Cement was used to seal around the outside of the pipe above the bedrock surface. At site B2, the 1 meter-deep well of 1990 could not be relocated in 2012, and instead a nearby 5 cm diameter well installed by the U.S. Geologic Survey in 1989 was used. This well was $3 \mathrm{~m}$ deep and screened along its entirety.

Beginning in January 1991, all $1 \mathrm{~m}$ deep wells were sampled at bi-monthly intervals. The sampling interval became monthly in December 1991 and continued through 1992; this sampling is hereafter referred to as 1990s sampling. Prior to obtaining the sample, wells 
were evacuated using a syringe and tube to remove standing water and the well was allowed to refill with surrounding groundwater. The $3 \mathrm{~m}$ deep well was sampled approximately every two weeks beginning August 1989 to June 1990, was not evacuated prior to sampling, and is hereafter referred to as part of the 1990s sampling. Salinity of each groundwater sample was measured using a handheld refractometer with a resolution of $0.1 \mathrm{ppt}$ and accuracy of +/- $0.1 \mathrm{ppt}$. Twenty years later, wells were sampled every two months beginning May 2012 and ending May 2013; this sampling is hereafter referred to as 2010s sampling. Wells were pumped for several minutes with a peristaltic pump to clear approximately three well volumes before a sample was obtained. Salinity was measured with a YSI model 30 handheld probe with a resolution of 0.1 ppt and accuracy of $+/-0.1$ ppt.

\subsubsection{GIS Data Processing}

Plot boundaries were digitized in ArcMap 10.2 from the plot corners. Average plot elevation in NAVD88 (m) was determined for each permanent plot from the lower Keys Lidar-derived Digital Terrain Model (DTM) (Zhang et al. 2007) with a 5 m horizontal resolution using the zonal function in Spatial Analyst tools of ArcGIS 10.2. For each well location and centroid calculated for each permanent plot, the distance to the nearest coastline was calculated with the Near tool in ArcMap 10.2. NAVD88 elevations were converted to height above local mean sea level (LMSL) in meters using NOAAs Vertical Datum Transformation program, VDatum v. 3.4 (http://vdatum.noaa.gov/). Three of the permanent plot centroids and wells were located at distances from the coast beyond that considered in the program and values for height above LMSL could not be extracted 
directly. For these locations, the difference between NAVD88 elevation and height above LMSL for the nearest plot and shoreline was used to estimate height above LMSL. The average difference between NAVD88 elevation and height above LMSL of wells and plot centroids was $0.20 \mathrm{~m}$.

Permanent plots were designated as either occurring within the central core of the freshwater lens (inside lens) or outside the boundary of the central core of the freshwater lens (outside lens) on both islands (Figure 3.2). Boundaries were obtained for Big Pine Key from the wet season map developed by Wightman (1990) and for Upper Sugarloaf Key from the map developed by Caballero (1993) using electromagnetic profiling. These maps were georeferenced in ArcMap 10.2 into the datum and projection to correspond with that of the permanent plot boundaries and well locations. A comparison of the average and range of coastal proximity and height above LMSL of permanent plots located inside and outside the freshwater lens is presented in Table 3.2.

\subsubsection{Sea Level and Meteorological Data}

Annual mean sea level data was obtained from the Permanent Service for Mean Sea Level (http://www.psmsl.org/data/obtaining/stations/188.php) for the Key West Tide Gauge (N 24.56, W 81.81) and mean sea level trends for both the last 100 years (1914 to 2013) and 30 years (1984 to 2013) corresponding to the time period of the study were calculated. The rate of increase of sea level over 100 years was multiplied by the time span of the study to adjust the height above LMSL for well and plot locations for 1990. 
Daily climate data was downloaded from the National Climate Data Center (http://www.ncdc.noaa.gov/) for Key West International Airport from 1984 to 2013. Deviations from the 30-year average (1984 - 2013) annual rainfall were plotted to qualitatively examine whether sample years received less or more precipitation than the average. The total amount of rain that fell in the 30 days prior to each groundwater sampling event was calculated and included in subsequent modeling to determine if any relationship existed between groundwater salinity and recent precipitation.

\subsubsection{Data Analysis}

Linear mixed effects modeling with repeated measures (Zuur et al., 2009) was used to determine the relationship between geographic location (LENS: inside and outside), sampling period (PERIOD: 1990s and 2010s), total amount of precipitation received 30 days prior to sampling (PRECIP), and groundwater salinity (SAL). Six fixed effects were considered in the full model, which included two categorical variables (LENS and PERIOD), one continuous variable (PRECIP), and all two-way interactions between those variables. The interaction between LENS and PERIOD was included to determine if SAL at sites inside and outside the lens had different responses to the effect of PERIOD. The interaction between PERIOD and PRECIP was included to assess whether SAL was differently affected by PRECIP in each PERIOD. Finally, the interaction between LENS and PRECIP tested whether SAL was similarly affected by PRECIP at both LENS locations. Random effects for the intercepts of sampling well (WELL) $(\mathrm{n}=7)$ and sampling day (DAY) $(n=65)$ addressed non-independence related to repeated measures and accounted for any inherent differences at the sampling locations and times. 
Additionally I included a random slope for the effect of PERIOD for WELL that allowed salinity to vary independently at each well during each period. An investigation of residuals showed that groundwater salinity was heteroscedastic, therefore salinity data was $\log$ transformed after adding an integer of 1 to each salinity value (LOG ${ }_{10} \mathrm{SAL}$ ). Models were run in R v.3.1.2 (R core team, 2014) using the lmer function in the lme4 package and p-values were obtained for each effect using the Satterthwaite approximations to degrees of freedom (merModLmerTest) (Bates, D., Maechler, M., Bolker, B., and Walker S., 2014). Restricted maximum likelihood (REML) was used to correct the estimator for the variance. Competing models were evaluated using the krmodcomp function in the pbkrtest package with the Kenward-Roger approximation for F-test with p-value for the comparison between the full-model with effect in question compared to a model minus that effect (Halekoh and Højsgaard, 2014). Means +/- SE for each factor level of the pairwise interaction between PERIOD and LENS were obtained using the lsmeans package (Lenth, R. and Herva, M., 2015). P-values were obtained for pairwise contrasts using Bonferonni 2-sided tests. For each well, I calculated and plotted the mean groundwater salinity $+/-\mathrm{SE}$ for each time period and determined whether groundwater salinity increased, decreased, or remained constant between 1990s and 2010s sampling. Finally, I compared the average PRECIP between the 1990s and 2010s sampling using a student's t-test.

Paired t-tests in R v.3.1.2 (R core team, 2014) were used to assess changes in abundance and species richness between sites inside and outside the lens between the two sampling periods. Levene's test was used to check for homeogeneity of variances prior to 
conducting all t-tests. Percent change in basal area per hectare in the tree strata and change in total percent cover in the high shrub and low shrub strata were calculated as averages for each plot and compared between lens locations using paired t-tests. Species richness was calculated as the total number of species occurring within all subplots in each plot at each time period and was similarly compared between lens locations. Both diversity indices (abundance and species richness) were calculated using DECODA (version 3.01, Anutech Pty. Ltd, Canberra, AU).

Composition data were analyzed for tree, high shrub, and low shrub strata using NonMetric Multidimensional Scaling (NMDS) in DECODA. Ten random starts were selected, and a solution scaling option based on half-changes was used. No transformations were applied to abundance data (basal area for trees, percent cover for shrubs), but data were standardized to the species maximum across all plots. Fourteen samples (seven permanent plots and two sampling periods) were chosen for the ordination and all species with at least one occurrence in a plot were used in each stratum. Bray-Curtis distance was chosen to calculate the dissimilarity matrix (Bray and Curtis, 1957). Vector fitting in DECODA was used to best fit environmental variables to the composition data (Kantvilas and Minchin, 1989). Average groundwater salinity for each plot in each time period, distance to nearest coastline from each well location, and height above local mean sea level of each plot at each time period were selected as fitted variables. The 2-D result of the ordination was rotated to align with the groundwater salinity vector on the primary axis. The 2-D ordination results were saved and the minimum stress reported. Correlation coefficients quantified the relationship between the composition data for each stratum and the three vectors. In the rotated ordination space, 
the NMDS axis 1 score is equivalent to the response of the vegetation composition to the groundwater salinity within the plots in the two time periods. This score was used to assess change in composition attributable to salinity along that vector between the 1990s and 2010s sampling events for inside lens versus outside lens locations using paired ttests in R v.3.1.2 ( $\mathrm{R}$ core team, 2014).

\subsection{Results}

\subsubsection{Changes in Climate and Sea Level}

The calculated rate of sea level rise for the past 30 years (1984 to 2013) was $2.66 \mathrm{~mm} \mathrm{yr}^{-1}$ based on the tide gauge at Key West, while the rate based on 100 years of data (1914 to 2013) was $2.30 \mathrm{~mm} \mathrm{yr}^{-1}$. Increase in sea level over the 22 year period (1990 to 2012) was $5 \mathrm{~cm}$ as derived from the 100-year record (Figure 3.3). While sea level was variable over the 22-year time period, having a range of $12 \mathrm{~cm}$ from the lowest to highest stand, during the majority of both sampling periods, mean sea level was several $\mathrm{cm}$ above the regression line based on 100 years of data. The average annual precipitation (+/- SE) over a 30 year time period (1984 - 2013) was $102.2+/-2.67 \mathrm{~cm}$. Departures from the average were observed during both periods of groundwater sampling. In the 2010s sampling, 2012 and 2013 received an above average amount of precipitation, approximately $17 \mathrm{~cm}$ more than the annual average (Figure 3.4). In contrast, three of the four years during the 1990s sampling were drought years, and 1989 was especially dry, receiving only 79.2 $\mathrm{cm}$. 


\subsubsection{Changes in Groundwater Salinity}

Including interactions between LENS and PERIOD and LENS and PRECIP added significantly to the model that included only three main effects. The inclusion of the interaction of PERIOD and PRECIP did not add significantly to the model and was not included in the final model. The preferred model included five fixed effects and the two random effects (WELL and DAY), and best explained the relationship between the independent variables and groundwater salinity:

$$
\begin{aligned}
& L O G_{10} S A L \sim L E N S+P E R I O D+P R E C I P+L E N S: P E R I O D+L E N S: P R E C I P+ \\
& (1+P E R I O D \mid W E L L)+(1 \mid D A Y)
\end{aligned}
$$

Estimates of each fixed effect (Table 3.3) indicate that locations inside the freshwater lens have groundwater salinities 2.83 ppt less on average than those located outside the lens. The estimate of difference between PERIOD in the model is $1.67 \mathrm{ppt}$, with salinity increasing from the 1990s to 2010s. The effect of PRECIP was to decrease the groundwater salinity. The significant interaction between total precipitation received 30 days prior to sampling and lens location indicates that the salinity of inside lens sites are decreased by recent precipitation while outside lens sites are not similarly affected by precipitation. The significant interaction between LENS and PERIOD indicates that the change in groundwater salinity over time differed between the two groups. A comparison of means (Table 3.4) between inside and outside lens sites confirms that the groundwater salinity differed significantly between LENS in each PERIOD $(\mathrm{p}<0.001)$, and the difference was much higher in the 2010s as mean salinity increased only at the outside lens sites over the 22-year time period $(\mathrm{p}=0.02)$. At outside lens wells, the mean salinity increased between the two periods and the variability of salinities observed 
increased at the two most saline sites (Figure 3.5). The slightly lower mean salinities observed in the inside lens sites in 2010s compared with the 1990s are attributable to the greater amount of precipitation received 30 days prior to the 2010s than the 1990s sampling (1990s mean: $8.49 \mathrm{~cm}$, 2010s mean: $12.42 \mathrm{~cm}, \mathrm{p}=0.001)$.

\subsubsection{Changes in Stand Structure, Species Composition, and Richness}

In both hardwood hammock and pine rockland communities, basal area significantly decreased between 1990 and 2012 (paired t-test; p < 0.01), with five of the seven plots decreasing by amounts greater than $40 \%$ of their 1990 values (Figure 3.6). However, when lens location (inside vs. outside lens) was considered separately, decreases were not statistically significant at $\mathrm{p}<0.05$. By coastal forest type, losses in basal area in pine rockland were greater than in hammock, and were attributable almost entirely to the loss of the dominant species, Pinus elliottii var. densa, in two out of the three plots. In pine rockland, the largest decreases in basal area occurred at the lowest elevation site (61\% decrease at S3) and at minimum distance to coast (77\% decrease at B2). In hardwood hammock, the largest decreases in basal area (40 to 48\%) occurred at elevations below $0.6 \mathrm{~m}$ or at distance to coast less than $200 \mathrm{~m}$. The only sites without significant decreases in basal area were restricted to hardwood hammocks inside the freshwater lens boundary located greater than $200 \mathrm{~m}$ from coast and at elevations above $0.5 \mathrm{~m}$ (3 to 6\% decrease).

Changes in percent cover of the lower strata did not appear to closely track changes in basal area. Percent change in the high shrub stratum did not differ statistically from zero for either lens location. However, Conocarpus erectus L., buttonwood, a mangrove 
associate, increased in abundance throughout the majority of plots in both shrub layers. In the high shrub stratum, the increase in percent cover of C. erectus at each plot was highly correlated $(r=0.92, p=0.003)$ with the $\log _{10}$ of the change in groundwater salinity at each site. Increases in percent cover in the low shrub stratum were observed in plots located outside the lens boundary but were not statistically significant between the two sampling events. In contrast, the low shrub cover of plots located within the lens boundary decreased by almost $40 \%(\mathrm{p}<0.05)$. Changes in species richness were not statistically significant in any strata inside- or outside-lens. However, in the outside lens locations, species characteristic of coastal buttonwood scrub forest colonized the low shrub stratum of the lowest elevation pine rockland and hammock plots.

\subsubsection{Relationship between Community Composition and Environmental Variables}

Ordination and vector fitting across all sites and survey periods demonstrated strong fits between vegetation composition and the environmental variables --- average groundwater salinity, height above local mean sea level, and distance to coast (Table 3.5). The composition of the low shrub stratum was significantly correlated with all three environmental variables, but had the best relationship with groundwater salinity. While composition of the other two strata was also correlated with the groundwater salinity vector, correlations with distance to coast and height above local mean sea level were not significant for the tree stratum and high shrub stratum, respectively.

There was little consistency among sites in how tree composition changed between the 1990s and 2010s (Figure 3.7a). Accordingly, the mean position of 1990s tree 
assemblages did not differ significantly from that of the 2010s tree communities along the salinity vector, whether all plots were included in the analysis or inside lens and outside lens sites were considered separately. In contrast, for both shrub strata, the general movement of sites in ordination space was in the direction of increasing salinity (Figures 3.7b and 3.7c). For the high shrub stratum, the mean site score along Axis-1 for the 2010s scores was significantly greater than that for 1990s score for outside lens ( $\mathrm{p}<$ 0.05) but not for inside lens plots. For the low shrub stratum, plant composition on outside lens sites was characteristic of higher salinity in forests of the 2010s compared to forests of the 1990s ( $\mathrm{p}<0.05)$, but no similar difference was observed on sites inside the freshwater lens.

\subsection{Discussion}

In the lower Keys, the effect of sea level rise - a press disturbance impacting forests that rely on a coastal groundwater aquifer - is visible through the relationship between increasing groundwater salinity and associated changes in forest composition and structure, above and beyond the effects of hurricane storm surge flooding. Evidence for salt water intrusion attributable to $5 \mathrm{~cm}$ of sea level rise over the 2-decade study period was found using linear mixed effects modeling, which identified an increase in groundwater salinity at outside lens sites, but not at locations inside the boundaries of the

freshwater lens. The influence of these changes on vegetation were demonstrated through ordination with vector fitting, which provided evidence for a shift in species composition along a gradient of groundwater salinity, particularly in lower forest strata. 


\subsubsection{The Effect of Climate on Groundwater Resources and Coastal Forests}

Increasing sea level clearly has the impact of decreasing lens geometry by allowing the gradient of fresh-salt water mixing to move inland. In this study, the rise in sea level of the last few decades has resulted in non-uniform increases in groundwater salinity in the mixing zone. The lower Keys islands originated as oolitic banks that lithified and underwent karstification (Hoffmeister et al., 1967), resulting in an undulating topography and islands that do not conform to an idealized conceptual model for Ghyben-Herzberg lens as areas of high elevation do not necessarily coincide with fresh water. Additionally, the large amount of tidal pumping in the high permeability bedrock of these islands leads to a wide zone of fresh-salt water mixing which becomes increasingly brackish as one moves away from the center of the freshwater lens (Meadows et al., 2004). While heights above LMSL on Big Pine and Upper Sugarloaf Keys are generally greater inside the freshwater lens than outside of it (Table 3.2), localized highs are observed at close coastal proximity and extensive overlap of the two variables across lens locations results in neither elevation nor coastal proximity individually predicting change in groundwater salinity nor forest structure and composition. Beyond a particular threshold of sea level rise, areal decreases in island extent will result in the replacement of an interior freshwater lens by an aquifer having a zone of fresh-salt mixing which extends to the center of the lens as has been observed in Pacific atolls (Oberdorfer et al., 1990). Of the two study islands, this will first occur on Upper Sugarloaf Key, as it is significantly smaller than Big Pine, and pine rockland and hardwood hammock forests should change more rapidly to halophytic vegetation as a result of the press of sea level rise. 
The importance of aquifer recharge from precipitation is illustrated by the lower groundwater salinity recorded at sites inside the freshwater lens during the most recent sampling period of greater than average rainfall. The decrease in salinity at these sites, despite the $5 \mathrm{~cm}$ of sea level rise, indicates that interior lens locations are still primarily influenced by seasonal and inter-annual variation in precipitation. This has important ramifications for the freshwater-requiring coastal forests that rely on a combination of precipitation and groundwater resources. Predicted summer drying trends in the Central American-Caribbean region for the late $21^{\text {st }}$ century (Neelin et al., 2006) would lead to greater occurrences of drought and simultaneously decrease aquifer recharge, hastening the press disturbance of sea level rise. Coastal forests in south Florida would be especially vulnerable to drying trends as the majority of rainfall occurs during the summer and fall. The effect of drought on plants is similar to the initial effects of increasing salinity (Munns, 2002). Drought would limit water availability, which has been found to constrain increases in stand basal area in European forests (Ruiz-Benito et al., 2014). In combination with groundwater salinization, drought conditions will likely lead to decreased primary productivity and species turnover in these forests.

\subsubsection{Press and Pulse Effects by Strata}

In coastal forests, when a pulse event causes immediate change to forest composition and structure, the conditions and resources available for recovery are influenced by the background press of sea-level rise. While direct mortality of individuals is attributable to the pulse disturbance, recovery is dependent on species regeneration capabilities combined with differential species tolerances to salinity, which affect growth through 
salinity effects on photosynthetic capacity (McLeod et al., 1996). While the pulse event resulted in tree mortality across all plots, changes related to increasing groundwater salinity attributable to the press disturbance of sea level were largely observed in the low shrub stratum in this study. A possible explanation is that $5 \mathrm{~cm}$ of sea level rise over the time period was not enough to result in mortality of overstory trees, but for some species in the low shrub strata which includes a combination of ephemeral species, shrubs, and seedlings of overstory trees, germination and establishment could be affected by higher groundwater salinities associated with the rise in sea level.

In pine rockland plots, the greatest change in structure in the tree stratum was attributable to the loss of $P$. elliottii var. densa. Slash pine was absent from the low shrub / herbaceous layer in most of the sites in 2010s sampling despite being present at those plots in the 1990s. Low pine regeneration results from a combination of factors. First the elimination of the majority of adult trees from storm surge decreases the availability of seed source. Secondly the environmental conditions necessary for germination may cease to exist once more halophytic shrubby plants invade the understory and soil salinity increases. Additionally, the loss of pine trees and associated pine needle litter with an increase in woody shrubs alters the fire regime, eventually leading to a forest dominated by woody hardwood species (Ross et al., 2009). A lack of recruitment of new individuals limited by salt-saturated soils was observed for loblolly pine, Pinus taeda L., in Maryland, and it was presumed that combined with a loss of adults from storm surge events, recruitment failure would lead to stepwise retreat of these forests (Kirwan et al., 2007). 
While the loss of pine trees in this study resulted primarily from the pulse event, whether new individuals can recruit into these sites will determine if these pine forests similarly follow a step-wise retreat. Seed from adjacent areas of surviving pines on these islands would be required to re-establish pine in these locations, assuming soil and litter conditions remain suitable at those locations. At sites outside the lens, where groundwater salinity has increased over the time period, regeneration seems highly unlikely. A lack of regeneration of this species will eventually lead pine rocklands to lose the diverse herbaceous understory and succeed to communities resembling those of hammocks.

\subsubsection{Species Turnover}

While anthropogenic changes in environment are predicted to lead to species turnover and loss of species diversity (Tilman and Lehman 2001), this pattern has not yet been observed in the Keys. While I did observe species turnover, as loss in species in the shrub strata were balanced by gains in new species, species richness did not significantly change over the time period. Instead, a non-significant increase in species was observed in the low shrub stratum at sites outside the lens having the highest change in salinity over the time period. These results suggest that the combination of disturbance and increasing groundwater salinity have created conditions that favor the colonization of new species at a greater rate than the disappearance of the previous inhabitants, which is a phenomenon that has been observed in other plant communities (Walther et al., 2002).

Specifically, the loss of woody species in the low shrub stratum was eclipsed by an increase in the number of new woody trees and shrubs, grasses, vines, and herbaceous species. Several species with relatively high salt tolerance but low shade tolerance 
colonized these sites over the sampling period. The appearance of two woody shrubs typical of saline environments, Borrichia arborescens (L.)DC., tree seaside oxeye, and Borrichia frutescens (L.)DC., bushy seaside oxeye, was restricted to plots with the greatest increase in salinity over the study period. Similarly, two grass species Spartina spartinae (Trin.)Merr. ex Hitchc., Gulf cordgrass, and Sporobolus virginicus (L.)Kunth, seashore dropseed, colonized the two lowest elevation sites, while one sedge, Fimbristylis spadicea (L.)Vahl, marsh fimbry, appeared at three of the outside lens locations having the greatest increase in groundwater salinity. The aforementioned species occur in abundance within the mangrove adjacent supratidal scrub community that is found coastward of both pine rockland and hardwood hammock forests.

Changes in the abundance of Conocarpus erectus, not only in the tree strata, but across all strata, were particularly notable. The dominant woody species of supratidal scrub community, which is infrequently inundated with salt water during high tide, C. erectus increased in abundance or had newly colonized all but one of the plots in at least one strata, with the exception of small decreases in basal area at sites S3 and S4 (lowest elevation sites) as a result of mortality from the pulse event. The widespread increase of this species seems to provide early evidence of a succession of hardwood hammocks to mangrove from a combination of press and pulse disturbance as proposed by numerical modeling (Sternberg et al., 2007; Teh et al., 2008) and conceptual model for south Florida coastal forests (Ross et al., 2009). The increase of C. erectus across communities and strata, combined with the loss of $P$. elliottii var. densa in pine forests, supports the 
hypothesis that change from freshwater-requiring coastal forests to salinity tolerant forests is ongoing.

\subsection{Conclusions}

The study has provided evidence of sea level rise-induced changes to community composition in both hardwood hammock and pine rockland communities, focused especially on areas outside the boundary of the fresh groundwater resource. The synergistic effects of pulse and press disturbances have variable outcomes to community composition and structure. Despite a relatively small number of sites whose dynamics over time could be documented, a distinction between sites affected and not affected by the press disturbance was evident in changes in species composition. As observed in other locales in Florida, the interaction of disturbance events shaping the future of coastal forests will likely become the norm. Coastal forests in Waccasassa Bay Preserve on the west coast of Florida declined faster than predicted from sea level rise alone and a drought (pulse event) was suspected to have played an important role in that forest decline (Desantis et al., 2007). While the expected end point of the trajectory for these coastal forests is a halophytic, mangrove community, novel assemblages of species could result during this transition as environmental gradients shift (Williams and Jackson, 2007). Currently, changes in composition of the low shrub stratum appear to be an early indicator of the effects of sea level rise on these coastal forests. Given the prediction of increased frequency of severe hurricanes in the western Atlantic (Bender et al., 2010), it is expected that the pace of these changes should increase over time, as the interaction between pulse and press disturbance in the low-lying coastal areas push succession along 
new trajectories to halophytic assemblages. Understanding the dynamics of how these changes will unfold, including in which strata changes first occur, should allow land managers to make decisions that conserve the coastal resource as long as possible. 


\subsection{References}

Alexander, T.R., 1974. Evidence of recent sea level rise derived from ecological studies on Key Largo, FL. Miami Geological Society 2, 219-222.

Bender, M.A., Knutson, T.R., Tuleya, R.E., Sirutis, J.J., Vecchi, G.A., Garner, S.T., Held, I.M., 2010. Modeled impact of anthropogenic warming on the frequency of intense Atlantic hurricanes. Science 327, 454-458.

Bray, J.R., Curtis, J.T., 1957. An ordination of the upland forest communities of southern Wisconsin. Ecological Monographs 27, 325-349.

Caballero, J.P., 1993. Salinity variation in the upper saturated zone of Sugarloaf Key, Florida. (M.S. Thesis). Univerisity of South Florida, Tampa, FL.

Coniglio, M., Harrison, R.S., 1983. Facies and diagenesis of late Pleistocene carbonates from Big Pine Key, FL. Bulletin of Canadian Petroleum Geology 31, 135-147.

Conner, W.H., Inabinette, L.W., 2003. Tree growth in three South Carolina (USA) swamps after Hurricane Hugo: 1991-2001. Forest Ecology and Management 182, 371-380.

Desantis, L.R.G., Bhotika, S., Williams, K., Putz, F.E., 2007. Sea-level rise and drought interactions accelerate forest decline on the Gulf Coast of Florida, USA. Global Change Biology 13, 2349-2360.

Ellison, J.C., 1993. Mangrove retreat with rising sea-level, Bermuda. Estuarine, Coastal and Shelf Science 37, 75-87.

Ford, C.R., Brooks, J.R., 2002. Detecting forest stress and decline in response to increasing river flow in southwest Florida, USA. Forest ecology and management 160, 45-64.

Gardner, L.R., Michener, W.K., Blood, E.R., Williams, T.M., Lipscomb, D.J., Jefferson, W.H., 1991. Ecological impact of Hurricane Hugo - salinization of a coastal forest. Journal of Coastal Research 8, 301-317.

Glasby, T.M., Underwood, A.J., 1996. Sampling to differentiate between pulse and press perturbations. Environmental Monitoring and Assessment 42, 241-252.

Gornish, E.S., Miller, T.E., 2010. Effects of storm frequency on dune vegetation. Global Change Biology 16, 2668-2675.

Guha, H., Panday, S., 2012. Impact of sea level rise on groundwater salinity in a coastal community of south Florida. Journal of the American Water Resources Association 48, 510-529. 
Halekoh, U., Højsgaard, S., 2014. A Kenward-Roger approximation and parametric bootstrap methods for tests in linear mixed models-the $\mathrm{R}$ package pbkrtest. Journal of Statistical Software 59, 1-32.

Hoffmeister, J.E., Multer, H.G., 1968. Geology and origin of the Florida Keys. Geological Society of America Bulletin 79, 1487-1502.

Hoffmeister, J.E., Stockman, K.W., Multer, H.G., 1967. Miami Limestone of Florida and its recent Bahamian counterpart. Geological Society of America Bulletin 78, 175190.

Kantvilas, G., Minchin, P.R., 1989. An analysis of epiphytic lichen communities in Tasmanian cool temperate rainforest. Vegetatio 84, 99-112.

Kasper, K., 2007. Hurricane Wilma in the Florida Keys. National Oceanic and Atmospheric Administration (NOAA)/National Weather Service (NWS) Weather Forecast Office (WFO), Key West, FL.

Kirwan, M.L., Kirwan, J.L., Copenheaver, C.A., 2007. Dynamics of an estuarine forest and its response to rising sea level. Journal of Coastal Research 457-463.

Lake, P.S., 2000. Disturbance, patchiness, and diversity in streams. Journal of the North American Benthological Society 19, 573-592.

Lidz, B.H., Shinn, E.A., 1991. Paleoshorelines, reefs, and a rising sea: South Florida, U.S.A. Journal of Coastal Research 7, 203-229.

McLeod, K.W., McCarron, J.K., Conner, W.H., 1996. Effects of flooding and salinity on photosynthesis and water relations of four southeastern coastal plain forest species. Wetlands Ecology and Management 4, 31-42.

Meadows, D.G., Caballero, J.P., Kruse, S.E., Vacher, H.L., 2004. Variation of salinity in brackish-water lenses of two Florida Keys. Journal of Coastal Research 20, 386400.

Munns, R., 2002. Comparative physiology of salt and water stress. Plant, Cell and Environment 25, 239-250.

Neelin, J.D., Münnich, M., Su, H., Meyerson, J.E., Holloway, C.E., 2006. Tropical drying trends in global warming models and observations. Proceedings of the National Academy of Sciences 103, 6110-6115.

Oberdorfer, J.A., Hogan, P.J., Buddemeier, R.W., 1990. Atoll island hydrogeology: flow and freshwater occurrence in a tidally dominated system. Journal of Hydrology 120, 327-340. 
Perkins, R.D., 1977. Depositional framework of Pleistocene rocks in south Florida, in: Enos, P., Perkins, R.D. (Eds.), Quarternary Sedimentation in South Florida. Geological Society of America, pp. 131-198.

Rahmstorf, S., 2007. A semi-empirical approach to projecting future sea-level rise. Science 315, 368-370.

Ross, M.S., Carrlngton, M., Flynn, L.J., Ruiz, P.L., 2001. Forest succession in tropical hardwood hammocks of the Florida Keys: effects of direct mortality from Hurricane Andrew. Biotropica 33, 23-33.

Ross, M.S., Coultas, C.L., Hsieh, Y.P., 2003. Soil-productivity relationships and organic matter turnover in dry tropical forests of the Florida Keys. Plant and soil 253, 479-492.

Ross, M.S., O’Brien, J.J., da Silveira Lobo Sternberg, L., 1994. Sea-level rise and the reduction in pine forests in the Florida Keys. Ecological Applications 4, 144-156.

Ross, M.S., O’Brien, J.J., Flynn, L.J., 1992. Ecological site classification of Florida Keys terrestrial habitats. Biotropica 24, 488-502.

Ross, M.S., O’Brien, J.J., Ford, R.G., Zhang, K., Morkill, A., 2009. Disturbance and the rising tide: the challenge of biodiversity management on low-island ecosystems. Frontiers in Ecology and the Environment 7, 471-478.

Rotzoll, K., Fletcher, C.H., 2012. Assessment of groundwater inundation as a consequence of sea-level rise. Nature Climate Change 3, 477-481.

Ruiz-Benito, P., Madrigal-González, J., Ratcliffe, S., Coomes, D.A., Kändler, G., Lehtonen, A., Wirth, C., Zavala, M.A., 2014. Stand structure and recent climate change constrain stand basal area change in European forests: a comparison across boreal, temperate, and Mediterranean biomes. Ecosystems 17, 1439-1454.

Saha, A.K., Saha, S., Sadle, J., Jiang, J., Ross, M.S., Price, R.M., Sternberg, L.S.L.O., Wendelberger, K.S., 2011. Sea level rise and south Florida coastal forests. Climatic Change 107, 81-108.

Sah, J.P., Ross, M.S., Snyder, J.R., Ogurcak, D.E., 2010. Tree mortality following prescribed fire and a storm surge event in slash pine (Pinus elliottii var. densa) forests in the Florida Keys, USA. International Journal of Forestry Research 2010, $1-13$.

Scheffer, M., Carpenter, S., Foley, J.A., Folke, C., Walker, B., 2001. Catastrophic shifts in ecosystems. Nature 413, 591-596. 
Snyder, J.R., Herndon, A., Robertson, W.B., 1990. South Florida rockland, in: Myers, R.L., Ewel, J.J. (Eds.), Ecosystems of Florida. University of Central Florida Press, Orlando, FL, pp. 230-277.

Sternberg, L. da S.L., Teh, S.Y., Ewe, S.M.L., Miralles-Wilhelm, F., DeAngelis, D.L., 2007. Competition between hardwood hammocks and mangroves. Ecosystems 10, 648-660.

Tanner, E.V.J., Bellingham, P.J., 2006. Less diverse forest is more resistant to hurricane disturbance: evidence from montane rain forests in Jamaica. Journal of Ecology 94, 1003-1010.

Tebaldi, C., Strauss, B.H., Zervas, C.E., 2012. Modelling sea level rise impacts on storm surges along US coasts. Environmental Research Letters 7, 1-11.

Teh, S.Y., DeAngelis, D.L., Sternberg, L. da S.L., Miralles-Wilhelm, F.R., Smith, T.J., Koh, H.-L., 2008. A simulation model for projecting changes in salinity concentrations and species dominance in the coastal margin habitats of the Everglades. Ecological Modelling 213, 245-256.

Tomlinson, P.B., 1986. The botany of mangroves. Cambridge University Press, New York, NY.

Vacher, H.L., Wightman, M.J., Stewart, M.T., 1992. Hydrology of meteroic diagenesis: effect of Pleistocene stratigraphy on freshwater lenses of Big Pine Key, Florida, in: Fletcher, C.H., III, Wehmiller, J.F. (Eds.), Quarternary Coasts of the United States: Marine and Lacustine Systems, SEPM (Society for Sedimentary Geology. pp. 213-219.

Van Bloem, S.J., Lugo, A.E., Murphy, P.G., 2006. Structural response of Caribbean dry forests to hurricane winds: a case study from Guanica Forest, Puerto Rico. Journal of Biogeography 33, 517-523.

Vandermeer, J., 2000. Hurricane disturbance and tropical tree species diversity. Science 290, 788-791.

Walther, G.-R., Post, E., Convey, P., Menzel, A., Parmesan, C., Beebee, T.J., Fromentin, J.-M., Hoegh-Guldberg, O., Bairlein, F., 2002. Ecological responses to recent climate change. Nature 416, 389-395.

Wightman, M.J., 1990. Geophysical analysis and Dupuit-Ghyben-Herzberg modeling of freshwater lenses on Big Pine Key, Florida (M.S. Thesis). University of South Florida, Tampa, FL

Williams, J.W., Jackson, S.T., 2007. Novel climates, no-analog communities, and ecological surprises. Frontiers in Ecology and the Environment 5, 475-482. 
Williams, K., Ewel, K.C., Stumpf, R.P., Putz, F.E., Workman, T.W., 1999. Sea-level rise and coastal forest retreat on the west coast of Florida, USA. Ecology 80, 20452063.

Zervas, C. 2009. Sea level variations of the United States 1854-2006 (NOAA Technical Report NOS CO-OPS 053). National Oceanic and Atmospheric Administration, National Ocean Service, Silver Spring, MD.

Zuur, A.F., Ieno, E.N., Walker, N.J., Saveliev, A.A., Smith, G.M., 2009. Mixed Effects Models and Extensions in Ecology with R. Springer, New York, NY. 


\subsection{Tables}

Table 3.1. Permanent plot environmental variables and average salinity in ppt for each sample period. Island codes: BPK = Big Pine Key, SLK = Sugarloaf Key. Habitat codes: $\mathrm{PR}=$ pine rockland; $\mathrm{HH}=$ hardwood hammock. ${ }^{*}$ Distance to coast.

\begin{tabular}{|c|c|c|c|c|c|c|c|c|c|c|}
\hline Plot & Island & Hab & $\begin{array}{c}\text { Lens } \\
\text { Loc }\end{array}$ & $\begin{array}{c}\text { \# of } \\
\text { sub } \\
\text { plots }\end{array}$ & $\begin{array}{c}\text { DTC* } \\
\text { (m) }\end{array}$ & $\begin{array}{c}\text { Ht (m) } \\
\text { above } \\
\text { LMSL }\end{array}$ & $\begin{array}{c}\text { 1990s } \\
\text { ave } \\
\text { (ppt) }\end{array}$ & $\begin{array}{c}2010 \mathrm{~s} \\
\text { ave } \\
\text { (ppt) }\end{array}$ & $\begin{array}{c}1990 s \\
\mathrm{n}\end{array}$ & $\begin{array}{c}2010 \mathrm{~s} \\
\mathrm{n}\end{array}$ \\
\hline B2 & BPK & PR & On & 6 & 189 & 0.69 & 2.26 & 1.13 & 24 & 6 \\
\hline B3 & BPK & HH & Off & 6 & 46 & 0.91 & 4.29 & 7.67 & 34 & 6 \\
\hline S2 & SLK & HH & Off & 6 & 282 & 0.66 & 9.76 & 10.48 & 34 & 6 \\
\hline S3 & SLK & PR & Off & 6 & 758 & 0.59 & 9.29 & 12.68 & 35 & 6 \\
\hline S4 & SLK & HH & Off & 5 & 633 & 0.52 & 10.51 & 28.57 & 35 & 6 \\
\hline S5 & SLK & PR & On & 6 & 535 & 0.91 & 1.74 & 0.67 & 34 & 6 \\
\hline S7 & SLK & HH & On & 6 & 308 & 0.88 & 2.77 & 2.57 & 35 & 6 \\
\hline
\end{tabular}

Table 3.2 Mean +/- SE of distance to coast and height above local mean sea level for sites on and off the freshwater lens. * Distance to coast.

\begin{tabular}{|c|c|c|c|c|c|}
\hline $\begin{array}{c}\text { Lens } \\
\text { Location }\end{array}$ & $\mathrm{n}$ & Mean DTC* (m) & $\begin{array}{c}\text { Min - Max } \\
\text { DTC* (m) }\end{array}$ & $\begin{array}{c}\text { Mean ht above } \\
\text { LMSL (m) }\end{array}$ & $\begin{array}{c}\text { Min - Max ht } \\
\text { above LMSL (m) }\end{array}$ \\
\hline Inside & 3 & $344+/-102$ & 189 to 535 & $0.83+/-0.07$ & 0.69 to 0.91 \\
\hline Outside & 4 & $430+/-163$ & 46 to 758 & $0.67+/-0.08$ & 0.52 to 0.91 \\
\hline
\end{tabular}


Table 3.3 Estimate and standard error for each fixed effect from linear mixed effect modeling of $\log _{10}$ salinity at 7 wells with 65 sampling events from 1990s to 2010s. Estimates and SE are reported as salinity in ppt, $\mathrm{n}=237$.

\begin{tabular}{|l|c|c|c|c|}
\hline Fixed Effects & Estimate & $\begin{array}{c}\text { Std. } \\
\text { Error }\end{array}$ & df & P value \\
\hline Intercept & 9.77 & 1.19 & 6.8 & $<0.001$ \\
\hline Lens Location (Inside) & -2.83 & 1.28 & 5.4 & $<0.01$ \\
\hline Period (2010s) & 1.67 & 1.23 & 9.5 & 0.032 \\
\hline 30 days previous precipitation & -1.01 & 1.01 & 80.2 & 0.034 \\
\hline Lens Location (Inside) : Period (2010s) & -1.87 & 1.31 & 5.1 & 0.065 \\
\hline Lens Location (Inside) : 30 days precipitation & -1.01 & 1.01 & 223.8 & 0.017 \\
\hline
\end{tabular}

Table 3.4 Means +/- SE of groundwater salinity (PPT) for inside and outside lens locations in each period (1990s and 2010s). P-values for each pairwise comparison are reported.

\begin{tabular}{|c|c|c|c|}
\hline & Inside & Outside & p-value \\
\hline $1990 \mathrm{~s}$ & $2.77+/-1.21$ & $8.71+/-1.18$ & 0.001 \\
\hline $2010 \mathrm{~s}$ & $2.41+/-1.33$ & $14.85+/-1.29$ & $<0.001$ \\
\hline p-value & ns & 0.020 & \\
\hline
\end{tabular}

Table 3.5 Fitted vectors with correlation coefficients for each stratum. Significant correlations are indicated as ${ }^{* * *} \mathrm{p}<0.001,{ }^{* *} \mathrm{p}<0.01,{ }^{*} \mathrm{p}<0.05$

\begin{tabular}{|c|l|c|c|}
\hline Vector & Tree & High Shrub & Low Shrub \\
\hline Mean groundwater salinity & $0.76^{* *}$ & $0.75^{* *}$ & $0.88^{* * *}$ \\
\hline Plot height above LMSL & $0.74^{*}$ & 0.54 & $0.81^{* *}$ \\
\hline Distance to coast (well) & 0.56 & $0.88^{*}$ & $0.79^{*}$ \\
\hline
\end{tabular}




\subsection{Figures}

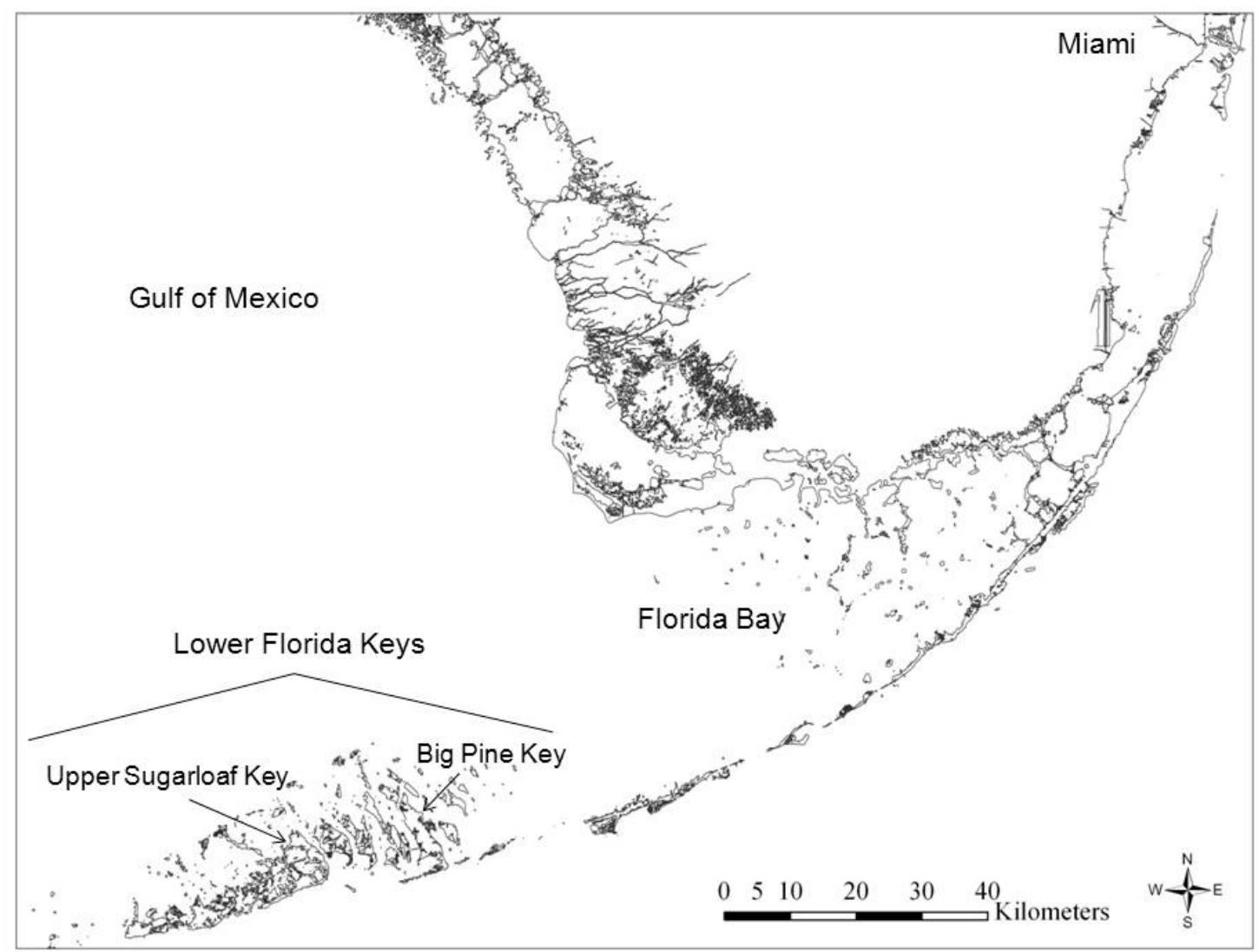

Figure 3.1 Study area includes the islands of Big Pine Key and Upper Sugarloaf Key, indicated by the arrows. Two permanent plots are located on Big Pine Key and five are located on Upper Sugarloaf Key. 

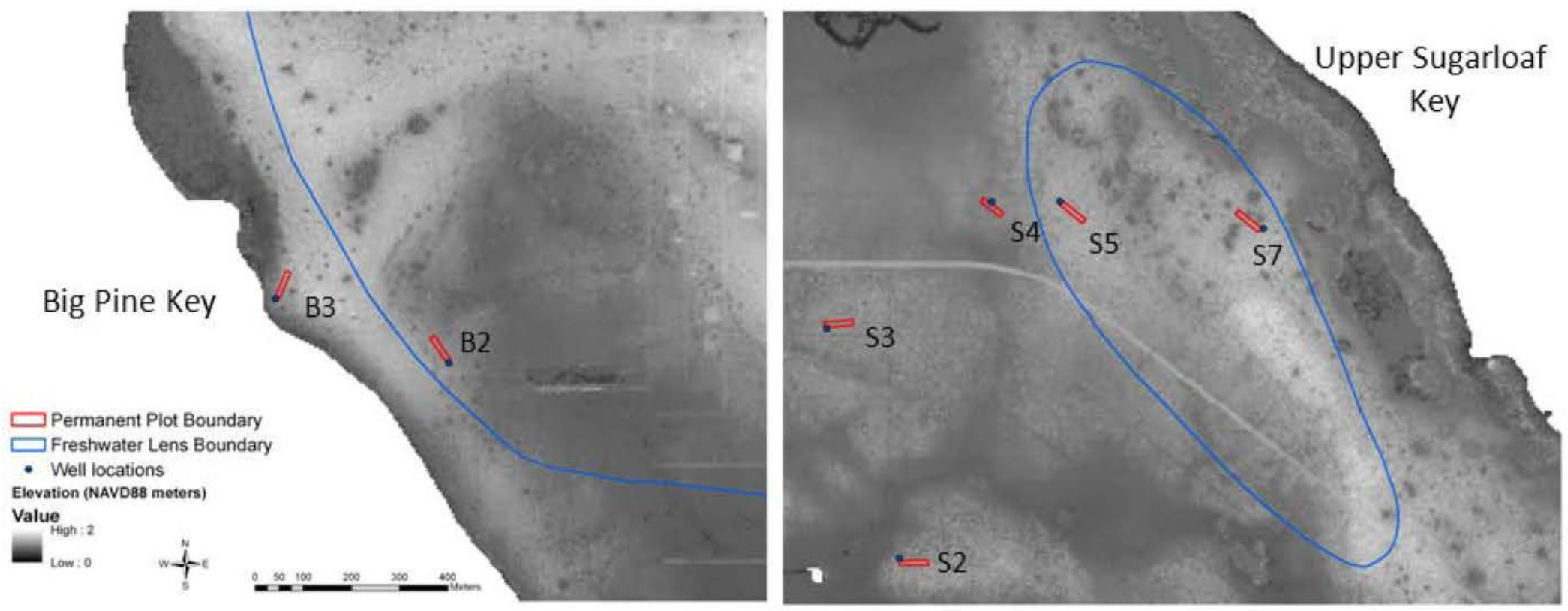

Figure 3.2 Location of $600 \mathrm{~m} 2$ permanent plots and associated groundwater monitoring wells on Big Pine (BPK) and Upper Sugarloaf Keys (SLK) are displayed on a digital elevation map derived from LiDAR data (2007). Areas of higher elevation are white, while areas of lower elevation are black. The boundary of the freshwater lens on each island is indicated in blue (BPK boundary is from Aug 1987 survey, Wightman 1990; and SLK boundary is from a 1990 survey, Caballero 1993). 


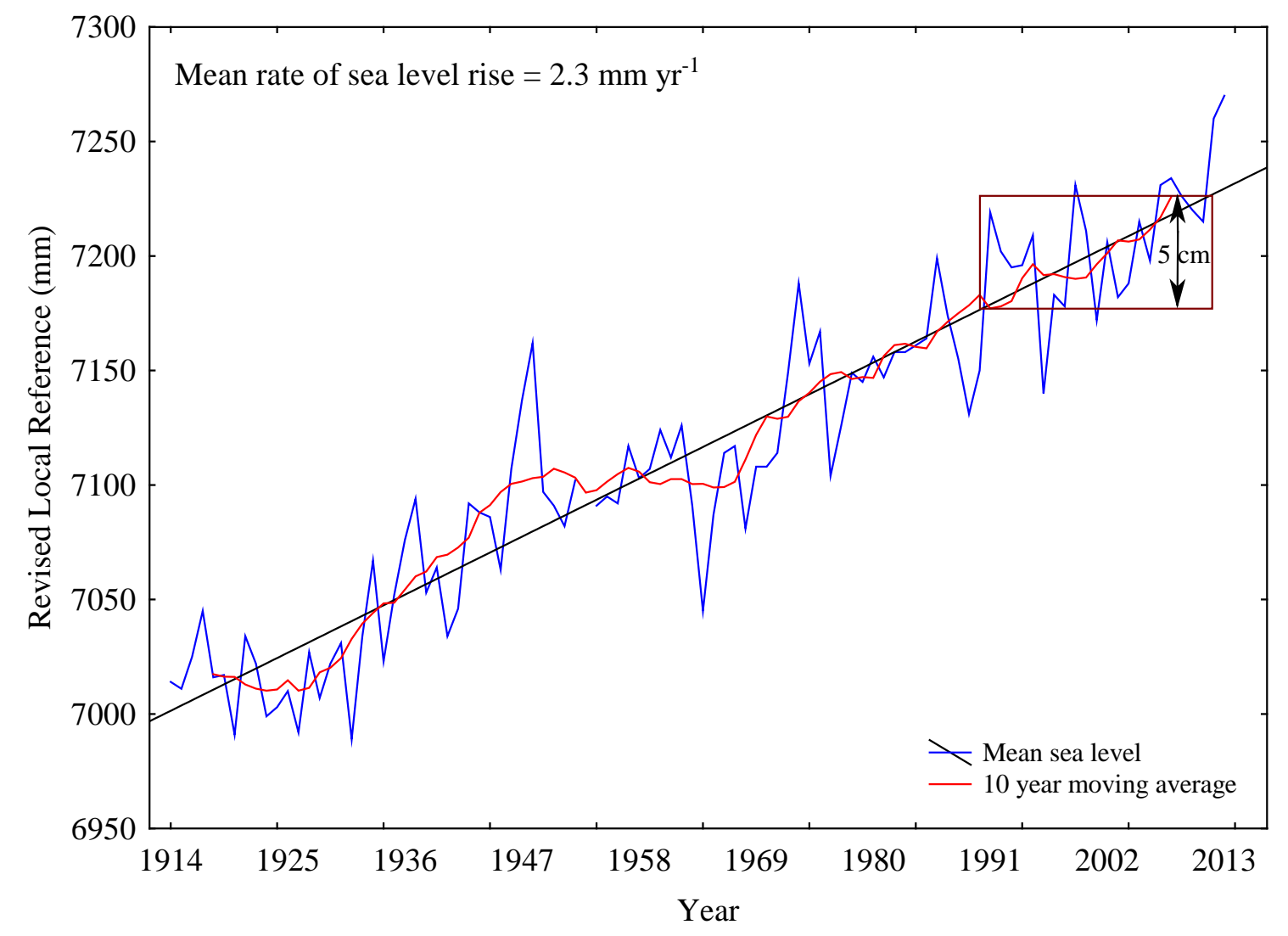

Figure 3.3 Annual mean sea level (mm) at Key West Tide Gauge (1914 - 2013). Data obtained from the Permanent Service for Mean Sea Level (PSMSL). Rate of sea level rise is equal to the slope of the regression line. 


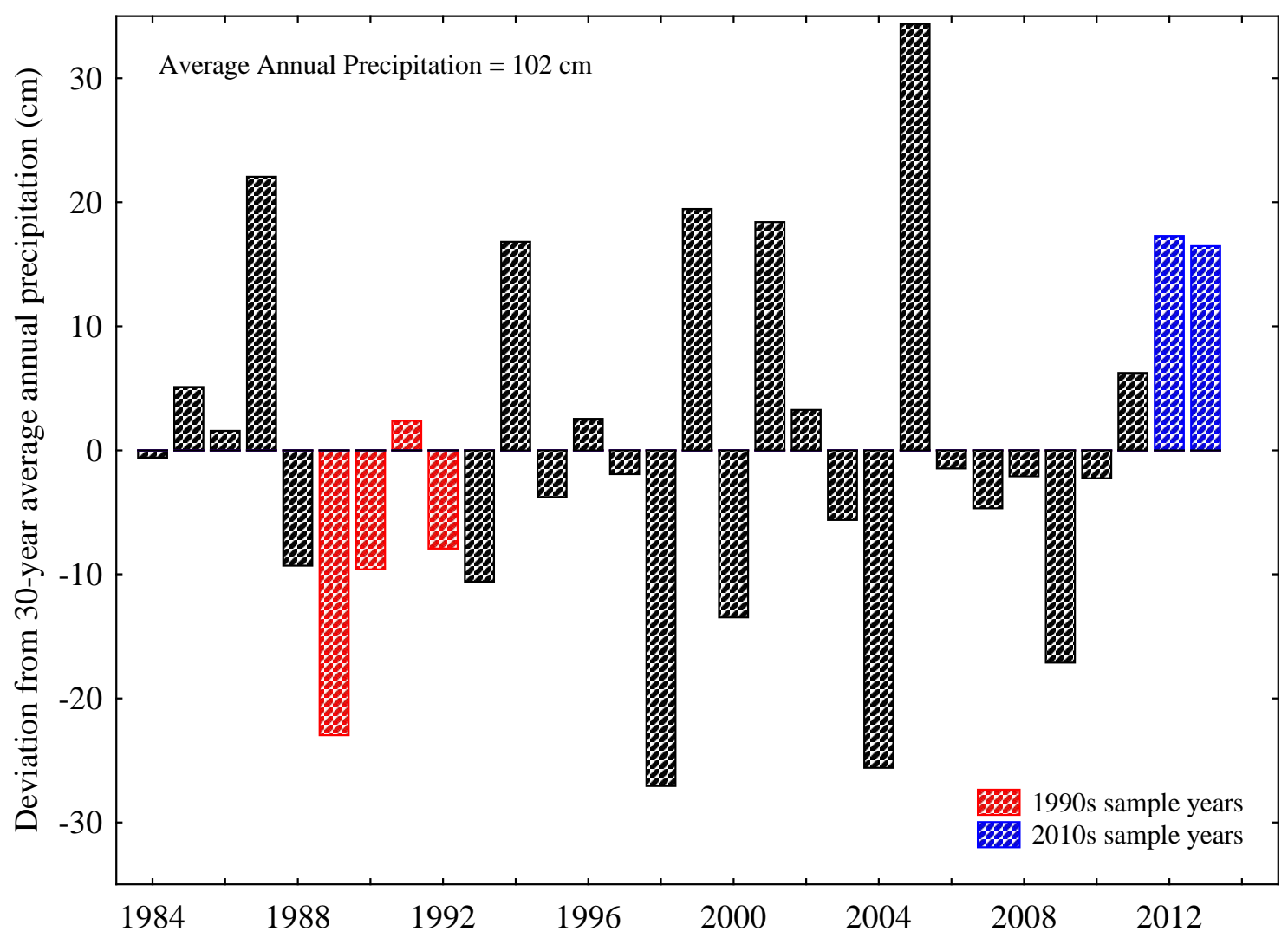

Figure 3.4 Deviation from the 30-year average annual precipitation received at Key West International Airport from 1984 to 2013 (http://www.ncdc.noaa.gov), SD of mean = $14.57 \mathrm{~cm}$. Years of groundwater monitoring are indicated in red for 1990s and blue for 2010s. 


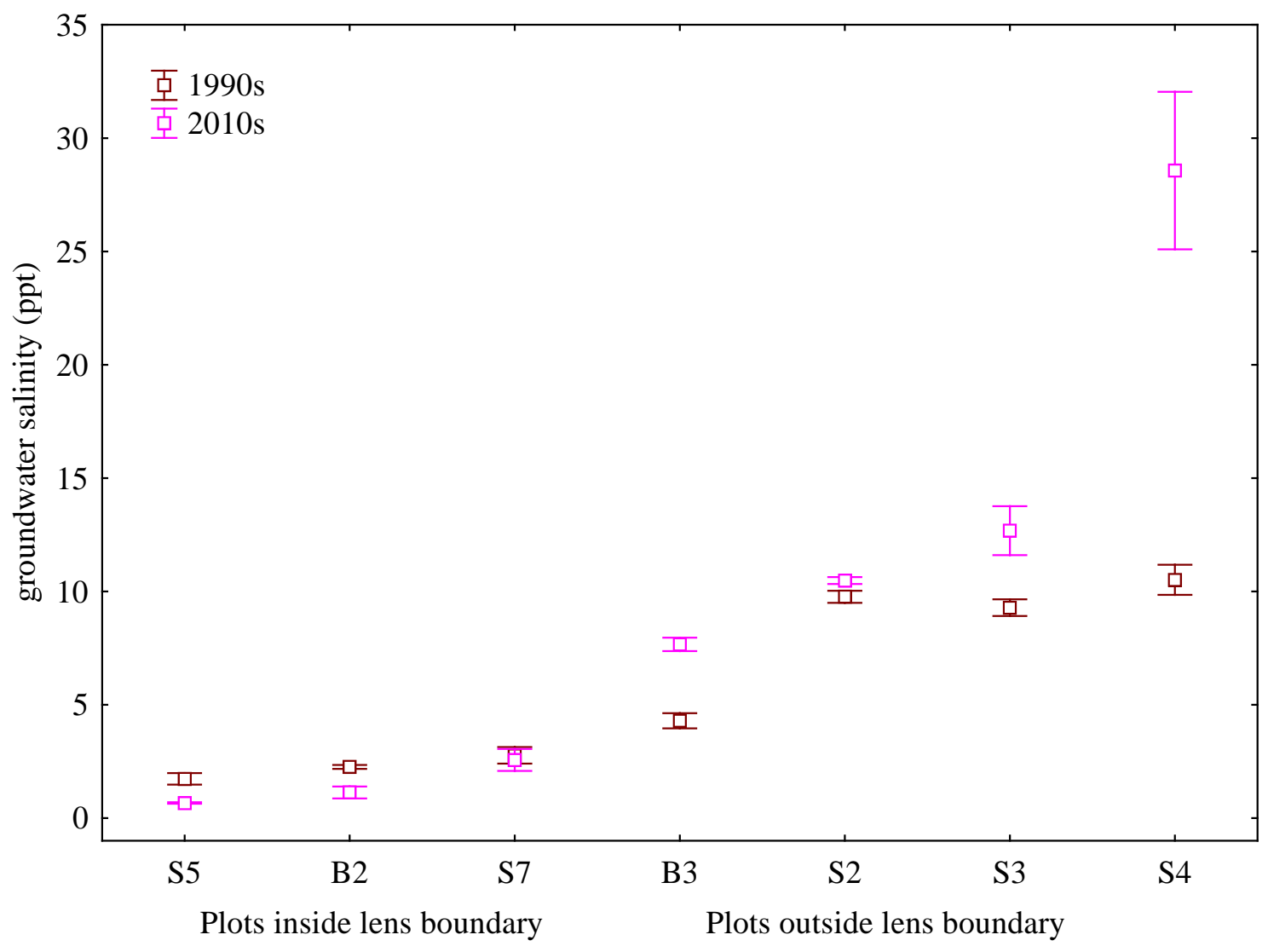

Figure 3.5 Mean +/- SE groundwater salinity (ppt) at each plot in each sampling period (1990s versus 2010s). Plots are arranged from left to right according to increasing groundwater salinity in 2010s. For 2010s sampling, $n=6$. For 1990s sampling, $n=34$ or 35 for all wells, except for B2 where $n=24$. 


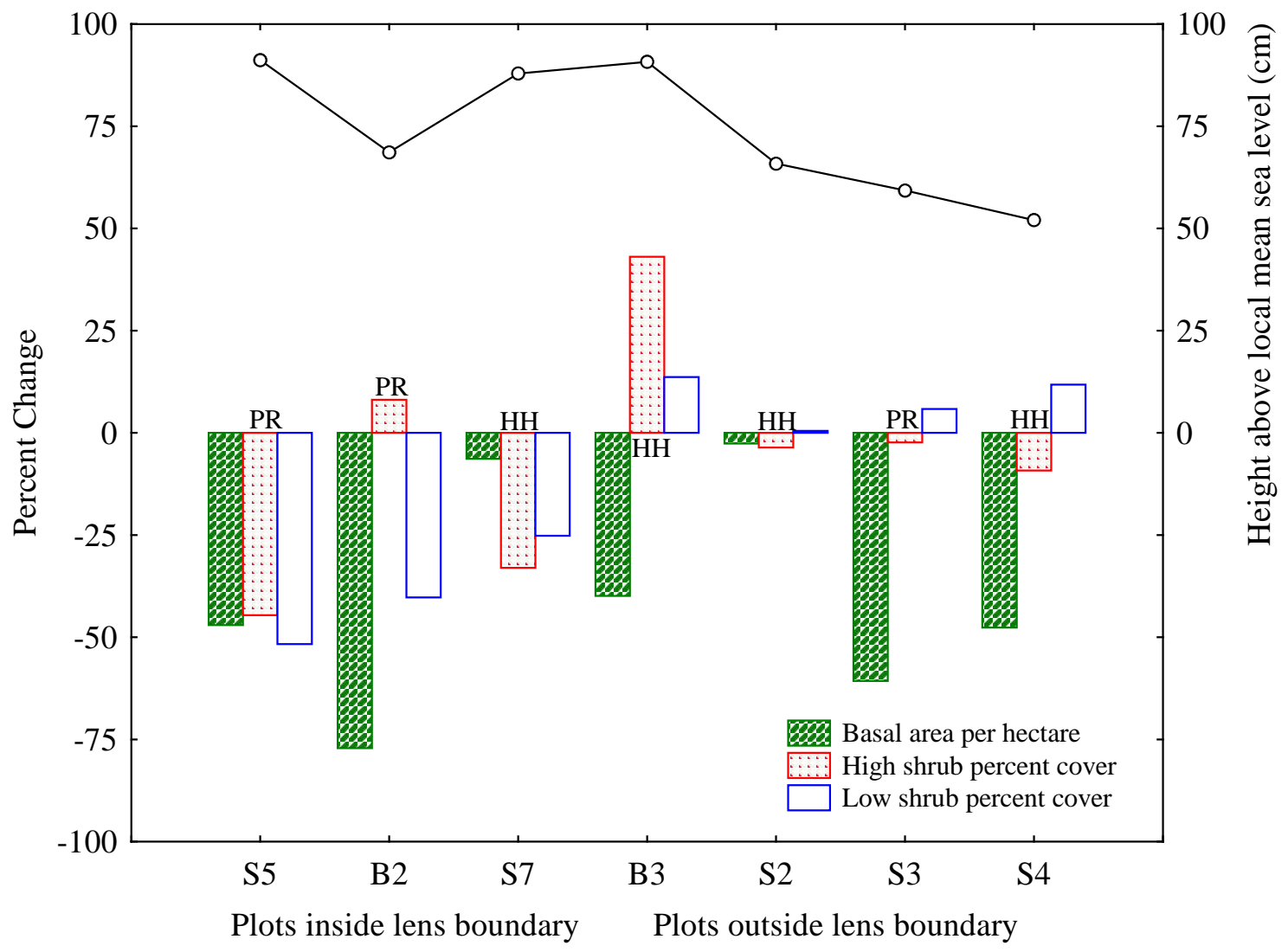

Figure 3.6 Percent change in tree stratum basal area per hectare and change in percent cover of high and low shrub strata (left y-axis) between 1990 and 2012 sampling events with corresponding height above local mean sea level (right y-axis) for each site. Sample sites, either pine rockland (PR) or hardwood hammock $(\mathrm{HH})$, are arranged from left to right according to increasing groundwater salinity in the 2010 s. 


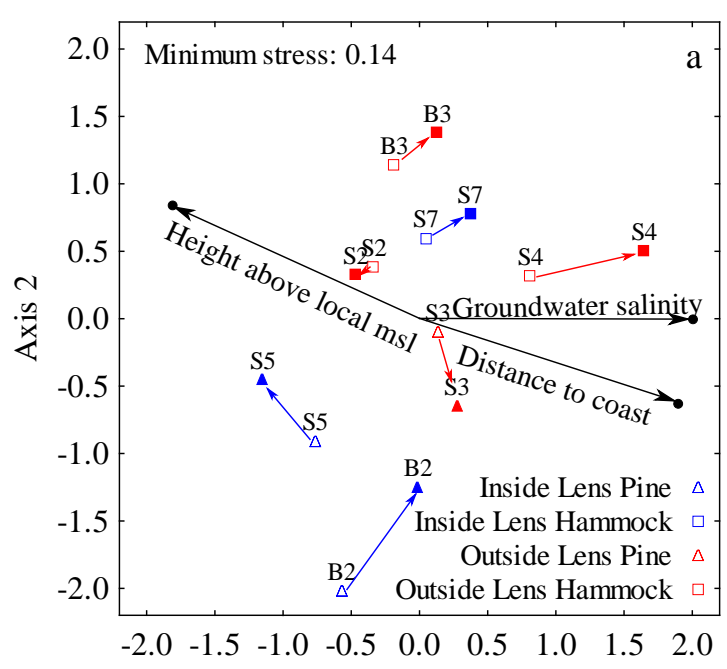

Axis 1

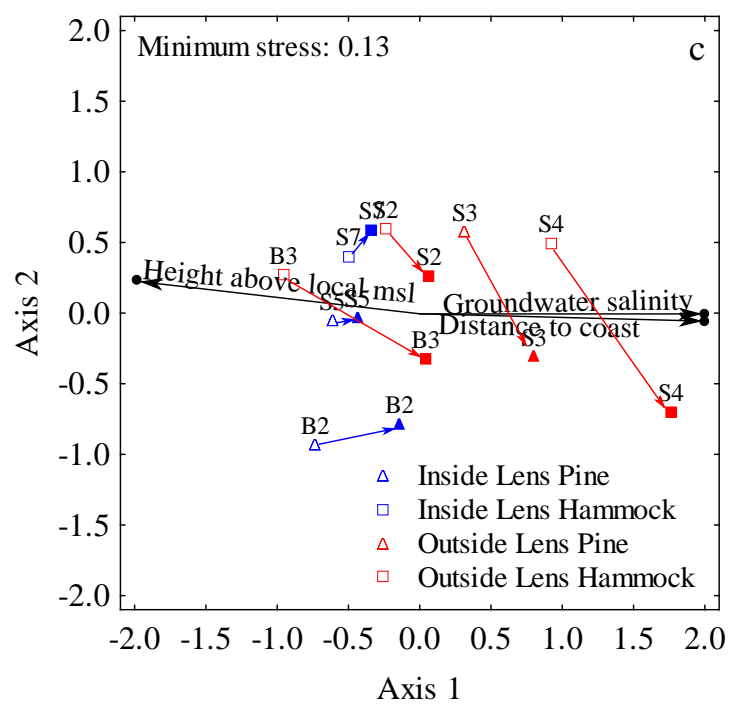

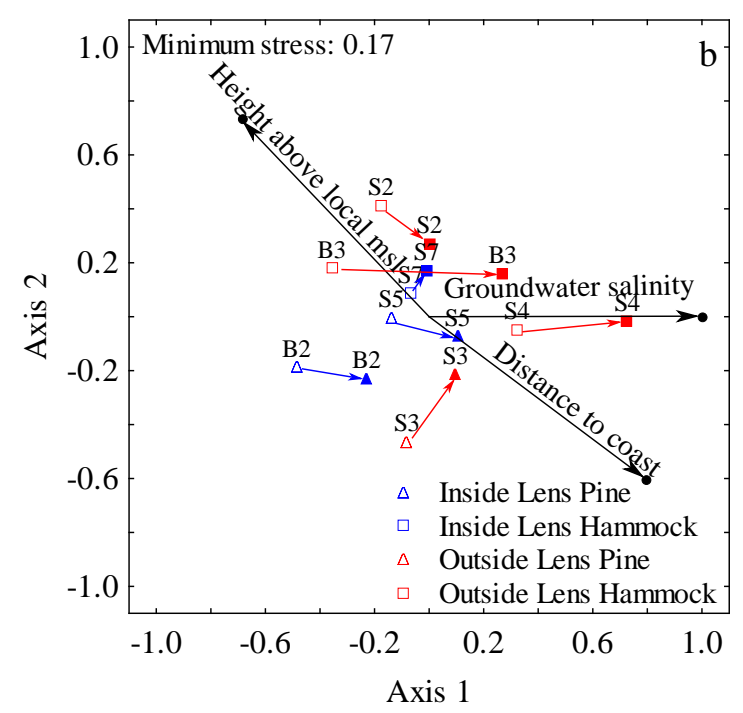

Axis 1

Figure 3.7 NMDS ordination of (a) tree stratum, (b) high shrub / sapling stratum, and (c) low shrub / herb stratum at seven sites in the 1990s (open symbols) and 2010s (closed symbols). Inside lens sites are colored blue, while outside lens sites are colored red. Pine rockland sites are represented by triangles and hardwood hammock sites are represented by squares. Vectors (black arrows) indicating increasing values of three environmental variables (groundwater salinity in ppt, distance to coast in $\mathrm{m}$, and height above local mean sea level in m). Colored arrows indicate movement from 1990s to 2010s composition for each plot. 


\section{CHAPTER 4. THE RELATIONSHIP BETWEEN CLIMATE, GROUNDWATER SALINITY, AND COASTAL FOREST ZONATION ON THE LIMESTONE ISLANDS OF THE LOWER FLORIDA KEYS (FLORIDA, USA)}

\subsection{Abstract}

Species zonation in low-elevation coastal communities is driven by a variety of factors, including those related to tolerance to flooding and saline conditions. On the islands of the lower Florida Keys, three freshwater-requiring communities (pine rockland, hardwood hammock, and supratidal scrub) having assemblages of glycophytic species, occur in close proximity to the coast. Species in these forests rely on a freshwater resource that fluctuates throughout the year as a consequence of the seasonality of precipitation. My study investigated the relationship between precipitation, evapotranspiration, and changes in groundwater salinity through direct groundwater monitoring and electrical resistivity tomography (ERT) surveys conducted over one year (2011-2012) along transects which traverse a coastal gradient on two islands. Vegetation sampling and subsequent split-moving window analysis delineated boundaries between adjacent coastal forest communities. The ERT-derived groundwater salinity values in May and November, as well as topographic location were assessed for their ability to predict the location of forest communities. Decreases in groundwater salinity were generally observed subsequent to large rain events on the smaller of the two islands, while locations on the larger island were less affected by those events. Similarly, while vertical increases in the lens depth occurred between May and November on both islands, lateral increases in lens extent were restricted to the smaller island. Using random forest 
classification, coastal proximity and groundwater salinity were identified as important variables in the determination coastal forest location. Pine rockland was restricted to salinities of $3 \mathrm{ppt}$ or less and the supratidal scrub community was associated with groundwater salinities generally greater than 10 ppt. Both hardwood hammock and low pine rockland occurred at locations with a wider range of groundwater salinities and were compositionally more similar to one another than the other habitat types.

\subsection{Introduction}

Plants growing at the intersection of land and sea cope with a variety of physical stresses including tidal inundation, high salinity groundwater, salt spray, and a particular frequency of storm disturbance. Community zonation in low-elevation coastal habitats is attributable to combinations of these abiotic factors as well as biotic factors and has been studied extensively in salt marshes (Baldwin and Mendelssohn, 1998; Pennings et al., 2005; Moffett et al., 2010), dune systems (Oosting and Billings, 1942; Gornish and Miller, 2010), and mangrove forests (Ellison et al., 2000; Méndez Linares et al., 2007). Species occurring in these habitats are often halophytic or have some ability to tolerate such stresses and are often arranged in zones parallel to the coast based on their tolerance to salinity, inundation, and disturbance frequency. In south Florida, several forest communities composed primarily of glycophytic species exist within close proximity of the shoreline, in areas underlain by fresh to brackish groundwater. Species are situated on the landscape with those having greater tolerance to salt exposure typically located at the lowest elevations (Ross et al., 1994; Saha et al., 2011). On lower Florida Keys’ islands, formed from an exposed carbonate platform (Lidz and Shinn, 1991), three distinct 
glycophyte-dominated coastal forests are found over a vertical range of two meters above mean sea level (amsl) and a horizontal distance of a couple hundred meters to the coast. Pine rockland, hardwood hammock, and supratidal scrub forests display a degree of zonation at the community level with pine rockland typically found at the highest elevations and at locations interior of hardwood hammock and the most coastward supratidal scrub forest (Ross et al., 1992). The configuration of these forests in this coastal setting is likely a complex mixture of stress tolerance (Ross et al., 1994), response to disturbance (Sah et al., 2010), and the competitive abilities of the constituent species.

The species in these forests rely on a combination of free water in the soil, water trapped in rock within the vadose zone, and groundwater present in the form of a freshwater lens to maintain positive water balance. Consequently, the distinct seasonality of precipitation received in south Florida both exacerbates the stress on the species in these communities and dictates timing of aquifer recharge. The extended dry season of the lower Florida Keys, typically 7 months, makes the presence of a Ghyben-Herzberg lens an essential resource of available freshwater for plants throughout the year (Ross et al., 1994). On oceanic islands composed of a permeable bedrock, lower density freshwater can exist as a floating lens on underlying salt water with dimensions that can be roughly approximated by island elevation and area. However, such lenses are not static and lateral flow exists with discharge related to saturated aquifer thickness according to Depuit assumptions (Vacher, 1988). Additionally, the permeability of the underlying bedrock combined with tidal pumping can result in a wide zone of intermediate groundwater salinity attributable to fresh-salt water mixing; this has been observed on islands in the lower Keys (Meadows 
et al., 2004) coincident with particular community types (Ross et al., 1992). The karstic nature of the bedrock and low relief provide for rapid infiltration of rainwater into the lens with little surface runoff, while secondary diagenesis of the limestone provides preferential conduits through which lateral flow moves to the coast (Mylroie and Carew, 1995). Combined with loss of the water through evapotranspiration processes that increase with temperature (Kosa, 2011), the timing and quantity of precipitation dictates the extent to which fresh water is present in a given location in this dynamic system.

The wide availability of spatially explicit data, including high resolution elevation datasets, allow for easy extraction of variables to test the relationships between environmental drivers and plant communities at the landscape scale. While coastal distance and elevation combined with groundwater monitoring at discrete locations can be used to estimate the underlying groundwater salinity at coarse scale, these easily measured geographic proxies fail to adequately describe differences at a fine scale nor can they predict seasonal changes in the resource. Previous work in the lower Keys employing geophysical methods, specifically electrical resistivity tomography (ERT) and electromagnetic induction (EM) surveys, identified the locations and lateral extents of the freshwater lens on Upper Sugarloaf (Caballero, 1993) and Big Pine Keys (Wightman, 1990). These methods model the bulk electrical resistivity (reciprocal of conductivity) of the subsurface (Lesmes and Friedman, 2005). In combination with strategic groundwater sampling, geophysical surveys enable the calculation of groundwater salinity across the gradient of low elevation, near-coast habitats to interior higher elevation locations. 
The undeveloped portions of coastal forest located in the island setting of the lower Florida Keys provide an ideal location to investigate how the relationship between precipitation, evapotranspiration, and fresh water balance affect forest community zonation in a coastal setting. My research builds on previous work that successfully categorized the terrestrial communities of the Florida Keys, including tidal and interior wetlands and upland forest types, according to the combination of geographic location, soil type and depth, elevation, and groundwater salinity (Ross et al., 1992). Here, I specifically investigated the role that groundwater salinity plays in structuring plant community zonation in three lower Keys' upland coastal forests on two islands, Big Pine Key and Upper Sugarloaf Key. I hypothesized that underlying groundwater salinity is a primary driver of coastal forest zonation. After first characterizing the seasonality of climate using the ratio of precipitation to potential evapotranspiration received in the lower Keys, I investigated whether seasonal changes in climate variables are reflected in groundwater salinity across a gradient of near coast to interior island locations. Using a combination of groundwater monitoring at monthly intervals and electrical resistivity tomography (ERT) surveys conducted at the height of the dry and wet seasons in 2011, I determined how the freshwater lens responded to seasonal trends in climate and individual precipitation events. Finally, I considered whether freshwater-requiring coastal forest communities located along this gradient are associated with specific ranges in groundwater salinity or patterns of seasonal change. Using random forest classification and conditional density curves, I determined a combination island topographic variables and groundwater salinity optima to explain coastal forest community zonation. 


\subsection{Study Area}

The islands of Big Pine Key (N 24.67, W 81.36) and Upper Sugarloaf Key (N 24.66, W 81.53) are located toward the distal end of the chain of islands known as the Florida Keys (Figure 4.1). A large portion of both of these islands is protected and managed as part of the USFWS National Key Deer Refuge. The surficial bedrock of the Florida Keys was deposited in the late Pleistocene during the last interglacial period and has been dated to 134,000 years BP (Perkins, 1977). The exposed bedrock formation in the upper and middle keys is Key Largo Limestone, derived from a shallow water shelf margin coral reef (Harrison and Coniglio, 1985) of peloid-bioclast packstone-grainstone (Hoffmeister and Multer, 1968). In the lower Keys, the surficial bedrock is the Miami Limestone, which was formed in a backbay environment as a former tidal sandbar (Hoffmeister et al., 1967) and consists of ooid grainstone. Beginning on Big Pine Key and trending to the southwest, the Miami Limestone outcrops over the underlying Key Largo Limestone and contacts are separated by subaerial exposures (Coniglio and Harrison, 1983). While both formations are moderately to highly porous (average porosity of 20 to 40\%) (Robinson, 1967; DiFrenna et al., 2008), the Key Largo Limestone is more permeable than the Miami Limestone as a result of the greater development of secondary porosity (Coniglio and Harrison, 1983). Longer periods of meteoric diagenesis of the underlying Key Largo Limestone are responsible for the increase in secondary porosity and interconnected pore spaces (Vacher et al., 1992).

According to Ghyben-Herzberg assumptions, the depth to the salt water interface of a freshwater lens can be approximated by multiplying the water table's elevation above sea 
level by a factor of 40 . However, in the lower Keys, the depth is truncated at the location of the contact between the facies as a result of higher hydraulic conductivity of the Key Largo Limestone (Vacher, 1988). On Big Pine Key, the difference in permeability between the Key Largo Limestone and Miami Limestone results in much greater hydraulic conductivity in the former, whose conductivity of $1400 \mathrm{~m}$ per day compares with 120 m per day in the Miami Limestone (Vacher et al., 1992). Groundwater sampling on Big Pine Key verified a five-fold increase in conductivity of the groundwater just below the contact, which occurs at approximately $5 \mathrm{~m}$ below the ground surface (Hanson, 1980).

Residential development on the islands has impacted both aquifer recharge and discharge. Compared to pre-development conditions, dredging for canals is estimated to have resulted in a 20\% loss of the lens volume on Big Pine Key (Langevin et al., 1998). While some residents do extract water from the lenses for outdoor residential use, this is likely a negligible output from the system. Additional inputs to the system do occur from septic seepage as potable water is provided via the Florida Aqueduct Authority to residential homes and businesses from the Biscayne Aquifer on the mainland. However, many of these homes are associated with the network of canals and the additional source of water very likely flows to the adjacent Florida Bay or Atlantic Ocean. In the undeveloped portions of the islands where I focus my research efforts, these additional inputs and outputs should have minimal effect on seasonal lens dynamics. 
The climate of south Florida is humid subtropical becoming increasingly warm and dry as one moves south through the chain of islands of the Florida Keys. Precipitation is seasonal with a distinct wet season (June through October) in which approximately twothirds of the rain in any given year falls, followed by a dry season (November through May). In the lower Keys, the annual average rainfall is $102.2 \mathrm{~cm}$ and temperatures range from an average monthly low of $20^{\circ} \mathrm{C}$ to a high of $29^{\circ} \mathrm{C}$, in January and August, respectively (30-year average 1984-2013 at Key West International Airport, http://www.ncdc.noaa.gov). Rainfall events can be sporadic, with large quantities of precipitation accompanying tropical storms. For south Florida, the average tropical storm/hurricane return interval is 3 years, with Cat 3 - 5 storms occurring at an interval of every 15 years for Key West (Keim et al., 2007). The majority of hurricane landfalls occur August through October (Elsner and Kara, 1999). The last major hurricane to impact the lower Keys occurred in 2005; Hurricane Wilma, a Category 3 storm, flooded the islands with salt water to locations up to 1 meter above mean sea level, but was accompanied by very little precipitation (Kasper, 2007).

Freshwater-requiring coastal forest communities on these islands include supratidal scrub forest, hardwood hammock, and pine rockland. Pine rocklands are found on the interior of the islands, typically inland of hardwood hammocks, with the final freshwaterrequiring community, supratidal scrub, occurring coastward of both and adjacent to mangrove. In the lower Keys, these communities are found at elevations ranging from 0.2 to 2 meters amsl. Soils are shallow $(0$ to $20 \mathrm{~cm}$ ) and predominately organic in pine rockland and hardwood hammock (Ross et al., 2003), while supratidal scrub has lower 
litter input and is typified by more rocky/ mineral soils (Ross et al., 1992). Supratidal scrub forests are dominated by Conocarpus erectus L., buttonwood, with a maximum height of $7 \mathrm{~m}$ and have an understory of graminoids and/or succulents (Ross et al., 1992). These forests are often inundated with salt water at high tide. Hardwood hammocks are of low stature (3 to $7 \mathrm{~m}$ ) and consist of a variety of West Indian hardwood species and palms. As defined here, the community spans the full elevation range found in the lower Keys, and at low elevations is occasionally subjected to tidal flooding. Pine rockland is characterized by a single canopy dominant, Pinus elliottii var. densa Engelm., south Florida slash pine, ranging in height from 7 to 14 meters. While many of the species found in hardwood hammock also occur in varying abundance in pine rockland, the more open canopy in pine rockland allows a diverse herbaceous understory to flourish. However, without periodic fire, pine rockland succeeds to a hardwood hammock

community (Snyder et al., 1990). Pine rockland is restricted to elevations typically greater than 0.4 meters. Here, pine rockland was divided into high and low elevation communities, with low elevation pine rockland typified by many standing dead trees that resulted from Hurricane Wilma storm surge flooding in 2005.

\subsection{Materials and Methods}

\subsubsection{Climate Data}

Weather data were obtained from a station (TS607) operated by the National Key Deer Refuge and located at the north end of Big Pine Key (N 24.72422, W 81.38864). Hourly precipitation, temperature, and solar radiation data, available beginning in 2007, were downloaded from MesoWest (website maintained by the University of Utah, 
(http://raws.wrh.noaa.gov/cgi-bin/roman/meso_base.cgi?stn=TS607). Data recorded by the station were used to generate daily totals and monthly averages for precipitation and to calculate a daily ratio of precipitation to potential evapotranspiration (P:E). The weather station is equipped with a pyranometer placed at a height of $2 \mathrm{~m}$ above the ground surface to record solar radiation and a tipping bucket gauge to record the amount of rainfall received. The Simple Abtew method (Abtew, 1996) was used to estimate daily potential evapotranspiration (ET) with the following equation:

$$
E T=K_{1} * R_{s} / \lambda
$$

where $E T$ is potential evapotranspiration in $\mathrm{mm} / \mathrm{day}, K_{1}$ is a dimensionless coefficient equal to $0.53, R_{s}$ is solar radiation as measured in $\mathrm{MJ} / \mathrm{m}^{2} /$ day, and $\lambda$ is equal to the latent heat of vaporization of water with units of $\mathrm{MJ} / \mathrm{kg}$ and varies with temperature according to the following equation:

$$
\lambda=2.501-0.00263 * T
$$

where $T$ is equal to daily average temperature in ${ }^{\circ}$ Celsius.

Results obtained from this method for Everglades' wetlands are comparable to other methods of ET estimation requiring a greater number of parameters (Abtew, 1996). Fiveyear monthly averages (Jun 2007 to May 2012) were calculated for precipitation, ET, and $\mathrm{P}:$ E ratio.

\subsubsection{Groundwater Salinity Sampling and Analysis}

Beginning in May 2011 and ending in April 2012, groundwater salinity was sampled on a monthly basis in shallow monitoring wells. Wells were installed within each coastal forest type occurring along five transects coincident with trails located within the 
USFWS National Key Deer Refuge on Big Pine and Upper Sugarloaf Keys for a total of 24 wells (Table 4.1, Figure 4.1). Wells were named with an alpha-numeric code that includes the first letter of each island name, the transect number for each island, and the well position along each transect in relation to the coast (Table 1). Boreholes with diameters of $8.89 \mathrm{~cm}$ were drilled through bedrock to a depth of 1 to $1.25 \mathrm{~m}$ below the ground surface. Within each borehole I placed a PVC pipe with an internal diameter of $3.175 \mathrm{~cm}$, screened along the bottom $0.5 \mathrm{~m}$ so that groundwater entered the well at a depth of 0.5 to $1.25 \mathrm{~m}$ below the ground surface. Wells were packed with sand to a level above the well screen and finished with cement. Prior to each sampling event, the depth (cm) to the water table was recorded and three well volumes were evacuated with a peristaltic pump. Groundwater salinity in PPT, specific conductivity in $\mathrm{mS} / \mathrm{cm}$, and temperature were measured with a YSI model 30 handheld probe with a resolution of 0.1 ppt and accuracy of +/- 0.1 ppt.

Monthly groundwater salinity at each well was plotted over the course of the study period with daily precipitation totals and the mean salinity calculated for each well location. I calculated a z-score for each sampling event given the mean and standard deviation of salinity values over the 12 month sample period for each well. Z-scores for the month of November were compared using t-tests to determine the effect of island on response of groundwater salinity to precipitation at all sample locations. 


\subsubsection{ERT Theory and Background}

Electrical resistivity tomography is a geophysical method used to generate a profile of subsurface resistivity by applying a direct current into the ground and measuring changes in electrical potential as the current flows through the subsurface. The method is derived from the relationship between resistivity, current, and voltage potential measured in a typical electrical circuit according to Ohm's Law:

$$
V=I R
$$

where $V$ is voltage in volts, $I$ is current in amperes, and $R$ is resistance in ohms. As resistance of an object is related both to its geometry and the ability of the material to conduct current -- the intrinsic property of the material, resistivity is calculated using the following equation:

$$
\rho=R A / L
$$

where $\rho$ is resistivity in ohm-m, and $A$ and $L$ are equal to area and length in meters. In locations of known lithology, as in the case of the islands of the lower Florida Keys, differences in apparent resistivity are attributable to pore fluid conductivity (reciprocal of resistivity) according to Archie’s Law (1942):

$$
\rho_{\text {bulk }}=\rho_{\text {fluid }} * A^{*} \phi^{-m}
$$

where $\rho=$ resistivity in ohm-m, $\phi=$ porosity, and $A$ and $m$ are empirically derived constants specific to the bedrock formation. Archie defined the relationship between bulk resistivity and pore fluid resistivity as the formation factor, $F$ :

$$
F=\frac{\rho_{\text {bulk }}}{\rho_{\text {fluid }}}
$$


For limestones, the cementation factor, $m$, is approximately 2 , and the tortuosity factor, $A$, averages 1 , therefore the equation can be rewritten to show the relationship to bedrock porosity (Tiab and Donaldson, 2004):

$$
F=\frac{1}{\phi^{2}}
$$

Thus, it is possible to solve for the resistivity and calculate corresponding salinity of the underlying groundwater from the output of the ERT survey combined with the calculated formation factor.

\subsubsection{ERT Data Collection}

The ERT surveys were conducted twice along each transect except for B2 (Table 4.2, Figure 4.1) during field campaigns in May and November 2011. Surveys began near the coast at the ecotone between supratidal scrub and adjacent mangrove community and ended in interior pine rockland. An AGI (Advanced Geophysical Instruments) SuperSting R1 IP multi-electrode resistivity system, which includes 28 stainless steel electrodes, a control box, cable, and switching box, was used to inject electrical current into the ground through two current electrodes, while the voltage drop was measured across two potential electrodes. Electrodes were placed according to a Wenner Array with a fixed spacing of 2 meters. In a Wenner Array, all electrodes are placed at equal distances from one another, known as the a-spacing. In this commonly used array, apparent resistivity $\left(\rho_{a}\right)$ is calculated on the basis of how current flows through a unit area of an equipotential surface (Telford et al., 1990):

$$
\rho_{a}=\frac{2 \pi a \Delta V}{I}
$$


The current and potential electrodes switch throughout the survey, resulting in 118 measurements (92 for each subsequent section) taken along an interval of $54 \mathrm{~m}$ to a depth of $9.3 \mathrm{~m}$. After each individual segment run, the cable is disconnected in the middle and moved to the end, and a new segment is surveyed, allowing for continuous profiling. The survey is termed a roll-along as each segment of the survey overlaps the last segment by 28 meters. Coincident with each ERT survey, groundwater salinity and temperature were measured in each well along each transect. The GPS coordinates were obtained for each well, ERT survey start point and end point using a Magellan Promark 3 system, with a horizontal accuracy of $10 \mathrm{~cm}$. The location for each electrode was calculated from the start and end points of each survey line. NAVD88 elevation was obtained for each electrode location from digital terrain models (DTMs) derived from LiDAR data having a spatial resolution of $1 \mathrm{~m}^{2}$ for Big Pine Key and $5 \mathrm{~m}^{2}$ for Upper Sugarloaf Key (Robertson and Zhang, 2007; Zhang et al., 2010).

\subsubsection{ERT Inverse Modeling}

Resistivity sections were generated by modeling the apparent resistivity values obtained from the ERT survey using the 2-D inversion program (Binley and Kemna, 2005), R2 v.2.7 (Binley, 2011). Modeling of ERT data is an underdetermined problem that leads to non-unique results and requires an optimization algorithm. The desired model is the smoothest one that fits the data within a specific tolerance; Occam's inversion achieves this (Constable et al., 1987). Occam's inversion for ERT (LaBrecque et al., 1996) was

used. A quadrilateral mesh was created for the inversion having a horizontal spacing of $0.5 \mathrm{~m}$ (4 nodes between each electrode) and a vertical spacing of $0.2 \mathrm{~m}$ at the surface that 
increased with depth by a factor of 1.1 to a maximum of $9.3 \mathrm{~m}$ below the ground. In R2 settings, patch size was set to 2 blocks in the $\mathrm{x}$ direction and 1 block in the $\mathrm{y}$ direction, inverse type was set to regularized with a linear filter, and the error variance model parameters were set to 0.01 and 0.02 ohms for a and b respectively, where $\operatorname{var}(R)=a_{\text {weight }}^{2}+b_{\text {weight }}^{2} * R^{2}$.

\subsubsection{Groundwater Salinity Calculation}

A formation factor was calculated by Tucker (2013) for each island using orthogonal regression. Specific conductivity of the groundwater measured in wells during the surveys was converted to pore water resistivity and regressed against corresponding bulk resistivity output from the R2 inversions. As the formation factor for each island was similar and within each island's range of uncertainty, an average formation factor of 9.05 with a SD of 1.44 was used to calculate salinity (Tucker, 2013). Bulk resistivity values were converted to pore water resistivity by dividing by the above formation factor according to Archie's Law. Pore water resistivity in ohm-m was then converted to conductivity $(\sigma)$ in $\mathrm{mS} / \mathrm{cm}$ using the following equation:

$$
\sigma=\frac{10}{\rho_{\text {fluid }}}
$$

Finally, conductivity was converted to salinity (S) in PPT at $25^{\circ} \mathrm{C}$ :

$S=0.012+\left(-0.217 * R^{1 / 2}\right)+(25.328 * R)+\left(13.77+R^{3 / 2}\right)+\left(-6.48 * R^{2}\right)+\left(2.58 * R^{5 / 2}\right)$ where $R$ is the ratio of the calculated conductivity to that of standard sea water at $25^{\circ} \mathrm{C}$ (53.087 mS/cm) (Wagner et al., 2006). 
Dry season (May 2011) and wet season (November 2011) salinity sections for each transect were plotted using Surfer 8.0. Based on salinity associated with living pine trees from previous work (Ross et al., 1994), I chose the 3 ppt contour line to delineate the boundary of the freshwater lens for dry to wet season comparison. This value is higher than that which would be considered for a potable freshwater source $(250 \mathrm{mg} / \mathrm{L},<1 \mathrm{ppt})$. Since the average depth to contact between the formations occurs at approximately $5 \mathrm{~m}$ below the surface and the calculated formation factor is valid only for the Miami limestone, I show modeled groundwater salinity to a maximum depth of $5 \mathrm{~m}$. Modeled May and November salinity values at a depth of $1.07 \mathrm{~m}$ below the ground surface were extracted at each 1 meter interval along the profile for use in subsequent random forest classification. The depth of $1.07 \mathrm{~m}$ was selected as it corresponds to the approximate location of measured groundwater salinities in wells and is a location that was within the saturated zone during the ERT surveys. At each groundwater well location, the modeled salinity values beginning at the water table to a depth of $5.25 \mathrm{~m}$ below the surface were extracted to generate a depth profile and compare measured to modeled groundwater salinities.

\subsubsection{Transect Vegetation Characterization}

Vegetation was sampled along a 4 meter-wide belt transect that ran parallel to each of the four ERT survey transects (Figure 4.1). Each vegetation transect began in the near coast community and was offset from the ERT transect by 20 meters. The belt transect was

divided into 5-meter intervals, such that percent cover was estimated for all woody species having a height greater than or equal to $1 \mathrm{~m}$ in a series of $4 \mathrm{~m}$ by $5 \mathrm{~m}$ rectangular 
plots. Cover was estimated using the following six categories, the midpoint of which was used for subsequent analyses: $1=<1 \%, 2=1-4 \%, 3=4-16 \%, 4=16-32 \%, 5=32-66 \%$, and $6=66-100 \%$. Along each transect, boundaries between adjacent coastal forest communities were defined based on discontinuities in vegetation composition. I used a moving split-window analysis (Ludwig and Cornelius, 1987; Wierenga et al., 1987) to locate peaks in Bray-Curtis (BC) dissimilarity between adjacent sampling units along each transect. Bray-Curtis dissimilarity is a distance measure calculated between sampling units that is derived from Sorenson similarity -- the shared abundance in species between two sample sites divided by total abundance (McCune and Grace, 2002). I varied window size from two to six sample units to determine the size with the best separation. Bray-Curtis dissimilarity ranges from 0, where adjacent units are identical in composition, to 1 where adjacent units contain no overlapping species. Extracted ERTsalinity values falling along each transect (1-meter interval spacing) were assigned to one of six community types based on the results of the moving split-window analysis: supratidal scrub (STS), hardwood hammock (HH), very low elevation hardwood hammock (HHl), interior occurring low elevation pine rockland (LPi), exterior occurring low elevation pine rockland (LPe), or high elevation pine rockland (HP). Characteristic species for each community type were determined using the SIMPER routine in Primer 6.1.9 based on the four major community types: hardwood hammock, high elevation pine rockland, low elevation pine rockland, and supratidal scrub. The SIMPER routine calculates the average similarity between all samples in each community type. Species with high percent contribution to community similarity between samples are considered to be characteristic of that community. Composition data was analyzed using Non-Metric 
Multidimensional Scaling (NMDS) in Primer 6.1.9. No transformation was applied to the percent cover data, but data were standardized to the species maximum across all plots. All plots from each transect were considered in the ordination for a total of 169 samples and 41 species, with samples assigned to each of the six community types based on the results of the moving split-window analysis.

\subsubsection{Prediction of Community Types}

Random forest classification was used to predict coastal forest type from a combination of ERT-generated groundwater salinities at $1.07 \mathrm{~m}$ depth, NAVD88 elevation (cm), and coastal proximity (m) for 873 data points. In ArcGIS 10.2, elevation was extracted for each 1 meter location along the transects from Lidar-derived DTMs and distance to coast was calculated using the Near tool. Models were run in R v.3.1.2 (R core team, 2014) using the Caret package. The dataset was sub-sampled using five-fold cross validation so that all data was part of both the training and testing data sets. Ten repeats were selected, and for each iteration 1000 trees were built. The average percent accuracy was recorded with a 95\% confidence interval and variable importance was calculated. Conditional densities for each community type along each gradient (elevation, distance to coast, May groundwater salinity, and November groundwater salinity) were derived using the package 'sm' in R v.3.1.2 (R core team, 2014). These plots provided information on the

proportional abundance of each community compared to all other communities along each point of the environmental gradient (Gann and Richards, 2015). 


\subsection{Results}

\subsubsection{Precipitation and Potential Evapotranspiration}

While the time frame spanned by this study (April 2011 through March 2012) fell within a period of average annual precipitation (110.5 cm fell during the study period), monthly rainfall varied substantially (>1 SE) from the 5-year average for Big Pine Key (Figure 4.2). For most months during the study period, including those of the June-October wet season, less than average rainfall resulted in drought conditions. However, $40 \%$ of the total annual precipitation fell over the course of five days in October 2011. The total amount of precipitation received during October 2011 was more than three times the 5year average (2007 to 2012) for the month of October on Big Pine Key.

The relationship between precipitation and evapotranspiration over the study period was also indicative of drought conditions, as 8 of 12 months fell below their 5-year average. On average, the water balance of the wet season (June through October) is positive with a $\mathrm{P}$ to $\mathrm{E}$ ratio greater than 1, while the dry season months display $\mathrm{P}$ to $\mathrm{E}$ ratios less than 1. The five-year average for Big Pine Key confirms this typical climatic pattern of the Keys (Figure 4.3). However, considering the climate conditions six months prior to both the dry and wet season ERT surveys, P to E ratios were below the 5-year average for several months, while the $\mathrm{P}$ to $\mathrm{E}$ ratio for the month of October immediately preceding the wet season ERT survey was well above average for that month. 


\subsubsection{Seasonal Changes in the Freshwater Lens}

Results of monthly groundwater monitoring indicated that not only was groundwater salinity highest near the coast, but monthly changes were generally of larger magnitude at these coastal locations (Figures 4.4 through 4.8). Wells on Upper Sugarloaf Key show a pattern of increasing variability around the mean salinity measurement along each transect from interior to coast that is not present on Big Pine Key (Table 4.1). Between sample events, decreasing groundwater salinity was observed following the two largest rain events of the study period (June $6^{\text {th }}-7^{\text {th }}$ and October $15^{\text {th }}-19^{\text {th }}$ ). While the majority of wells at sites on Upper Sugarloaf Key (Figure 4.7 and 4.8) followed this trend, fewer sites on Big Pine Key exhibited the same decrease in groundwater salinity in response to precipitation (Figures 4.4, 4.5, and 4.6). In fact, groundwater salinity in several wells on transects B1 (Figure 4.4) and B3 (Figure 4.6) actually increased after these rain events. While not statistically significant at $\mathrm{p}<0.05$, sample locations on Upper Sugarloaf Key generally had more negative z-scores for November compared to sites on Big Pine Key. The generally lower z-score for this month, especially for Upper Sugarloaf Key locations is attributable to decreases in groundwater salinity presumably from the large rain event in October.

The salinity sections derived from the ERT surveys are displayed for each transect (Figures 4.9 through 4.12). The expectation is that between the dry season and wet season survey, sites would increase in both the lateral extent and depth of the freshwater lens. The lateral boundary of the fresh water lens (designated as $3 \mathrm{ppt}$ ) did not move between surveys for transect B1 (Figure 4.9). However, there is a clear increase in depth 
of the freshwater lens from dry to wet season along this transect. The seasonal increase in salinity observable near the coast for transect B1 is most likely attributable to incoming tide. Along transect B3 no appreciable change occurred in the extent or depth of the freshwater lens (Figure 4.10) which could be attributable to the number of homes in the nearby vicinity just to the south (Figure 4.1) providing a year round supply of freshwater from septic input. For the Upper Sugarloaf Key transects, S2 and S3, there was an increase in depth of the freshwater lens between May and November and lateral increase in extent along S3 (Figure 4.11 and 4.12). On the basis of results of the ERT surveys, the lens on Upper Sugarloaf appears to break up during the dry season. A visual comparison of freshwater lens and community boundaries shows that high elevation pine rockland is restricted to salinities of 3 ppt or lower, while a much greater range exists for both low elevation pine rockland and hardwood hammock. Supratidal scrub is typified by salinities greater than $10 \mathrm{ppt}$, but observed at locations as low as $6 \mathrm{ppt}$. The average groundwater salinity for both May and November ERT-modeled salinities, along with average elevation and coastal proximity for each community type is display in Table 4.3.

\subsubsection{Porosity and Seasonality Effects Evident in Profiles}

Depth profiles for May and November were extracted from ERT-modeled salinities at each well location (Figures 4.13 through 4.16). For the majority of locations, the measured groundwater salinity in the monitoring well agreed with the ERT-modeled salinity at that depth. Exceptions occurred where the measured salinity was much lower or higher than that of the estimated value. The result is expected given the use of an average value for the formation factor. The overall agreement between measured and 
modeled values provides confidence for use of modeled data in subsequent analyses. A comparison between dry and wet season depth profiles mirrored the results presented in the salinity sections; a general increase in depth of the freshwater lens with the wet season. Wet season salinities were less than those of the corresponding dry season (Figures 4.15 and 4.16) or did not change appreciably between seasons (Figure 4.13 and 4.14). Wells having wet season depth profiles that were more saline than that of the corresponding dry season occurred primarily in locations near to the coast influenced by incoming tide at the time of the survey. ERT-modeled salinities at $1.07 \mathrm{~m}$ depth are shown with corresponding community types derived from moving split-window analysis in Figures 4.17 through 4.20. Dry season salinities at this depth are typically more saline than those of the wet season survey in agreement with the salinity sections and differences between wet and dry season salinity at this depth are much greater on Upper Sugarloaf than compared to Big Pine Key transects. Salinities in both surveys steadily decreased from the near coast community to the interior coastal forest and the slopes of these lines flatten out when the boundary of the fresh water lens (3 ppt contour) is reached. Deviations from a smooth line that are observable in both surveys are attributable to local eccentricities in porosity; for instance, Figure 4.18, meter 20 is likely an area of lower porosity bedrock. However, differences in ERT-modeled salinity between surveys at a particular location (e.g., Figure 4.20, meter 160) must be attributable to differences in pore water salinity between the two surveys. 


\subsubsection{Community Boundaries and Characteristic Species}

A moving split-window of size 5 provided the best discrimination between adjacent community types. Spikes in Bray-Curtis dissimilarity indicated the breakpoints between community-types and can be considered the boundary between adjacent communities on each transect (Figures 4.17 through 4.20). Peaks in BC dissimilarity greater than 0.5 (0.6 for transect B1) were considered to be breakpoints. Characteristic woody species of each coastal forest type were designated by their percent contribution. Only species that contributed $5 \%$ or more to the similarity within each community type were included (Table 4.4). The analysis found STS to be overwhelmingly dominated by C. erectus (buttonwood). The other three communities were characterized by several species, including $C$. erectus, several which were found in more than one community type, but in varying proportions. Species constituting the largest percent cover include: Leucothrinax morrisii (H.Wendl.)C.Lewis \& Zona (Key thatch palm), Metopium toxiferum (L). Krug \& Urb. (poisonwood), Manilkara jaimiqui (C.Wright ex. Griseb)Dubard ssp. emarginata (L.)Cronquist (wild dilly), and Byrsonima lucida (Mill.)DC. (locustberry). Species abundance varied between communities along a gradient of decreasing average groundwater salinity with a decrease in abundance for buttonwood and wild dilly and increase in abundance for Key thatch pine. Although contributing less than $5 \%$ to similarity among samples, P. elliotti var. densa was present but restricted to high elevation pine rockland. Low elevation pine rockland had pine snags, but no living pines as a result of Hurricane Wilma storm surge. The overlap between species composition between community types is evident in the ordination results (Figure 4.21) where hardwood hammock and low elevation pine rockland overlap to a large extent in species 
space. However, the general clustering of each community type within a distinct portion of species space supports the efficacy of the moving split-window analysis to successfully delineate these communities across both islands.

\subsubsection{Prediction of Coastal Forest Communities}

Using random forest classification, community types were predicted from a combination of elevation, distance to coast, and May and November ERT-modeled groundwater salinities with an accuracy of $98.5 \%$ with a $95 \%$ confidence interval of (0.975 to 0.992$)$ and having an out-of-bag estimate of error rate of $1.49 \%$. Variable importance was assessed through a calculation of the mean decrease in accuracy resulting from the elimination of each variable, with the largest decrease in accuracy attributable to distance to coast and May and November groundwater salinity as next most important (Table 4.5). Conditional probabilities for each community type along the May and November gradients (Figure 4.22a-d) identified peaks in likelihood of occurrence for high elevation pine rockland, hardwood hammock, and supratidal scrub (Figure 4.22c and d). However, probability distributions along the gradients in elevation and distance to coast for each community type were either multi-modal or not well-defined by any optima (Figure 4.22a and b).

\subsection{Discussion}

The seasonal aspect of precipitation in the lower Keys results in coastal plant communities reliant on fresh water to be composed of stress tolerant species that are adapted to periods of drought punctuated by heavy rainfall events. The study period 
(2011-2012) occurred during a period highly illustrative of this phenomenon - many months of below average precipitation followed by a several-day rain event in which close to half of the rain for the entire study period fell. The combination of a drier than normal dry season prior to the May survey and a wetter than normal October prior to the November survey resulted in climate extremes that enabled the testing of differences in dry season versus wet season climate impacts on the fresh water lenses of these two islands.

\subsubsection{Effects of Bedrock Porosity on ERT-Estimation of Groundwater Salinity}

From the formation factor as calculated by Tucker (2013), the porosity of the Miami oolite used in modeling is equal to approximately 33\%, well within the bounds of previous estimates (Robinson, 1967; DiFrenna et al., 2008). Underestimations of the measured salinity at a well by the ERT-estimated value indicate a location where bedrock porosity is lower than this average, while overestimations indicate locations of higher bedrock porosity. Higher and lower bedrock porosities occur locally from dissolution and precipitation of calcium carbonate, respectively. Locations of higher bedrock porosity can result from dissolution in the freshwater - saltwater mixing zone, a process that elsewhere leads to the development of flank margin caves in relatively short time spans (Mylroie and Carew, 1995). Conversely, lower porosities can result from calcrete formation as $\mathrm{CaCO}_{3}$ is precipitated in locations of evaporation as well as in areas of saline upconing where water is supersaturated with respect to calcium carbonate (Mylroie and Carew, 1995). The noticeable dip in some depth profiles around $2 \mathrm{~m}$ in depth (Figure 4.14) is coincident with a low porosity layer 5 to $20 \mathrm{~cm}$ thick occurring at a depth of 1.8 
to 2.1 m reported by Hanson (1980) for Big Pine Key. Conversely, terrain conductivity surveys indicate a zone of higher porosity at shallow depths to $1 \mathrm{~m}$ below the surface on Upper Sugarloaf Key (Meadows et al., 2004). The above processes do not appear to affect the values extracted from the ERT-modeled groundwater salinity at a depth of 1.07 $m$ in this study.

\subsubsection{Effects of Precipitation and ET on the Freshwater Lens}

Recharge of the lens occurs during the months of the year when precipitation is greater than losses from evapotranspiration (P:E > 1) which occurs primarily during the wet season, June through October. However, during the study year, the P:E ratio was greater than 1 only in the month of July and October, associated with short periods of heavy rainfall, illustrating that recharge to the freshwater lens is sometimes more reliant on input from severe events then from a continuous rainy season. Given the predicted summer drying trend in the Caribbean region for the $21^{\text {st }}$ century (Neelin et al., 2006), this type of recharge may become the norm.

While large changes in salinity over the course of the study at wells located closest to the coast can be partially attributed to the effects of tide and the timing of sample collection, the decrease in groundwater salinity post-rain events was larger than the change attributable to tide for near coast wells on the SLK and B2 transects. For reference, the groundwater salinity measured at well B11 was found to vary by approximately $0.5 \mathrm{ppt}$ over the course of the tidal cycle (Tucker, 2013) and at S31 by approximately 2 ppt (Ogurcak, unpublished data 2012). The increase in groundwater salinity observed after 
rain events at interior well locations, specifically at wells on the B1 and B2 transects (Figure 4.4 and 4.5), could be the result of salts in the soil being flushed into the aquifer. Overall, decreases in groundwater salinity subsequent to large rain events in July and October were observed for the majority of wells on SLK but not on BPK. Additionally, the dry season ERT surveys showed that lenses lost depth on both islands, but only on Upper Sugarloaf Key did a lateral decrease occur along with apparent breaking up of the lens into smaller areas of fresh water surrounded by areas of apparent upconing saline water.

The difference in response of the two lenses is most certainly linked to their areal extent on each island, which is dictated by the amount of contiguous land area above a certain height above sea level. Estimates of the size of each island's freshwater lens based on the work of Wightman (1990) and Caballero (1993) indicate that the lens on BPK is more than an order of magnitude larger in size than that of SLK. While the apparent breakup of the lens on SLK could be an artefact of how the inverse modeling procedure handles high surface resistivities present in the dry season survey, the disintegration of the lens could also be attributable to evapo-transpirative processes. The presence of a shallow vadose zone (less than 1 meter thick) filled with dissolution holes allows deep-rooted species to easily reach the water table as many sub-tropical hardwood species and slash pine have rooting depths of several meters (van Rees and Comerford, 1986; Querejeta et al., 2007) . The withdrawal of groundwater by established woody species can lead to transpiration driven advective flux of deeper groundwater, especially in the dry season (Sullivan, 2011). Additionally, larger sinkholes with standing water serve as foci of evaporation. In 
the case of the freshwater lenses of the Florida Keys, the deeper groundwater is higher in salinity. Locations of saline water upconing as modeled from ERT surveys along the SLK transects correspond to locations of sinkholes and large pine trees. The smaller lens on SLK is apparently below a minimum size threshold, causing it to be especially sensitive to these dry season processes. Similarly, the smaller size of the SLK aquifer is likely the reason for the responsiveness in terms of groundwater salinity decrease post-rain events, whereas an aquifer the size of the one on northern BPK responds at longer time intervals to the balance between recharge and water loss.

\subsubsection{Characteristic Species, Environmental Drivers, and Community Succession}

The overlap in characteristic species, samples in the ordination space, and groundwater salinity conditional density curves between exterior low elevation pine rockland and hardwood hammock point to low pine rockland as a location of succession to hardwood hammock that accompanies increasing groundwater salinity. Increases in groundwater salinity are driven by variable aquifer recharge, in conjunction with the current rate of sea level rise. As sea level rise rises brings the water table nearer to the ground surface, interior locations of low elevation pine rockland might be expected to instead succeed to freshwater wetlands.

Hurricane disturbance in the form of storm surge flooding may provide a tipping point to quickly move from one community type to the other. The lack of dominance of $P$. elliottii var. densa in high elevation pine rockland is an artifact of where transects were located in this study combined with the widespread loss of pine trees post-Hurricane Wilma. On 
Upper Sugarloaf Key, which has a relatively small area of elevations approaching only 1 m amsl, mortality of pine trees from Hurricane Wilma was extensive. On Big Pine Key, many areas of denser pine are located beyond the end points of transects. Slash pine still functions as a keystone species despite having lower coverage than other species in the community. Pine needles provide the flashy fuels necessary to carry fire through the community, thereby maintaining an open, high light environment that favors a high diversity herbaceous layer. Without a certain percent cover of pine and frequent fire, pine communities succeed to hardwood hammock, which hold many species in common. The transition to hammock will be hastened by the loss of a source of fresh groundwater as the lens shrinks from the lack of recharge and increasing sea level. Mid-20 $0^{\text {th }}$ century surveys of coastal forests of the lower Keys indicated presence of pine trees on all islands with fresh groundwater resources for at least part of the year (Dickson, 1955). The locations noted for having pine trees present have declined since that time. These changes confirm the importance of a freshwater lens as an essential water source for pine trees and pine rockland forests.

\subsection{Conclusions}

Over the course of the study, changes in groundwater salinity attributable to the timing of precipitation varied across near-coast to interior transect locations and between islands. Decreases in groundwater salinity subsequent to the two large rain events were observed primarily on SLK. A comparison of the two ERT surveys showed that while lenses increased in depth on both islands from the May to November survey, lateral increases occurred only on SLK. The finding that groundwater salinity in both seasons was an 
important variable in the classification of community types while elevation provided much less explanatory power coincides with findings in salt marsh zonation where edaphic factors performed better than geographic proxies (Moffett et al., 2010). Coastal proximity clearly plays a role in predicting coastal forest community type, especially near the coasts where low elevation forests have a high probability of being flooded with saline water. However, the distinct peaks in conditional probabilities for community types along the groundwater salinity gradient points to the strong connection between the extent of the freshwater resource on these islands and coastal forest community zonation, and the wider overlap of low elevation pine rockland along the gradient suggests that this community is the process of succeeding to hardwood hammock. 


\subsection{References}

Abtew, W., 1996. Evapotranspiration measurements and modeling for three wetland systems in South Florida. JAWRA J. Am. Water Resour. Assoc. 32, 465-473.

Archie, G.E., 1942. The electrical resistivity log as an aid in determining some reservoir characteristics. Pet. Trans. AIME 146, 54-62.

Baldwin, A.H., Mendelssohn, I.A., 1998. Effects of salinity and water level on coastal marshes: an experimental test of disturbance as a catalyst for vegetation change. Aquat. Bot. 61, 255-268.

Binley, A., Kemna, A., 2005. DC resistivity and induced polarization methods, in: Rubin, Y., Hubbard, S.S. (Eds.), Hydrogeophysics. Springer, Netherlands, pp. 129-159.

Caballero, J.P., 1993. Salinity variation in the upper saturated zone of Sugarloaf Key, Florida. (Master of Science). Univerisity of South Florida, Tampa, FL.

Coniglio, M., Harrison, R.S., 1983. Facies and diagenesis of late Pleistocene carbonates from Big Pine Key, FL. Bull. Can. Pet. Geol. 31, 135-147.

Constable, S.C., Parker, R.L., Constable, C.G., 1987. Occam’s inversion: A practical algorithm for generating smooth models from electromagnetic sounding data. Geophysics 52, 289-300.

Dickson, J.H.I., 1955. An ecological study of the Key deer (Florida Game and Freshwater Fish Commission Technical Bulletin).

DiFrenna, V.J., Price, R.M., Savabi, M.R., 2008. Identification of a hydrodynamic threshold in karst rocks from the Biscayne Aquifer, south Florida, USA. Hydrogeol. J. 16, 31-42.

Ellison, A.M., Mukherjee, B.B., Karim, A., 2000. Testing patterns of zonation in mangroves: scale dependence and environmental correlates in the Sundarbans of Bangladesh. J. Ecol. 88, 813-824.

Elsner, J.B., Kara, A.B., 1999. Hurricanes of the North Atlantic: Climate and Society. Oxford University Press.

Gann, D., Richards, J. 2015. Quantitative comparison of plant community hydrology using large-extent, long-term data. Wetlands 35, 81-93.

Gornish, E.S., Miller, T.E., 2010. Effects of storm frequency on dune vegetation. Glob. Change Biol. 16, 2668-2675. 
Hanson, C.E., 1980. Freshwater resources of Big Pine Key, FL (No. OF 80-447). U.S. Department of the Interior Geologic Survey, Tallahassee, FL.

Harrison, R.S., Coniglio, M., 1985. Origin of the Key Largo Limestone, Florida Keys. Bull. Can. Pet. Geol. 33, 350-358.

Hoffmeister, J.E., Multer, H.G., 1968. Geology and origin of the Florida Keys. Geol. Soc. Am. Bull. 79, 1487-1502.

Hoffmeister, J.E., Stockman, K.W., Multer, H.G., 1967. Miami Limestone of Florida and its recent Bahamian counterpart. Geol. Soc. Am. Bull. 78, 175-190.

Kasper, K., 2007. Hurricane Wilma in the Florida Keys. National Oceanic and Atmospheric Administration (NOAA)/National Weather Service (NWS) Weather Forecast Office (WFO), Key West, FL.

Keim, B.D., Muller, R.A., Stone, G.W., 2007. Spatiotemporal patterns and return periods of tropical storm and hurricane strikes from Texas to Maine. J. Clim. 20, 34983509.

Kosa, P., 2011. Evapotranspiration, in: Labedzki, L. (Ed.), The effect of temperature on actual evapotranspiration based on Landsat 5 TM satellite imagery. INTECH Open Access Publisher, pp. 209-229.

LaBrecque, D.J., Miletto, M., Daily, W., Ramirez, A., Owen, E., 1996. The effects of noise on Occam's inversion of resistivity tomography data. Geophysics 61, 538548.

Langevin, C.D., Stewart, M.T., Beaudoin, C.M., 1998. Effects of sea water canals on freshwater resources: an example from Big Pine Key, FL. Groundwater 36, 503513.

Lesmes, D.P., Friedman, S.P., 2005. Relationships between the electrical and hydrogeological properties of rocks and soils, in: Rubin, Y., Hubbard, S.S. (Eds.), Hydrogeophysics. Springer, Netherlands, pp. 87-128.

Lidz, B.H., Shinn, E.A., 1991. Paleoshorelines, reefs, and a rising sea: South Florida, U.S.A. J. Coast. Res. 7, 203-229.

Ludwig, J.A., Cornelius, J.M., 1987. Locating discontinuities along ecological gradients. Ecology 68, 448-450.

McCune, B., Grace, J.B. 2002. Analysis of ecological communities. MjM Software Design, Gleneden Beach, OR. 
Meadows, D.G., Caballero, J.P., Kruse, S.E., Vacher, H.L., 2004. Variation of salinity in brackish-water lenses of two Florida Keys. J. Coast. Res. 20, 386-400.

Méndez Linares, A.P., López-Portillo, J., Hernández-Santana, J.R., Ortiz Pérez, M.A., Oropeza Orozco, O., 2007. The mangrove communities in the Arroyo Seco deltaic fan, Jalisco, Mexico, and their relation with the geomorphic and physicalgeographic zonation. CATENA 70, 127-142.

Moffett, K.B., Robinson, D.A., Gorelick, S.M., 2010. Relationship of salt marsh vegetation zonation to spatial patterns in soil moisture, salinity, and topography. Ecosystems 13, 1287-1302.

Mylroie, J.E., Carew, J.L., 1995. Karst development on carbonate islands, in: Unconformities and Porosity in Carbonate Strata, American Association of Petroleum Geologists Memoir. pp. 55-76.

Neelin, J.D., Münnich, M., Su, H., Meyerson, J.E., Holloway, C.E., 2006. Tropical drying trends in global warming models and observations. Proc. Natl. Acad. Sci. 103, 6110-6115.

Oosting, H.J., Billings, W.D., 1942. Factors effecting vegetational zonation on coastal dunes. Ecology 23, 131-142.

Pennings, S.C., Grant, M.-B., Bertness, M.D., 2005. Plant zonation in low-latitude salt marshes: disentangling the roles of flooding, salinity and competition. J. Ecol. 93, 159-167.

Perkins, R.D., 1977. Depositional framework of Pleistocene rocks in south Florida, in: Enos, P., Perkins, R.D. (Eds.), Quarternary Sedimentation in South Florida. Geological Society of America, pp. 131-198.

Querejeta, J.I., Estrada-Medina, H., Allen, M.F., Jiménez-Osornio, J.J., 2007. Water source partitioning among trees growing on shallow karst soils in a seasonally dry tropical climate. Oecologia 152, 26-36.

Rahmstorf, S., 2007. A semi-empirical approach to projecting future sea-level rise. Science 315, 368-370.

Robertson, W., Zhang, K., 2007. Big Pine Key Survey Commissioned by The Nature Conservancy: Airborne LIDAR Data and Digital Elevation Models of Big Pine Key, Florida. Miami, FL, International Hurricane Research Center Florida International University.

Robinson, R.B., 1967. Diagnesis and porosity development in recent and Pleistocene oolites from southern Florida and the Bahamas. J. Sediment. Petrol. 37, 355-364. 
Ross, M.S., Coultas, C.L., Hsieh, Y.P., 2003. Soil-productivity relationships and organic matter turnover in dry tropical forests of the Florida Keys. Plant Soil 253, 479492.

Ross, M.S., O’Brien, J.J., da Silveira Lobo Sternberg, L., 1994. Sea-level rise and the reduction in pine forests in the Florida Keys. Ecol. Appl. 4, 144-156.

Ross, M.S., O’Brien, J.J., Flynn, L.J., 1992. Ecological site classification of Florida Keys terrestrial habitats. Biotropica 24, 488-502.

Saha, A.K., Saha, S., Sadle, J., Jiang, J., Ross, M.S., Price, R.M., Sternberg, L.S.L.O., Wendelberger, K.S., 2011. Sea level rise and South Florida coastal forests. Clim. Change 107, 81-108.

Sah, J.P., Ross, M.S., Snyder, J.R., Ogurcak, D.E., 2010. Tree Mortality following prescribed fire and a storm surge event in slash pine (Pinus elliottii var. densa) forests in the Florida Keys, USA. Int. J. For. Res. 2010, 1-13.

Snyder, J.R., Herndon, A., Robertson, W.B., 1990. South Florida rockland, Myers, R.L., Ewel, J.J. (Eds.), Ecosystems of Florida. University of Central Florida Press, Orlando, FL, pp. 230-277.

Sullivan, P.L., 2011. Groundwater-surface water interactions on tree islands in the Everglades, South Florida. Florida International University, Miami, FL.

Telford, W.M., Geldart, L.P., Sheriff, R.E., 1990. Applied Geophysics, 2nd ed. Cambridge University Press, Cambridge.

Tiab, D., Donaldson, E.C., 2004. Petrophysics: theory and practice of measuring reservoir rock and fluid transport properties, 2nd ed. Gulf Professional Pub, Boston.

Tucker, N.M., 2013. Analyzing tidal fluctuations in the Big Pine Key freshwater lens with time-lapse resistivity (M.S. Thesis). Florida International University, Miami, FL.

Vacher, H.L., 1988. Dupuit-Ghyben-Herzberg analysis of strip-island lenses. Geol. Soc. Am. Bull. 100, 580-591.

Vacher, H.L., Wightman, M.J., Stewart, M.T., 1992. Hydrology of meteroic diagenesis: effect of Pleistocene stratigraphy on freshwater lenses of Big Pine Key, Florida, in: Fletcher, C.H., III, Wehmiller, J.F. (Eds.), Quarternary Coasts of the United States: Marine and Lacustine Systems, SEPM (Society for Sedimentary Geology. pp. 213-219. 
van Rees, K.C.J., Comerford, N.B., 1986. Vertical root distribution and strontium uptake of a slash pine stand on a Florida spodosol. Soil Sci. Soc. Am. J. 50, 1042-1046.

Wagner, R.J., Boulger, R.W., Oblinger, C.J., Smith, B.A., 2006. Guidelines and standard procedures for continuous water-quality monitors-Station operation, record computation, and data reporting, U.S. Geological Survey Techniques and Methods 1-D3,. U.S. Geological Survey, Reston, VA.

Wierenga, P.J., J. M. H. Hendrickx, M. H. Nash, J. Ludwig, L. A. Daugherty, 1987. Variation of soil and vegetation with distance along a transect in the Chihuahuan Desert. J. Arid Environ. 13, 53-63.

Wightman, M.J., 1990. Geophysical analysis and Dupuit-Ghyben-Herzberg modeling of freshwater lenses on Big Pine Key, Florida (M.S. Thesis). University of South Florida, Tampa, FL.

Zhang, K., Ross, M.S., Ogurcak, D.E., Houle, P., 2010. Lower Florida Keys digital terrain model and vegetation analysis for the National Key Deer Refuge (Final Report submitted to the U.S. Fish and Wildlife Service National Key Deer Refuge, Big Pine Key, FL). Florida International University, Miami, FL. 


\subsection{Tables}

Table 4.1. Well codes and location, habitat (Hab), elevation, distance to coast (DTC), and average depth to water table (m) and average salinity (ppt) measured monthly in each well sampled during the study time period (May 2011 to April 2012). Means +/- SE are reported $(n=12)$ for depth to water table and salinity. Elevation is the average of pixels from Lidar DTM contained within a 10 m radius circle inscribing each well. Habitat types: hardwood hammock (HH), high elevation pine rockland (HP), low elevation pine rockland (LP), and supratidal scrub (STS).

\begin{tabular}{|c|c|c|c|c|c|c|c|}
\hline Well & Hab & Lon $(\mathrm{W})$ & Lat $(\mathrm{N})$ & $\begin{array}{c}\text { Elev } \\
(\mathrm{m})\end{array}$ & $\begin{array}{c}\text { DTC } \\
(\mathrm{m})\end{array}$ & $\begin{array}{c}\text { Depth to } \mathrm{H}_{2} \mathrm{O} \\
\text { table }(\mathrm{m})\end{array}$ & Salinity (ppt) \\
\hline B11 & STS & 81.39357 & 24.71279 & 0.21 & 37 & $0.31+/-0.03$ & $6.68+/-0.09$ \\
\hline B12 & HP & 81.39331 & 24.71278 & 0.56 & 53 & $0.58+/-0.03$ & $2.63+/-0.16$ \\
\hline B13 & HP & 81.39268 & 24.71287 & 0.69 & 113 & $0.71+/-0.03$ & $1.46+/-0.05$ \\
\hline B14 & LP & 81.39089 & 24.71289 & 0.53 & 277 & $0.47+/-0.03$ & $0.73+/-0.04$ \\
\hline B15 & LP & 81.38957 & 24.71287 & 0.38 & 401 & $0.35+/-0.03$ & $0.49+/-0.02$ \\
\hline B21 & STS & 81.36469 & 24.69552 & 0.19 & 191 & $0.39+/-0.04$ & $19.45+/-1.79$ \\
\hline B22 & HH & 81.36536 & 24.69545 & 0.41 & 249 & $0.50+/-0.03$ & $8.14+/-0.14$ \\
\hline B23 & HH & 81.36633 & 24.69549 & 0.61 & 332 & $0.48+/-0.03$ & $1.64+/-0.06$ \\
\hline B24 & LP & 81.36842 & 24.69552 & 0.47 & 532 & $0.44+/-0.03$ & $0.74+/-0.08$ \\
\hline B25 & HP & 81.36933 & 24.69555 & 0.57 & 621 & $0.64+/-0.03$ & $2.56+/-0.12$ \\
\hline B26 & HP & 81.37100 & 24.69556 & 0.87 & 682 & $0.76+/-0.03$ & $0.43+/-0.02$ \\
\hline B31 & STS & 81.36216 & 24.69343 & 0.20 & 150 & $0.34+/-0.03$ & $14.27+/-0.17$ \\
\hline B32 & HH & 81.36216 & 24.69303 & 0.33 & 188 & $0.31+/-0.03$ & $13.02+/-0.39$ \\
\hline B33 & HH & 81.36219 & 24.69265 & 0.31 & 227 & $0.53+/-0.03$ & $6.03+/-0.16$ \\
\hline B34 & LP & 81.36219 & 24.69238 & 0.45 & 254 & $0.52+/-0.03$ & $2.93+/-0.25$ \\
\hline B35 & HP & 81.36219 & 24.69186 & 0.51 & 300 & $0.50+/-0.03$ & $3.08+/-0.02$ \\
\hline S21 & HH & 81.54875 & 24.67645 & 0.20 & 394 & $0.14+/-0.03$ & $20.27+/-1.09$ \\
\hline S22 & LP & 81.54833 & 24.67696 & 0.35 & 456 & $0.28+/-0.04$ & $5.63+/-0.19$ \\
\hline S23 & HP & 81.54784 & 24.67751 & 0.42 & 525 & $0.29+/-0.04$ & $2.43+/-0.03$ \\
\hline S31 & STS & 81.54434 & 24.67871 & 0.29 & 239 & $0.33+/-0.04$ & $28.40+/-1.50$ \\
\hline S32 & HH & 81.54451 & 24.67850 & 0.62 & 261 & $0.44+/-0.04$ & $7.68+/-0.96$ \\
\hline S33 & HH & 81.54477 & 24.67822 & 0.80 & 295 & $0.57+/-0.03$ & $2.38+/-0.30$ \\
\hline S34 & HP & 81.54507 & 24.67786 & 1.16 & 338 & $0.91+/-0.04$ & $1.02+/-0.14$ \\
\hline S35 & LP & 81.54562 & 24.67717 & 0.58 & 405 & $0.40+/-0.04$ & $0.95+/-0.08$ \\
\hline
\end{tabular}


Table 4.2 ERT transect location, length (m), elevation range (m), number of wells located along each transect, and dates of each survey $(\mathrm{BPK}=$ Big Pine Key, SLK = Upper Sugarloaf Key).

\begin{tabular}{|c|c|c|c|c|c|c|}
\hline Transect & Island & $\begin{array}{c}\text { Length } \\
(\mathrm{m})\end{array}$ & $\begin{array}{c}\text { \# of } \\
\text { wells }\end{array}$ & $\begin{array}{c}\text { Elevation range } \\
\text { (min to max in m) }\end{array}$ & $\begin{array}{c}\text { Dry season } \\
\text { survey }\end{array}$ & $\begin{array}{c}\text { Wet season } \\
\text { survey }\end{array}$ \\
\hline B1 & BPK & 222 & 3 & $0.21-0.76$ & $5 / 20 / 2011$ & $11 / 13 / 2011$ \\
\hline B3 & BPK & 250 & 5 & $0.20-0.67$ & $5 / 21 / 2011$ & $11 / 11 / 2011$ \\
\hline S2 & SLK & 166 & 3 & $0.03-0.50$ & $5 / 23 / 5011$ & $11 / 13 / 2011$ \\
\hline S3 & SLK & 250 & 5 & $0.24-1.20$ & $5 / 22 / 2011$ & $11 / 12 / 2011$ \\
\hline
\end{tabular}

Table 4.3 Mean +/- SE of ERT-derived groundwater salinity at $107 \mathrm{~cm}$ below ground surface for May and November 2011 in each community type. Salinity (ppt) was determined at $1 \mathrm{~m}$ intervals along each transect. Elevation is in NAVD88 meters. DTC is distance to nearest coastline in meters.

\begin{tabular}{|l|c|c|c|c|c|}
\hline Habitat & $\mathrm{n}$ & Elevation (m) & DTC (m) & $\begin{array}{c}\text { May Salinity } \\
(\mathrm{ppt})\end{array}$ & $\begin{array}{c}\text { Nov Salinity } \\
(\mathrm{ppt})\end{array}$ \\
\hline High Pine & 426 & $0.60+/-0.01$ & $275+/-7.0$ & $1.91+/-0.06$ & $1.55+/-0.05$ \\
\hline Low Pine & 167 & $0.44+/-0.01$ & $347+/-6.9$ & $4.95+/-0.36$ & $4.44+/-0.32$ \\
\hline Hammock & 180 & $0.53+/-0.02$ & $281+/-5.4$ & $8.52+/-0.52$ & $7.01+/-0.46$ \\
\hline Supratidal Scrub & 100 & $0.31+/-0.01$ & $148+/-7.2$ & $13.49+/-0.73$ & $11.70+/-0.35$ \\
\hline
\end{tabular}


Table 4.4 Average percent cover and percent contribution and cumulative contribution of species to the similarity between samples assigned to each community type. Only species contributing greater than $5 \%$ to species composition of the community are included. Habitat types include: supratidal scrub (STS), hardwood hammock (HH), low elevation pine rockland (LP), and high elevation pine rockland (HP).

\begin{tabular}{|c|l|c|c|c|}
\hline Habitat & \multicolumn{1}{|c|}{ Species } & $\begin{array}{c}\text { Percent } \\
\text { Cover }\end{array}$ & $\begin{array}{c}\text { Percent } \\
\text { Contribution }\end{array}$ & $\begin{array}{c}\text { Cumulative } \\
\text { Contribution }\end{array}$ \\
\hline STS & Conocarpus erectus & 58.68 & 94.57 & 94.57 \\
\hline \multirow{3}{*}{ HH } & Metopium toxiferum & 28.59 & 22.34 & 22.34 \\
& Conocarpus erectus & 23.46 & 20.86 & 43.20 \\
& Manilkara jaimiqui & 16.59 & 13.63 & 56.83 \\
& Leucothrinax morrisii & 20.61 & 11.02 & 67.85 \\
& Pithecellobium keyense & 13.30 & 10.99 & 78.84 \\
& Eugenia foetida & 16.96 & 10.80 & 89.64 \\
\hline \multirow{5}{*}{ LP } & Leucothrinax morrisii & 35.86 & 47.78 & 47.78 \\
& Metopium toxiferum & 15.77 & 13.23 & 61.01 \\
& Manilkara jaimiqui & 11.02 & 9.47 & 70.48 \\
& Conocarpus erectus & 10.47 & 9.23 & 79.72 \\
\hline \multirow{5}{*}{ HP } & Leucothrinax morrisii & 28.21 & 40.18 & 40.18 \\
& Metopium toxiferum & 19.79 & 22.02 & 62.20 \\
& Byrsonima lucida & 8.64 & 7.86 & 70.06 \\
& Pithecellobium keyense & 8.04 & 6.49 & 76.56 \\
& Serenoa repens & 6.75 & 6.18 & 82.73 \\
\hline
\end{tabular}

Table 4.5 Mean decrease in accuracy of random forest classification of 4 variables for 6 community types.

\begin{tabular}{|l|c|}
\hline Environmental Variable & Mean Decrease in Accuracy \% \\
\hline May Groundwater Salinity & 26.8 \\
\hline November Groundwater Salinity & 26.6 \\
\hline Elevation & 16.9 \\
\hline Distance to Coast & 41.1 \\
\hline
\end{tabular}




\subsection{Figures}
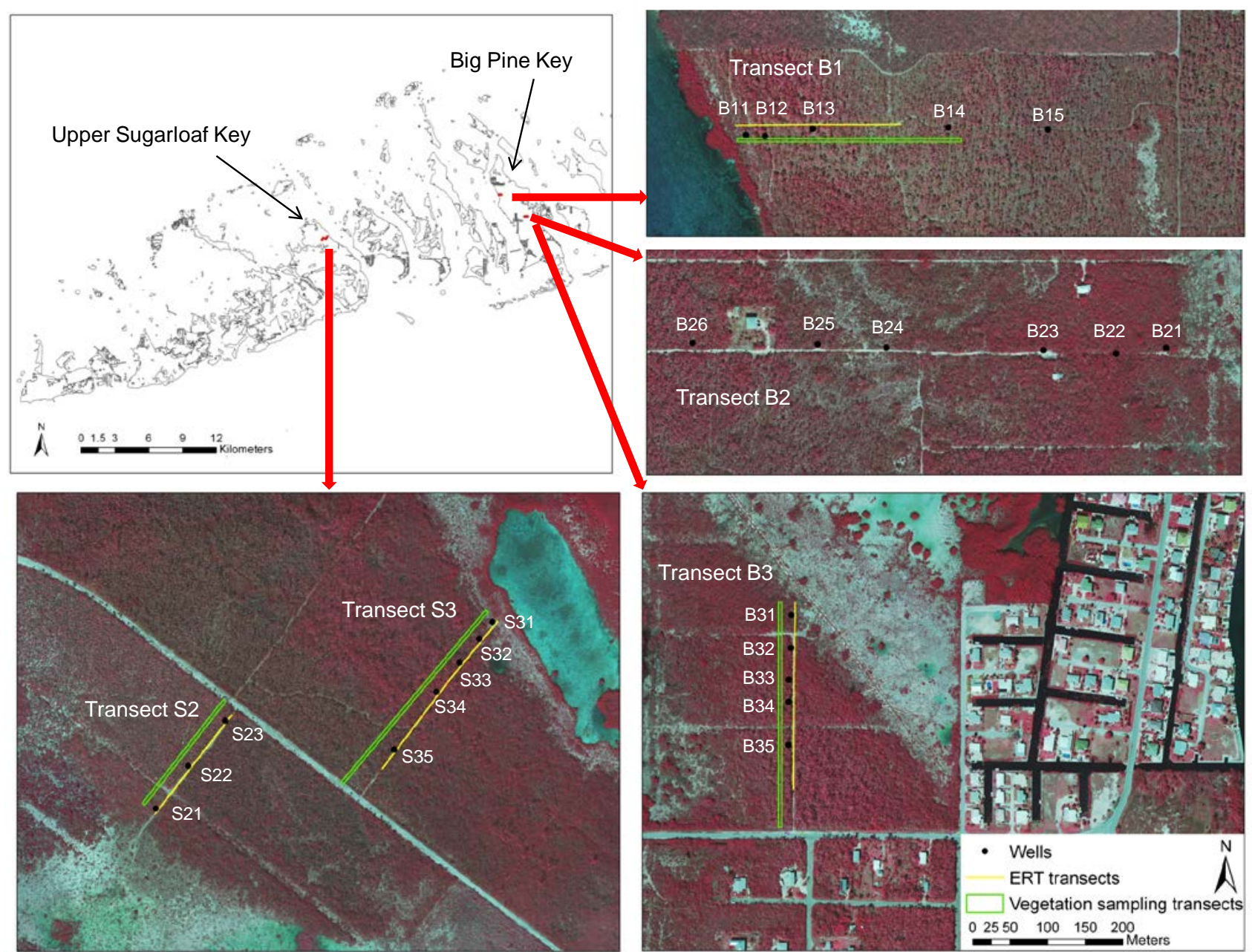

Figure 4.1 Big Pine and Upper Sugarloaf Key ERT transects, vegetation transects, and well locations. 


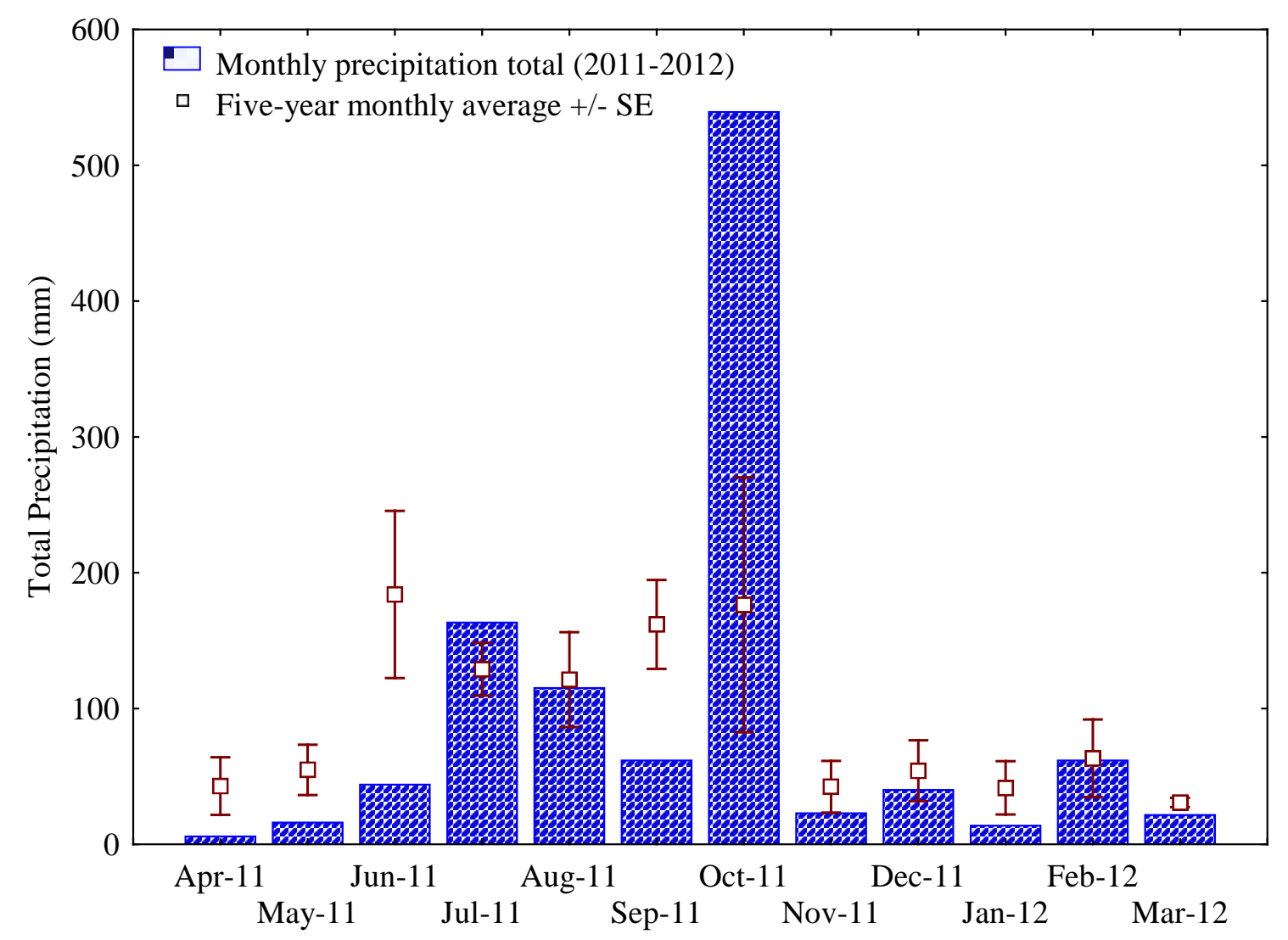

Figure 4.2 Total precipitation (mm) received on Big Pine Key in each month prior to groundwater monitoring (May 2011 through April 2012). Five-year average monthly precipitation totals $(\mathrm{mm})$ for the time period starting at the onset of the wet season in June 2007 to the end of the dry season in May 2012 are included for comparison. 


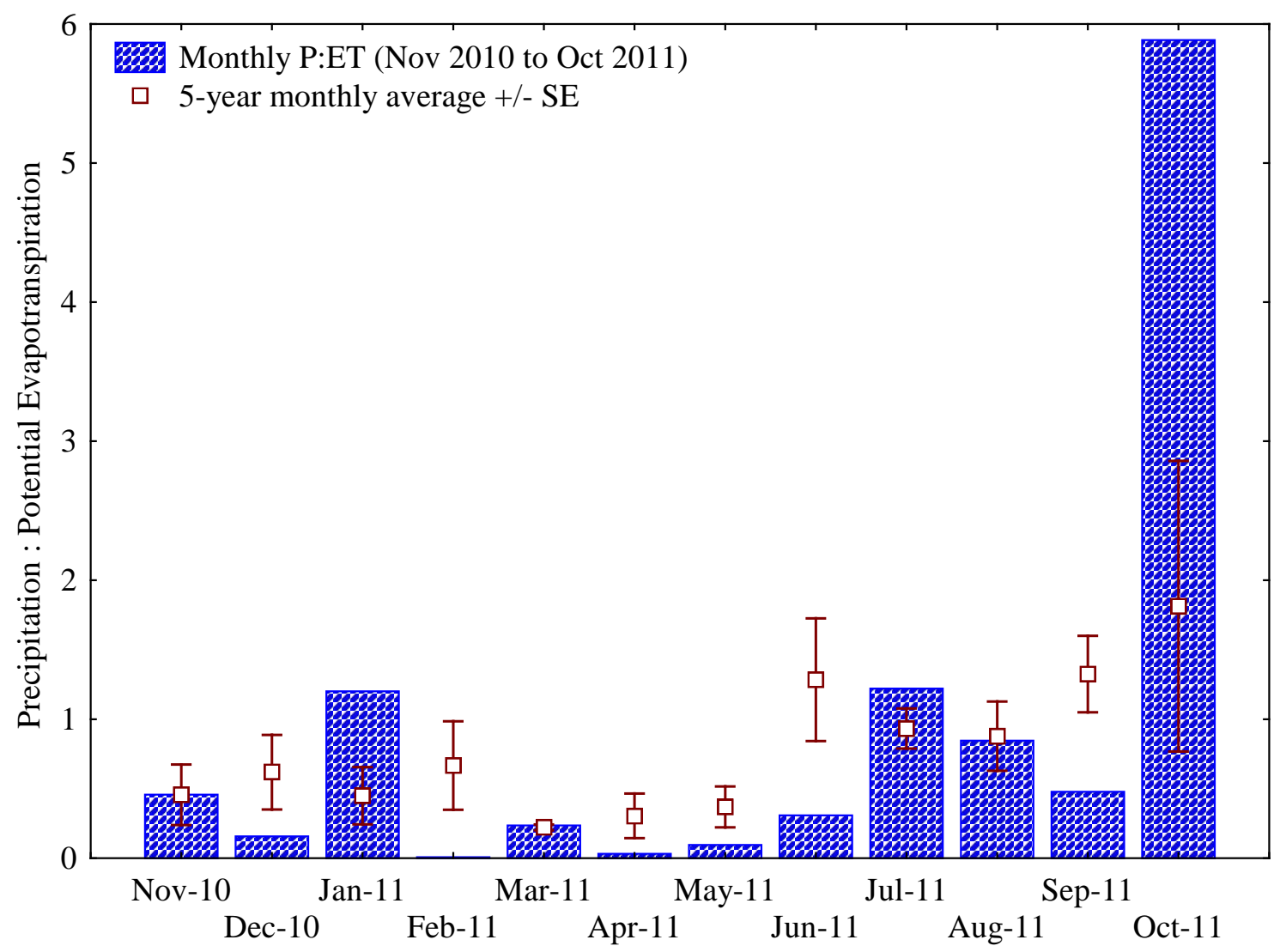

Figure 4.3 Ratio of total monthly precipitation to potential evapotranspiration (P:ET) beginning November 2010 (6 months prior to dry season ERT survey) through October 2011 (month prior to wet season ERT survey) with 5-year monthly averages plotted (Jun07 through May-12) for comparison. 


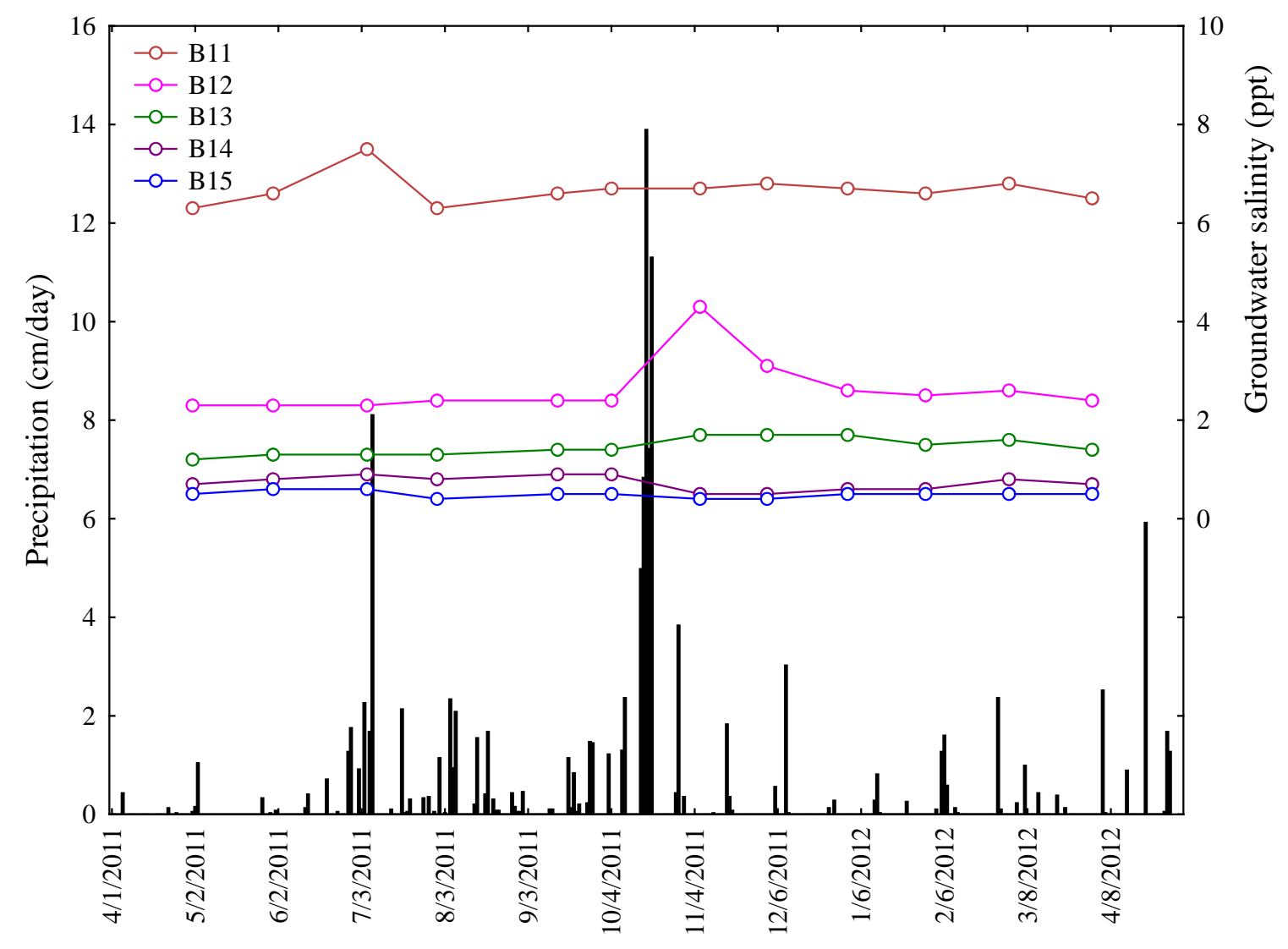

Figure 4.4 Relationship between measured groundwater salinities at wells along transect B1 (obtained at monthly intervals) and daily precipitation totals from April 1, 2011 to April 30, 2012. Wells are located along the transect with B11 nearest and B15 farthest from the coast. 


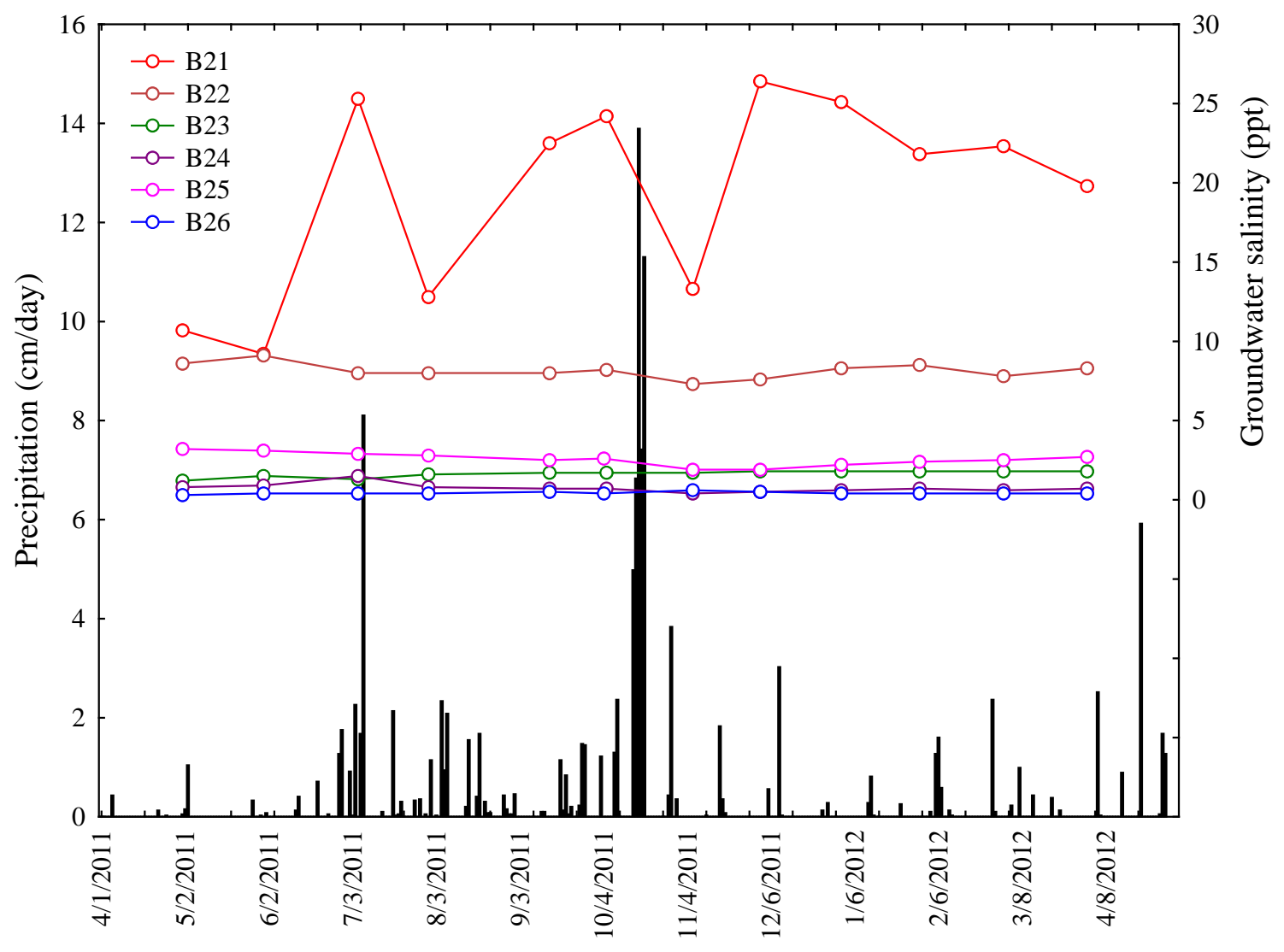

Figure 4.5 Relationship between measured groundwater salinities at wells along transect B2 (obtained at monthly intervals) and daily precipitation totals from April 1, 2011 to April 30, 2012. Wells are located along the transect with B21 nearest and B26 farthest from the coast. 


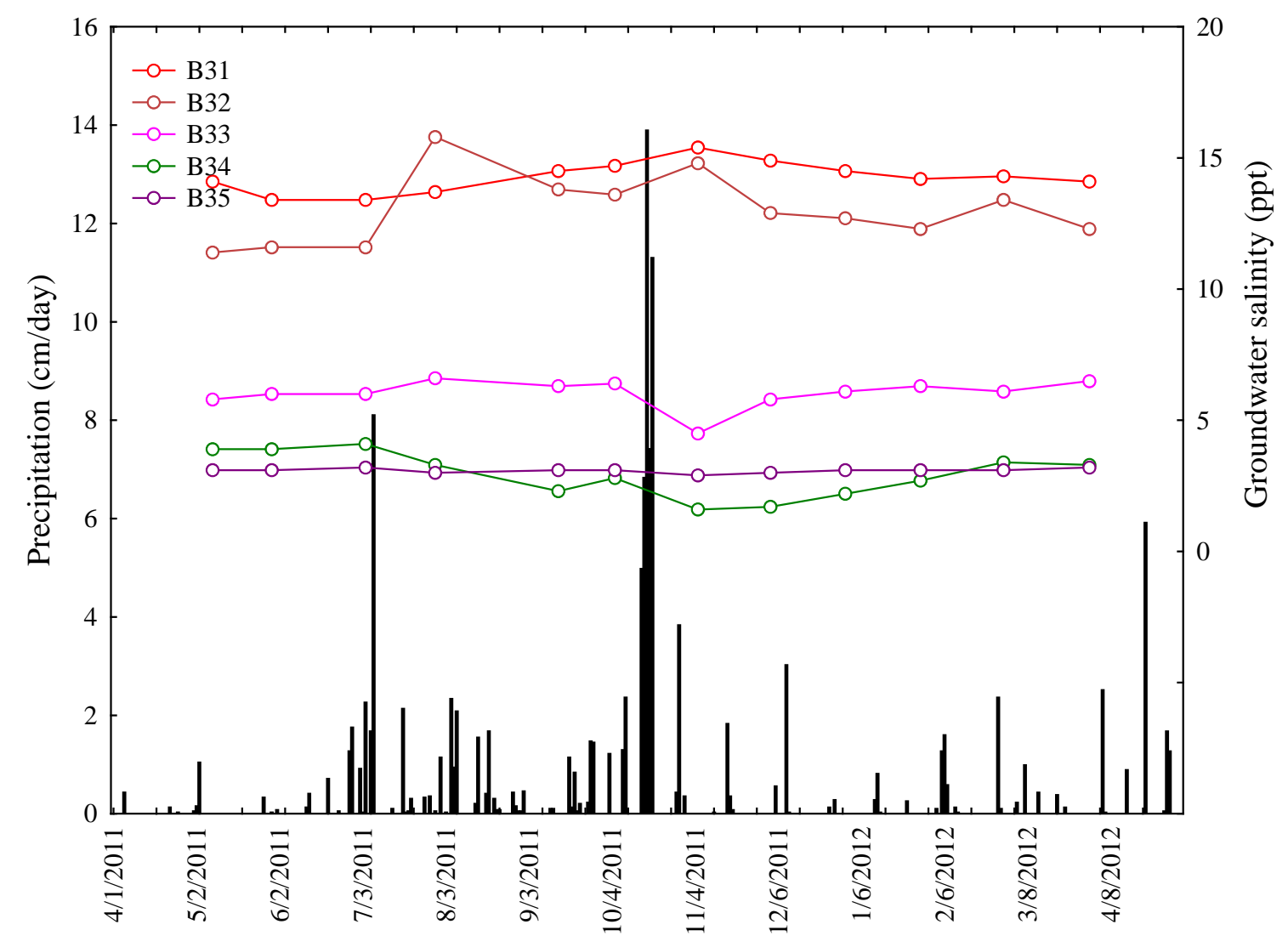

Figure 4.6 Relationship between measured groundwater salinities at wells along transect B3 (obtained at monthly intervals) and daily precipitation totals from April 1, 2011 to April 30, 2012. Wells are located along the transect with B31 nearest and B35 farthest from the coast. 


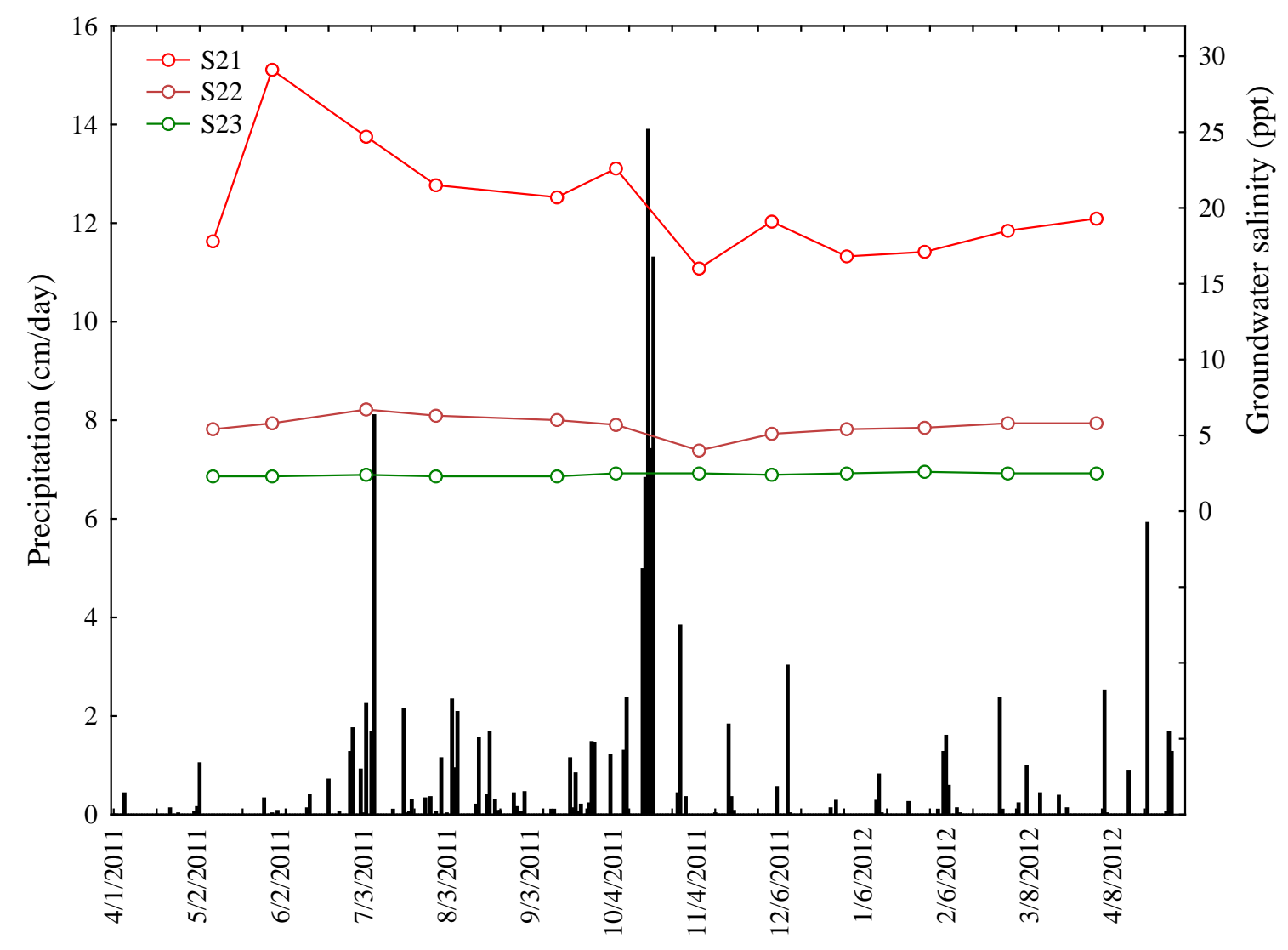

Figure 4.7 Relationship between measured groundwater salinities at wells along transect S2 (obtained at monthly intervals) and daily precipitation totals from April 1, 2011 to April 30, 2012. Wells are located along the transect with S21 nearest and S23 farthest from the coast. 


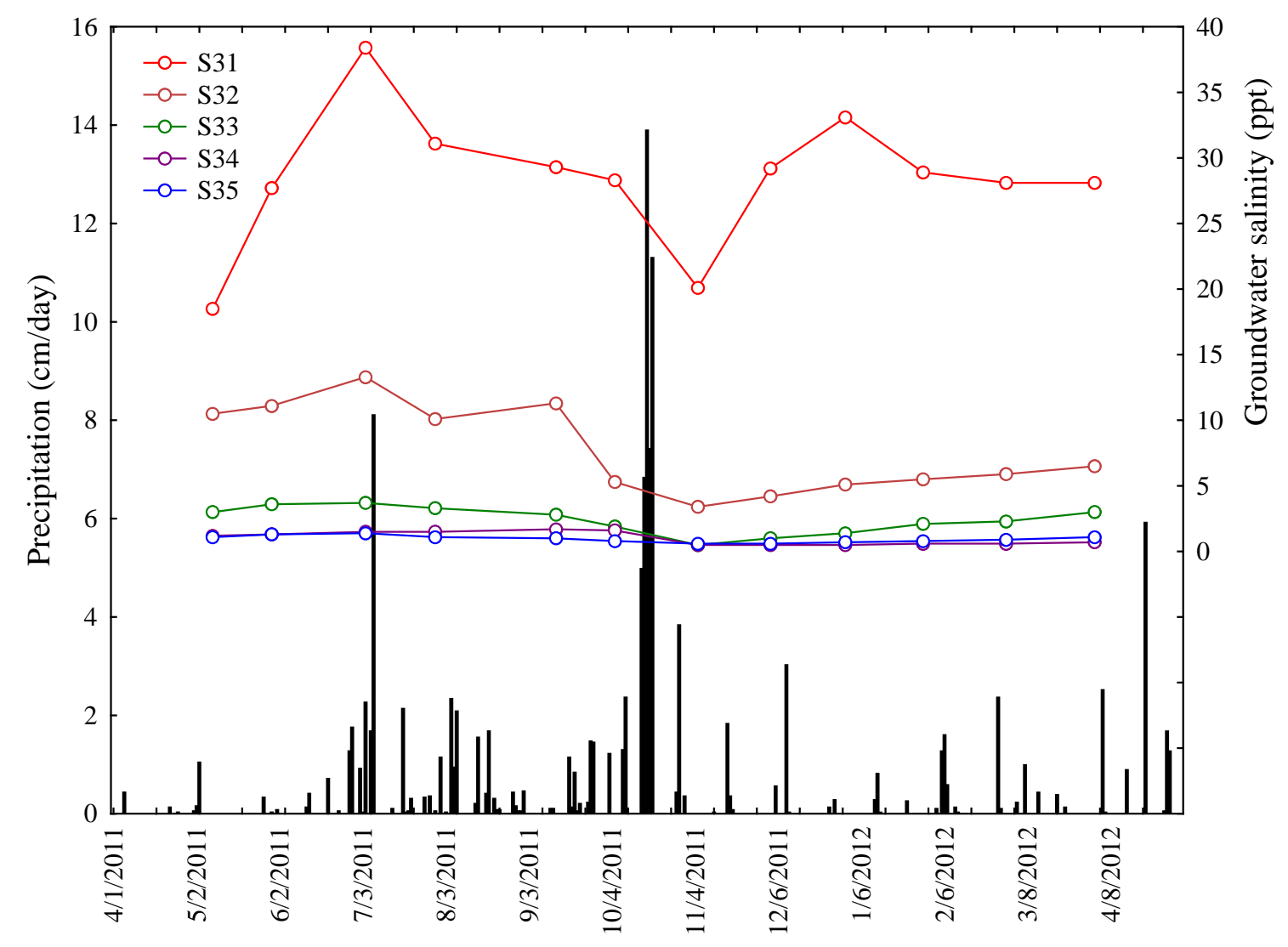

Figure 4.8 Relationship between measured groundwater salinities at wells along transect S3 (obtained at monthly intervals) and daily precipitation totals from April 1, 2011 to April 30, 2012. Wells are located along the transect with S31 nearest and S35 farthest from the coast. 
May B1

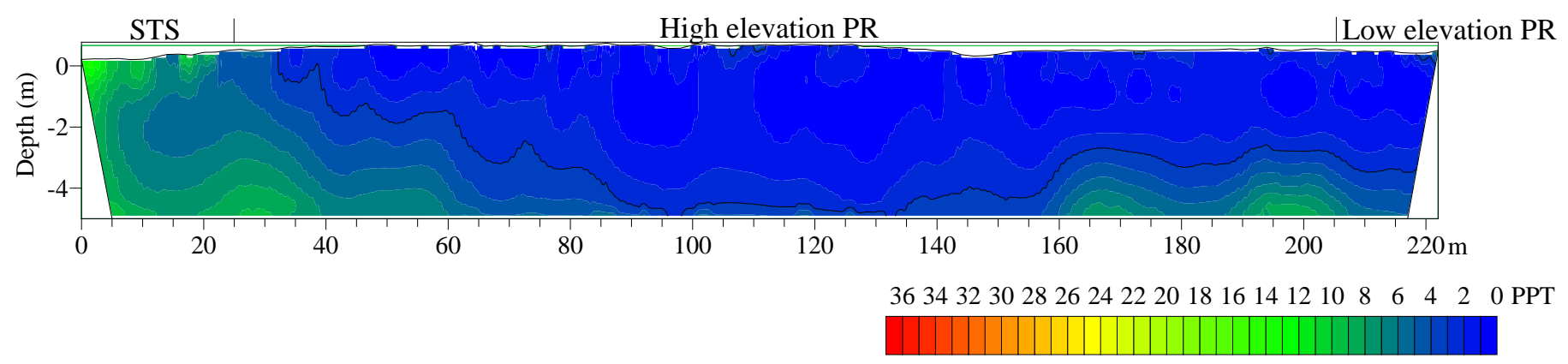

November B1

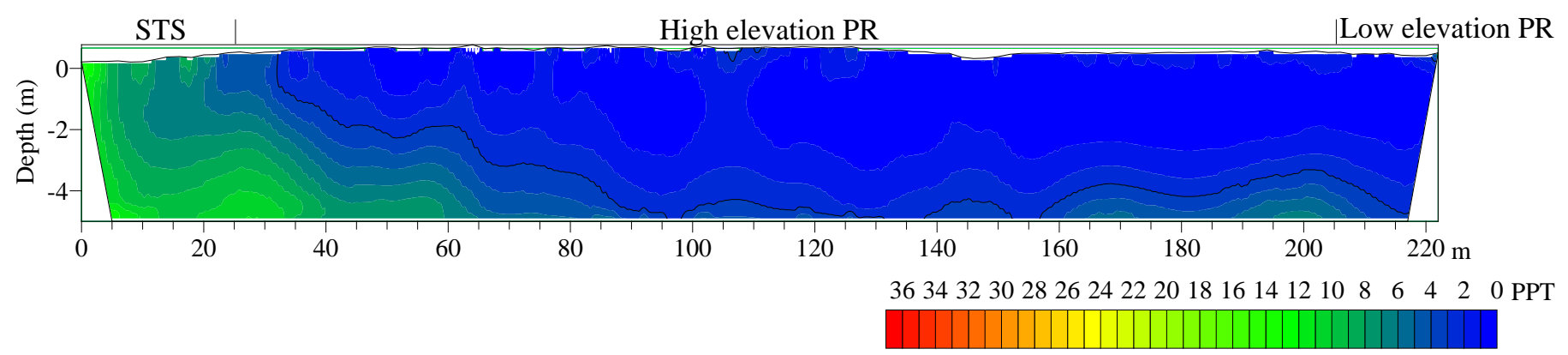

May - November 3 ppt salinity contours

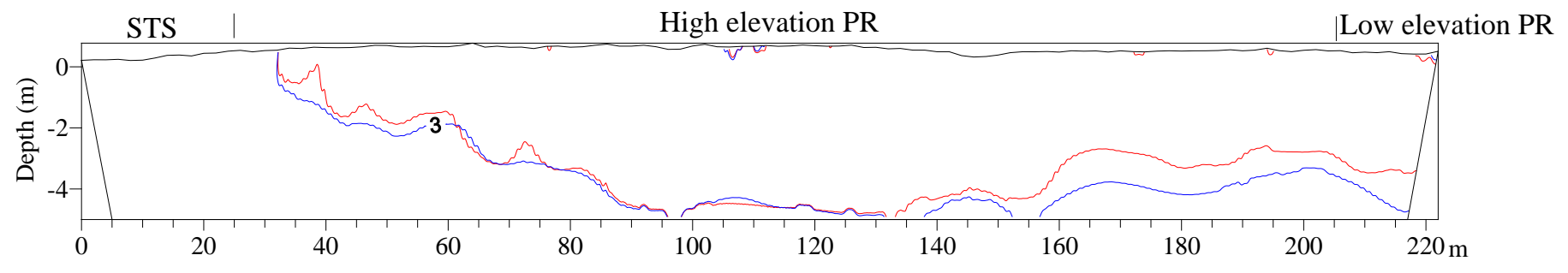

Figure 4.9 Transect B1 groundwater salinity profile derived from May and November 2011 ERT surveys with 3 ppt contour lines identified, red for May survey, blue for November survey (PR = pine rockland, STS = supratidal scrub). 


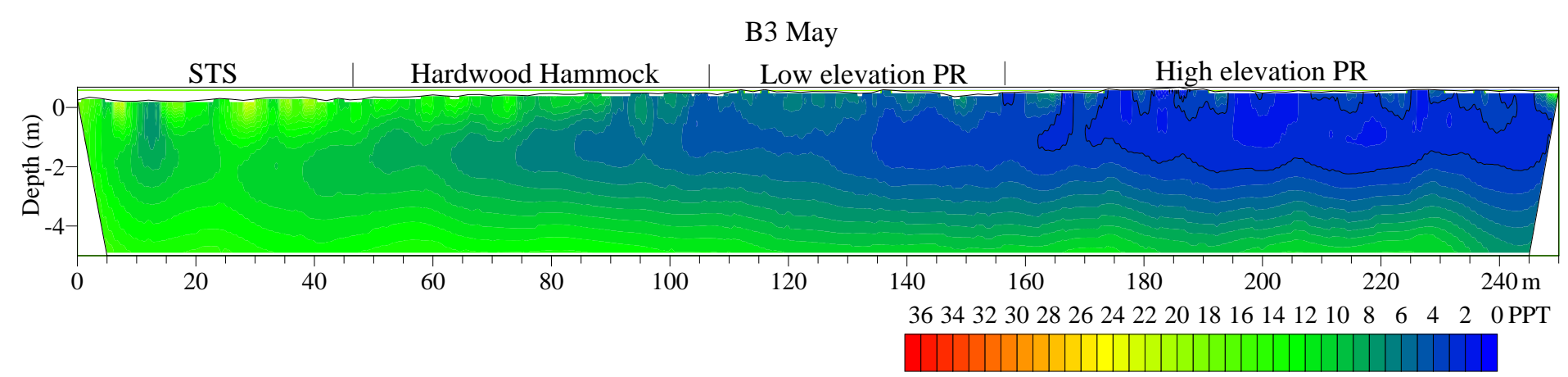

B3 November

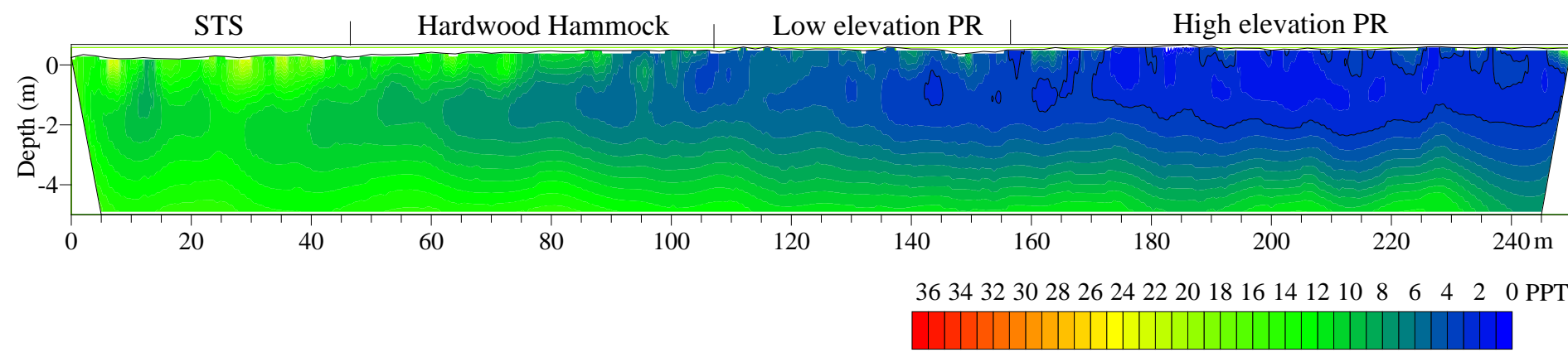

May - November 3 ppt salinity contours

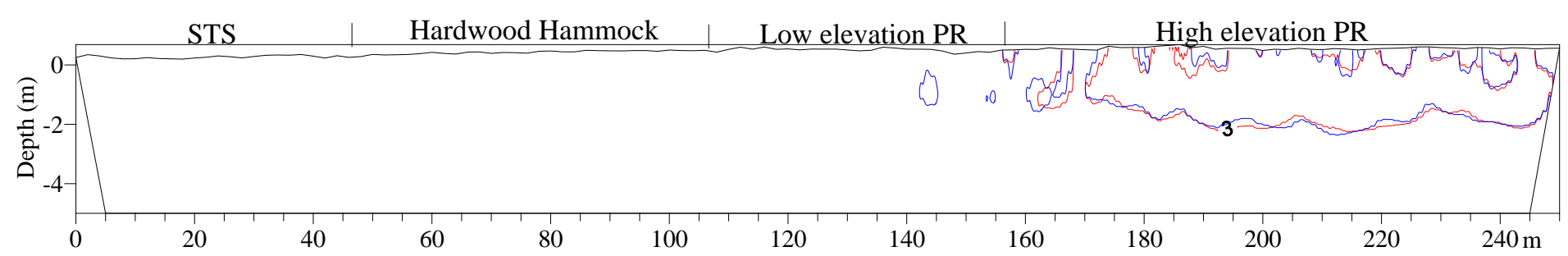

Figure 4.10 Transect B3 groundwater salinity profile derived from May and November 2011 ERT surveys with 3 ppt contour lines identified, red for May survey, blue for November survey (PR = pine rockland, STS = supratidal scrub). 
S2 May

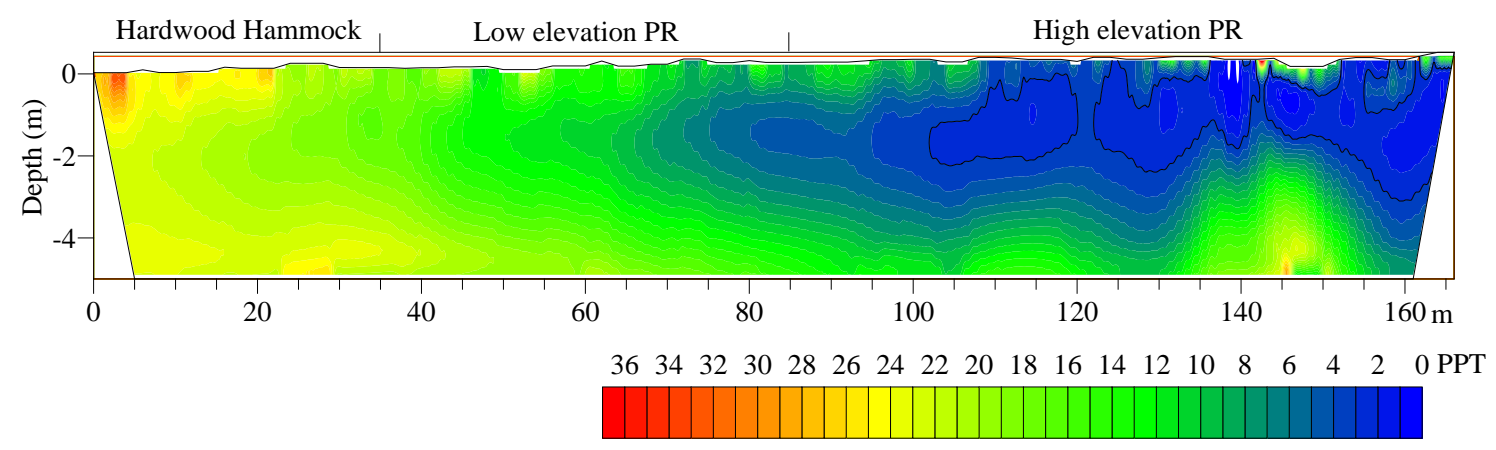

\section{S2 November}

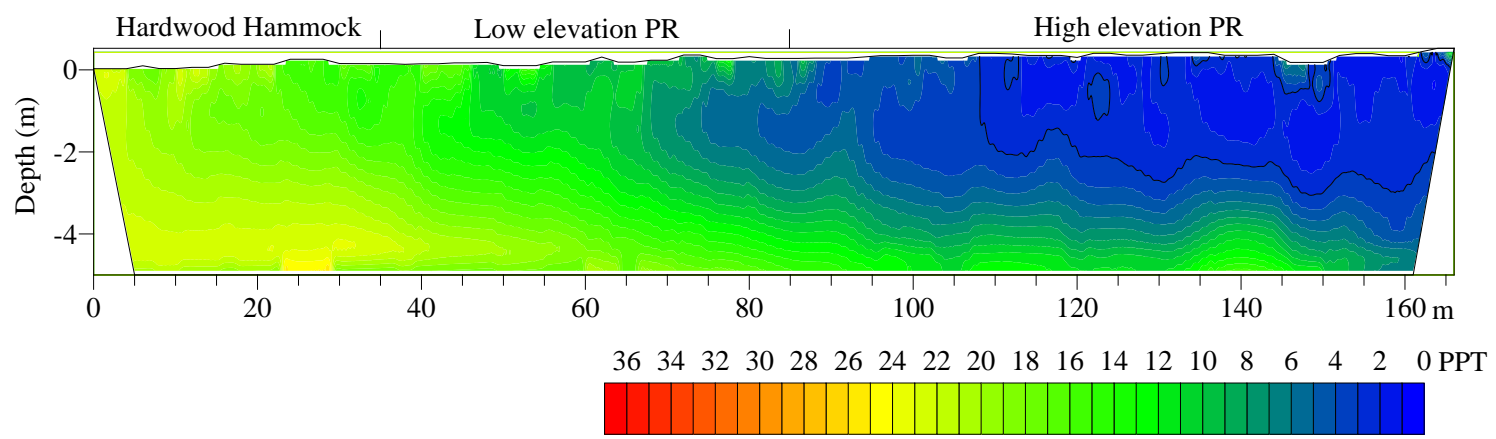

May - November 3 ppt salinity contours

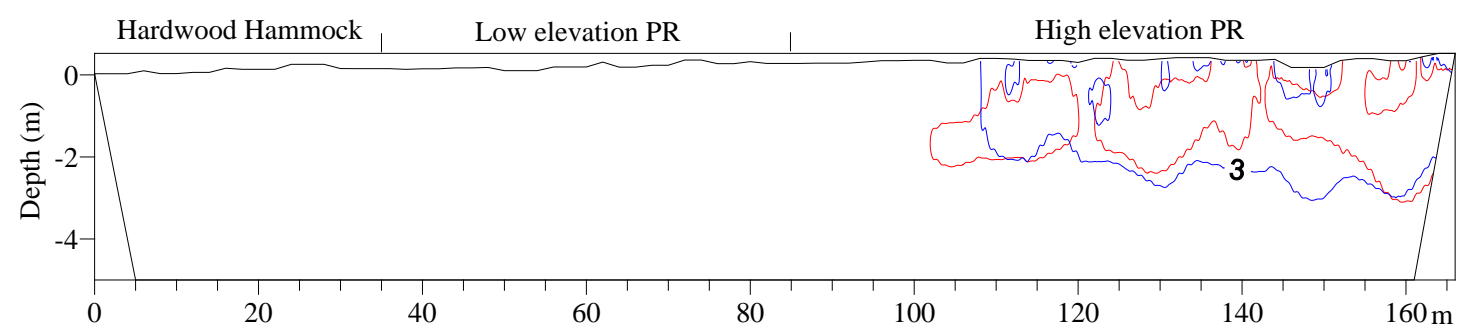

Figure 4.11 Transect S2 groundwater salinity profile derived from May and November 2011 ERT surveys with 3 ppt contour lines identified, red for May survey, blue for November survey $(\mathrm{PR}=$ pine rockland $)$. 


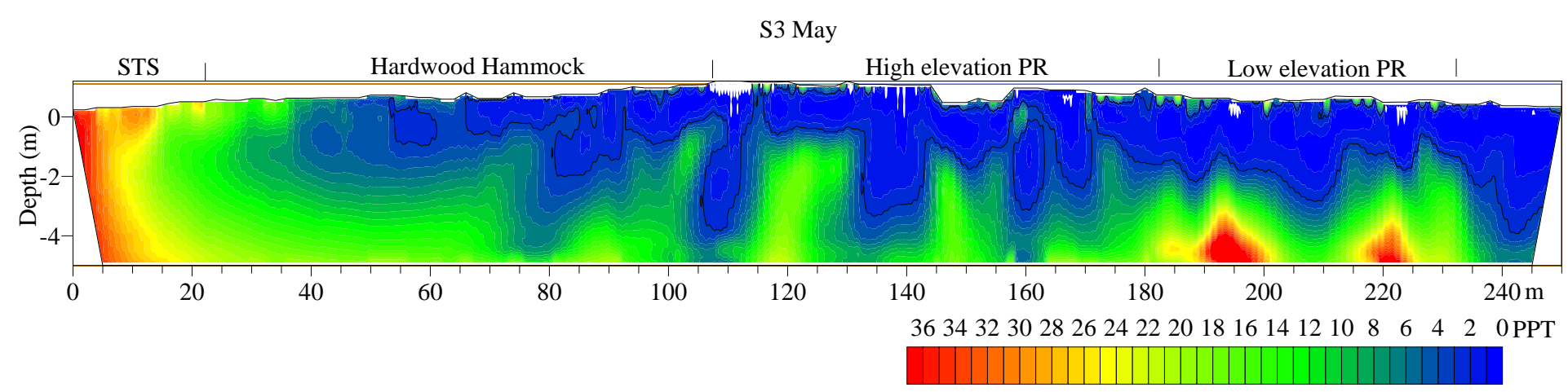

S3 November

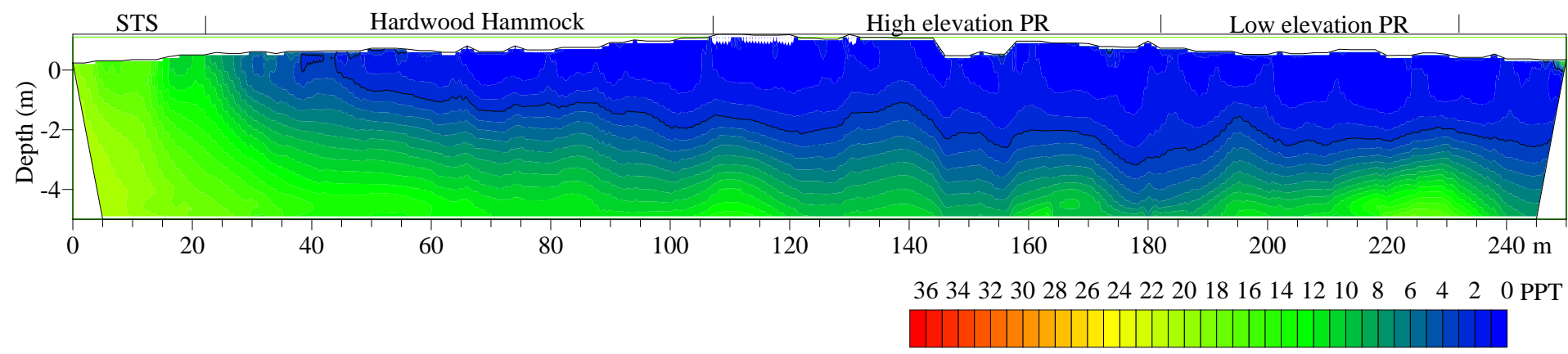

May - November 3 ppt salinity contours

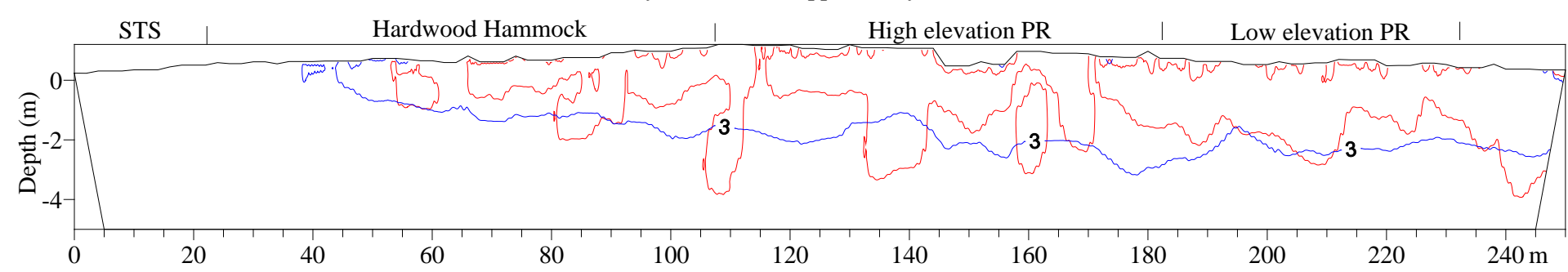

Figure 4.12 Transect S3 groundwater salinity profile derived from May and November 2011 ERT surveys with 3 ppt contour lines identified, red for May survey, blue for November survey (PR = pine rockland, STS = supratidal scrub). 

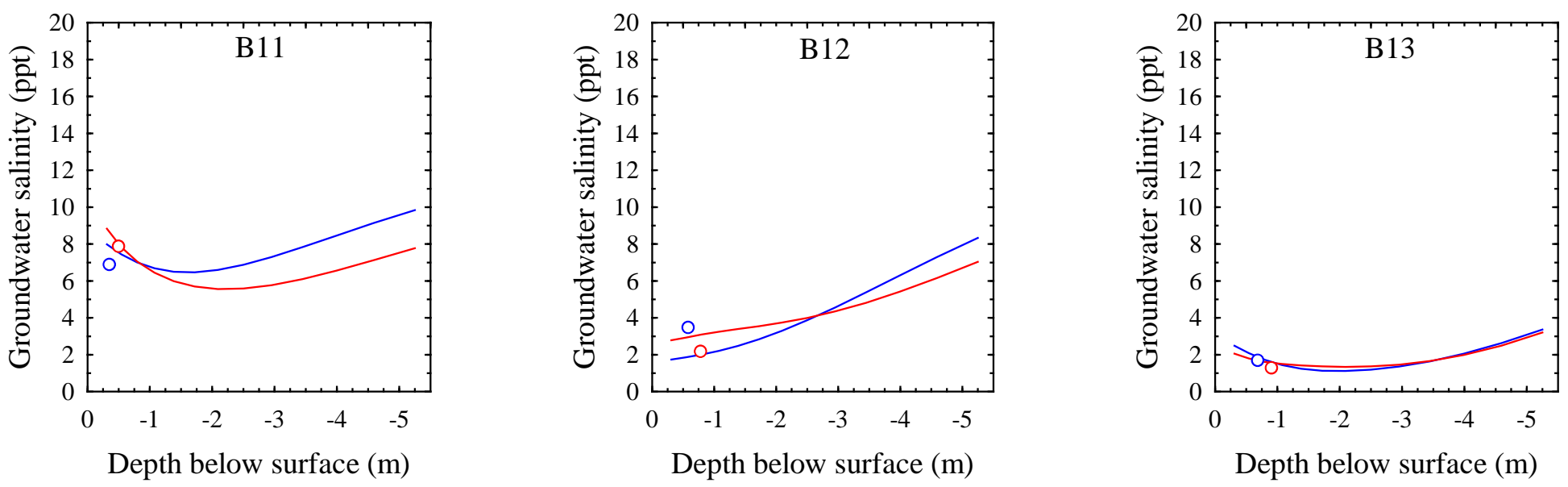

Figure 4.13 ERT-derived groundwater salinity profiles for wells on transect B1 for May 2011 (red line) and November 2011 (blue line) surveys compared to salinity measured in wells at time of each survey (circles). 

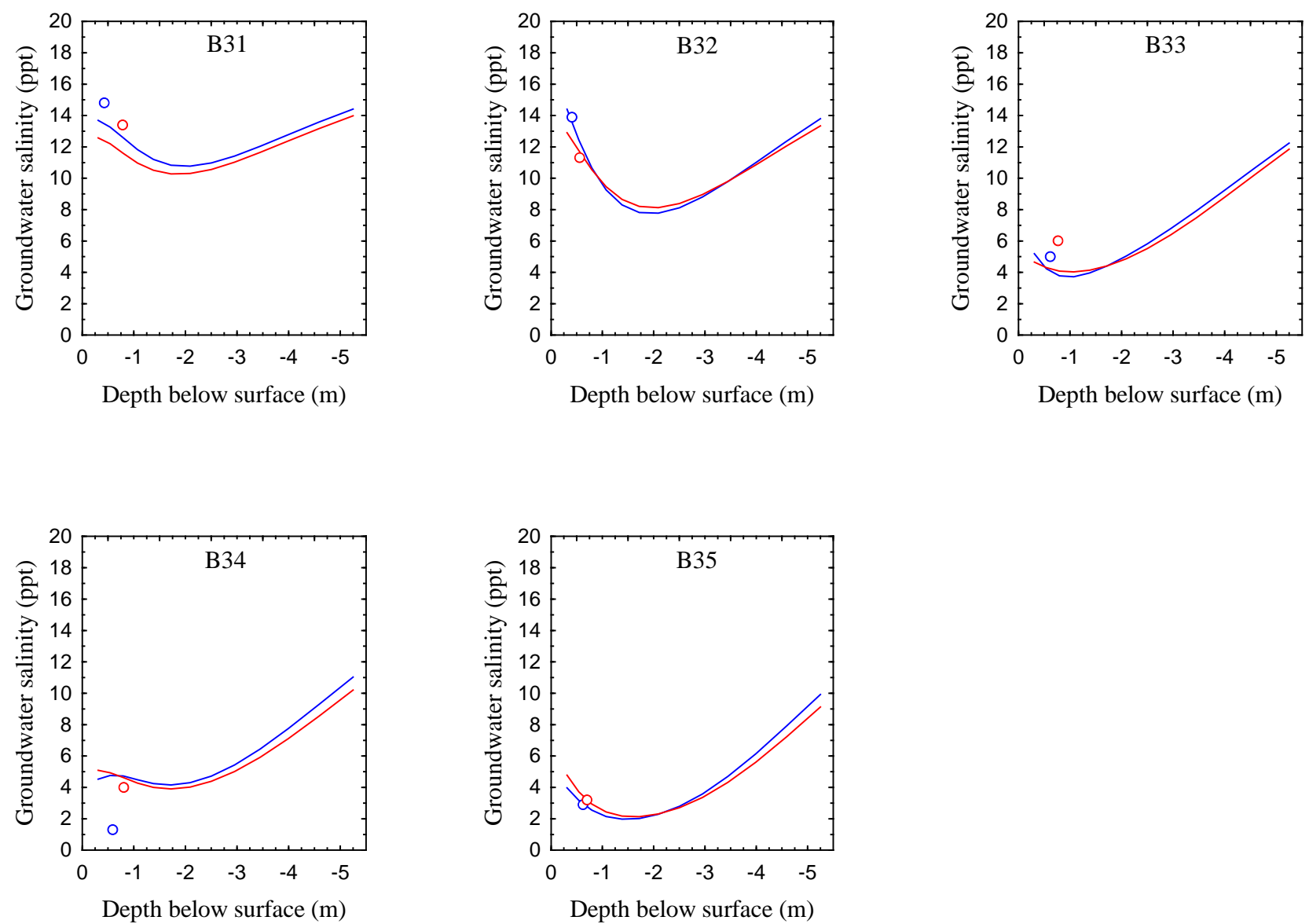

Figure 4.14 ERT-derived groundwater salinity profiles for wells on transect B3 for May 2011 (red line) and November 2011 (blue line) surveys compared to salinity measured in wells at time of each survey (circles). 

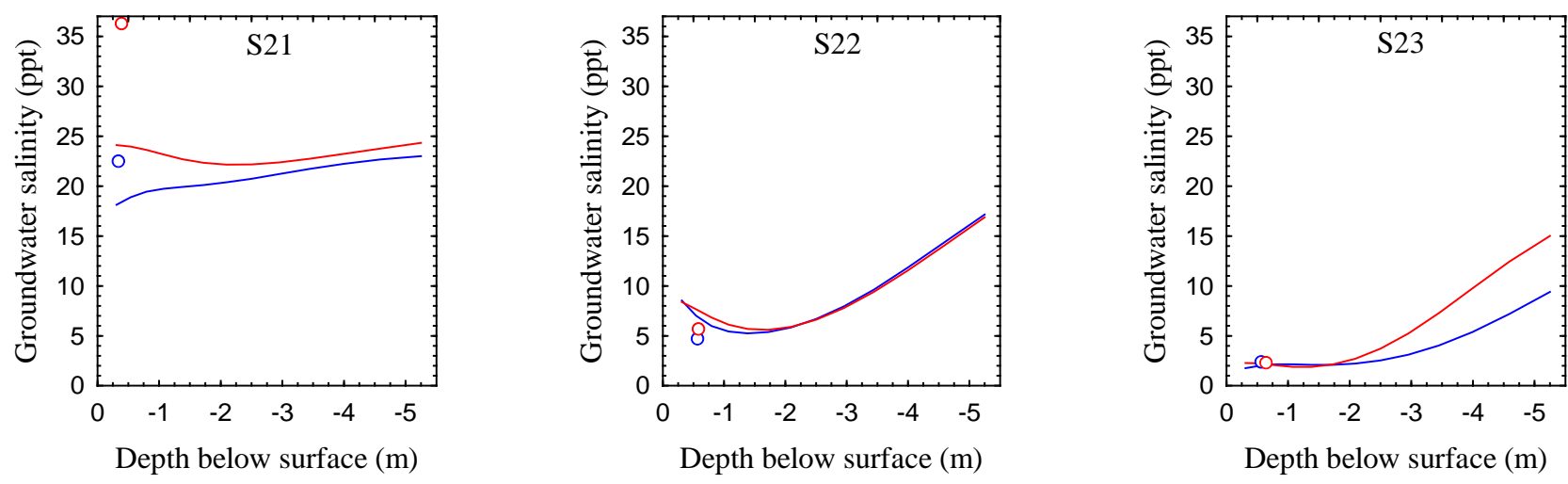

Figure 4.15 ERT-derived groundwater salinity profiles for wells on transect S2 for May 2011 (red line) and November 2011 (blue line) surveys compared to salinity measured in wells at time of each survey (circles). 

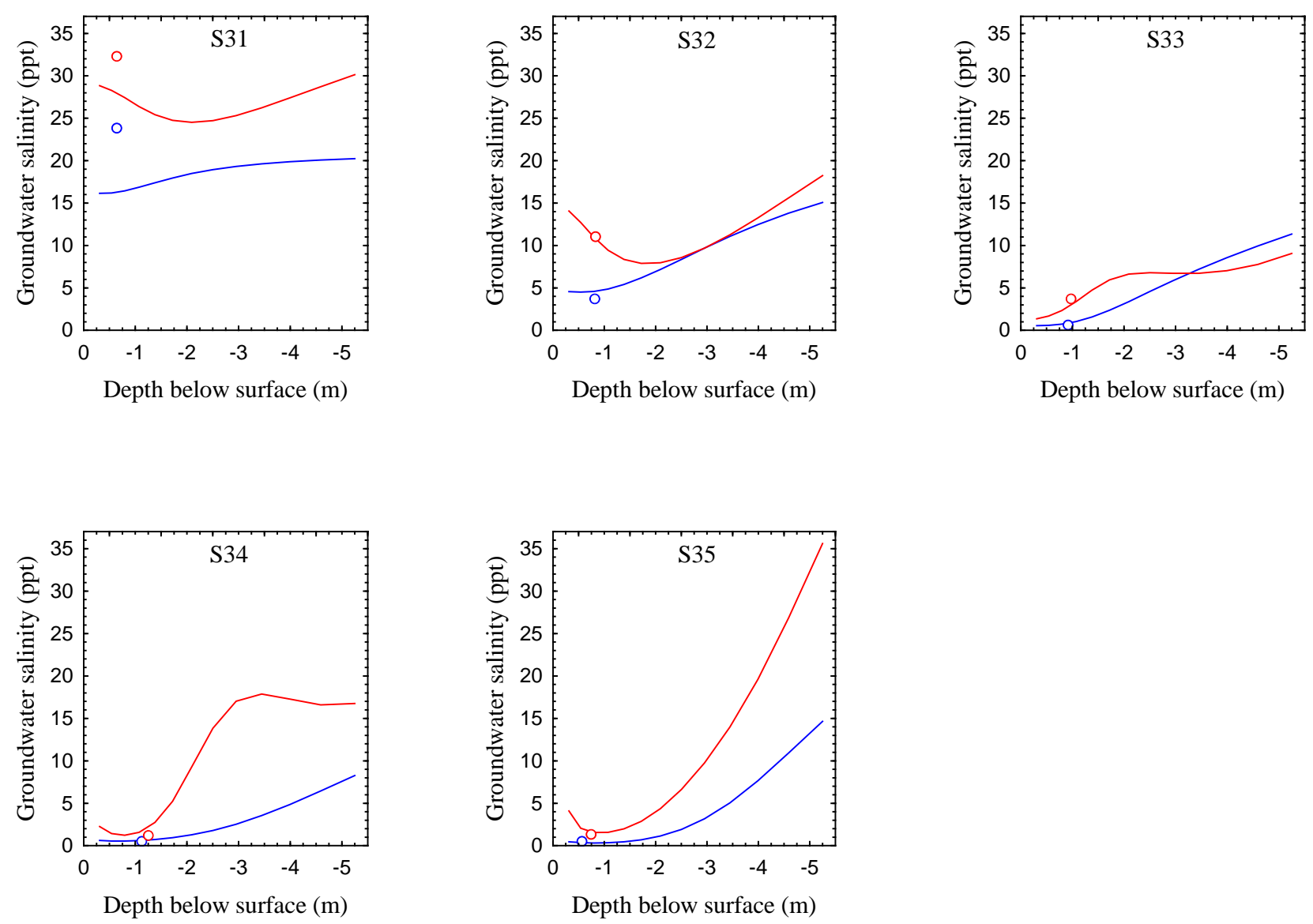

Figure 4.16 ERT-derived groundwater salinity profiles for transect S3 in May 2011 (red) and November 2011 (blue) compared to salinity measured in wells at time of each survey (circles). 


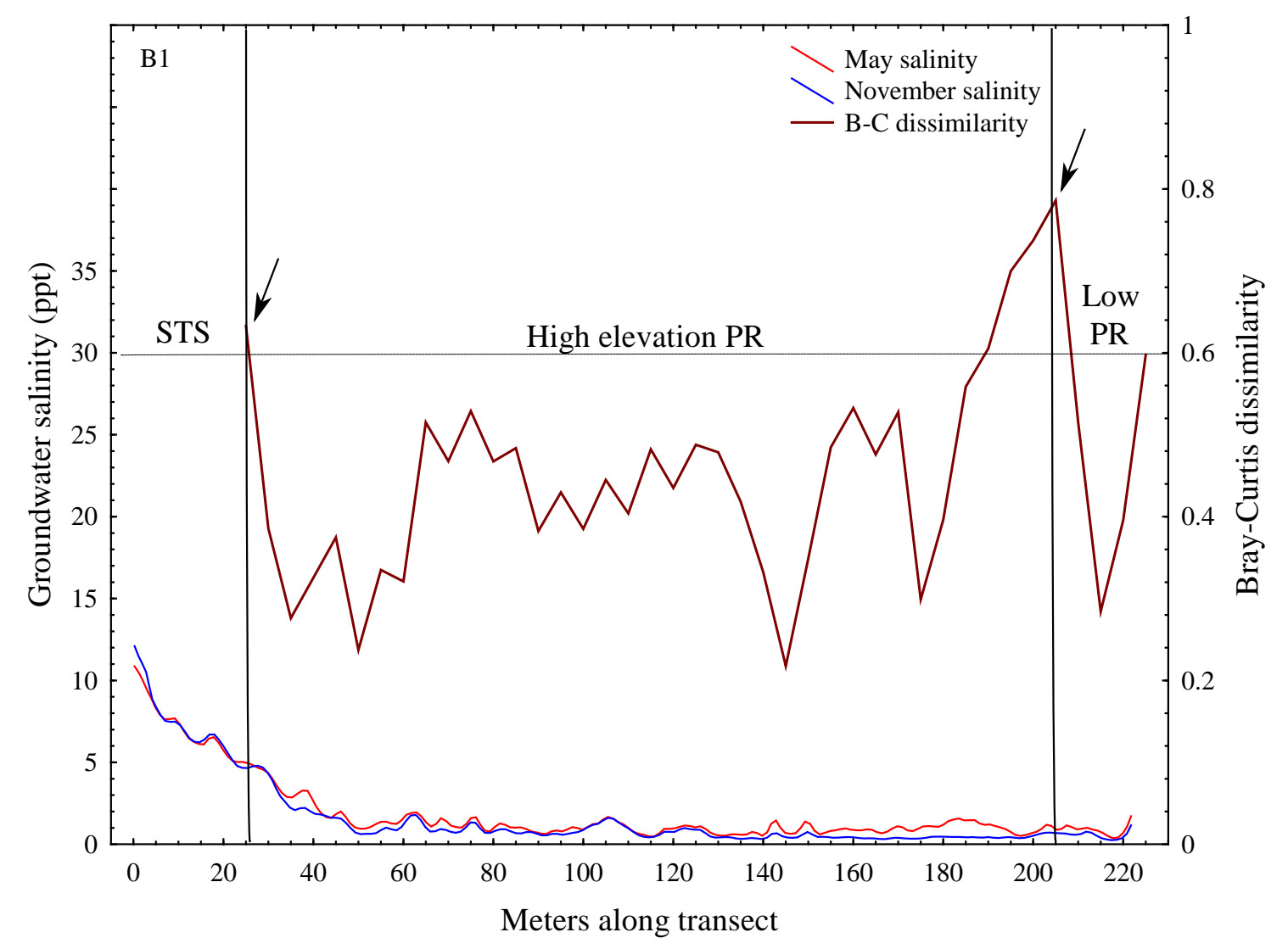

Figure 4.17 ERT-derived groundwater salinity at a depth of $107 \mathrm{~cm}$ below ground surface for May 2011 and November 2011 surveys on transect B1 with associated coastal forest communities as defined by Bray-Curtis dissimilarity for woody vegetation $\geq 1.0 \mathrm{~m}$ in height using a moving window of size 5. Arrows indicate breakpoints that distinguish boundaries between adjacent communities. Coastal forest types include: supratidal scrub (STS), high elevation pine rockland (PR), and low elevation pine rockland (PR). 


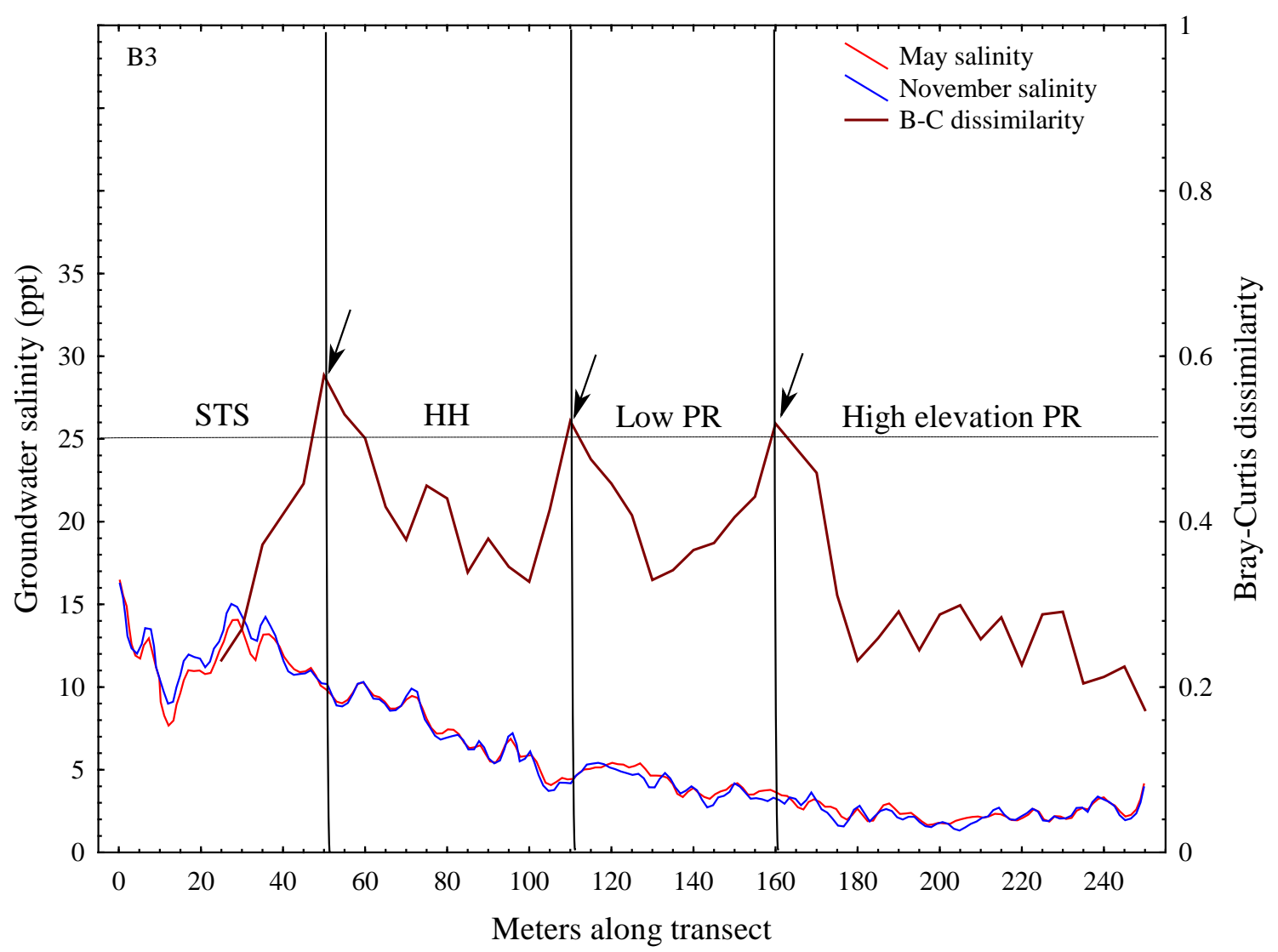

Figure 4.18 ERT-derived groundwater salinity at a depth of $107 \mathrm{~cm}$ below ground surface for May 2011 and November 2011 surveys on transect B3 with associated coastal forest communities as defined by Bray-Curtis dissimilarity for woody vegetation $\geq 1.0 \mathrm{~m}$ in height using a moving window of size 5 . Arrows indicate breakpoints that distinguish boundaries between adjacent communities. Coastal forest types include: supratidal scrub (STS), HH (hardwood hammock), low elevation pine rockland (PR), and high elevation pine rockland (PR). 


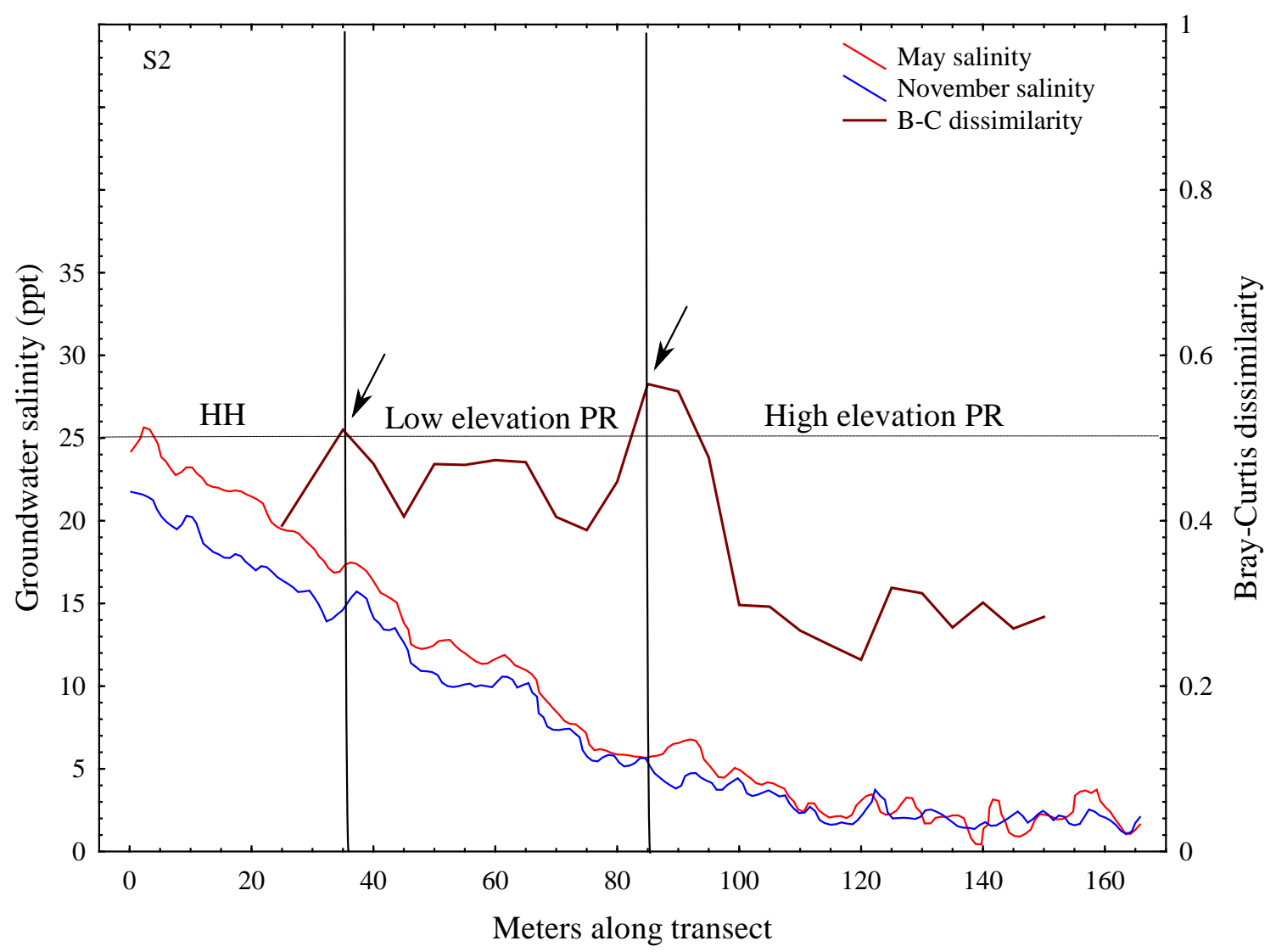

Figure 4.19 ERT-derived groundwater salinity at a depth of $107 \mathrm{~cm}$ below ground surface for May 2011 and November 2011 surveys on transect S2 with associated coastal forest communities as defined by Bray-Curtis dissimilarity for woody vegetation $\geq 1.0 \mathrm{~m}$ in height using a moving window of size 5 . Arrows indicate breakpoints that distinguish boundaries between adjacent communities. Coastal forest types include: HH (hardwood hammock), low elevation pine rockland, and high elevation pine rockland. 


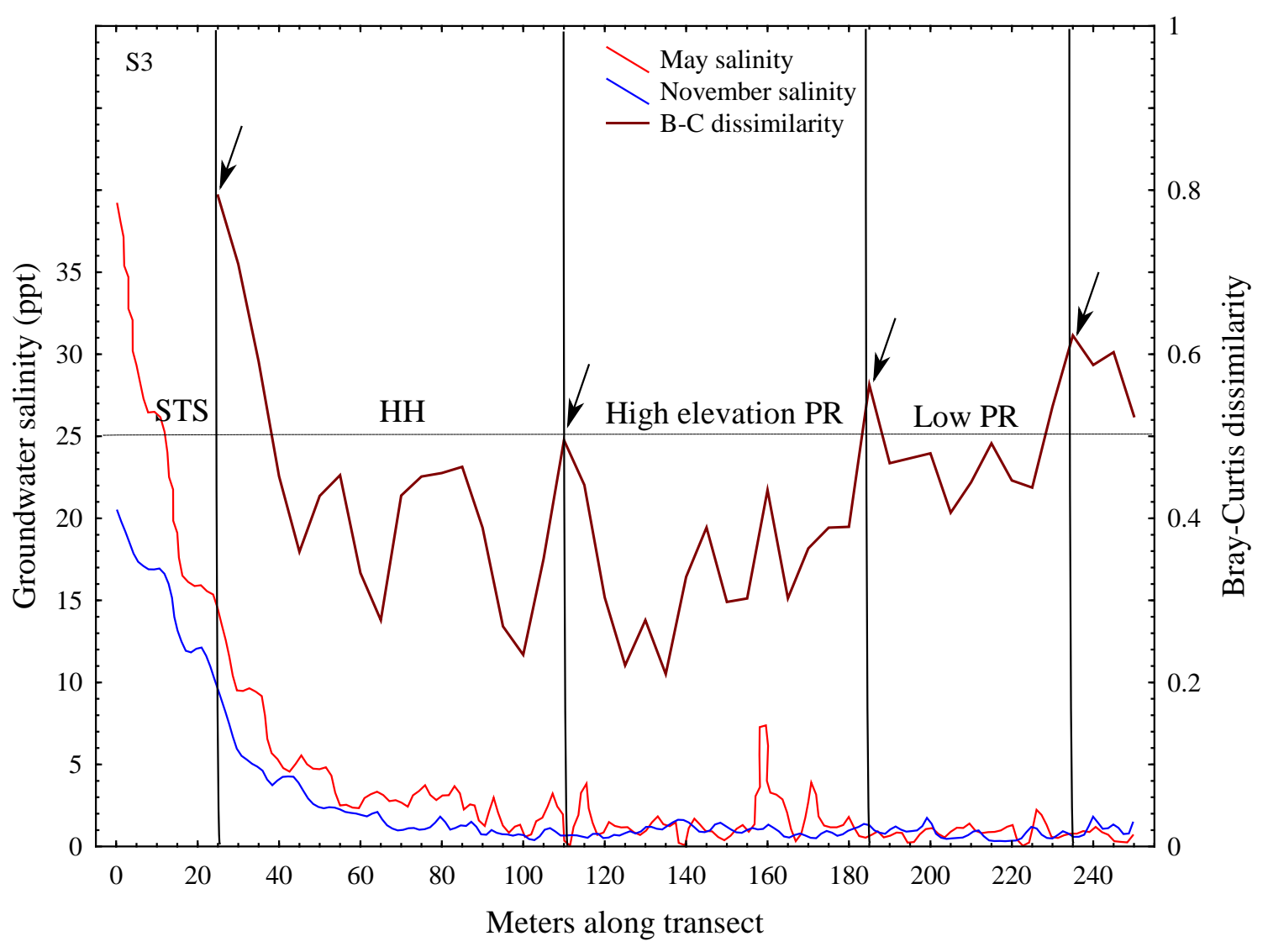

Figure 4.20 ERT-derived groundwater salinity at a depth of $107 \mathrm{~cm}$ below ground surface for May 2011 and November 2011 surveys on transect S3 with associated coastal forest communities as defined by Bray-Curtis dissimilarity for woody vegetation $\geq 1.0 \mathrm{~m}$ in height using a moving window of size 5 . Arrows indicate breakpoints that distinguish boundaries between adjacent communities. Coastal forest types include: STS (supratidal scrub), HH (hardwood hammock) high elevation pine rockland (PR), and low elevation pine rockland (PR). The zone to the right of low PR is a freshwater wetland. 


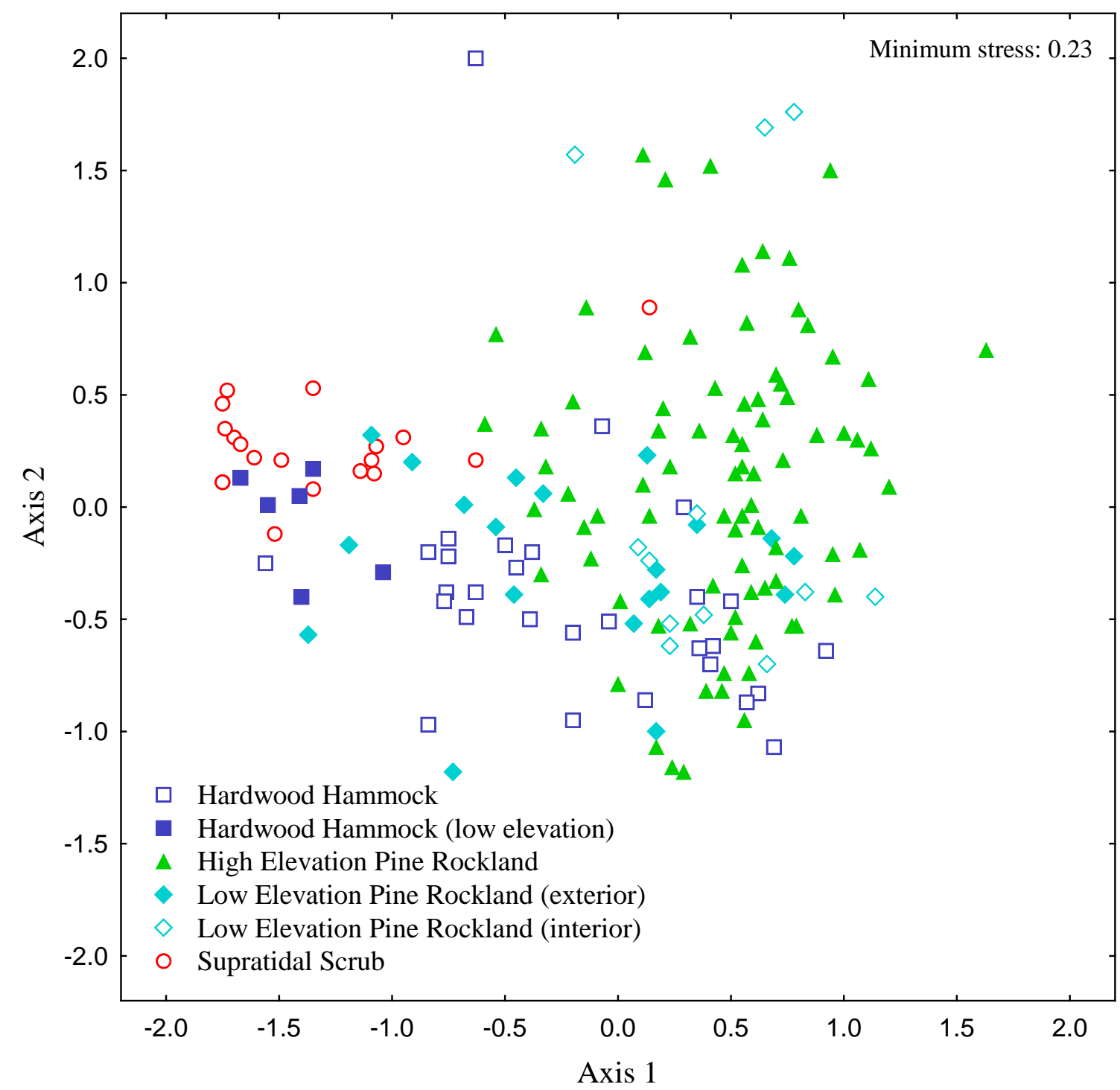

Figure 4.21 NMDS ordination of sample plots in 4 transects separated into 6 community types. Community types are as follows: hardwood hammock (purple open square), low elevation hardwood hammock (purple solid square), high elevation pine rockland (green solid triangle), exterior low elevation pine rockland (blue solid diamond), interior low elevation pine rockland (blue open diamond) and supratidal scrub (red circle), n= 169. 

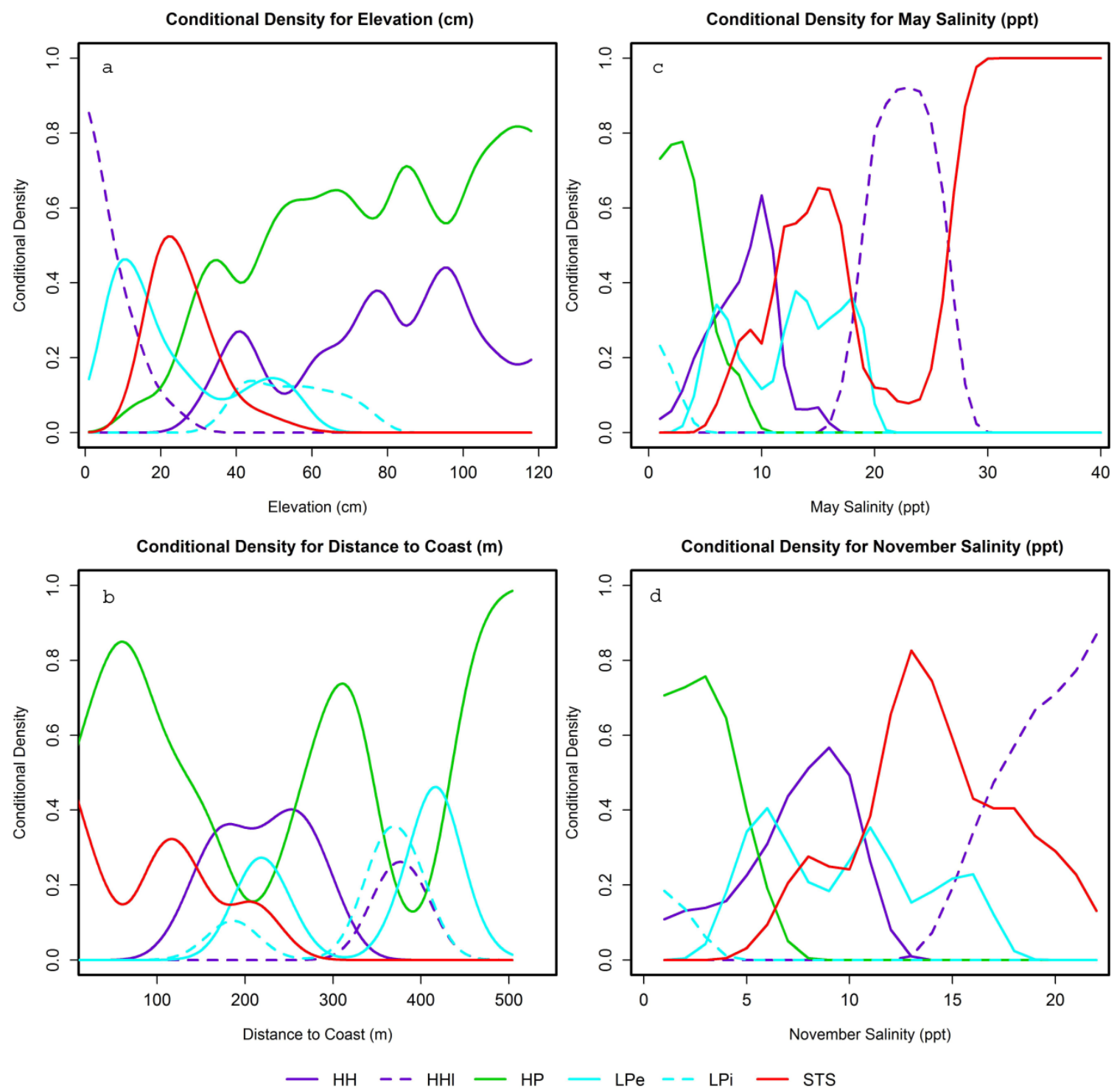

Figure 4.22 Conditional density plots of each coastal forest community type along each environmental gradient (a) elevation (cm), (b) distance to coast (m), (c) ERT-derived May 2011 salinity (ppt), and (d) ERT-derived November 2011 salinity (ppt). Community types are as follows: high elevation pine rockland (HP), hardwood hammock (HH), low elevation hardwood hammock (HHl), exterior low elevation pine rockland (LPe), interior low elevation pine rockland (LPi) and supratidal scrub (STS). 
CHAPTER 5. WATER SOURCE PARTITIONING AND PLANT STRESS IN TWO COASTAL TREE SPECIES, PINUS ELLIOTTII VAR. DENSA AND CONOCARPUS ERECTUS

\subsection{Abstract}

Seasonal drought and salinity stress co-occur in coastal communities typified by seasonality of precipitation. Glycophytic species in these communities must uptake adequate water to maintain cellular functions while minimizing salt exposure. As plant available water occurs in different pools and these pools differ isotopically, it is possible to identify the sources of water species are accessing. I investigated plant water source partitioning and plant water stress as indicated by foliar $\delta^{13} \mathrm{C}$ over temporal and spatial scales in two species dominants of lower Keys’ coastal forests, slash pine, Pinus elliottii var. densa, and buttonwood, Conocarpus erectus. For each species, I sampled stem water $\delta^{18} \mathrm{O}$ and leaf $\delta^{13} \mathrm{C}$ at three time periods (late dry season, late wet season, and mid dry season) at locations along a gradient of increasing groundwater salinity (interior freshwater lens to tidally influenced zone). Groundwater salinity was sampled on a monthly basis (May 2011 - April 2012). Both species, with the exception of buttonwood located within the tidally influenced zone, accessed a high proportion of groundwater compared to water available in the unsaturated vadose zone during the dry season sampling events, and switched to other water sources in the wet season sampling. The wet season sampling occurred two weeks after a large rain event, in which slash pine was observed to use a large percentage of soil water derived from the precipitation event. However, buttonwood used a wide variety of sources, but used a minimal amount of soil 
water derived directly from the precipitation event. Plant stress as indicated by $\delta^{13} \mathrm{C}$ increased throughout the extended drought that occurred over the study period and was highly correlated with increasing groundwater salinity. Slash pine located at sites outside the freshwater lens (sites with maximum salinity > 3ppt) had significantly larger changes in foliar $\delta^{13} \mathrm{C}$ enrichment than sites within the lens boundary.

\subsection{Introduction}

Seasonal water stress is a condition typical of plants growing in sub-humid climates. In the coastal zone where plants are growing adjacent to areas of brackish and saline water, the situation is even more pronounced as plants balance adequate water uptake while minimizing salt exposure. Woody plants have devised a variety of solutions to tolerate conditions of drought and high salinity, including those that prevent water loss through stomatal regulation and thick leaf cuticles, and mechanisms that either actively exclude salts or tolerate increased salinity in stems and leaves (Kozlowski, 1997). As most glycophytic species in terrestrial coastal forests have neither the ability to exclude salt uptake actively by roots or to sequester salt in leaves, having access year-round to a freshwater source is essential. The freshwater resources of coastal ecosystems are often in flux, driven by the tidal cycle over the course of a day, and by seasonal precipitation regimes over the year. The ability of a species to access freshwater from multiple pools and tolerate stress during episodes of fresh water scarcity are traits that allow for success and contribute to competitive dominance in coastal forest ecosystems. 
Fresh water available to plants can occur in several reservoirs, including groundwater, soil water that is tightly held in micropores, and water in soil above field capacity from recent precipitation events. Deep-rooted woody species (phreaophytes) can potentially access water from both soil and the underlying groundwater aquifer while shallow rooted species would be limited to water available in the vadose zone (Zencich et al. 2002). In coastal forests, water source partitioning and water stress are likely driven not only by species rooting depth, but also by environmental variables such as groundwater salinity and tidal inundation frequency. Additionally, the community in which the species is located could affect water source use and stress through competition or emergent properties of the community like primary production and the amount of canopy cover. Water acquisition of a species might allow it to tolerate conditions better in one environment while the same strategy puts it at a competitive disadvantage in an adjacent environment.

In the lower Florida Keys, with a seasonal precipitation regime, three freshwaterrequiring forest communities exist within close proximity to the coast and at elevations no greater than $2 \mathrm{~m}$ above mean sea level (amsl). Pine rockland, hardwood hammock, and supratidal scrub forests are arranged on these islands based on a combination of topography, inundation tolerance, groundwater salinity, and fire history (Ross et al., 1992). Across these habitat types, soils, productivity, and litter vary as a function of the underlying abiotic conditions and the species that dominate these community types. Compared to pine rocklands, hammocks typically have deeper soils, greater litter accumulations, and higher canopy cover, increasing shade and possibly soil moisture 
conditions. Pine rocklands that are subject to frequent fire have comparatively more open canopies and lower litter accumulations and minimal soil. Supratidal scrub has pockets of deep marl soil as well as exposed surficial rock, with typically minimal litter accumulation (Ross et al. 1992). The supratidal scrub is typically inundated with salt water during spring tides and storm events. Groundwater exists on these islands in the form of freshwater lenses, whose lateral extent is affected by island topography, underling bedrock, and recharge by precipitation. The three coastal forests types occur either within the boundaries of the central freshwater lens or within the mixing zone between fresh water and surrounding sea water. The depth to the shallow water table is no greater than 1.5 meters at the highest elevation, which is well within the known rooting depth for slash pine - 2 to 3 meters deep in north central Florida (van Rees and Comerford, 1986). While some species in dry tropical forests have shallow roots, many species have roots which extend several meters below the surface (Canadell et al., 1996), with trees often sending roots through bedrock to obtain water deeper within the soil/bedrock profile (Querejeta et al., 2007).

In species that access a large amount of water from the groundwater resource, the expectation is that the amount of water stress experienced by the plant is related to groundwater salinity. A species growing in a location of higher groundwater salinity should experience greater water stress than the same species growing at sites of lower groundwater salinity. Conversely, species that primarily use water from the vadose zone to meet water demands should be unaffected by underlying groundwater salinity and instead would show stress related to drought conditions. However, during the course of a 
year in a location where precipitation is distributed unevenly, temporal changes in both plant water use and water stress might be expected as plants take advantage of freshwater recharge conditions. Water use and stress caused by both drought and salt exposure should vary by species, both spatially and temporally, as species employ different strategies to balance water acquisition and tolerance to drought and salinity.

The current research considers two freshwater-requiring species that occur at the extremes of the gradient in relation to salinity tolerance, south Florida slash pine (Pinus elliottii var. densa Engelm.) and buttonwood (Conocarpus erectus L.). While pine is restricted to the pine rockland ecosystem, buttonwood occurs in all three coastal environments. Previous work has demonstrated that many hammock species rely primarily on soil water, while pines depend on groundwater for at least part of the year (Ish-Shalom et al., 1992; Ross et al., 1994). Plant stress in coastal forests has been shown to be highly correlated with the frequency of tidal inundation (Desantis et al., 2007). I ask how water source partitioning and plant water stress vary spatially along a groundwater salinity gradient from interior to near-coast locations and I follow temporal changes from the peak of the dry season through the wet season and into the middle of the subsequent dry season. For buttonwood, I additionally determine whether habitat influences either water source partitioning or plant stress. I assess water source through $\delta^{18} \mathrm{O}$ isotopes of stem water and track changes in plant stress in these two species as determined through measurements of foliar $\delta^{13} \mathrm{C}$ abundance. 


\subsection{Study Area}

Big Pine Key (BPK) (N 24.67, W 81.36) and Upper Sugarloaf Key (SLK) (N 24.66, W 81.53) are located within the lower Florida Keys, toward the distal end of the chain of islands that forms a southwest trending arc from mainland Florida. The maximum elevation in the undeveloped portions of the islands is just over $1 \mathrm{~m}$ amsl. Originating from late Pleistocene shallow marine deposits, the surficial bedrock of these islands is Miami Limestone (Hoffmeister et al., 1967) which is underlain by Key Largo Limestone at several meters or more depth (Hoffmeister and Multer, 1968). While both formations are highly permeable, the Key Largo Limestone has much greater secondary porosity with interconnected pore spaces (Coniglio and Harrison, 1983). Within the lower permeability Miami Limestone, Ghyben-Herzberg lenses form and serve as potential sources of fresh water for plants in the overlying plant communities. On Big Pine and Upper Sugarloaf Keys, the lateral extent and depths of the lenses have been established using geophysical methods (Caballero, 1993; Wightman, 1990). However, the boundary between fresh and salt water is not discrete, but is instead better described as a gradient of increasingly brackish water as one moves away from the central lens toward the coast. The lens is recharged by seasonal precipitation and water is lost from the system through evapotranspiration and discharge to the coast.

The climate of the lower Keys is humid tropical with a distinct seasonality in rainfall. The average annual precipitation is $102.2 \mathrm{~cm}$ and the monthly average temperature ranges from a minimum of $20^{\circ} \mathrm{C}$ in January to a high of $29^{\circ} \mathrm{C}$ in August (30 year average, 19842013, Key West International Airport, http://www.ncdc.noaa.gov). The wet season (June 
through October), in which approximately two-thirds of the precipitation falls annually, is followed by a prolonged dry season of 7 months (November through May). Additionally, the wet season is bimodal, with a peak in precipitation typically occurring in June, followed by another peak later in the summer. Large amounts of precipitation can accompany storm events including tropical storms and hurricanes that impact south Florida an average of every 3 years, with 15 years for category 3 - 5 storms (Keim et al., 2007). The majority of these storms impact the Keys during August through October (Elsner and Kara, 1999). The last hurricane to significantly impact the Keys, Hurricane Wilma in 2005, flooded the islands with salt water to elevations of $1 \mathrm{~m}$, but was accompanied by little precipitation (Kasper, 2007).

The freshwater-requiring coastal forests considered in this study include the following: pine rockland (PR), hardwood hammock (HH), and supratidal scrub (STS). Pine rockland, which occurs at the interior-most locations on these islands and at elevations as low as $0.3 \mathrm{~m}$ (Ross et al., 1992), is characterized by a the single-canopy dominant species, south Florida slash pine, with an understory of palm trees and woody shrubs of West Indian origin (Snyder et al., 1990). Tree heights for pine range from 10 to 14 meters and the canopy remains relatively open in the presence of frequent fire. However, fire suppression leads to succession to the hardwood hammock community (Snyder et al., 1990). Hardwood hammocks are typically found coastward of pine rockland and occur at all elevations greater than $0.2 \mathrm{~m}$ on these islands. Canopies are shorter ( $3-7$ meters in height) and denser than pine rockland. The supratidal scrub community is found coastward of both pine rockland and hardwood hammock, separating them from the 
adjacent mangrove forest that fringes the coast. It can be flooded with salt water during high tides and is dominated by the mangrove associate species Conocarpus erectus (Tomlinson, 1986). Soils of all three communities are relatively shallow (10 to $20 \mathrm{~cm}$, less in pine rockland) and much exposed rock is present particularly in pine rockland and supratidal scrub. Organic soils are found in pine rockland and hardwood hammocks and rocky marl soils are found in supratidal scrub (Ross et al., 2003).

\subsection{Materials and Methods}

\subsubsection{Climate Data}

Hourly precipitation data were obtained from a station (TS607) operated by the USFWS National Key Deer Refuge and located at the north end of Big Pine Key (N 24.72422, W 81.38864). Data were available beginning in 2007 and were downloaded from MesoWest (website maintained by the University of Utah, http://raws.wrh.noaa.gov/cgibin/roman/meso_base.cgi?stn=TS607) for the time period covering June 2007 through May 2012. Data recorded by the station were used to generate daily and monthly precipitation totals for the duration of the study period, as well as one year prior to the start of the study. Additionally, five-year monthly averages were calculated. The weather station is equipped with a tipping bucket gauge to record the amount of rainfall received.

\subsubsection{Groundwater Salinity Sampling}

Two sampling transects (ranging in length from 200 to $700 \mathrm{~m}$ ) were established on each island on land owned and managed by the USFWS National Key Deer Refuge and a small portion of private land (Figure 5.1). On Big Pine Key, an additional sampling 
location was established nearby one of the two transects within pine rockland. Groundwater salinity (ppt) was sampled in shallow monitoring wells on a monthly basis over the course the one-year study period (May 2011 - April 2012). Twenty wells were installed along these transects, including representation in each coastal forest type. Boreholes having diameters of $8.89 \mathrm{~cm}$ were drilled through bedrock to a depth of 1 to $1.25 \mathrm{~m}$ below the ground surface. PVC pipe, screened at the base for $0.5 \mathrm{~m}$ and having an internal diameter measuring $3.175 \mathrm{~cm}$, was placed in the borehole, packed with sand to a level above the well screen, and sealed with cement. Wells were named according to an alphanumeric code with the letter corresponding to the island (Big Pine or Sugarloaf), the first number corresponding to the number of each transect, and the second number corresponding to the location of the well in reference to the coast. GPS coordinates were obtained for each well using a Magellan Promark 3 system having a horizontal accuracy of $10 \mathrm{~cm}$. Prior to sampling, three well volumes were evacuated using a peristaltic pump. Groundwater salinity was sampled using a YSI model 30 handheld probe with a resolution of $0.1 \mathrm{ppt}$ and accuracy of $+/-0.1 \mathrm{ppt}$. The value was recorded at each well and the mean + - SE for the study period was calculated. Monthly groundwater salinity was plotted over the course of the study period with sites grouped by coastal forest habitat and the range of salinity for each site was calculated. Sites were categorized into three salinity zones based on the maximum groundwater salinity observed during the year. Sites with maximum groundwater salinities below 3 ppt were categorized as being within the freshwater lens (FWL). Sites having a groundwater salinity measurement greater than 3 ppt in any month were classified as being within the mixing zone (MZ), 
while sites that fluctuated in salinity by more than $10 \mathrm{ppt}$ throughout the course of the sampling period were considered tidally influenced (TDL).

\subsubsection{Collection of Source Waters and Stem Waters}

Using the stable isotopes of oxygen and hydrogen, water within a plant stem can be traced to various pools in the environment. The method relies on previous work which established that the stable isotope ratio of oxygen $\left({ }^{18} \mathrm{O} /{ }^{16} \mathrm{O}\right)$ in plant stem water was equivalent to that of the available source waters (Wershaw et al., 1966; White et al., 1985), and that the ${ }^{18} \mathrm{O} /{ }^{16} \mathrm{O}$ for freshwater in south Florida differs from that of ocean water (Sternberg and Swart, 1987). Additionally, groundwater in humid environments, not subject to saline intrusion, has approximately the same isotopic composition as that of the weighted average annual precipitation (Gat, 1980), while rain water that stays within the vadose zone (soil water) goes through isotopic fractionation from evaporative processes (Gonfiantini, 1986) leading to discrete isotopic signatures present in plant available water. Groundwater in areas located outside the central core of the freshwater lens should have a signature that is a mixture of the weighted average annual precipitation and the surrounding sea water. The water of actively transpiring trees should reflect that of recent uptake on the scale of a couple of days (James et al., 2003). Collections for water isotopic analysis were conducted on three occasions: May 2011 in the late dry season, November 2011 in the late wet season, and February 2012 in the middle of the subsequent dry season. In the vicinity of each groundwater monitoring well, five individuals of $P$. elliottii var. densa and five individuals of $C$. erectus were selected for sampling at each site located along each transect in community types where 
they were present (Figure 1). Additionally, at the most coastward sampling site on each transect, individuals of the mangrove species Rhizophora mangle L., red mangrove, Avicennia germinans (L.)L., black mangrove, and Laguncularia racemosa (L.)C.F.Gaertn., white mangrove, were also sampled where present.

At each location, a suberized stem of approximately $1 \mathrm{~cm}$ diameter was collected for stem water analysis from five mature individuals (1 stem per plant). Collected stems contained fully flushed sun leaves whenever possible. High canopy branches were accessed with a telescoping pole pruner. After removal of bark and phloem, a 3 to $4 \mathrm{~cm}$ length of stem, located at sufficient distance from leaves to avoid evaporative enrichment (Dawson and Ehleringer, 1993), was clipped and immediately placed within a glass vial with dimensions of $18 \mathrm{~cm}$ length and internal diameter of $10 \mathrm{~mm}$. After placement of a stainless steel mesh screen, vials were subsequently corked with a silicone stopper and sealed with Parafilm ${ }^{\circledR}$ to prevent evaporation. At each site, soil was collected for subsequent extraction of water from the unsaturated vadose zone, hereafter referred to as soil water. First, a small hole was dug to bedrock at 3 randomly selected locations in the vicinity of sample trees. Samples were obtained by pushing a $4 \mathrm{~cm}$ length glass vial having an internal diameter of $7 \mathrm{~mm}$ into the side of each hole at depths below the surface at approximately $5 \mathrm{~cm}$, and $10 \mathrm{~cm}$ where depth permitted, resulting in three to six soil samples collected for each site. Soil samples were similarly placed in vials and sealed. Vials were placed on dry ice during field collection and were subsequently placed in the freezer in the lab until further processing during the following week. Groundwater samples for isotopic analysis were collected at the time of each groundwater salinity 
sampling event which occurred within 1 week of stem and soil water collection. Groundwater samples were filtered with a Millipore ${ }^{\circledR}$ groundwater sampling filter of $0.45 \mu \mathrm{m}$ and were kept refrigerated in $60 \mathrm{ml}$ plastic bottles until analysis. An average value for Florida Bay water was obtained from surface samples taken near Tarpon Belly Keys (N 24.73, W 81.52) on April 26, 2011, July 25, 2011, December 7, 2011, and February 8, 2012.

Precipitation was collected at the end of each month from collectors, i.e., 2-liter reservoir glass bottles, established on both islands. At the top of each bottle, a $7.5 \mathrm{~cm}$ diameter funnel was placed securely into a silicone stopper which was vented with a small diameter needle. Collectors were of the oil-type, which uses a $1 \mathrm{~cm}$ layer of mineral oil to prevent evaporation (Scholl et al., 1996). Collectors had an outlet valve at their base to obtain a sample that minimized the amount of oil included in the sample for subsequent isotopic analysis. The total monthly volume of precipitation accumulated in the bottle was recorded. On each island, collectors were placed in open areas free of overhanging branches or obstructions. The collector on Big Pine was located on the grass outside of the refuge headquarters building. The collector on Upper Sugarloaf was located on open rock in a clearing along transect S3. Both collectors were placed on low concrete platforms approximately $5 \mathrm{~cm}$ off the ground and were housed inside a wooden box in which only the funnel opening was visible at the top to the outside. The structure provided both a stable platform and shade to further minimize potential evaporation. The weighted mean (WM) $\delta^{18} \mathrm{O}$ and $\delta^{2} \mathrm{H}$ of collected precipitation at each collector for the 
sampling period of April 2011 through March 2012 was calculated using the following equation:

$$
W M \delta=\sum_{i=1}^{n}\left(\delta_{\text {month }} * \frac{\text { Volume Pr ecip }_{\text {month }}}{\text { Volume Pr ecip }_{\text {study }}}\right)
$$

\subsubsection{Stem and Source Water Extraction and Analysis}

Stem and soil water were extracted using the cryodistillation method of Vendramini and Sternberg (2007). Following the procedure of Ellsworth and Sternberg (2015), extracted stem and soil water, groundwater, surface water, and precipitation samples were analyzed at the Laboratory of Stable Isotope Ecology in Tropical Ecosystems (LSIETE) at the University of Miami for oxygen and hydrogen isotope ratios by equilibration with carbon dioxide on a GV IsoPrime ${ }^{\mathrm{TM}}$ isotope ratio mass spectrometer (IRMS) attached to a Multiflow system. The results have a precision of $+/-0.1 \%$ and $+/-2.0 \%$ standard deviation for oxygen and hydrogen, respectively. A subset of samples from the May 2011 sample collection were analyzed on a Los Gatos DTL-100 ${ }^{\mathrm{TM}}$ liquid-water isotope analyzer having a precision of $0.1 \%$ and $+/-1.0 \%$. While values for soil samples were found to be similar on both machines, the presence of small amounts of plant alcohols in the stem water samples led to incorrect values obtained from the DTL and all subsequent samples were analyzed with the IRMS. Oxygen and hydrogen isotopic ratios for each sample were calculated according to the following equation:

$$
\delta \%=\left[\left(R_{\text {sample }} / R_{\text {SMOW }}\right)-1\right] * 1000
$$

where $R_{\text {sample }}$ and $R_{\text {SMOW }}={ }^{18} \mathrm{O} /{ }^{16} \mathrm{O}$ or ${ }^{2} \mathrm{H} / \mathrm{H}$ of the sample and standard mean ocean water (SMOW)(Craig, 1961). 


\subsubsection{Leaf Collection and Foliar $\delta^{13} \mathrm{C}$ Analysis}

The carbon isotope ratio of leaves provide an indication of the amount of water stress a plant experiences over the course of the leaf lifespan. During the process of photosynthesis, С $\mathrm{C}_{3}$ plants discriminate against the heavier carbon isotope, ${ }^{13} \mathrm{C}$, first through stomatal diffusion and secondly as a result of the carboxylation enzyme, Rubisco, according to the following equation (Farquhar et al., 1982):

$$
\delta^{13} C_{\text {plant }}=\delta^{13} C_{\text {atmosphere }}-a-(b-a) * p_{i} / p_{a}
$$

where $a$ is the fractionation factor related to stomatal diffusivity (4\%), $b$ is the fractionation factor resulting from discrimination by Rubisco (29\%), $p_{i}$ is the partial pressure of $\mathrm{CO}_{2}$ inside the leaf, $p_{a}$ is the partial pressure outside the leaf, and $\delta^{13}$ Catmosphere has been measured at $-8 \%$. When water-stressed plants reduce the stomatal opening to limit further water loss, they also limit entry of atmospheric $\mathrm{CO}_{2}$ into the leaf, leading to a decrease in the discrimination process by Rubisco against ${ }^{13} \mathrm{C}$ and subsequent enrichment in the leaf (Farquhar et al., 1982).

Ten leaves, including the petiole, were selected from each stem sampled for oxygen and hydrogen isotopes. Leaves were placed in paper bags and kept cool until they could be dried in the lab oven at $50{ }^{\circ} \mathrm{C}$ for 72 hours. After being hand-crushed and homogenized, leaf samples were placed in $2.0 \mathrm{~mm}$ polymer microcentrifuge tubes along with two $5 \mathrm{~mm}$ diameter stainless steel balls and were ground to fine powder using a Retsch ${ }^{\circledR}$ mixer mill MM 200 at a frequency of $25 \mathrm{~s}^{-1}$. Two to $3 \mathrm{mg}$ of each sample was placed in a tin Elemental MicroAnalysis capsule and rolled into a small ball. Samples were analyzed on a Finnigan Delta C Elemental Analyzer connected to an IRMS having a precision of 0.2 
+/- standard deviation for $\delta^{13} \mathrm{C}$. The instrument simultaneously analyzes samples for percent nitrogen, high values of which can also result in $\delta^{13} \mathrm{C}$ enrichment (Cordell et al 1999). The carbon isotopic ratio for each sample was calculated according to the following equation:

$$
\delta \% \mathrm{o}=\left[\left(R_{\text {sample }} / R_{P D B}\right)-1\right] * 1000
$$

where $R_{\text {sample }}$ and $R_{P D B}={ }^{13} \mathrm{C} /{ }^{12} \mathrm{C}$ of the leaf sample and that of the standard from the PeeDee beleminite formation of South Carolina.

\subsubsection{Collection of Site Environmental Variables and Species Metrics}

The GPS coordinates were obtained for each sampled tree using a Garmin GPSmap76Cx with $5 \mathrm{~m}$ horizontal accuracy (Figure 1). Diameter at breast height (dbh, in $\mathrm{cm}$ ) was measured, as was the height (m) to each tree's tallest branch, using a telescoping height pole. For trees greater than $10 \mathrm{~m}$ in height, a TruPulse ${ }^{\mathrm{TM}} 200$ laser range finder was used to measure height. For each sampling site, soil depth was measured at three randomly selected locations on 4 separate occasions. NAVD88 elevation (m) for each site was extracted from Lidar-derived digital terrain models (DTMs) having a horizontal resolution of $1 \mathrm{~m}^{2}$ for Big Pine Key and $5 \mathrm{~m}^{2}$ for Upper Sugarloaf Key (Robertson and Zhang, 2007; Zhang et al., 2010). The value for each site was obtained by averaging all pixels contained within the $10 \mathrm{~m}$ radius circle circumscribing each well. The distance to nearest coastline (DTC, in meters) was obtained for each site from the well location with the Near tool in ArcGIS 10.2. Percent species cover of all woody species having a height greater than $1 \mathrm{~m}$ was estimated at each site. A 4 meter-wide belt transect, aligned parallel to the transect, was run through each site and was divided into 5-meter intervals, such 
that percent cover was estimated in a series of $4 \mathrm{~m}$ by $5 \mathrm{~m}$ rectangular plots with an average of 4 plots per site. Cover was estimated using the following six categories, the midpoint of which was used for subsequent analyses: $1=<1 \%, 2=1-4 \%, 3=4-16 \%, 4=$ $16-32 \%$, $5=32-66 \%$, and $6=66-100 \%$. As total cover was calculated for each plot by summing the cover for each species in each plot, it was possible for total cover to be greater than $100 \%$. Therefore, mean canopy cover for each habitat was derived by standardizing by the highest mean percent cover value recorded at a site to scale the values from 0 to $100 \%$. The mean species cover of $C$. erectus and $P$. elliottii var. densa in each community type was calculated by averaging sites in which each species occurred.

\subsubsection{Data Analysis}

The percentage of groundwater being used by a plant at each site during each sample period was calculated using $\delta^{18} \mathrm{O}$ via two separate methods. The $\delta^{18} \mathrm{O}$ value was used instead of $\delta^{2} \mathrm{H}$ as plants taking in water through their roots do not fractionate $\delta^{18} \mathrm{O}$, while

some halophytic and xerophytic species have been observed to fractionate $\delta^{2} \mathrm{H}$ (Lin and Sternberg, 1993; Ellsworth and Williams, 2007). As groundwater and soil water were the only sources available for each site in May 2011 and February 2012, a two-end-member mixing model was used to determine percent groundwater use in those months, using the following equation:

$$
\% \text { Groundwater }=\frac{\left(\delta_{\text {stem }}-\delta_{\text {soil }}\right)}{\left(\delta_{\text {groundwater }}-\delta_{\text {soil }}\right)} * 100
$$

Values of $\delta^{18} \mathrm{O}$ for soil water varied slightly between $5 \mathrm{~cm}$ and $10 \mathrm{~cm}$ soil depths, but the difference was not large enough to justify separating soil layers into separate end members. For the November 2011 sampling, the large amount of precipitation received at 
the end of October necessitated the use of a three end member mixing model as the isotopic value of the water available to plants in the saturated vadose zone was different from both the groundwater and the soil water. For each stem sample, the $\delta^{18} \mathrm{O}$ value of each species, along with the corresponding groundwater, soil water (average per site), and the $\delta^{18} \mathrm{O}$ of October precipitation was input into Isosource (EPA v.1.3.1). Isosource finds the range of all possible solutions in specified small increments (1\%) when the number of potential sources is greater than $n+1$, $n$ being equal to the number of isotopes used in the mixing model (Phillips and Gregg, 2003). Combinations summing to the isotopic signature of the observed value (stem) within a specified tolerance ( 0.1 was used in this study) are considered feasible solutions. The mean value for each end-member (groundwater, soil water, and precipitation) output by Isosource was used in statistical analyses.

Linear mixed effects modeling with repeated measures (Zuur et al., 2009) was used to test the effect of groundwater salinity zone (FWL, MZ, TDL) or habitat type (PR, HH, STS), sample month (May, November, February), average groundwater salinity at a site, and the interactions between spatial and temporal factors on 1) the percentage of groundwater used by each species and 2) plant stress expressed as foliar $\delta^{13} \mathrm{C}$. Random effects of site within the month of sampling were included to address non-independence arising from repeated measures. Models were run in R v.3.1.2 (R core team, 2014) using the lmer function in the lme4 package and p-values were obtained for each effect using the Satterthwaite approximations to degrees of freedom (merModLmerTest) (Bates, D., Maechler, M., Bolker, B., and Walker S., 2014). Restricted maximum likelihood (REML) 
was used to correct the estimator for the variance. Competing models were evaluated using the krmodcomp function in the pbkrtest package with the Kenward-Roger approximation for F-test with p-value for the comparison between the full-model that included the effect in question compared to a model minus that effect (Halekoh and Højsgaard, 2014). Factor level means +/- SE (for categorical variables) and average slopes (for continuous variables) were obtained using the lsmeans package (Lenth, R. and Herva, M., 2015). P-values were obtained for pairwise contrasts using Bonferonni 2sided tests.

\subsection{Results}

\subsubsection{Climate Conditions}

The amount of precipitation received during the study period (April 2011 through March 2012) was $110.5 \mathrm{~cm}$, which is well within the average annual rainfall observed in the lower Keys. However, in more than half of the months within the period, the monthly rainfall totals fell below the 5-year average rainfall amount for that month (Figure 5.2). Since the typical leaf lifespan of $C$. erectus is 5 months (Tovilla Hernandez and de la Lanza Espino, 1999) and that of P. elliottii is up to 2 years (Sargent, 1922; Ewers and Schmid, 1981), I considered the climate conditions of the previous dry season and previous year, respectively, to have implications on foliar $\delta^{13} \mathrm{C}$ in the study species. The precipitation received in the dry season prior to the start of the study (November 2010 through April 2011) was $23.1 \mathrm{~cm}$, well below the 5-year average, while the $77.7 \mathrm{~cm}$ of rainfall in the previous wet season of June 2010 through October 2010 was near the 5year average. Thus, drought conditions were present in the lower Keys for almost 12 
months, beginning with the end of the wet season in October 2010 and extending throughout the majority of the 2011 wet season. These dry conditions were interrupted in October 2011 by the largest rain event of the year, when more than $40 \%$ of the total annual precipitation for 2011 fell over the course of five days.

\subsubsection{Groundwater Salinity}

While large rain events which occurred in July and October 2011 are reflected in the groundwater salinity of a majority of sites, in none of the community types does the groundwater salinity of all sites change to the same degree, pointing to site-specific factors of topography affecting groundwater availability (Figures 5.3, 5.4, and 5.5). At tidally influenced sites in the supratidal scrub community, the largest decreases in groundwater salinity are observed post-rain event in October, however sites return to preevent salinity in the subsequent month (Figure 5.3). At the majority of sites in hardwood hammock, decreases in groundwater salinity persist for several months (Figure 5.4), and smaller decreases were similarly persistent in the pine rocklands (Figure 5.5). Over the entirety of the study period, groundwater salinity of pine rockland sites varied from less than 1 ppt to as much as $6.7 \mathrm{ppt}$, with the majority of the sites characterized as occurring within the freshwater lens boundary and only a few sites characterized as within the mixing zone (salinities greater than 3ppt) (Table 5.1, Figure 5.5). Supratidal scrub was at the other end of the groundwater salinity range, and maximum salinities at some sites approached that of sea water (Table 5.1); these sites were characterized as tidally influenced, or located within the mixing zone (Figure 5.3). Hardwood hammock sites 
were found overlying the entire range of groundwater salinities from those within the freshwater lens to those in tidally influenced locations (Figure 5.4).

\subsubsection{Species Cover and Site Environmental Variables}

Sample locations for $P$. elliottii var. densa were restricted to pine rockland. While comprising a relatively small percentage of overall percent cover $(13.5+/-3 \%$ on average), pine trees typically contribute most to pine rockland biomass (Sah et al. 2006) (Table 5.2). In contrast, C. erectus was found across all community types with the highest percent cover in supratidal scrub and lowest in pine rockland. Tree height of sampled individuals was similar in supratidal scrub and hardwood hammock with much smaller trees available for sampling in pine rockland (Table 5.2). Soil depths were generally shallow regardless of community type, with pine rockland soils being the thinnest of the three types. Hardwood hammock had the densest canopy cover, which coincides with the relatively high values of litter production reported for this community (Ross et al., 1992).

\subsubsection{Plant Water Use End-Member Identification}

The values obtained for the weighted-mean precipitation over the study period for $\delta^{18} \mathrm{O}$ and $\delta^{2} \mathrm{H}$ on BPK and SLK were $-3.80 \%$, $-20.2 \%$, and $-3.69 \%$, $-17.43 \%$, respectively for each island, and corresponded closely to the previously reported value for precipitation collected on Long Key, located 65 km northeast of Big Pine ( -3.64\%o, -20.2\%o) (Price et al., 2008). Similarly, the average bay water value measured near Tarpon Belly Keys (1.54\%o for $\delta^{18} \mathrm{O}, 8.3 \%$ for $\left.\delta^{2} \mathrm{H}\right)$ agreed closely with previously reported values for sea

water in Biscayne Bay near Elliott Key (1.7\% for $\delta^{18} \mathrm{O}$, 14\% for $\delta^{2} \mathrm{H}$ ) (Sternberg and 
Swart, 1987). As groundwater at each sampling site is a mixture of precipitation and sea water, its isotopic characteristics should fall between these two end-members at all sites (Figure 5.6). As sites become more saline, they approach the values of the surrounding sea water for $\delta^{18} \mathrm{O}$ and $\delta^{2} \mathrm{H}$, while those within the freshwater lens fall close to the value of the weighted-mean precipitation and fall along the global mean water line (GMWL) (Figure 5.7). Tidally influenced sites have a groundwater composition more highly influenced by sea water and move off the GMWL toward the bay end-member. Soil water, which is derived from the precipitation of prior months, goes through evaporative enrichment and average values observed in each groundwater salinity zone fall approximately along an evaporative line having an origin on the GMWL (Figures 5.8, 5.9, and 5.10).

\subsubsection{Plant Water Use}

Stem water of all species fell between the soil and groundwater end-members for sites within the freshwater lens and mixing zone in May 2011, with C. erectus, P. elliottii var. densa, and mangrove species using a larger percentage of groundwater than soil water, while the opposite scenario was observed at the tidally influenced sites (Figure 5.8). In November 2011, plant stem water of samples in the freshwater lens and mixing zone sites was more depleted than both the soil water and groundwater end-members and fell on a line between October precipitation and soil water (Figure 5.9). The average soil water for all sites in all three salinity zones had similar $\delta^{18} \mathrm{O}$ values in November. The values were highly depleted compared to the average soil water in May and February, indicating the strong influence of the recent rainfall event on soil water isotopic composition. At tidally 
influenced sites, C. erectus $\delta^{18} \mathrm{O}$ values coincided closely with soil water, while mangroves values fell between soil water and groundwater. In February 2012, without a substantial rain event prior to sampling, stems again fell between the groundwater and soil water end-members (Figure 5.10). Within the freshwater lens, both $C$. erectus and $P$. elliottii plotted closer to the groundwater end-member, however in the mixing zone, $P$. elliottii primarily used soil water. At tidally influenced sites, C. erectus and mangrove species fell between the groundwater and soil water end-members, indicating the use of a combination of the two sources. Several of the C. erectus stems in the February 2012 sampling had $\delta^{18} \mathrm{O}$ values which were more highly enriched than the soil end-member. These samples were not used in calculation of percent groundwater usage as those plants may not have been actively transpiring at the time of collection. Stem water enrichment occurs in plants on stems that have been defoliated and do not yet have fully mature leaves (Ellsworth and Sternberg, 2015). While C. erectus is not drought deciduous, it does go through a period of extended dormancy during the winter months (Tomlinson, 1986), which is the most likely explanation for the enriched stem water for these samples.

The results of linear mixed effects modeling for P. elliottii var. densa considered temporal and spatial differences in the percentage of groundwater usage and included a random intercept and slope for site within sample month (Table 5.3). Significant differences in the percentage of groundwater used were found between the sampling months of May and November $(\mathrm{p}=0.004)$, but no difference was found between groundwater salinity zone (FWL vs. MZ) in any sampling month. Mean annual groundwater salinity at a site did not predict the proportion of groundwater used in any 
sampling period (Figure 5.11a). Slash pine used a large proportion of groundwater in May, but used substantially less groundwater in November when water derived from the recent rain event was available in the unsaturated zone (Table 5.4). In February, pine trees again used a higher proportion of groundwater compared to water available in the vadose zone, however a large variation in groundwater usage was observed in this month.

For C. erectus, I considered models based on the relationship between month and habitat and month and groundwater salinity zone. The model that considered sampling month, habitat, and the interaction between the two was significant $(\mathrm{p}=0.02)$ compared to the model with only month, while models that included groundwater salinity zone with month were not significant. The addition of groundwater salinity at the time of sampling to the habitat $\mathrm{x}$ month model was not significant. Similar to what was observed in slash pine, there was no relationship between mean groundwater salinity and the proportion of groundwater usage in any month (Figure 5.11b). Estimates for fixed effects in the model are presented in Table 5.5, read as the proportion of groundwater usage that varies for each factor level compared to the intercept (hardwood hammock in May 2011). On average, buttonwood used a higher proportion of groundwater in both May and February compared to November (Table 5.6). Only in the month of February was there a significant difference in proportion of groundwater used between habitat types (Figure 5.12). While the proportion of groundwater as a source varied across sample months in $C$. erectus growing in hardwood hammock and pine rockland, groundwater use did not change within the supratidal scrub habitat throughout the study period. Instead, trees in 
this habitat generally used a smaller proportion of groundwater compared to water available in the vadose zone.

In November, while both $C$. erectus and P. elliottii var. densa both continued to use groundwater, slash pine used a much larger proportion of water having a signature heavily influenced by recent precipitation and very little soil water, with the majority of sites falling in an area of the ternary plot constituting a mixture of $30 \%$ groundwater, $20 \%$ soil water, and $50 \%$ precipitation (free water in the vadose zone that had not undergone evaporation) (Figure 5.13). Conocarpus had a much wider variability of proportional water usage from all three sources.

\subsubsection{Plant Water Stress}

As assessed by foliar $\delta^{13} \mathrm{C}$, plant water stress in C. erectus was positively correlated with average annual groundwater salinity in all sample months (Figure 5.14a). As groundwater salinity increased across the study area, leaves of buttonwood were increasingly enriched in $\delta^{13} \mathrm{C}$. The addition of habitat as a categorical variable to describe the relationship between sampling month, average site groundwater salinity, and C. erectus foliar $\delta^{13} \mathrm{C}$ did not add explanatory power to the model. The preferred model considered sampling month, mean average groundwater salinity, and the interaction of the two variables (Table 5.7). The slope of the relationship between average groundwater salinity and foliar $\delta^{13} \mathrm{C}$ increased over the study period (Figure 5.14a), with significant differences between May and November $(p=0.013)$ and May and February $(p=0.03)$. This is an indication that plants at sites having greater average groundwater salinity recorded increasingly stressful 
conditions over the course of the study period. While a similar positive linear relationship between mean groundwater salinity and $\delta^{13} \mathrm{C}$ was observed in $P$. elliottii var. densa, it was not significant at $\mathrm{p}<.05$ in any month (Figure 5.14b). The lack of significance may be attributable to the lower number of sites and narrower range in groundwater salinity for pine. Additionally, despite visually increasing over the time period, the slope of the relationship between average site groundwater salinity and pine $\delta^{13} \mathrm{C}$ did not differ significantly between sampling months (Figure 5.14b). However, when the effect of the categorical variable of groundwater salinity zone (FWL or MZ) was considered in the model, differences between sampling month and zone were statistically significant (Table 5.8). While the preferred model did not include the interaction, paired contrasts between factors in that model were significant (Figure 5.15). Compared to sites on the freshwater lens, sites located in the mixing zone experienced much larger changes in foliar $\delta^{13} \mathrm{C}$ from May to February and were more enriched by the end of the study.

\subsection{Discussion}

The results of this research indicate that both P. elliottii var. densa and C. erectus access and rely on the freshwater lenses on these islands as a primary source of water throughout the year. While the time period of the study fell within a year of average annual rainfall, drought conditions preceded the study and persisted well into the typical wet season. As a result, I was able to capture plant water use and stress during extremes of the driest and wettest conditions experienced in the Keys. The species investigated in this study span the range of salinity tolerance for glycophytes, from the salt intolerant slash pine to a 
mangrove associate, buttonwood. Yet water use was not directly correlated with underlying groundwater salinity. However, the strong relationship observed between increasing groundwater salinity and enrichment in leaf $\delta^{13} \mathrm{C}$ in both species is an indication of the importance of groundwater across these communities.

\subsubsection{Plant Water Source Partitioning}

The identification of groundwater as an important freshwater source for slash pine in the dry season has been previously established in the lower Florida Keys (Ross et al., 1994), but it was not determined to what extent, if any, the proportion of groundwater used varied as a function of seasonal changes in precipitation. On mainland south Florida in a seasonally dry, but non-saline environment, species in the pine rockland community, including slash pine, have been observed to primarily use groundwater throughout the year, using a slightly smaller percentage only in the late wet season (October) (Ewe et al., 1999; Saha et al., 2009). Pines in the lower Keys used a much lower proportion of groundwater in November than reported for the same season on the mainland; instead, most of the water use was derived from a storm event that occurred two weeks prior to sampling. The tight cluster of pine in the ternary plot suggests that the species was able to switch quickly from a water conservation strategy employed during the extended dry season to utilize the pulse of fresh water from the storm event. Additionally, given the projected summer drying trend for the Caribbean region (Neelin et al., 2006), extended drought conditions could become common, necessitating a shift in thinking about climate in the Keys from one defined by wet and dry seasons as found currently in south Florida, to one increasingly typified by periods of drought punctuated by sporadic rain events 
more typical of arid regions. The ability of slash pine to take advantage of pulses in precipitation as observed in this study is likely an advantage for this species in this climate compared to species that are have slower reaction times to changes in water status.

While buttonwood similarly used a much lower proportion of groundwater on average in November across all sites, its percentage use of water within the vadose zone available from recent precipitation was much lower than for slash pine. Given the small range in groundwater salinity across the sites occupied by pine ( $\sim 3 \mathrm{ppt})$, a direct relationship between water use patterns in slash pine and groundwater salinity might not be expected. However, the lack of a relationship between groundwater salinity and buttonwood water use was a bit more surprising, given that the salinity of groundwater available to some of the sample trees approached sea water concentrations. Instead, different patterns in water use were revealed when among-community differences were explored. The high percentage of groundwater used in both May and February in the hardwood hammock is in contrast to previous work on Upper Sugarloaf Key (Ish-Shalom et al., 1992), where hammock species as a group were observed to use primarily soil water. However, buttonwood was not one of the species sampled in that study. It is possible that within the hardwood hammock, buttonwood cannot successfully compete with other species for water available in the shallow vadose zone and as a result makes use of deeper groundwater. In coastal buttonwood hammocks of Everglades National Park, buttonwood was found to use a high percentage of groundwater in the dry season and switched to soil water in the wet season (Saha et al., 2015), although the salinity underlying sites in ENP 
was much higher ( $30 \mathrm{ppt})$ in comparison to that of the hammock sites in this study $(\sim 8$ ppt). In the supratidal scrub community, buttonwood used a smaller proportion of groundwater throughout the study, though groundwater use varied widely by site and sampling period. In this tidally influenced community, the large changes in groundwater salinity make groundwater a less reliable water source, likely leading to increased site to site variability. The generally wide use of evaporatively-enriched soil water by buttonwood in November may reflect a delayed response of buttonwood to the storm event in October, perhaps signifying that its stomatal sensitivity to plant water status is lower than species better adapted to such pulse events (Schwinning and Ehleringer, 2001).

\subsubsection{Plant Water Stress}

The strong positive correlation between annual average groundwater salinity and foliar $\delta^{13} \mathrm{C}$ in buttonwood confirms my hypothesis that water stress is related to groundwater salinity in species that use a significant portion of groundwater as a water source. Species are essentially recording the availability of freshwater across the spatial dimension. Temporally, the increases in $\delta^{13} \mathrm{C}$ over the time period of the study record the extended drought that lasted well into the typical wet season in 2011. As leaf life spans differ between species, the $\delta^{13} \mathrm{C}$ value that is obtained from each sample will integrate different time periods of available resources and environmental stressors, 5 months for buttonwood and up to two years for pine. Damesin et al. (1998) report that the $\delta^{13} \mathrm{C}$ of a mature leaf is determined by differing carbon reserves at budburst, carbon assimilation at expansion, and finally assimilates produced during the onset of drought when the leaf is mature. The 
significant increase in the slope of the relationship between groundwater salinity and buttonwood $\delta^{13} \mathrm{C}$ over the course of the study suggests that as drought conditions persisted, the effects of water stress became more severe for trees located at higher groundwater salinities. In both species, the depletion in leaf $\delta^{13} \mathrm{C}$ in February compared to November, while statistically non-significant, suggests that in the aftermath of the storm event in October, conditions became less stressful for trees at many locations, despite lower than average monthly precipitation during the period from November through January.

While a significant correlation was not observed between groundwater salinity and slash pine foliar $\delta^{13} \mathrm{C}$ in any sampling period, this was likely a result of the small range in groundwater salinity among sites occupied by the species along the transects. Previous work on Upper Sugarloaf Key comparing pine at locations inside the freshwater lens $(<1$ ppt) to those within the mixing zone (8 ppt) found that pine sapwood was comparatively enriched in $\delta^{13} \mathrm{C}$ at the higher salinity site, indicative of plant stress (Ross et al., 1994). The significant difference in leaf $\delta^{13} \mathrm{C}$ for slash pine between sites within the freshwater lens compared to those located in the mixing zone, where groundwater salinities greater than 3 ppt occur during part of the year, was surprising given the small range in groundwater salinity across these sites. While increasing foliar $\delta^{13} \mathrm{C}$ enrichment over time was expected given the extended drought conditions, the larger change in $\delta^{13} \mathrm{C}$ at sites located within the mixing zone compared to those within the freshwater lens points to the importance that small changes in groundwater salinity have on this species and suggests 
that slash pine may not be able to tolerate groundwater salinities beyond a particular threshold.

\subsection{Conclusions}

The results of the study indicate that groundwater serves as significant source of water for both species throughout the year, yet each species also utilizes water from the unsaturated vadose zone as well as free water in the soil immediately following large precipitation events, but to differing degrees. The observed enrichment in foliar $\delta^{13} \mathrm{C}$ for both species over the spatial and temporal scales of the study indicates increasing plant stress related to groundwater salinity and extended drought respectively. The ability of both species to access water at depth surely plays a considerable role in their success and dominance in this low elevation island setting, where soils are poorly developed and water sources are limited. However, the future for both species on these islands is uncertain given the predicted increase in sea level by the end of the century (Rahmstorf, 2007). The reduction of the pine rockland community will surely result from mortality of slash pine exposed to groundwater salinity beyond its tolerance and subsequent invasion by woody hammock species. However, it's location in the interior of these islands makes it likely that pine rockland will persist at least until the central core of the freshwater lens reaches salinities greater than 3 ppt, assuming this is not preceded by a large storm surge event leading to widespread pine mortality. Whereas buttonwood is clearly the more salt-tolerant species of the two, evidence from a 10-year study in the coastal forests of Everglades National Park found no change in the density of adult buttonwood while white mangrove increased in density over the same period (Saha et al., 2011). The reliance by buttonwood on 
groundwater as a water source and its lack of regeneration suggests that the supratidal scrub community could be overstepped by sea level rise, especially as it accelerates (Watson et al., 2015), as groundwater salinity surpasses the tolerance of this dominant species. As a result, it is entirely possible that hardwood hammock could be the most persistent of the three freshwater-requiring communities into the $21^{\text {st }}$ century. 


\subsection{References}

Caballero, J.P., 1993. Salinity variation in the upper saturated zone of Sugarloaf Key, Florida. (M.S. Thesis). Univerisity of South Florida, Tampa, FL.

Canadell, J., Jackson, R.B., Ehleringer, R.R., Mooney, H.A., Sala, O.E., Schulze, E.D., 1996. Maximum rooting depth of vegetation types at the global scale. Oecologia 108, 583-595.

Coniglio, M., Harrison, R.S., 1983. Facies and diagenesis of late Pleistocene carbonates from Big Pine Key, FL. Bull. Can. Pet. Geol. 31, 135-147.

Craig, H., 1961. Standard for reporting concentrations of deuterium and oxygen-18 in natural waters. Science 133, 1833-1834.

Dawson, T.E., Ehleringer, J.R., 1993. Isotopic enrichment of water in the "woody" tissue of plants: implications for plant water source, water uptake, and other studies which use the stable isotopic composition of cellulose. Geochim. Cosmochim. Acta 57, 3487-3492.

Desantis, L.R.G., Bhotika, S., Williams, K., Putz, F.E., 2007. Sea-level rise and drought interactions accelerate forest decline on the Gulf Coast of Florida, USA. Glob. Change Biol. 13, 2349-2360.

Ellsworth, P.Z., Sternberg, L.S.L., 2015. Seasonal water use by deciduous and evergreen woody species in a scrub community is based on water availability and root distribution. Ecohydrology 8, 538-551.

Ellsworth, P.Z., Williams, D.G., 2007. Hydrogen isotope fractionation during water uptake by woody xerophytes. Plant Soil 291, 93-107.

Elsner, J.B., Kara, A.B., 1999. Hurricanes of the North Atlantic: Climate and Society. Oxford University Press.

Ewers, F.W., Schmid, R., 1981. Longevity of needle fascicles of Pinus longaeva (bristlecone pine) and other North American pines. Oecologia 51, 107-115.

Ewe, S.M., da Silveira Lobo Sternberg, L., Busch, D.E., 1999. Water-use patterns of woody species in pineland and hammock communities of South Florida. For. Ecol. Manag. 118, 139-148.

Farquhar, G.D., O’leary, M.H., Berry, J.A., 1982. On the relationship between carbon isotope discrimination and the intercellular carbon dioxide concentration in leaves. Funct. Plant Biol. 9, 121-137. 
Gat, J.R., 1980. The isotopes of hydrogen and oxygen in precipitation, in: Fritz, P., Fontes, J.C. (Eds.), Handbook of Environmental Isotope Geochemistry. Elsevier, Amsterdam, pp. 21-47.

Gonfiantini, R., 1986. Environmental isotopes is lake studies, in: Fritz, P., Fontes, J.C. (Eds.), Handbook of Environmental Isotope Geochemistry. Elsevier, Amsterdam, pp. 113-168.

Halekoh, U., Højsgaard, S., 2014. A Kenward-Roger approximation and parametric bootstrap methods for tests in linear mixed models-the R package pbkrtest. J. Stat. Softw. 59, 1-32.

Hoffmeister, J.E., Multer, H.G., 1968. Geology and origin of the Florida Keys. Geol. Soc. Am. Bull. 79, 1487-1502.

Hoffmeister, J.E., Stockman, K.W., Multer, H.G., 1967. Miami Limestone of Florida and its recent Bahamian counterpart. Geol. Soc. Am. Bull. 78, 175-190.

Ish-Shalom, N., Sternberg, L. da S.L., Ross, M., O’Brien, J., Flynn, L., 1992. Water utilization of tropical hardwood hammocks of the lower Florida Keys. Oecologia 92, 108-112.

James, S., Meinzer, F., Goldstein, G., Woodruff, D., Jones, T., Restom, T., Mejia, M., Clearwater, M., Campanello, P., 2003. Axial and radial water transport and internal water storage in tropical forest canopy trees. Oecologia 134, 37-45.

Kasper, K., 2007. Hurricane Wilma in the Florida Keys. National Oceanic and Atmospheric Administration (NOAA)/National Weather Service (NWS) Weather Forecast Office (WFO), Key West, FL.

Keim, B.D., Muller, R.A., Stone, G.W., 2007. Spatiotemporal patterns and return periods of tropical storm and hurricane strikes from Texas to Maine. J. Clim. 20, 34983509.

Kozlowski, T.T., 1997. Responses of woody plants to flooding and salinity. Tree Physiol. Monogr. 1, 1-29.

Lin, G., Sternberg, L. daS. L., 1993. Hydrogen isotopic fractionation by plant roots during water uptake in coastal wetland plants, in: Ehleringer, J.R., Hall, A.E., Farquhar, G.D. (Eds.), Stable Isotopes and Plant Carbon-Water Relations. Academic Press, New York, NY, pp. 497-510.

Neelin, J.D., Münnich, M., Su, H., Meyerson, J.E., Holloway, C.E., 2006. Tropical drying trends in global warming models and observations. Proc. Natl. Acad. Sci. 103, 6110-6115. 
Phillips, D.L., Gregg, J.W., 2003. Source partitioning using stable isotopes: coping with too many sources. Oecologia 136, 261-269.

Price, R.M., Swart, P.K., Willoughby, H.E., 2008. Seasonal and spatial variation in the stable isotopic composition $(\delta 18 \mathrm{O}$ and $\delta \mathrm{D})$ of precipitation in south Florida. J. Hydrol. 358, 193-205.

Querejeta, J.I., Estrada-Medina, H., Allen, M.F., Jiménez-Osornio, J.J., 2007. Water source partitioning among trees growing on shallow karst soils in a seasonally dry tropical climate. Oecologia 152, 26-36.

Rahmstorf, S., 2007. A semi-empirical approach to projecting future sea-level rise. Science 315, 368-370.

Robertson, W., Zhang, K., 2007. Big Pine Key Survey Commissioned by The Nature Conservancy: Airborne LIDAR Data and Digital Elevation Models of Big Pine Key, Florida. Miami, FL, International Hurricane Research Center Florida International University.

Ross, M.S., Coultas, C.L., Hsieh, Y.P., 2003. Soil-productivity relationships and organic matter turnover in dry tropical forests of the Florida Keys. Plant Soil 253, 479492.

Ross, M.S., O’Brien, J.J., da Silveira Lobo Sternberg, L., 1994. Sea-level rise and the reduction in pine forests in the Florida Keys. Ecol. Appl. 4, 144-156.

Ross, M.S., O’Brien, J.J., Flynn, L.J., 1992. Ecological site classification of Florida Keys terrestrial habitats. Biotropica 24, 488-502.

Sah, J.P., Ross, M.S., Snyder, J.R., Koptur, S., Cooley, H.C., 2006. Fuel loads, fire regimes, and post-fire fuel dynamics in Florida Keys pine forests. Int. J. Wildland Fire 15, 463-478.

Saha, A.K., Lobo O’Reilly Sternberg, L. da S., Miralles-Wilhelm, F., 2009. Linking water sources with foliar nutrient status in upland plant communities in the Everglades National Park, USA. Ecohydrology 2, 42-54.

Saha, A.K., Saha, S., Sadle, J., Jiang, J., Ross, M.S., Price, R.M., Sternberg, L.S.L.O., Wendelberger, K.S., 2011. Sea level rise and South Florida coastal forests. Clim. Change 107, 81-108.

Saha, S., Sadle, J., van der Heiden, C., Sternberg, L., 2015. Salinity, groundwater, and water uptake depth of plants in coastal uplands of Everglades National Park (Florida, USA). Ecohydrology 8, 128-136. 
Sargent, C.S., 1922. Manual of the trees of North America (exclusive of Mexico), 2nd ed. Houghton Mifflin Co, Boston.

Scholl, M.A., Ingebritsen, S.E., Janik, C.J., Kauahikaua, J.P., 1996. Use of precipitation and ground water isotopes to interpret regional hydrology on a tropical volcanic island: Kileauea volcano area, Hawaii. Water Resour. Res. 32, 3525-3537.

Schwinning, S., Ehleringer, J.R., 2001. Water use trade-offs and optimal adaptations to pulse-driven arid ecosystems. J. Ecol. 89, 464-480.

Snyder, J.R., Herndon, A., Robertson, W.B., 1990. South Florida rockland, in: Myers, R.L., Ewel, J.J. (Eds.), Ecosystems of Florida. University of Central Florida Press, Orlando, FL, pp. 230-277.

Sternberg, L.S.L., Swart, P.K., 1987. Utilization of freshwater and ocean water by coastal plants of southern Florida. Ecology 68, 1898-1905.

Tomlinson, P.B., 1986. The botany of mangroves. Cambridge University Press, New York, NY.

Tovilla Hernandez, C., de la Lanza Espino, G., 1999. Ecologia, produccion y aprovechamiento del mangle Conocarpus erectus L., en Barra de Tecoanapa Guerrero, Mexico. Biotropica 31, 121.

van Rees, K.C.J., Comerford, N.B., 1986. Vertical root distribution and strontium uptake of a slash pine stand on a Florida spodosol. Soil Sci. Soc. Am. J. 50, 1042-1046.

Vendramini, P., Sternberg, L. da S.L., 2007. A faster plant stem-water extraction method. Rapid Commun. Mass Spectrom. 21, 164-168.

Watson, C.S., White, N.J., Church, J.A., King, M.A., Burgette, R.J., Legresy, B., 2015. Unabated global mean sea-level rise over the satellite altimeter era. Nat. Clim. Change 5, 565-568.

Wershaw, R.L., Friedman, I., Heller, S.J., 1966. Hydrogen isotopic fractionations of water passing through trees, in: Hobson, G.D., Spear, G.C. (Eds.), Advances in Organic Geochemistry. Pergamon, New York, NY, pp. 55-67.

White, J.W.C., Cook, E.R., Lawrence, J.R., Broecher, W.S., 1985. The D/H ratios of sap in trees: implications for water sources and tree ring $\mathrm{D} / \mathrm{H}$ ratios. Geochim. Cosmochim. Acta 49, 237-246.

Wightman, M.J., 1990. Geophysical analysis and Dupuit-Ghyben-Herzberg modeling of freshwater lenses on Big Pine Key, Florida (M.S. Thesis). University of South Florida, Tampa, FL. 
Zencich, S., Froend, R., Turner, J., Gailitis, V., 2002. Influence of groundwater depth on the seasonal sources of water accessed by Banksia tree species on a shallow, sandy coastal aquifer. Oecologia 131, 8-19.

Zhang, K., Ross, M.S., Ogurcak, D.E., Houle, P., 2010. Lower Florida Keys digital terrain model and vegetation analysis for the National Key Deer Refuge (Final Report submitted to the U.S. Fish and Wildlife Service National Key Deer Refuge, Big Pine Key, FL). Florida International University, Miami, FL.

Zuur, A.F., Ieno, E.N., Walker, N.J., Saveliev, A.A., Smith, G.M., 2009. Mixed Effects Models and Extensions in Ecology with R. Springer, New York, NY. 


\subsection{Tables}

Table 5.1 Location, habitat, elevation, distance to coast (DTC), and average salinity (ppt) measured monthly during the study time period (May 2011 to April 2012) for each well with associated plant samples. Means +/- SE are reported $(n=12)$ for salinity. Elevation is the average of pixels from Lidar DTM contained within a 10 m radius circle inscribing each well. Habitat (Hab) codes: supratidal scrub (STS), hardwood hammock (HH), and pine rockland (PR). Groundwater salinity zone (GW zone): freshwater lens (FWL), mixing zone (MZ), and tidal (TDL).

\begin{tabular}{|c|c|c|c|c|c|c|c|c|}
\hline Well & Hab & $\begin{array}{c}\text { GW } \\
\text { zone }\end{array}$ & Lon (W) & Lat (N) & $\begin{array}{c}\text { Elev } \\
\text { (m) }\end{array}$ & $\begin{array}{c}\text { DTC } \\
\text { (m) }\end{array}$ & $\begin{array}{c}\text { Average } \\
\text { Salinity (ppt) }\end{array}$ & $\begin{array}{c}\text { Max } \\
\text { Salinity } \\
\text { (ppt) }\end{array}$ \\
\hline B11 & STS & MZ & 81.39357 & 24.71279 & 0.21 & 37 & $6.68+/-0.09$ & 7.50 \\
\hline B12 & PR & MZ & 81.39331 & 24.71278 & 0.56 & 53 & $2.63+/-0.16$ & 4.30 \\
\hline B13 & PR & FWL & 81.39268 & 24.71287 & 0.69 & 113 & $1.46+/-0.05$ & 1.70 \\
\hline B14 & PR & FWL & 81.39089 & 24.71289 & 0.53 & 277 & $0.73+/-0.04$ & 0.90 \\
\hline B15 & PR & FWL & 81.38957 & 24.71287 & 0.38 & 401 & $0.49+/-0.02$ & 0.60 \\
\hline B21 & STS & TDL & 81.36469 & 24.69552 & 0.19 & 191 & $19.45+/-1.79$ & 26.40 \\
\hline B22 & HH & MZ & 81.36536 & 24.69545 & 0.41 & 249 & $8.14+/-0.14$ & 9.10 \\
\hline B23 & HH & FWL & 81.36633 & 24.69549 & 0.61 & 332 & $1.64+/-0.06$ & 1.80 \\
\hline B24 & PR & FWL & 81.36842 & 24.69552 & 0.47 & 532 & $0.74+/-0.08$ & 1.50 \\
\hline B25 & PR & MZ & 81.36933 & 24.69555 & 0.57 & 621 & $2.56+/-0.12$ & 3.20 \\
\hline B26 & PR & FWL & 81.37100 & 24.69556 & 0.87 & 682 & $0.43+/-0.02$ & 0.60 \\
\hline B35 & PR & MZ & 81.36219 & 24.69186 & 0.51 & 300 & $3.08+/-0.02$ & 3.20 \\
\hline S21 & HH & TDL & 81.54875 & 24.67645 & 0.20 & 394 & $20.27+/-1.09$ & 29.10 \\
\hline S22 & PR & MZ & 81.54833 & 24.67696 & 0.35 & 456 & $5.63+/-0.19$ & 6.70 \\
\hline S23 & PR & FWL & 81.54784 & 24.67751 & 0.42 & 525 & $2.43+/-0.03$ & 2.60 \\
\hline S31 & STS & TDL & 81.54434 & 24.67871 & 0.29 & 239 & $28.40+/-1.50$ & 38.40 \\
\hline S32 & HH & MZ & 81.54451 & 24.67850 & 0.62 & 261 & $7.68+/-0.96$ & 13.30 \\
\hline S33 & HH & MZ & 81.54477 & 24.67822 & 0.80 & 295 & $2.38+/-0.30$ & 3.70 \\
\hline S34 & PR & FWL & 81.54507 & 24.67786 & 1.16 & 338 & $1.02+/-0.14$ & 1.70 \\
\hline S35 & PR & FWL & 81.54562 & 24.67717 & 0.58 & 405 & $0.95+/-0.08$ & 1.40 \\
\hline
\end{tabular}


Table 5.2 Mean +/- SE of measured site environmental variables for each habitat and study species within that habitat: supratidal scrub (STS), hardwood hammock (HH), and pine rockland (PR). Groundwater salinity was measured at each site once each month for 12 months. Species cover refers to percent cover of either Conocarpus erectus (CE) or Pinus elliottii var. densa (PE) in the particular habitat only at sites where it was sampled. Site-level (average yearly salinity, elevation, DTC, and \% species cover) $n=3$ (CE STS), 5 (CE HH), 8 (CE PR), and 7 (PE PR). Soil depth n = 45 (CE STS), 72 (CE HH), 119 (CE PR), and 104 (PE PR). Tree height n = 15 (CE STS), 25 (CE HH), 40(CE PR), and 35 (PE PR). $\quad{ }^{\mathrm{a}} \mathrm{GW}=$ groundwater. ${ }^{\mathrm{b}} \mathrm{DTC}=$ distance to coast. ${ }^{\mathrm{c}}$ Canopy cover is equal to the average total percent cover of all species having a height greater than $1 \mathrm{~m}$ in each habitat type scaled to that of hardwood hammock. ${ }^{\mathrm{d}}$ Fine litter production values were obtained from Ross et al. 2002 for those habitat types in the Keys.

\begin{tabular}{|c|c|c|c|c|}
\hline Habitat & STS & HH & PR & PR \\
\hline Species & C. erectus & C. erectus & C. erectus & P. elliottii \\
\hline Tree height (m) & $4.50+/-0.37$ & $4.56+/-0.29$ & $2.40+/-0.18$ & $9.70+/-0.50$ \\
\hline Species Cover (\%) & $66.11+/-7.02$ & $36.03+/-14.29$ & $10.57+/-4.82$ & $13.51+/-3.1$ \\
\hline Soil Depth (cm) & $10.70+/-0.53$ & $11.42+/-0.54$ & $7.97+/-0.29$ & $7.67+/-0.32$ \\
\hline Mean GW ${ }^{\mathrm{a}}$ Sal. (ppt) & $18.18+/-5.33$ & $8.02+/-3.05$ & $2.02+/-0.57$ & $1.64+/-0.38$ \\
\hline Elevation (m) & $0.23+/-0.03$ & $0.53+/-0.09$ & $0.48+/-0.03$ & $0.66+/-0.10$ \\
\hline DTC $^{\mathrm{b}}(\mathrm{m})$ & $156+/-51.7$ & $306+/-24.1$ & $409+/-59.3$ & $426+/-70.3$ \\
\hline Canopy Cover $^{\mathrm{c}}$ & 0.45 & 1.0 & 0.45 & 0.64 \\
\hline Litter $^{\mathrm{d}}\left(\mathrm{g} / \mathrm{m}^{2} / \mathrm{yr}\right)$ & $176-376$ & $460-485$ & $281-409$ & $281-409$ \\
\hline
\end{tabular}


Table 5.3 Estimate and standard error for each fixed effect from linear mixed effect modeling of $P$. elliottii var. densa proportion groundwater use for 7 sites in 3 sample periods (May 2011, November 2011, and February 2012). $\mathrm{n}=102$

\begin{tabular}{|l|c|c|c|c|}
\hline Fixed Effect & Estimate & SE & df & p-value \\
\hline Intercept (May 2011) & 0.64 & 0.05 & 6 & $<0.001$ \\
\hline Month (Nov 2011) & -0.34 & 0.06 & 6 & 0.0013 \\
\hline Month (Feb 2012) & -0.08 & 0.06 & 5.88 & $\mathrm{~ns}$ \\
\hline
\end{tabular}

Table 5.4 Mean, standard error, and upper and lower 95\% confidence interval (CI) for each sampling month for $P$. elliottii var. densa proportion groundwater usage for 7 sites in 3 sample periods (May 2011, November 2011, and February 2012) (n = 102).

\begin{tabular}{|c|c|c|c|}
\hline Month & Mean +/- SE & Lower 95\% CI & Upper 95\% CI \\
\hline May 2011 & $0.64+/-0.05$ & 0.52 & 0.77 \\
\hline Nov 2011 & $0.31+/-0.03$ & 0.22 & 0.39 \\
\hline Feb 2012 & $0.57+/-0.07$ & 0.39 & 0.74 \\
\hline
\end{tabular}

Table 5.5 Estimate and standard error for each fixed effect from linear mixed effect modeling of $C$. erectus proportion groundwater use for 16 sites in 3 sample periods (May 2011, November 2011, and February 2012) $(n=219)$.

\begin{tabular}{|l|c|c|c|c|}
\hline Fixed Effect & Estimate & SE & df & p-value \\
\hline Intercept (May 2011 HH) & 0.81 & 0.1 & 13.09 & $<0.001$ \\
\hline Habitat (PR) & -0.16 & 0.13 & 13.07 & ns \\
\hline Habitat (STS) & -0.40 & 0.16 & 13.15 & 0.03 \\
\hline Month (Nov 2011) & -0.54 & 0.10 & 13.11 & $<0.001$ \\
\hline Month (Feb 2012) & 0.14 & 0.09 & 12.43 & ns \\
\hline Habitat (PR) : Month (Nov 2011) & 0.20 & 0.13 & 13.12 & ns \\
\hline Habitat (STS) : Month (Nov 2011) & 0.58 & 0.17 & 12.97 & 0.004 \\
\hline Habitat (PR) : Month (Feb2012) & -0.20 & 0.11 & 12.84 & 0.097 \\
\hline Habitat (STS) : Month (Feb2012) & -0.28 & 0.14 & 12.82 & 0.075 \\
\hline
\end{tabular}


Table 5.6 Mean, standard error, and upper and lower 95\% confidence interval (CI) for each sampling month for proportion groundwater usage by C. erectus for 16 sites in 3 sample periods (May 2011, November 2011, and February 2012) $(n=219)$.

\begin{tabular}{|c|c|c|c|}
\hline Month & Mean +/- SE & Lower 95\% CI & Upper 95\% CI \\
\hline May 2011 & $0.65+/-0.06$ & 0.52 & 0.79 \\
\hline Nov 2011 & $0.32+/-0.04$ & 0.24 & 0.40 \\
\hline Feb 2012 & $0.64+/-0.08$ & 0.47 & 0.81 \\
\hline
\end{tabular}

Table 5.7 Estimate and standard error for each fixed effect from linear mixed effect modeling of C. erectus $\delta^{13} \mathrm{C}$ for 16 sites in 3 sample periods (May 2011, November 2011, and February 2012) $(n=237)$.

\begin{tabular}{|l|c|c|c|c|}
\hline Fixed Effect & Estimate & SE & df & p-value \\
\hline (Intercept) (May 2011) & -29.45 & 0.19 & 14.4 & $<0.001$ \\
\hline Month (Nov 2011) & -0.17 & 0.13 & 19.14 & $\mathrm{~ns}$ \\
\hline Month (Feb2012) & -0.08 & 0.13 & 103.91 & $\mathrm{~ns}$ \\
\hline Average site salinity & 0.09 & 0.02 & 14.76 & $<0.001$ \\
\hline Month (Nov 2011) : Ave salinity & 0.04 & 0.01 & 20.08 & 0.003 \\
\hline Month (Feb 2012): Ave salinity & 0.04 & 0.01 & 107.83 & 0.004 \\
\hline
\end{tabular}

Table 5.8 Estimate and standard error for each fixed effect from linear mixed effect modeling of $P$. elliottii var. densa foliar $\delta^{13} \mathrm{C}$ for 7 sites in 3 sample periods (May 2011, November 2011, and February 2012) ( $\mathrm{n}=105)$.

\begin{tabular}{|l|c|c|c|c|}
\hline Fixed Effect & Estimate & SE & df & p-value \\
\hline Intercept (May 2011 FWL) & -29.60 & 0.18 & 6.86 & $<0.001$ \\
\hline Month (Nov 2011) & 0.78 & 0.23 & 6.23 & 0.015 \\
\hline Month (Feb 2012) & 0.92 & 0.17 & 6.18 & 0.002 \\
\hline GW salinity zone (MZ) & 1.01 & 0.28 & 8.84 & 0.006 \\
\hline
\end{tabular}




\subsection{Figures}
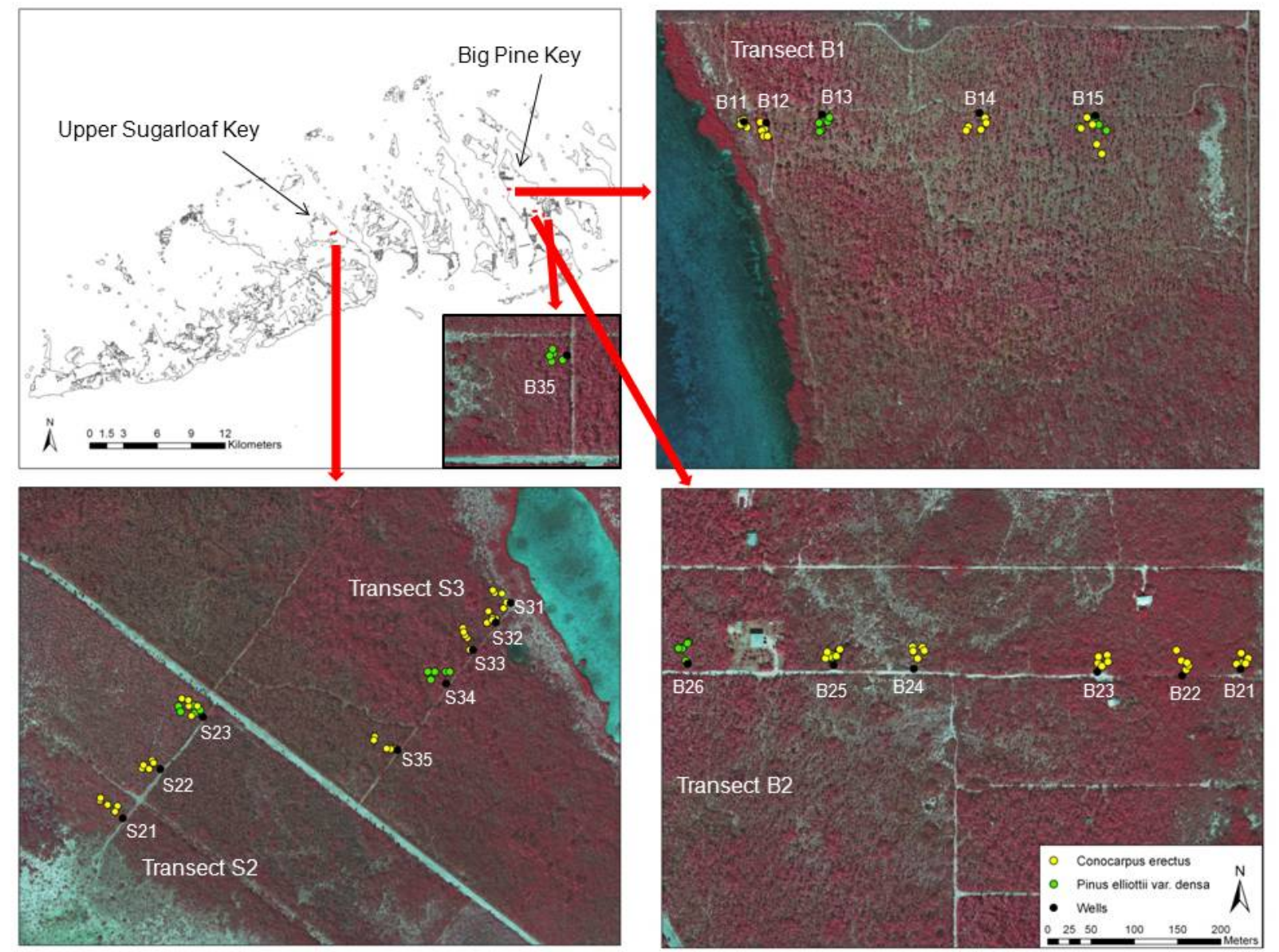

Figure 5.1 Transects on BPK (B1 - B3) and SLK (S2 - S3) with locations marked for each well and sampled trees. 


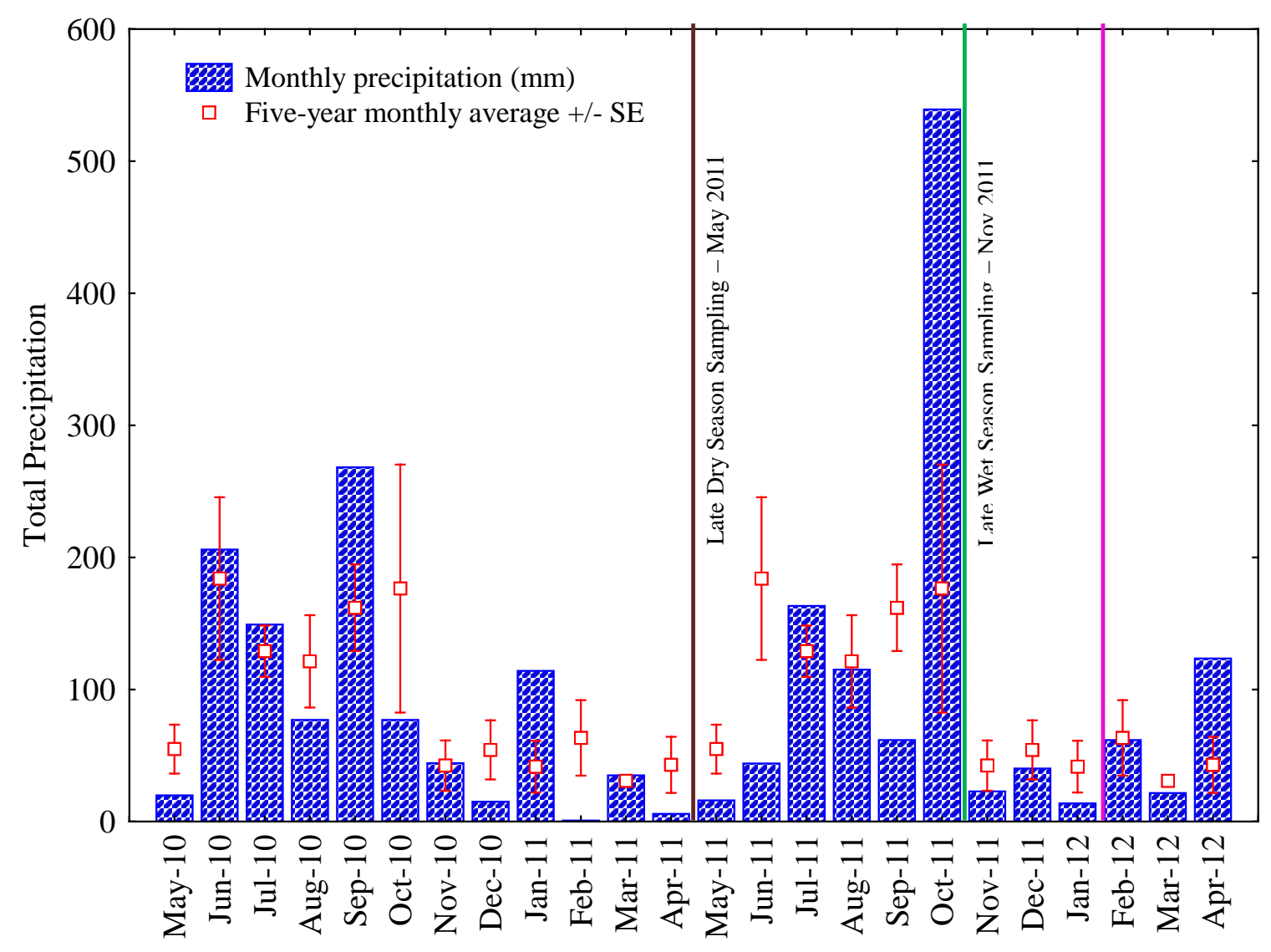

Figure 5.2 Total precipitation (mm) received on Big Pine Key for each month beginning in May 2010 through the end of the groundwater sampling period, April 2012. Five-year average monthly precipitation totals +/- SE for the time period beginning June 2007 through May 2012 are shown for comparison. Stem and leaf sampling occurred at the beginning of the month in May 2011, November 2011, and February 2012. 


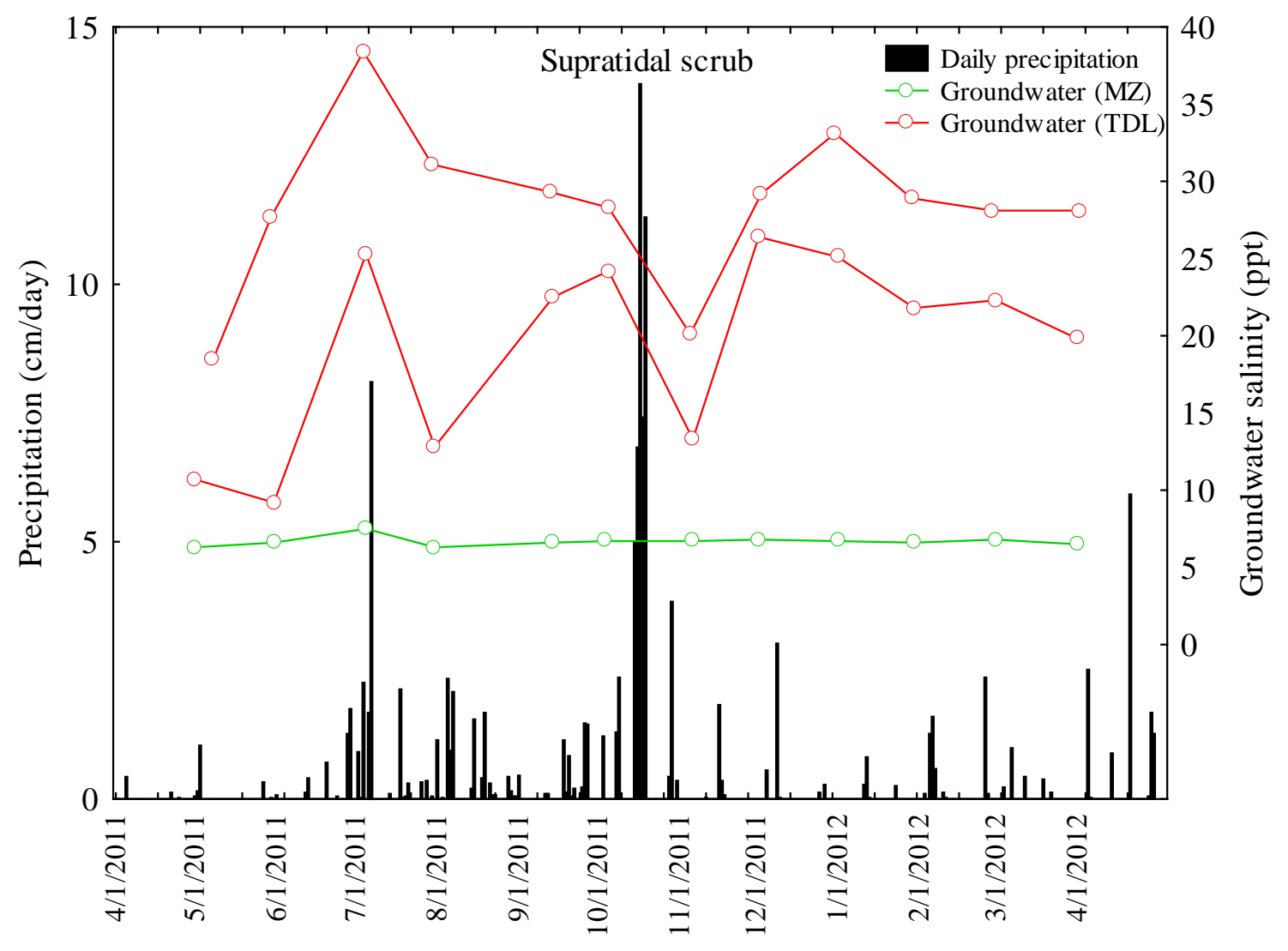

Figure 5.3 Monthly (May 2011 - April 2012) groundwater salinity (ppt) in monitoring wells (right $y$-axis) located in the supratidal scrub (STS) community with daily precipitation totals (cm) from April 1, 2011 to April 30, 2012 (left y-axis). Groundwater salinity zone codes: freshwater lens (FWL) and mixing zone (MZ). 


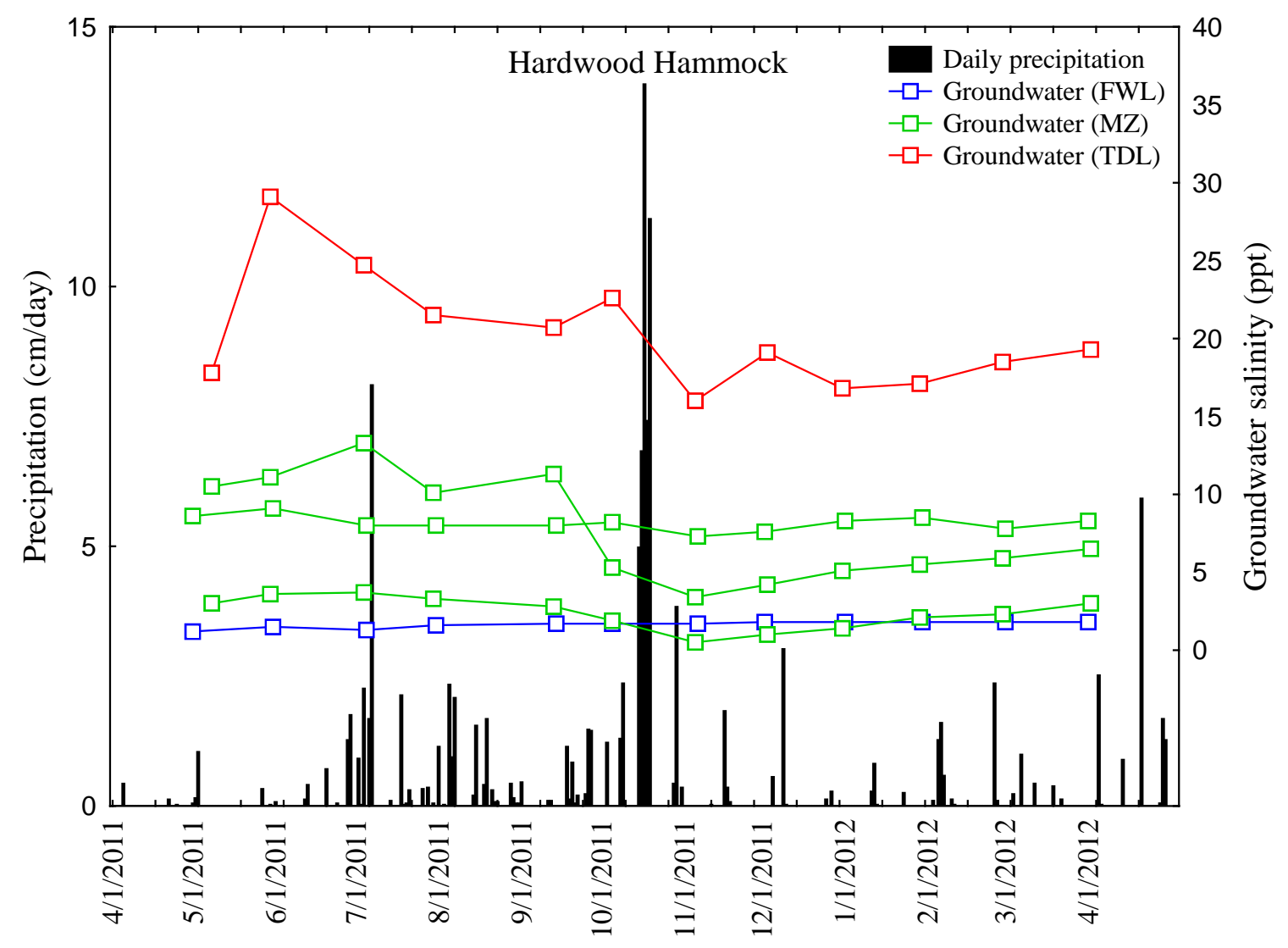

Figure 5.4 Monthly (May 2011 - April 2012) groundwater salinity (ppt) in monitoring wells (right y-axis) located in the hardwood hammock $(\mathrm{HH})$ community with daily precipitation totals (cm) from April 1, 2011 to April 30, 2012 (left y-axis). Groundwater salinity zone codes: freshwater lens (FWL), mixing zone (MZ), and tidal (TDL). 


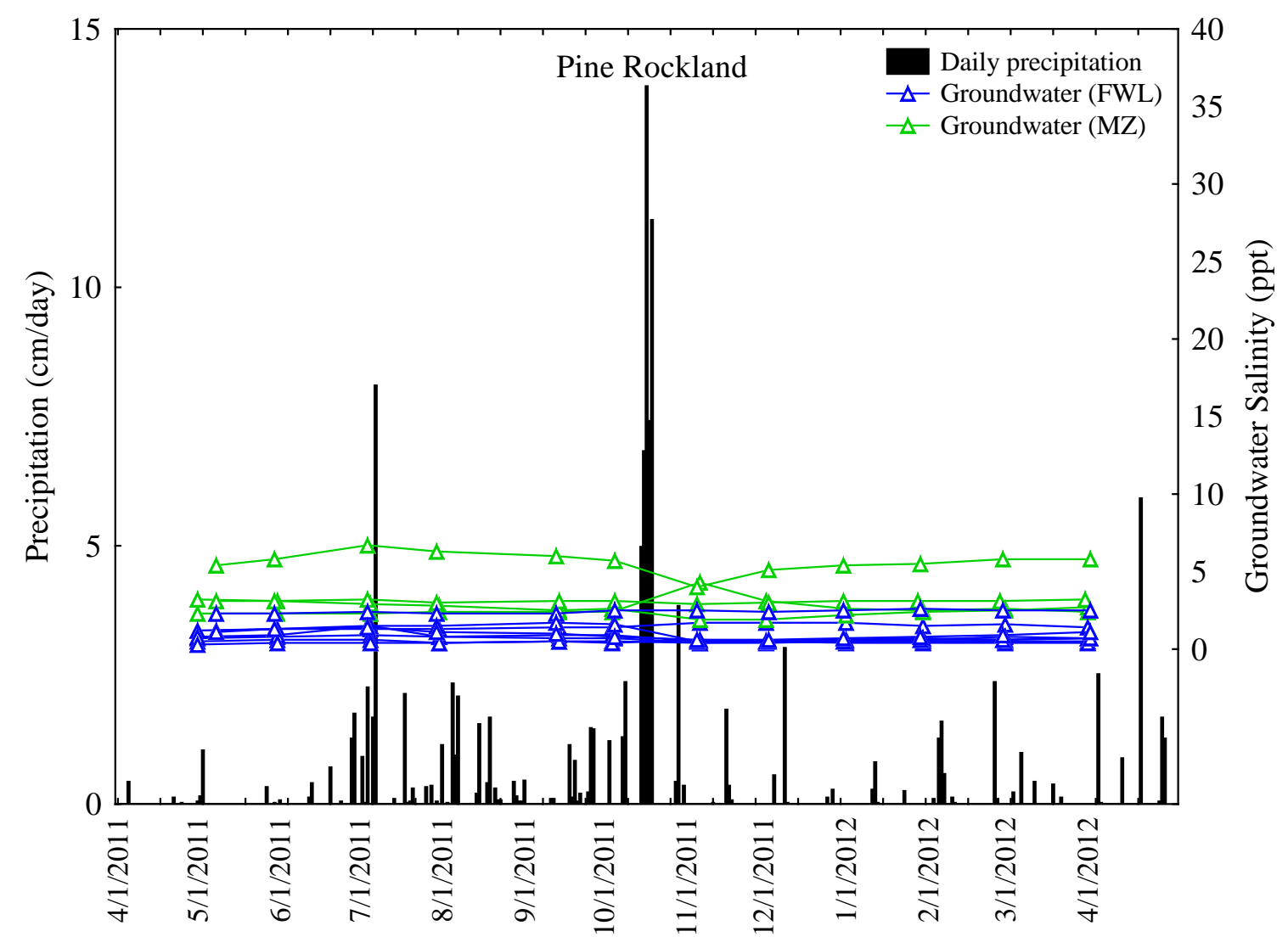

Figure 5.5 Monthly (May 2011 - April 2012) groundwater salinity (ppt) in monitoring wells (right y-axis) located in the pine rockland (PR) community with daily precipitation totals (cm) from April 1, 2011 to April 30, 2012 (left y-axis). Groundwater salinity zone codes: mixing zone (MZ) and tidal (TDL). 


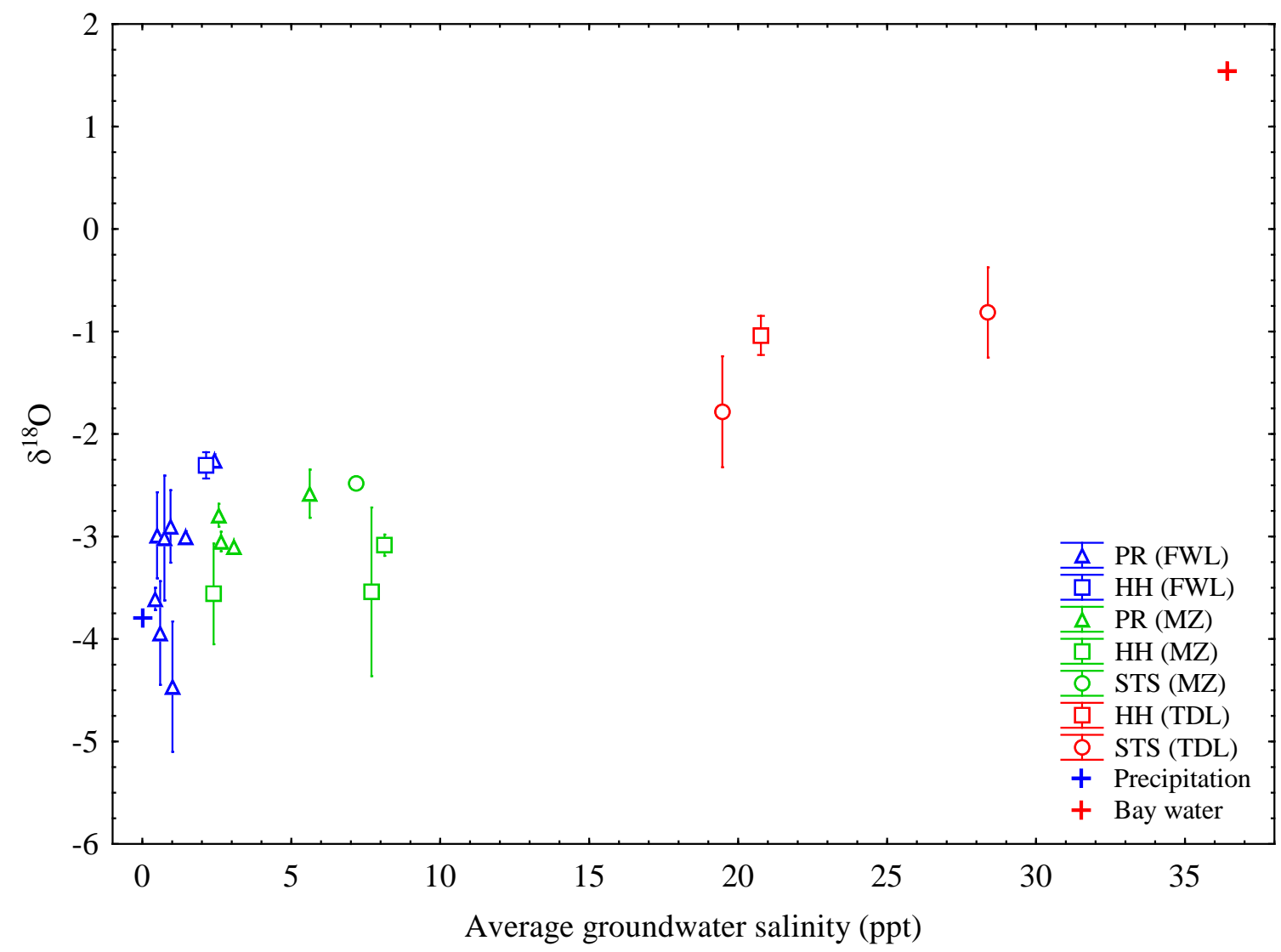

Figure 5.6 Relationship between average salinity and mean +/- SE for $\delta^{18} \mathrm{O}$ (\%) of groundwater at all sample sites organized by coastal forest community (pine rockland PR, hardwood hammock - HH, and supratidal scrub - STS) and groundwater salinity zone (freshwater lens - FWL, mixing zone - MZ, and tidal - TDL) for the three sample months (May 2011, November 2011, and February 2012). Bay water is the average value $(\mathrm{n}=4)$ from surface samples taken near Tarpon Belly Keys ( $\mathrm{N} 24.73$, W 81.52) on $4 / 26 / 11,7 / 25 / 11,12 / 7 / 11$, and 2/8/12. Precipitation is the weighted average value $(n=12)$ of monthly collections on Big Pine Key beginning April 3, 2011 and ending April 2, 2012. 


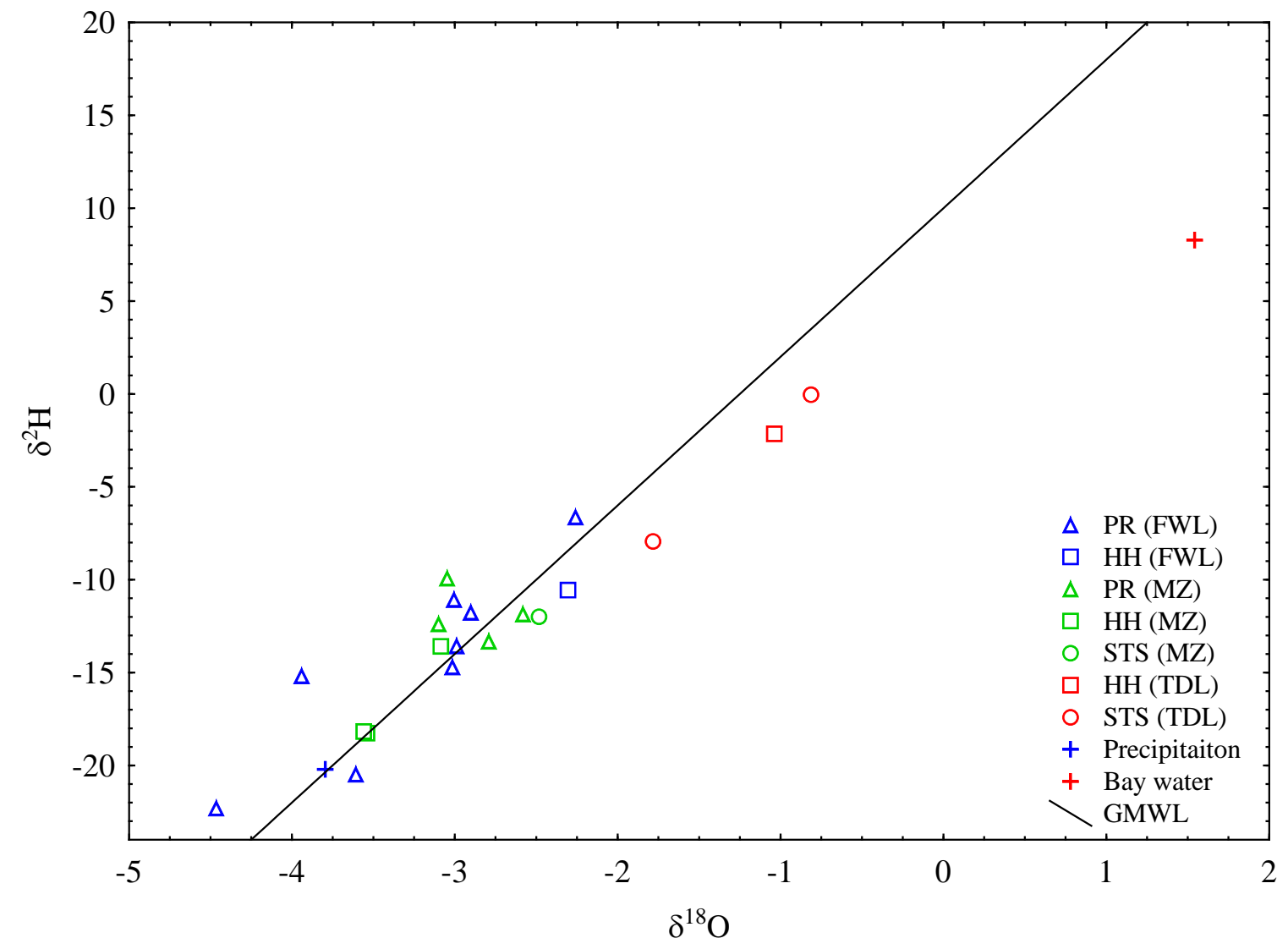

Figure 5.7 Average $\delta^{18} \mathrm{O}$ and $\delta^{2} \mathrm{H}$ (\%o) of groundwater at all sample sites organized by coastal forest community (pine rockland - PR, hardwood hammock - $\mathrm{HH}$, and supratidal scrub - STS) and groundwater salinity zone (freshwater lens - FWL, mixing zone - MZ, and tidal - TDL) for three sample months (May 2011, November 2011, and February 2012). Bay water is the average value $(n=4)$ from surface samples taken near Tarpon Belly Keys (N 24.73, W 81.52) on 4/26/11, 7/25/11, 12/7/11, and 2/8/12. Precipitation is the weighted average value $(n=12)$ of monthly collections on Big Pine Key beginning April 3, 2011 and ending April 4, 2012. Global mean water line (GMWL): $\delta^{2} \mathrm{H}=\delta^{18} \mathrm{O} * 8$ $+10 \%$. 


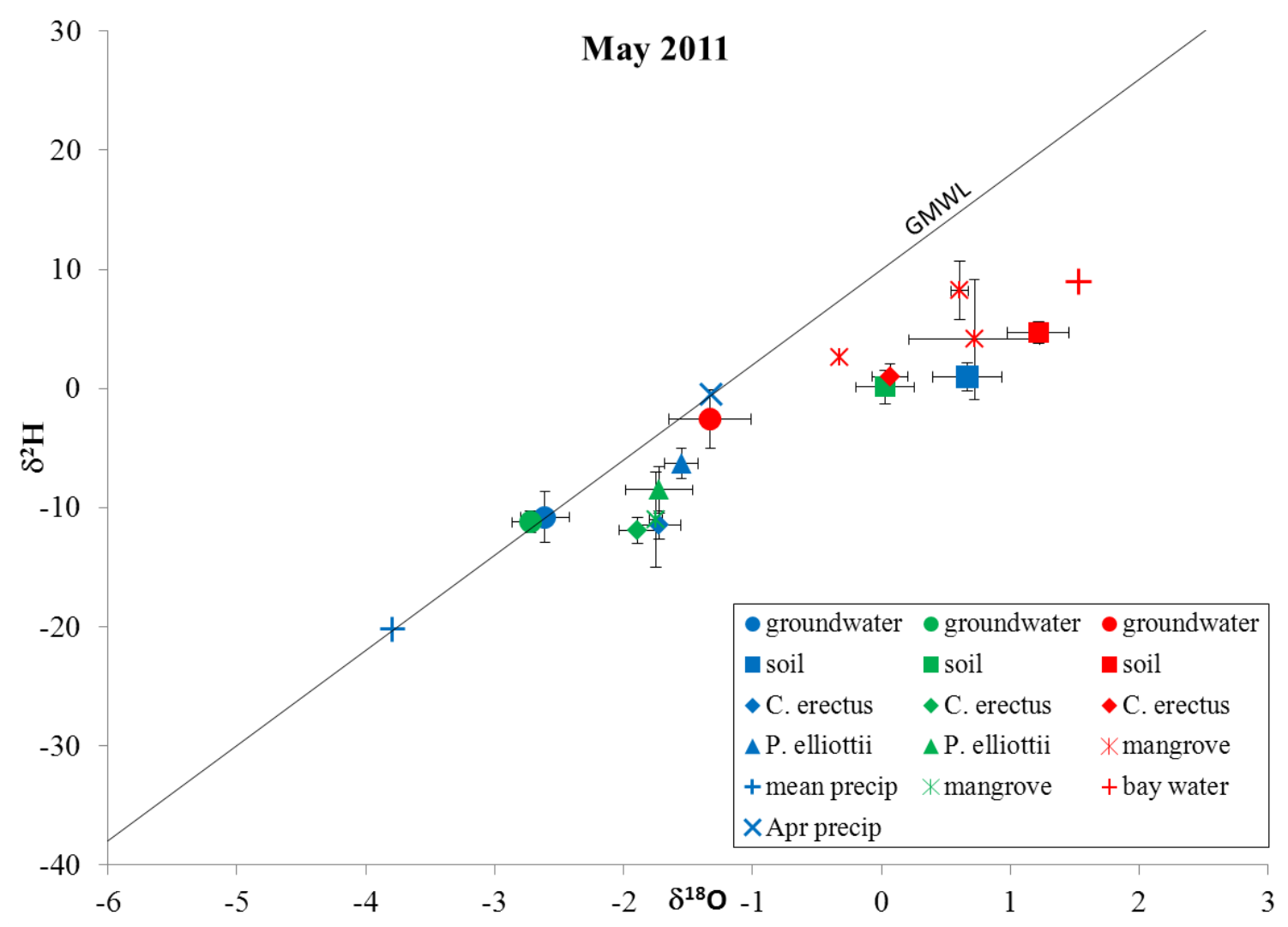

Figure 5.8 May 2011 average +/- SE $\delta^{18} \mathrm{O}$ and $\delta^{2} \mathrm{H}(\%)$ of stem water and source water end members organized by groundwater salinity zone: freshwater lens (blue), mixing zone (green), and tidal (red). Mean precip is the weighted average value ( $\mathrm{n}=12)$ of monthly precipitation collections on Big Pine Key beginning April 3, 2011 and ending April 4, 2012. Apr precip includes accumulated precipitation for the month of April preceding the sampling event. Bay water was sampled near Tarpon Belly Keys (N 24.73, W 81.52) on 4/26/11. Global mean water line (GMWL): $\delta^{2} \mathrm{H}=\delta^{18} \mathrm{O} * 8+10 \%$. 


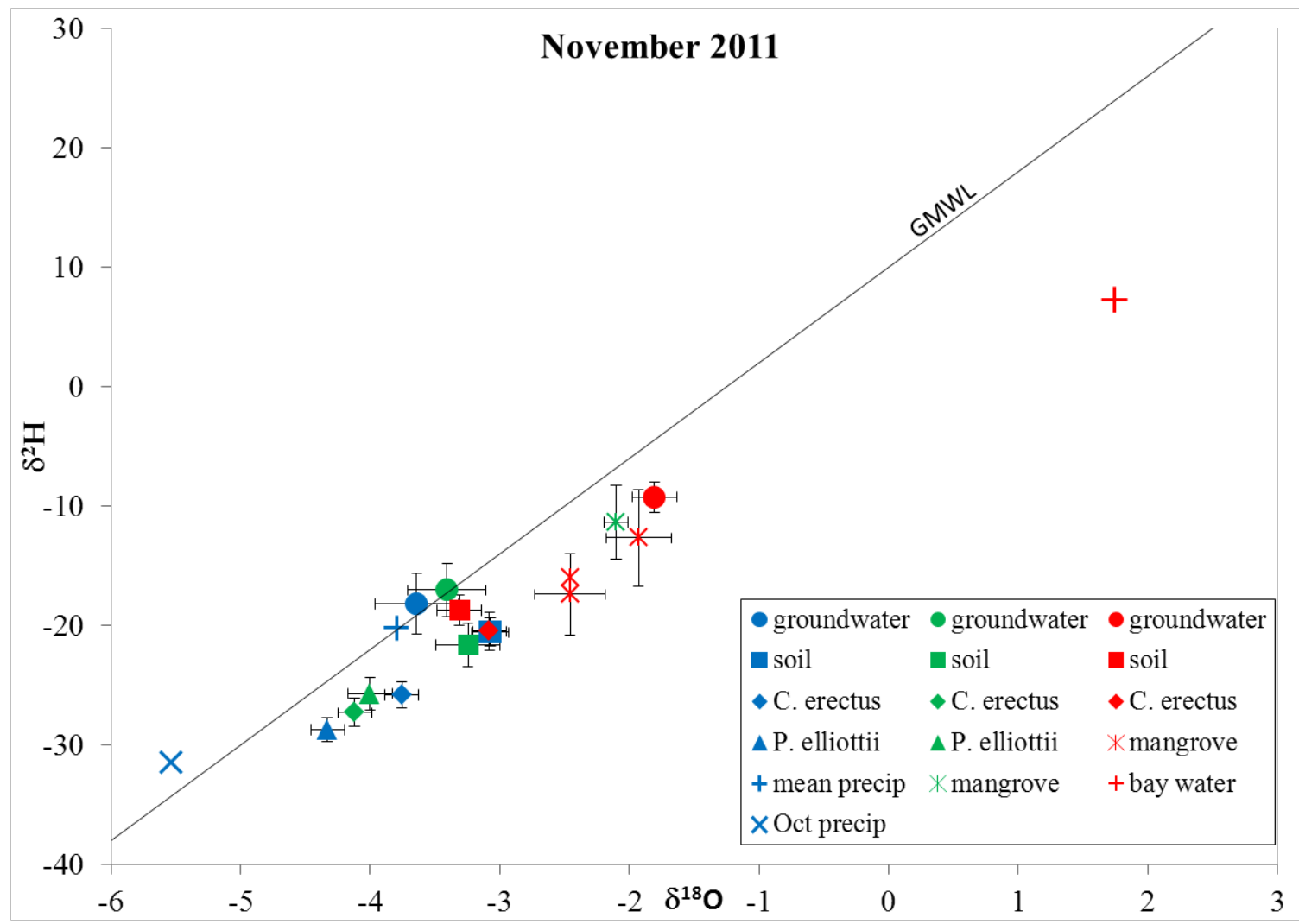

Figure 5.9 November 2011 average $+/-\mathrm{SE} \delta^{18} \mathrm{O}$ and $\delta^{2} \mathrm{H}$ (\%) of stem water and source water end members organized by groundwater salinity zone: freshwater lens (blue), mixing zone (green), and tidal (red). Mean precip is the weighted average value $(n=12)$ of monthly collections of precipitation on Big Pine Key beginning April 3, 2011 and ending April 4, 2012. Oct precip includes accumulated precipitation for the month of October preceding the sampling event. Bay water was sampled near Tarpon Belly Keys (N 24.73, W 81.52) on 12/7/11. Global mean water line (GMWL): $\delta^{2} \mathrm{H}=\delta^{18} \mathrm{O} * 8+10 \%$. 


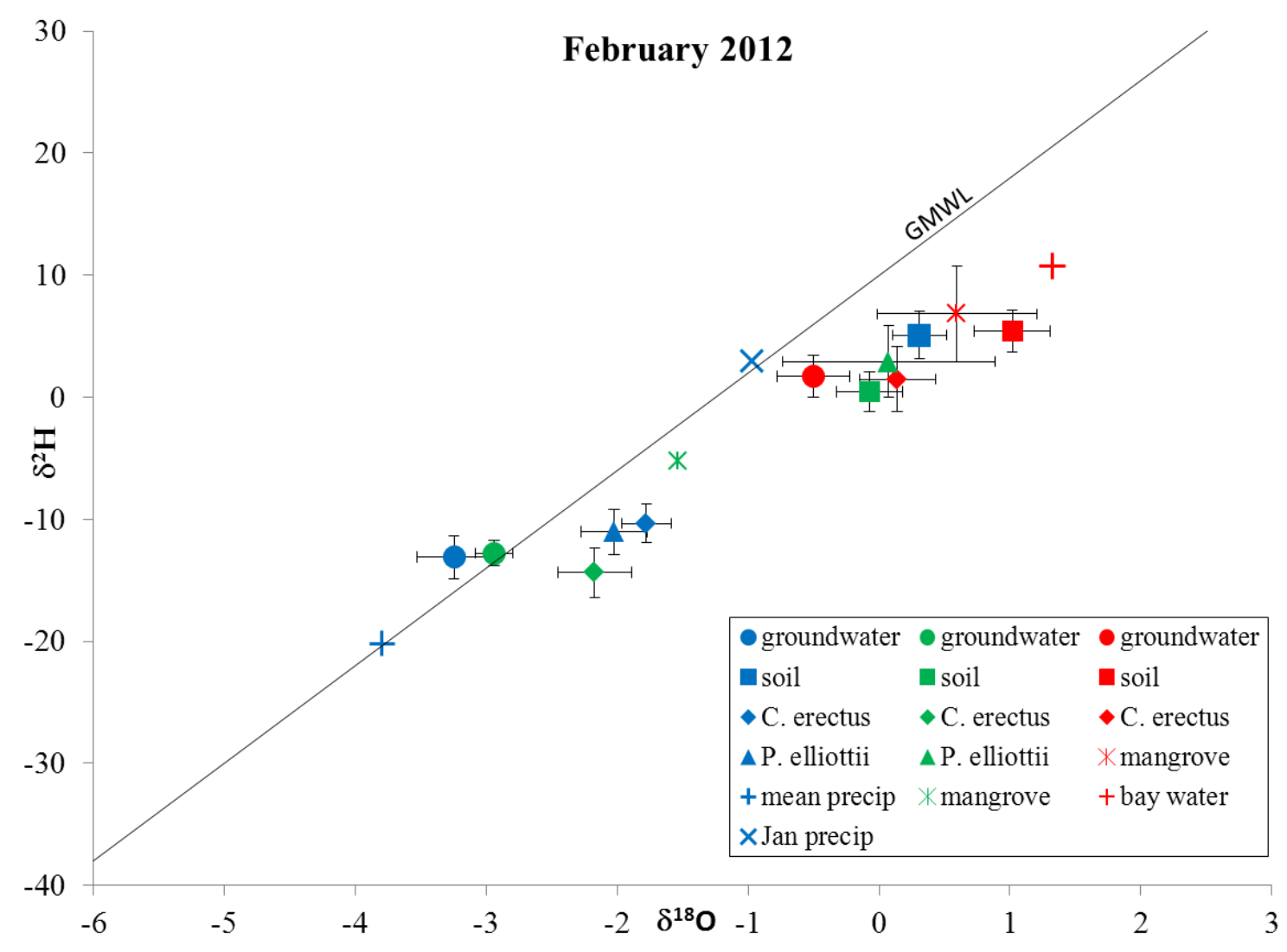

Figure 5.10 February 2012 average +/- SE $\delta^{18} \mathrm{O}$ and $\delta^{2} \mathrm{H}(\%)$ of stem water and source water end members organized by groundwater salinity zone: freshwater lens (blue), mixing zone (green), and tidal (red). Mean precip is the weighted average value ( $\mathrm{n}=12$ ) of monthly collections of precipitation on Big Pine Key beginning April 3, 2011 and ending April 4, 2012. Jan precip includes accumulated precipitation for the month of January preceding the sampling event. Bay water was sampled near Tarpon Belly Keys (N 24.73, W 81.52) on 2/8/12. Global mean water line (GMWL): $\delta^{2} \mathrm{H}=\delta^{18} \mathrm{O} * 8+10 \%$. 

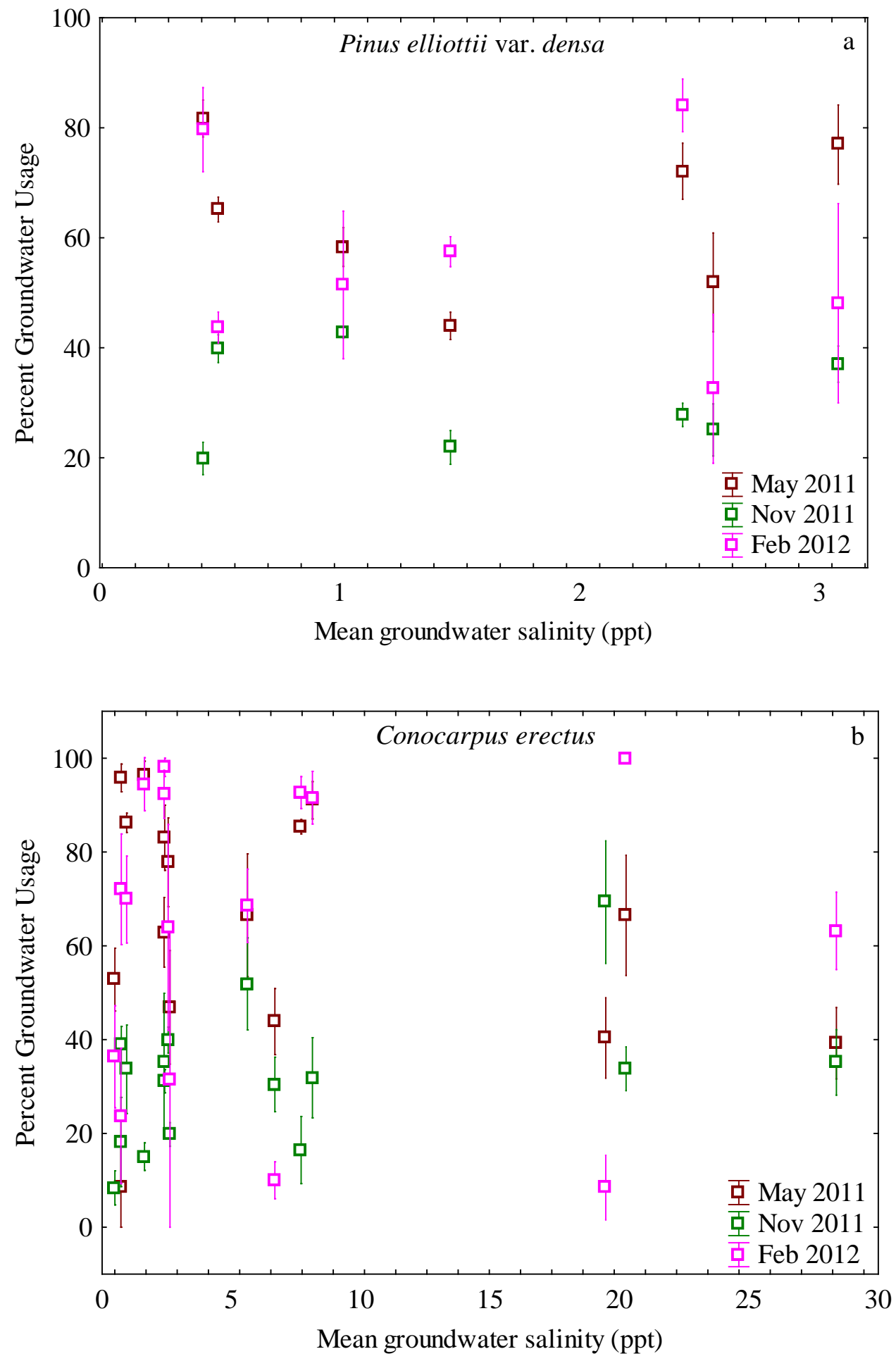

Figure 5.11 Relationship between site mean groundwater salinity (ppt) and percent groundwater use (\%) for (a) Pinus elliottii var. densa and (b) C. erectus in May 2011 (brown), November 2011 (green), and February 2012 (pink) where $\mathrm{n}=5$ for each site. 


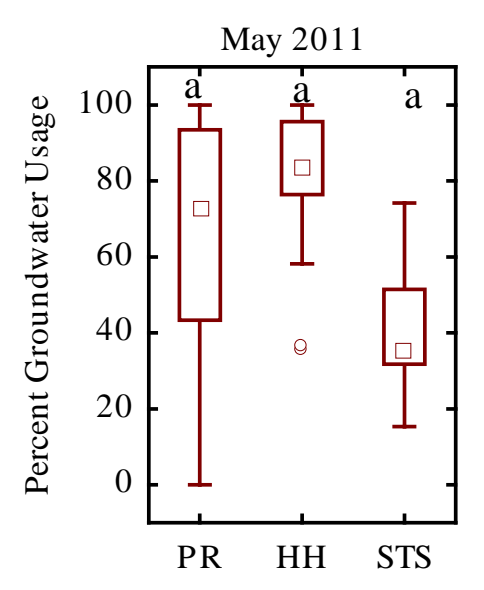

$\square$ Median $\square 25 \%-75 \%$

工 Non-Outlier Range O Outliers

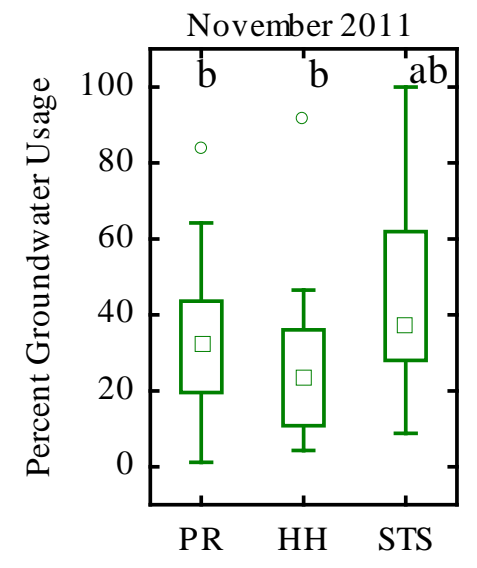

$\square$ Median $\square$ 25\%-75\% 工 Non-Outlier Range $\circ$ Outliers

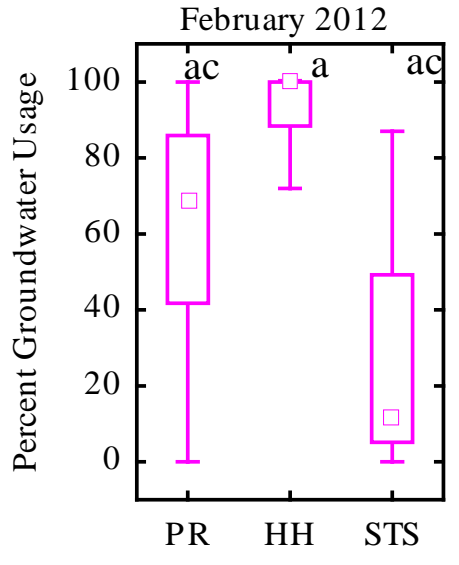

$\square$ Median $\square 25 \%-75 \%$

I Non-Outlier Range $\odot$ Outliers

Figure 5.12 Percent groundwater usage by C. erectus by habitat type in each sample period: May 2011 (brown), November 2011 (green), February 2012 (pink). Different subscripts indicate statistically significant difference between factor levels at p < 0.05 in pairwise contrasts using Bonferroni 2-sided tests. 
November 2011

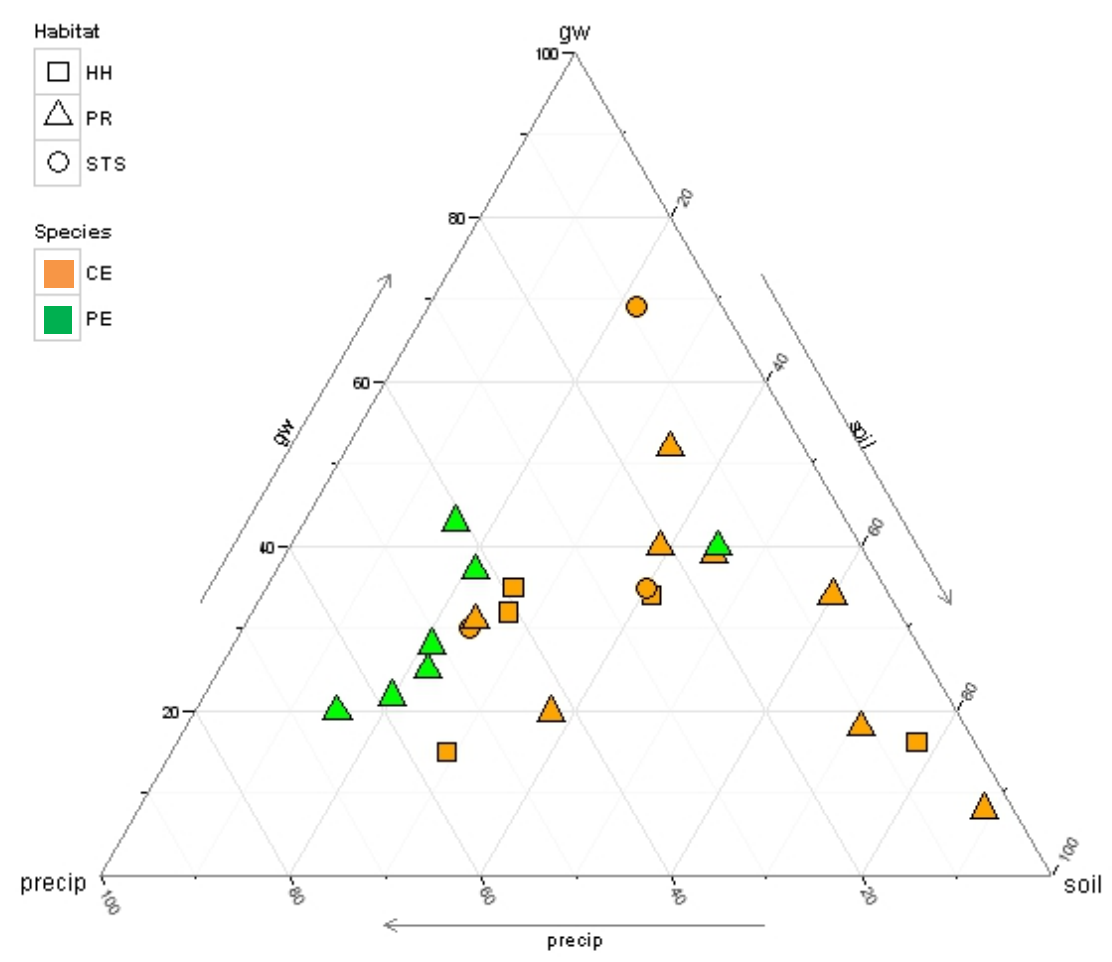

Figure 5.13 Average percent use of each source water type, groundwater (gw), soil water (soil), and precipitation (precip), in November 2011 by Pinus elliottii var. densa (PE) and Conocarpus erectus (CE) organized by habitat: hardwood hammock $(\mathrm{HH})$, pine rockland (PR), and supratidal scrub (STS). Each symbol represents the average for stems of each species at that site $(n=5)$. 

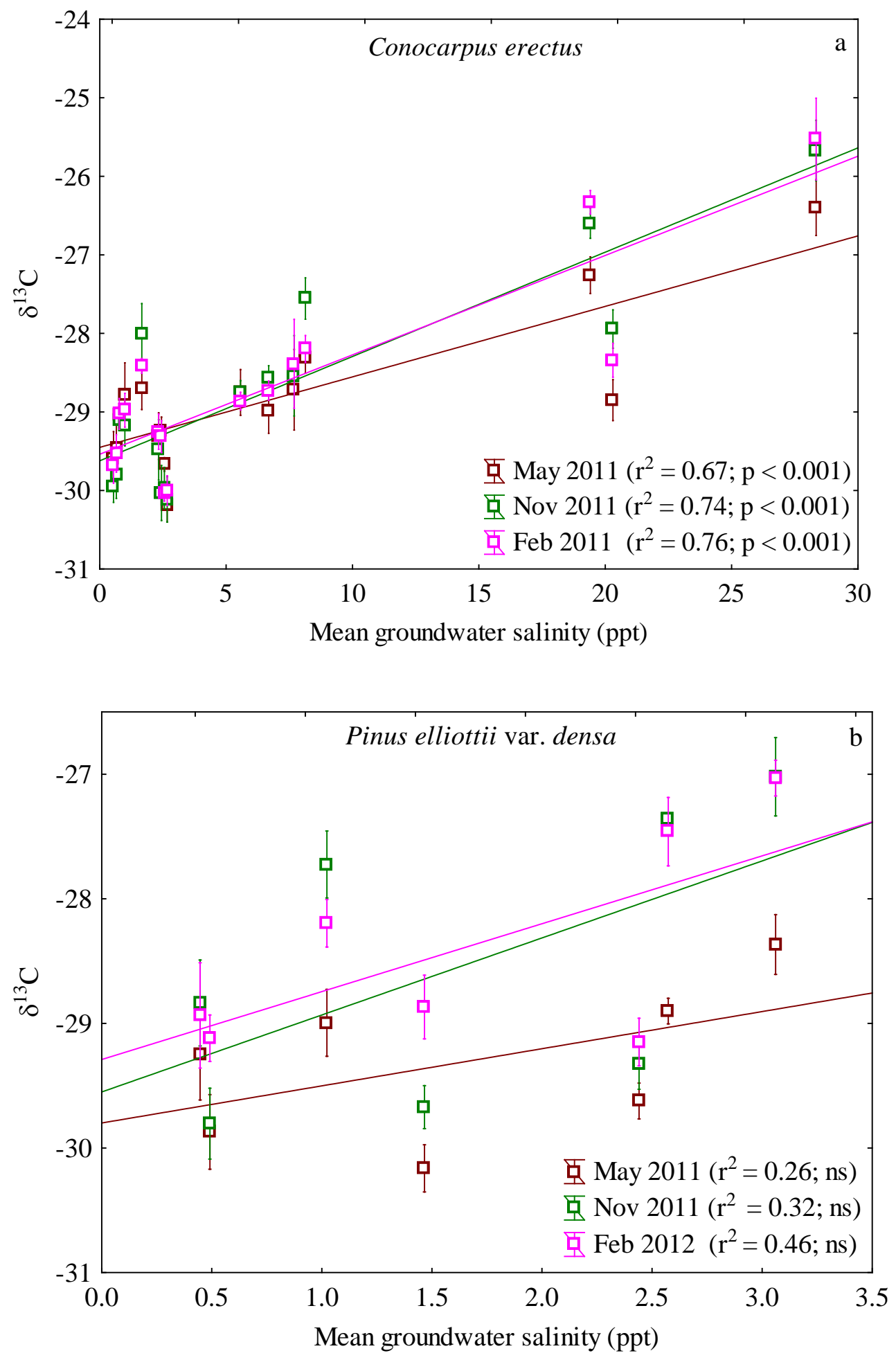

Figure 5.14 Relationship between site average annual groundwater and mean +/- SE foliar $\delta^{13} \mathrm{C}$ in \%o for (a) C. erectus and (b) P. elliottii var. densa in May 2011 (brown), November 2011 (green), and February 2012 (pink) where $\mathrm{n}=5$ for each site. 

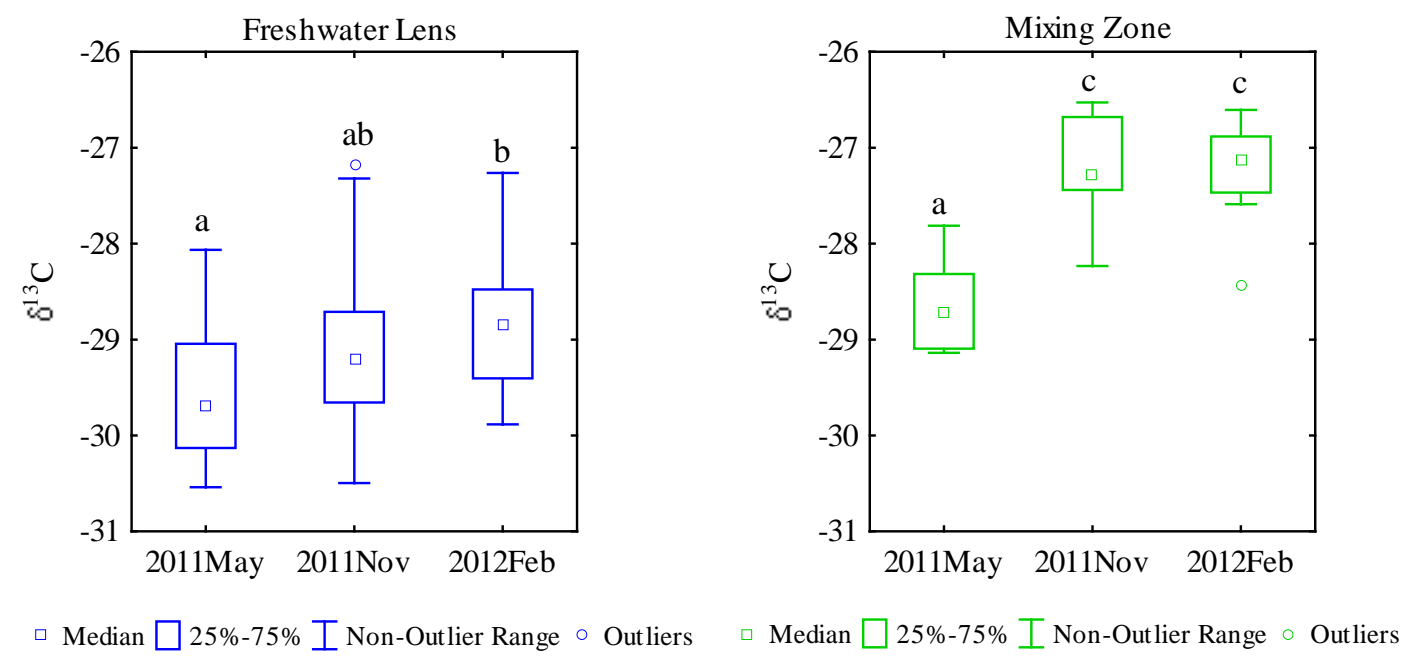

Figure 5.15 Box plots of median $\delta^{13} \mathrm{C}$ values for Pinus elliottii var. densa in freshwater lens sites (blue) and mixing zone sites (green) for three sample months: May 2011, November 2011, and February 2012. Different subscripts indicate statistically significant difference between factor levels at $\mathrm{p}<0.05$ in pairwise contrasts using Bonferroni 2sided tests. 


\section{CHAPTER 6: SUMMARY AND CONCLUSIONS}

The interaction between press (sea level rise) and pulse disturbances (hurricane storm surge) within the seasonal climate regime of the lower Florida Keys directly impacts species within coastal forest communities and alters the resources on which they rely. My work, which focused on three low-elevation freshwater-requiring coastal forests (pine rockland, hardwood hammock, and supratidal scrub), determined that changes in vegetation composition and structure over two decades were related to a combination of increasing groundwater salinity attributable to sea level rise and disturbance impacts from hurricane storm surge.

Storm surge from Hurricane Wilma (2005) was larger in magnitude than that of Hurricane Georges (1998), and hence impacted forests over a larger area, reaching into the interior of the islands to elevations of 1 meter and causing severe damage to vegetation. Differences in elevation on the scale of tens of centimeters were important in determining the magnitude of disturbance impact and the amount of storm surge flooding. Post-Hurricane Wilma responses differed sharply between forest types; hardwood hammocks appeared to recover within a couple years of the event, while pine rockland had still not attained pre-disturbance values of the vegetation indices six years post-Hurricane Wilma.

An assessment of two satellite-derived vegetation indices used to identify disturbance impact revealed that NDMI had a greater capacity to detect changes from hurricane disturbance in these forests compared to the more widely used NDVI. The presence in the 
index of the Landsat TM band 5, located in the mid infrared range and associated with plant water status, appears to be an important attribute for assessing post-storm surge forest recovery. Additionally, by using EOF analysis, I was able to investigate spatial patterns in the entire temporal sequence of Landsat TM data from 1986 to 2011. The results revealed diverging trajectories of disturbance recovery between hardwood hammock and pine rockland.

Over a 22-year period, changes in composition attributable to increasing groundwater salinity were primarily found within the low shrub-herbaceous stratum of these forests, but these effects were concentrated in locations outside the central core of the freshwater lens. In these locales, the appearance of halophytic species typical of the supratidal scrub community was first observed in hammocks and pinelands in 2012, having been absent from both types in 1990. Across all strata, at locations both inside and outside the boundary of the freshwater lens, general increases in the abundance of buttonwood were notable. While buttonwood currently accounts for a small percentage of total cover in communities other than supratidal scrub, both pulse and press events likely contribute to its increase in hardwood hammock and pine rockland. In these fresh water-dependent forests, species that are less salt tolerant but might be better competitors for other resources than buttonwood were highly impacted from the storm surge, thus allowing buttonwood to colonize. Combined with its ability to access groundwater as a year-round freshwater resource, buttonwood's tolerance to inundation by salt water likely explains this pattern. 
My studies indicated that changes in the groundwater resource coincided with precipitation events, especially on the smaller island of Upper Sugarloaf Key. While both islands experienced increases in the depth of the freshwater lens between the dry and wet season ERT surveys, lateral increases were restricted to Upper Sugarloaf Key. As coastal communities are frequently arranged according to the salinity tolerance of their dominant species, I investigated the accuracy with which presence of these terrestrial coastal forests could be predicted based on a combination of topography and ERT-derived groundwater salinity. Ranges of groundwater salinity were established for each community. Although coastal proximity was the most important variable, inclusion in the random forest classification of groundwater salinity from both ERT surveys were important variables in determining coastal forest location. Conditional density plots for each environmental variable included in the classification indicated a high probability of occurrence for the majority of forest community types in a distinct range along both salinity gradients that was not present for the elevation or coastal proximity gradient. The overlap in the range of low elevation pine rockland along the salinity gradients with hardwood hammock and supratidal scrub, combined with the significant overlap in the NMDS ordination of low elevation pine rockland and hardwood hammock samples, suggests that low pine rockland is in the process of succeeding to hardwood hammock.

Through an assessment of water use and plant water stress in two of the coastal landscape's dominant species, slash pine and buttonwood, I determined that both relied heavily on groundwater throughout the year but pine readily accessed precipitation after a large rain event. As indicated by foliar $\delta^{13} \mathrm{C}$, plant stress in both species increased 
throughout an extended drought that prevailed over the study period, bringing with it increasing groundwater salinity. Slash pine located at sites outside the boundary of the freshwater lens - at sites with groundwater salinity greater than 3 ppt during the year had significantly larger changes in foliar $\delta^{13} \mathrm{C}$ enrichment compared to pines at sites located inside the lens boundary, where maximum salinities did not surpass $2.6 \mathrm{ppt}$.

The identification of groundwater salinity as a critical variable in coastal forest location, combined with the year-round use of groundwater by the dominant species in two of the study communities, suggests that a major driver of plant community succession in these coastal forests is related to the freshwater lens present on these islands. While other drivers, especially inundation frequency and fire frequency, clearly interact to direct successional trajectories, these occur against a background governed by the underlying groundwater resource. The combined results of this work suggest a conceptual model for coastal forest community dynamics driven by the combination of press and pulse disturbances.

The sensitivity of pine trees at locations of relatively low groundwater salinity signifies more than the species' narrow threshold of tolerance. More broadly, it suggests the influence of the interactions of press and pulse in defining areas of optimal and suboptimal groundwater resource. The pulse effects from hurricane storm surge may have more severe consequences for trees in suboptimal habitat, perhaps causing increases in mortality among already stressed individuals, while also altering the groundwater resource on which the species relies. While post-storm surge dynamics of the freshwater 
lens are not currently understood, evidence from groundwater monitoring indicates that conditions of increased salinity can persist for a minimum of several years post-event. If conditions at the edge of the lens remain at higher salinities for longer time periods than those at more interior locations, the freshwater resource becomes increasingly suboptimal. Thus, succession to hardwood hammock becomes likely, as hardwood hammock species rely predominantly on soil water.

Post-storm surge dynamics of the freshwater lens, specifically changes in groundwater salinity throughout the lens after saltwater inundation, and the influence of recharge in shortening the time required for the lens to revert to pre-storm salinities is an area of research that is necessary for understanding the dynamics of coastal forests in the lower Florida Keys. One step in addressing this question would be establishment of permanent groundwater monitoring on these islands. Combined with continued monitoring of species composition in these forests, assessing changes in the groundwater resource will be essential as impacts from sea level rise, storm surge, and climate warming proceed. 
VITA

\section{DANIELLE E. OGURCAK}

1977

1999

$2005-2007$

$2010-2015$
Born, Lebanon, Pennsylvania

B.S., Natural Resources

Cornell University

Ithaca, NY

Biologist

University of Florida

Davie, FL

Doctoral Candidate

Florida International University

Miami, FL

\section{PUBLICATIONS AND PRESENTATIONS}

Farnsworth, E. J. and D. E. Ogurcak. 2006. Biogeography of decline of rare plants in New England: historical evidence and contemporary monitoring. Ecological Applications 16(4):1327-1337.

Farnsworth, E. J. and D. E. Ogurcak. 2008. Functional groups of rare plants differ in levels of imperilment. American Journal of Botany 95(8): 943-953.

Fujisaki, I., F. J. Mazzotti, K. M. Hart, K. G. Rice, D. Ogurcak, M. Rochford, B. M. Jeffery. 2012. Use of alligator hole abundance and occupancy rate as indicators for restoration of a human-altered wetland. Ecological Indicators 23: 627-633.

Laba, M., S. K. Gregory, J. Braden, D. Ogurcak, E. Hill, E. Fegraus, J. Fiore, and S. D. DeGloria. 2002. Conventional and fuzzy accuracy assessment of the New York Gap Analysis Project land cover map. Remote Sensing of the Environment 81(2): 443-455.

Laba, M., F. Tsai, D. E. Ogurcak, S. Smith, and M. E. Richmond. 2005. Field determination of optimal dates for the discrimination of invasive wetland plant species using derivative spectral analysis. Photogrametric Engineering and Remote Sensing 71(5): 603-612.

Lui, Z., L. A. Brandt, D. E. Ogurcak, and F. J. Mazzotti. 2013. Morphometric and hydrologic characteristics of alligator holes in Everglades National Park, Florida from 1994 to 2007. Ecohydrology 6(2): 275-286. 
Lynch, R. L., L. A. Brandt, H. Chen, D. E. Ogurcak, I. Fujisaki, and F. J. Mazzotti. 2011. Recruitment and growth of old world climbing fern in hurricane-caused canopy gaps. Journal of Fish and Wildlife Management 2(2): 199-206.

Ogurcak, D. E., J. P. Sah, and M. S. Ross. 2011. The effects of fire and storm surge on species heterogeneity and richness in the pine rockland community of Big Pine Key, FL, USA. Presented at the 54th Symposium of the International Association of Vegetation Science, June, 2011, p. 164. http://media.univ-lyon1.fr/iavs2011/abstract/IAVSlyon2011-book_of_abstracts.pdf

Ross, M. S., D. E. Ogurcak, J. P. Sah, and P. L. Ruiz. 2010. Using Florida Keys reference sites as a standard for restoration of forest structure in Everglades tree islands. International Journal of Forestry Research Vol. 2010. Article ID 176909. 8pp.

Sah, J. P., M. S. Ross, J. Snyder, and D. E. Ogurcak. 2010. Tree mortality following prescribed fire and a storm surge event in slash pine (Pinus elliottii var. densa) forests in the Florida Keys, USA. International Journal of Forestry Research. Vol. 2010. Article ID 204795. 13pp. 